Portland State University

PDXScholar

Winter 1-31-2018

\title{
Student Motivation Profiles as a Diagnostic Tool to Help Teachers Provide Targeted Support
}

Cailin Tricia Currie

Portland State University

Follow this and additional works at: https://pdxscholar.library.pdx.edu/open_access_etds

Part of the Developmental Psychology Commons, and the Elementary Education Commons Let us know how access to this document benefits you.

\section{Recommended Citation}

Currie, Cailin Tricia, "Student Motivation Profiles as a Diagnostic Tool to Help Teachers Provide Targeted Support" (2018). Dissertations and Theses. Paper 4229.

https://doi.org/10.15760/etd.6113

This Dissertation is brought to you for free and open access. It has been accepted for inclusion in Dissertations and Theses by an authorized administrator of PDXScholar. Please contact us if we can make this document more accessible: pdxscholar@pdx.edu. 
Student Motivation Profiles as a Diagnostic Tool to Help Teachers Provide Targeted Support

by

Cailin Tricia Currie

A dissertation submitted in partial fulfillment of the requirements for the degree of

Doctor of Philosophy

in

Applied Psychology

\author{
Dissertation Committee: \\ Ellen Skinner, Chair \\ Thomas Kindermann \\ Andrew Mashburn \\ Sybil Kelley
}

Portland State University

2018 


\begin{abstract}
Research has demonstrated that academic engagement is an important resource for students, promoting their learning and achievement. Less well documented is the possibility that students' classroom engagement may also be a valuable resource for their teachers, capable of influencing how teachers treat their students over time. The current study sought to examine the relationship between student motivation and teacher behavior to better understand how teachers perceive and respond to their students' classroom motivation and whether these motivational states contain diagnostic information about the types of supports students may need in order to be engaged, enthusiastic learners. The observable manifestations of motivation, engagement and disaffection, may contain valuable information about students' inner experiences that educators can use to optimize their teaching. Thus, the goal of the current study was to examine the reciprocal effects of student motivation on teachers' provision of support by using a longitudinal design, a more comprehensive assessment of behavioral and emotional engagement and disaffection, and a person-centered approach to investigate whether potential factors influencing the quality of students' classroom engagement can help inform more targeted intervention efforts.

Data from $10183^{\text {rd }}$ through $6^{\text {th }}$ grade students and their teachers were used to create two sets of teacher-reported student motivation profiles, namely, a theory-driven and an empirically-derived set of profiles. Using both sets of profiles, the current study failed to provide evidence that student engagement and disaffection profiles influence
\end{abstract}


changes in the quality of support students' received from their teachers over the school year. The current study also examined whether knowledge of the motivation profile into which a student falls can tell us something meaningful about their unobservable, inner experiences or self-system processes (SSP's) such that we can use their profile to 'diagnose' motivational issues stemming from these student inner experiences. Results indicated that, with one exception, students in different profiles did not report differential levels of the three SSP's; rather, if students in a given profile had low levels of one selfsystem process, they had low levels of all three. Finally, for two of the ten student motivation profiles, (At Risk and Checked-out) students in the high teacher support subgroup and the low teacher support subgroup experienced differential changes in their self-reported engagement from fall to spring such that the students who received the "treatment" (high levels of teacher support) started and ended higher than those who received low levels of teacher support, but also showed steeper declines over the year, because students with low teacher support started low and remained low (but did not lose any more ground) across the year.

Discussion focuses on the utility and potential drawbacks of using personcentered approaches to examining student motivation and potential causes for the lack of supported hypotheses. Implications discuss the need for further research and how we can help teachers gain a more nuanced and differential view of their students' motivated actions and emotions in the classroom. 


\section{Acknowledgments}

First and foremost, I would like to thank my advisor, Dr. Ellen Skinner, for her unending support, guidance, and devotion throughout this process. I could not have asked for a better mentor and am deeply grateful to be her student. Additionally, I would like to thank Dr. Thomas Kindermann, Dr. Andrew Mashburn, and Dr. Sybil Kelley for their constructive advice and thoughtful contributions to this project. I would also like to thank my PSU developmental psychology family and my coheart who remind me that together we are always greater than the sum of our parts. Finally, I would like to thank my family, especially my mother, grandmother, and partner, whose unwavering confidence in me allowed me to continue succeeding in my academic journey, even when I didn't believe I could. 
Table of Contents

Chapter Chapter title/subtitle

Page

Abstract

i.

Acknowledgments

iii.

List of Tables

vi.

List of Figures

viii.

1

Introduction

1.

Reciprocal Effects of Student Motivation on Teachers

3.

Current Study

5.

2

Literature Review

8.

Influence of Student Motivation on Teachers

8.

Reciprocal Effects

29.

Critique of Research on Reciprocal Effects

72.

3

Purpose of Study

83.

Person-Centered Approach

88.

Student Experience: Self-System Model of Motivational Development

109.

Research Questions

117.

4

Methods

135.

Participants \& Procedures

135.

Measures

136. 
Implications

Conclusion 


\section{List of Tables}

Table Title

Page

1.1. Studies Examining the Reciprocal Effects of Student Motivation on Teachers' Provision of Support and Relationship Quality.

3.1. Research Studies Utilizing Profiles of Student Motivation

90.

3.2 The Current Study’s Seven Hypothesized Student Motivation Profiles 108.

3.3 Summary of Hypotheses 3a-3d

5.1 Summary of Descriptive Statistics for each construct in Fall and Spring

144.

5.2 Intercorrelations among Teacher-reports (TR) and student reports (SR) of student Engagement and Disaffection in Fall and Spring

5.3 Intercorrelations Among student-reports of their Experience of Teacher Support in Fall and Spring

5.4 Intercorrelations among Student-reports of their Self-system Processes in Fall and Spring

5.5 Tertiary splits for mean levels of motivational components for all students in fall

5.6 Sample sizes and mean levels of motivational components in fall for theory-driven profiles 160.

5.7 Sample sizes and mean levels of motivational components in fall for empirically-derived profiles

165.

5.8 Alignment between theoretically-derived and empirically-derived student motion profiles in fall

5.9 Mean levels of teacher support in fall and spring for theory-driven profiles

5.10 Mean levels of teacher support in fall and spring for empirically-derived profiles 
5.11 Profiles with mean levels of SPP's that were significantly lower than at least one other profile

190.

5.12 Withdrawn profile: Mean levels of student-reported engagement in fall and spring for students' in the high and low teacher support subgroups

5.13 Burnt-out profile: Mean levels of student-reported engagement in fall and spring for students' in the high and low teacher support subgroups 195.

5.14 Going Through the Motions profile: Mean levels of student-reported engagement in fall and spring for students' in the high and low teacher autonomy support subgroups

5.15 At Risk profile: Mean levels of student-reported engagement in fall and spring for students' in the high and low teacher support subgroups 199.

5.16 Checked-out profile: Mean levels of student-reported engagement in fall and spring for students' in the high and low teacher support subgroups 201.

6.1 Summary of results 204. 


\section{List of Figures}

$\underline{\text { Figure }}$ Title

Page

3.1 The Self-System Model of Motivational Development (SSMMD)

111.

5.1 Z-scores of each Theory-driven profiles' mean levels of engagement and disaffection in fall

5.2 Z-scores of each empirically-derived profiles' mean levels of engagement and disaffection in fall

5.3 Changes in student-reports of teacher support from fall to spring for theory-derived profiles

5.4 Changes in student-reports of teacher support from fall to spring for empirically-derived profiles

5.5 Mean levels of relatedness for students in each theory-derived profile in fall

5.6 Mean levels of competence for students in each theory-derived profile in fall

5.7 Mean levels of identified self-regulation for students in each theoryderived profile in fall

178.

5.8 Mean levels of intrinsic, introjected, and external self-regulation for students in each theory-derived profile in fall

5.9 Mean levels of relatedness for students in each empirically-derived profile in fall

183.

5.10 Mean levels of competence for students in each empirically-derived profile in fall

184.

5.11 Mean levels of intrinsic self-regulation for students in each empirically-derived profile in fall

5.12 Mean levels of identified self-regulation for students in each empirically-derived profile in fall

186. 
5.13 Mean levels of extrinsic self-regulation for students in each empirically-derived profile in fall

5.14 Mean levels of self-system processes for theory-derived profiles in fall

5.15 Mean levels of self-system processes for empirically-derived profiles in fall

5.16 Withdrawn profile: Relationship between amount of teacher support received in fall and changes in student engagement

from fall to spring

194.

5.17 Burnt-out profile: Relationship between amount of teacher support received in fall and changes in student engagement from fall to spring 196.

5.18 Going Through the Motions profile: Relationship between amount of teacher support received in fall and changes in student engagement from fall to spring

198.

5.19 At Risk profile: Relationship between amount of teacher support received in fall and changes in student engagement from fall to spring 200.

5.20 Checked-out profile: Relationship between amount of teacher support received in fall and changes in student engagement from fall to spring 


\section{Chapter 1}

\section{Introduction}

Decades of research have demonstrated that academic engagement is an important resource for students, promoting their learning and achievement (Christenson, Reschly, \& Wylie, 2012; Archambault, Janosz, Morizot, \& Pagani, 2009; Upadyaya \& Salmela-Aro, 2013). Less well documented is the possibility that students' classroom motivation may also be a valuable resource for their teachers (Becker, Keller, Goetz, Frenzel \& Taxer, 2015; Sutton \& Wheatley, 2003; Split, Koomen \& Thijs, 2011). It is easy to imagine that teaching a class full of eager, hardworking students could be a validating and rewarding experience for an educator; The qualities that mark a student as engaged in the classroom are the same qualities that make a student a joy to teach. A classroom full of engaged students raising their hands, asking questions that indicate critical thinking, and proposing novel solutions that build on their previous knowledge communicates to teachers that their goal of inspiring high-quality learning in children has been successful and thus their work is meaningful. These engaged student behaviors create the type of classroom experience that reminds teachers why they chose to pursue their professions in the first place. In general, teachers choose their profession because they are passionately dedicated to and find enjoyment in helping children learn (Dinham \& Scott, 2000; Martin, 2006). Working with excited, driven, and curious students, as opposed to resistant or apathetic students, bolsters the dream of improving students' lives by shaping their learning. Thus, it could be suggested that engaged students provide their teachers with the set of essential experiences that supports teachers' own enjoyment in the 
classroom and sense of fulfillment in their careers (Pines, 2002; Frenzel, Goetz, Stephens, \& Jacob, 2009; Spilt, Koomen \& Thijs, 2011; Martin 2006).

Unfortunately, the converse, namely student disaffection, may exert an even more powerful effect on teachers' daily lives in the classroom and their personal and job satisfaction.

Specifically, disaffection may not only be a risk factor for students' underachievement and drop out but also for their teachers' job satisfaction and retention in the field of education (Chang 2009, Sutton \& Wheatley, 2003; Skaalvik \& Skaalvik 2011; Steven \& Myer, 2005). The only task more difficult than delivering seven hours of public speaking a day while maintaining a positive, encouraging demeanor at all times while juggling the varying and competing needs of 30 or more young people combined with the omnipresent pressure of helping students meet increasingly severe educational benchmarks, would be attempting to achieve all this in the face of a sullen, disruptive, unappreciative, or actively resistant audience. Indeed, research corroborates this common-sense intuition. Specifically, disaffected students are among the top stressors reported by teachers (Chang, 2009; Covell, McNeil, Howe; 2009).

Student disaffection isn't simply an annoyance that makes educators' jobs a bit more frustrating at times. Student disaffection not only takes away from precious instructional time, interrupts other students' attempts to learn, and corrodes teacherstudent relationships and overall classroom climate, but may potentially negatively influence teachers' experiences and behaviors in the classroom (Henricsson \& Rydell 2004; Ladd \& Burgess 1999; Newberry \& Davis 2008). Specifically, if teachers take their 
students' withdrawal, defiance, and apathy for learning personally and view student disaffection as the result of their failure as educators, then teachers may begin to feel incompetent, guilty, and hopeless. Alternatively, teachers may assume that disaffection is manifested by students' own personal failings or character flaws, so instead of blaming themselves, they will blame the student for her disaffection which may lead teachers' to feel frustration and resentment towards their disaffected students. Hence, due to the assumptions teachers make about the causes of student disaffection and the powerful emotional experiences they inevitably catalyze in teachers, student disaffection may be capable of producing powerful effects for teachers'. This hypothesis is supported by research that suggests aspects of student disaffection are capable of impacting a host of teacher experiences including job satisfaction, burnout, stress, negative emotions, and negative perceptions of the value and efficacy of their teaching (Chang, 2009).

\section{Reciprocal Effects of Student Motivation on Teachers}

The importance of student motivation to teachers, combined with the power of teachers' interpretations, may not only impact teachers' emotions and perceptions, but may also influence teachers' subsequent interactions with their students.

Recent research investigating the reciprocal effects of student motivation on teacher behavior suggests that student engagement and disaffection elicit differential teacher behaviors. This research suggests that, in addition to the well-documented feedforward effects of teachers on student motivation, there may exist reciprocal or feedback effects of student motivation on teachers. In the context of this study, the term 
reciprocal effects will refer to the feedback effects of students' influence on their teachers. Reciprocal effects findings suggest teachers are reacting to student engagement and disaffection in ways that support students with high motivation and exacerbate motivational problems for struggling students (Skinner \& Belmont, 1993; Furrer, Skinner, \& Kindermann, 2003).. This sparse but growing research suggests that engaged students receive more and better quality support from their teachers than do disaffected students. Teachers appear to withdraw their support from disaffected students and become more controlling and less involved in the lives of these more motivationally vulnerable students (Skinner \& Belmont, 1993; Furrer, Skinner, \& Kindermann, 2003). Although this reaction is understandable given the stress teachers experience from interacting with disaffected students, this response may have the potential to create more negative experiences and outcomes, not only for students but also for the teachers themselves.

If highly engaged students receive more subsequent teacher support, which in turn increases their engagement, which then elicits further teacher support, a cycle is created by which the motivationally rich get richer (Pitzer \& Skinner, 2016; Skinner, Furrer, Marchand, \& Kindermann; 2008). Unfortunately, the converse may represent an even more powerful response loop: Teachers' withdrawal of support from disaffected students could increase those students' levels of disaffection, which causes teachers to withdraw further or become coercive, bringing with it a greater likelihood of student underachievement and eventual drop out (Skinner \& Belmont, 1993). This suggests that by withdrawing from disaffected students, teachers may actually be contributing to 
increases in the very motivational state that they find so stressful and averse. The notion that the students who would benefit the most from increases in teacher support (those who show high disaffection and low engagement) are the least likely to receive it, carries weighty implications for researchers interested in supporting student academic success. Specifically, it suggests that helping teachers change the way they interpret and react to student motivational issues in the classroom may be a new avenue for decreasing student motivational issues and the subsequent risks associated with student disaffection.

\section{Current Study}

The current study posits that one approach to intervening on these potentially selfamplifying feedback loops between students' motivation and teachers' behavior is to alter the way teachers' view (and subsequently react to) student disaffection. Indeed, findings from the teacher coping literature suggest a key component in dictating how teachers' react to student behaviors is the antecedent appraisals that teachers make for student behaviors (Frenzel, Goetz, Stephens, \& Jacob, 2009; Chang \& Davis, 2009). These appraisals seem to be mediators that shape teachers' understanding of student behaviors and the regulation of their subsequent emotions and behaviors (Chang 2009; Hargreaves 1998). If we want teachers to react differently to student disaffection, in a compensatory instead of punitive manner, then we need to find a different way for them to understand these student behaviors. Specifically, if teachers were able to alter their appraisals of student disaffection, it may change their experience of student disaffection (negative 
emotions, stress) and thus change their subsequent reaction to it (withdrawal of support from disaffected students).

To that end, instead of appraising student engagement and disaffection as reflections of the quality of their teaching or as an indication of a student's character, what if teachers viewed student engagement and disaffection as important, actionable information that they could use to optimize their teaching? The observable behavioral manifestations of engagement and disaffection may contain valuable information about students' inner experiences. Specifically, according to research based on Selfdetermination Theory (SDT), students' inner self-perceptions are intricately tied to and robust predictors of their classroom motivation (Skinner, Kindermann, Furrer, 2009; Skinner, Kindermann, Connell, \& Wellborn, 2009). Under the STD framework, three key experiences, namely whether students feel like a sense of belonging in their classrooms (relatedness), whether they think they are capable of doing the course work (competence), and whether they have a sense of ownership over their academics and see learning activities as relevant and meaningful to them personally (autonomy), all have the power to shape their motivation (Deci \& Ryan, 1985, 2000). Thus, it follows that perhaps students' observable motivation in the classroom may provide teachers with a glimpse into how students are faring on these core student self-perceptions. If teachers can see student behavior as valuable sources of information to help "diagnose" the causes of motivational problems stemming from these student self-perceptions, teachers can use their observations to shape their responses into "treatments". 
Subsequently, the current study sought to examine the relationship between student motivation and teacher behavior to better understand how teachers view and respond to their students and whether they can view these motivational states as containing diagnostic information about the types of supports their students may need in order to be engaged, enthusiastic learners. Specifically, Chapter 2 explores the literature on the effects of student motivation on teachers' emotions and self-perceptions. Chapter 2 then reviews research on the reciprocal effects of student motivation on teachers' subsequent behavior to elucidate how student motivation may impact the quality of teachers' responses to and relationships with their students. Finally, Chapter 2 ends with a critique of the reciprocal effects research literature. Chapter 3 opens with a discussion of the purpose of the current study. In order to inform the current study's goal of bringing an innovative, holistic methodological perceptive to the examination of reciprocal effects, Chapter 3 briefly reviews studies utilizing person-centered approaches to examining student motivation. Relying on a self-determination theory framework, Chapter 3 then explores the unobservable student experiences that may be shaping the differential quality of students' manifested motivation in the classroom. Chapter 3 includes a discussion of what types of teacher support may, based on students' specific sets of experiences, be most helpful for students displaying different types of motivational issues. Finally Chapter 3 concludes with a discussion of the research questions and hypotheses. Chapter 4 outlines information about the participants, study design, and measures. Chapter 5 contains details about the analysis plan and results. Finally, strengthens, limitations, and directions for future research are discussed in Chapter 6. 


\section{Chapter 2}

\section{Literature Review}

This chapter aims to strengthen the current study's hypothesis that student engagement and disaffection may be capable of impacting teachers by reviewing empirical studies that examine how aspects of student motivation in the classroom may shape teachers' experiences and behavior in the classroom. Specifically, the first section of this review examines the potential positive impact of aspects of student engagement on teachers' experiences of positive emotions, and positive self-perceptions about their teaching efficacy and the meaningfulness of their work. Next, studies documenting the influence of aspects of student disaffection and misbehavior on teachers' stress and burnout, experience of negative emotions, and job satisfaction are explored. Finally, building on these findings, this chapter then reviews the limited research on the reciprocal effects of student engagement and disaffection on teachers' behavior and relationship quality. This chapter ends with a critique of the research literature.

\section{Influence of Student Motivation on Teachers}

Few studies have directly examined the potential impacts of student motivation on teachers' experiences. This subsection of the literature review focuses on a set of studies that have examined the ways in which aspects of student engagement and disaffection may impact teachers' emotions, self-perceptions, stress, and burnout. Research suggests that student engagement is linked to teacher emotions, such as enjoyment and satisfaction, and predicts teachers' feelings of self-efficacy and confidence (Mottet, 
Beebe, Raffeld, \& Medlock, 2004; Martin, Sass, \& Schmitt, 2011; Martin 2006;

Stenlund, 1995). An older and more robust literature documenting the influence of student misbehavior on teacher stress and burnout suggests that aspects of student disaffection are capable of negatively impacting teachers' wellbeing (Friedman, 1995; 2000; Hastings \& Bham, 2003; Yoon, 2002, Kokkinos, 2007). Taken together, these findings suggest that teaching highly engaged students can be extremely rewarding for teachers while working with disaffected students appears to be a major source of teacher stress.

Engagement. Conceptualized as the strength and emotional quality of children's initiation and participation in learning activities, engagement is a dynamic, multidimensional construct that reflects the ongoing process of students' attentive and energized involvement in learning tasks. (Jimerson, Campos, \& Greif, 2003; Marks, 2000; Skinner, Furrer, Marchand, \& Kindermann, 2008). Engagement refers to participation on academic tasks that is active, goal-oriented, constructive, persistent, focused, and emotionally positive (Furrer, Skinner, \& Pitzer, 2012). Engaged students are intrinsically motivated, enthusiastic learners. Engagement includes both behavioral (effort) and emotional (interest) components (Skinner, Kindermann, Connell, \& Wellborn, 2009; Skinner, Kindermann, \& Furrer 2009; Fredricks, Blumenfeld, \& Paris, 2004).

Until recently, engagement has been almost exclusively conceptualized as an important resource for student success. Research indicates that engaged students learn more than disaffected students, have higher GPAs, and higher achievement test scores 
(Skinner, Wellborn \& Connell, 1990; Janosz, Archambault, Morizot, \& Pagani, 2008; Klem \& Connell, 2004). Highly engaged students are more likely to graduate high school and to do so in a timely manner (Ullah \& Wilson, 2007; Fredricks, Blumenfeld, \& Paris, 2004). Engagement also appears to be a protective factor against a host of risky adolescent behaviors (Morrison, Robertson, Laurie, \& Kelly, 2002; Finn, 1989). Although the evidence for the positive influence of student engagement on students is robust, very little work has been done to examine whether student engagement may also be a positive force for teachers.

\section{Student Engagement is Rewarding for Teachers}

Because engagement is characterized by participation on academic tasks that is energetic, productive, determined, and enjoyable, it seems reasonable that student engagement could be a precious commodity to teachers as well as to students' themselves (Furrer, Skinner, \& Pitzer, 2014). Engaged students are enthusiastic, high-achieving students that are eager and willing to learn, making them a pleasure to teach. Teachers experience joy and satisfaction in their students' growth, particularly when students demonstrate learning and compliance with classroom rules (Frenzel, Goetz, Stephens, \& Jacob, 2007; Hargreaves, 2000; Stenlund, 1995). Positive relationships and interactions with students are often cited as the most important sources of enjoyment and job fulfillment for teachers (Sutton \& Wheatley, 2003; Dinham \& Scott, 2000). Engaged students' passion, dedication, and good behavior may make them the most likely candidates for having these mutually rewarding close relationships with their teachers. 
These positive interactions and close relationships between teachers and engaged students may afford teachers a sense of satisfaction, efficacy, and fulfillment (Chang \& Davis, 2009). It is thus conceivable that teachers' emotions and their self-perceptions of their success in their professions are likely to vary as a function of their students' engagement. The following subsections review the research on the impact of student motivation on teachers' positive emotions and perceptions of their teaching.

Teacher positive emotions. While interactions with students have long been considered an important factor influencing teacher emotions (see Sutton \& Wheatley 2003 for a review), a handful of recent studies have begun examining the specific influence of certain motivational behaviors and emotions on teachers' enjoyment and professional satisfaction. The few studies that have directly examined the impact of aspects of student engagement on teachers' emotions suggest that students' motivational states are capable of impacting their teachers' feelings of enjoyment and satisfaction in and outside the classroom. The following section summarizes four empirical studies that looked specifically at the impact of student motivation on teachers' emotions as well as discusses broader findings from two large cross-national projects that examine how aspects of student motivation are linked to teachers' experiences of enjoyment and job satisfaction.

A recent study by Becker and colleagues (2015) examined the impact of student motivation and classroom discipline as antecedents to teacher emotions in the classroom. The researchers were not only interested in whether students' classroom motivation and discipline were capable of impacting teachers' enjoyment, but also whether this 
relationship was mediated by teachers' appraisals. The study utilized likert-scale diaries in which $7589^{\text {th }}$ and $10^{\text {th }}$ grade mathematics' students reported on their motivation and the classroom discipline. Student motivation was measured by student-reports of positive emotional experiences and personal relevance or value during a given lesson. Classroom discipline was measured by student-reports of classroom disturbances (example item "In this lesson, instruction was often disrupted") and effective use of time ("In this lesson, a lot of time was wasted"). The students' 39 teachers reported on their own enjoyment during the same lessons.

Using multilevel structural equation modeling, the researchers found that student motivation and classroom discipline accounted for $24 \%$ of the variance in teacher enjoyment. Adding teacher appraisals of the lesson as goal congruent and controllable into the model as a mediator increased the explained variance to $65 \%$, suggesting that not only does student motivation and classroom management exert a strong influence on teachers' experience of positive emotions in the classroom, but how teachers view these aspects of the classroom context is a pathway through which students motivation may influence teachers' enjoyment. These findings suggest that aspects of student engagement are capable of having an impact on teachers sense of enjoyment in their work, and that this impact is at least partially explained by how teachers judge student motivation in relation to their own goals and coping potential.

A similar study by Kunter and colleagues (2011) lends support to the connection between well-managed, highly motivated students and teachers' experiences of positive emotions. The researchers' goal was to clarify the concept of teacher enthusiasm, not 
investigate the impact of student motivation on teacher positive emotions. Thus, the first three research questions addressed in this study, which examine the dimensionality and convergent validity of the authors' measure of teacher enthusiasm, are of little relevance to the current review. However, results from the fourth research question, concerning context specificity, examined relationship between teacher-reported enthusiasm and student characteristics.

Three subsamples of secondary teachers were used in the analysis; $\mathrm{N}=332$ secondary mathematics teachers (sample 1), $\mathrm{N}=205$ secondary mathematics teachers (sample 2), and $\mathrm{N}=113$ teachers from all state school types (sample 3 ). The students in each of the teacher participants classes (average 24 students per teacher) were administered achievement tests and questionnaires assessing their mathematics achievement and enjoyment that were then aggregated to produce a class mean.

Latent correlations between teacher enthusiasm and these class level variables and student characteristics revealed that teachers reported being more enthusiastic about their work when teaching classes characterized by less disruption, higher enjoyment, and higher achievement. Unsurprisingly given the robust findings that suggest girls are more likely to be better behaved and engaged in school, the teachers were also more enthusiastic while teaching classes with a larger proportion of girls. Taken together, these two empirical studies from Germany suggest some evidence for a connection between student motivation in the classroom and teachers experiences of enjoyment and enthusiasm in their work. 
In a third study, Frenzel and colleagues (2009) investigated how primary and secondary school teachers' perceptions of their students' motivation in the classroom relates to teachers' positive and negative emotional experiences during teaching. The authors hypothesized that the more positively teachers judge students' behaviors, the more likely teachers are to appraise the situation as consistent with their goals regarding student motivation, and thus the more enjoyable they will find teaching. Specifically, the authors investigated whether teacher-reports of their class's academic performance, motivation, and discipline were related to teachers' experiences of enjoyment, anger, and anxiety.

The authors examined this hypothesis using a multi-method approach that assessed how teachers generally feel during class (via questionnaires) and how teachers felt after a specific lesson (via daily diary entries) in an attempt to measure trait-like and state-like teacher emotions.

Data from a sample of 237 German primary and secondary school teachers was analyzed using multilevel multiple regression. For students across grades one through nine, teacher-reports of student motivation predicted teachers' trait-level and state-level emotions, lending support to the hypothesis that students can impact their teachers' emotions via their engagement in the classroom. Specifically, the higher teachers rated the motivation levels among their students, the more enjoyment and the less anger and anxiety they reported experiencing when teaching those classes (Frenzel et al, 2009).

Finally, Martin (2006) investigated the relationship between teachers' perceptions of their students' engagement and motivation and their own enjoyment of teaching. Data 
was collected from 1,019 primary and secondary Australian teachers. Student engagement and motivation was assessed via teacher-reports of six adaptive, two impeding, and two maladaptive dimensions of motivation; namely self-efficacy, valuing of school, mastery orientation, planning, study management and persistence: failure avoidance and anxiety: uncertain control and self-handicapping.

The author found that the adaptive dimensions, specifically, student self-efficacy, valuing of school, mastery orientation, planning, study management, and persistence, had the capacity to increase teacher enjoyment to a greater extent than the maladaptive dimensions had a capacity to reduce their enjoyment. Results showed that all the adaptive dimensions of student motivation were significantly correlated $(\mathrm{p}<.001)$ with teacher enjoyment, with students' mastery orientation being the strongest such correlate. Interestingly, the maladaptive dimensions of student engagement displayed a much weaker negative relationship to teacher enjoyment, which the author suggests indicates that some teachers may adaptively cope with aspects of student amotivation by focusing on the positive aspects of student motivation and giving less attention to negative aspects. These results suggest that both emotional and behavioral aspects of student motivation seem to be closely related to whether or not teachers enjoy their work.

Two additional across-national studies of teacher enthusiasm suggest that aspects of student motivation may have an impact on teachers' experiences of positive emotions. The first study by Stenlund (1995) utilized questionnaire data collected from Members of the Consortium for Cross-Cultural Research in Education. Specifically, the sample consisted of 256 American, 130 British, 212 German, 445 Japanese, 430 Singaporean, 
370 Canadian, and 233 Polish secondary school teachers. Results suggest that teachers identified students' motivation as the most important factor influencing their feelings of professional satisfaction and enthusiasm. Specifically, results indicated that teachers almost unanimously cherished student responsiveness and enthusiasm as critical factors in shaping their own enthusiasm for teaching.

The teachers in this large-scale study also consistently identified low motivation as a "discourager" of their own enjoyment and enthusiasm in the classroom. These results suggest that indicators of student engagement, such as enthusiasm and responsiveness, may be vital factors influencing how teachers feel about their jobs.

Similarly, these relationships were examined in a second large cross-cultural study of teacher satisfaction called The Teacher 2000 Project. Dinham \& Scott (2000) found that teachers' major sources of satisfaction were the personally meaningful rewards of teaching that centered around seeing students achieve and helping them change their behavior for the better. Due to their persistence and willingness to work, highly engaged students are more likely to experience success in school thus providing their teachers with the internal rewards related to helping them achieve. Taken together, the handful of studies that have examined the impact of student motivation on teacher emotions corroborate our common sense understanding of how such positive student behavior in the classroom could support teachers enjoyment and satisfaction.

Teacher positive self-perceptions. Moreover, aspects of student engagement may not only affect how teachers' feel but may also influence their perceptions of themselves as educators. Specifically, students' motivational states in the classroom can 
give teachers feedback about how well they are doing as educators. Just like any professional giving a presentation or facilitating a meeting, teachers look to their audiences' verbal and nonverbal cues to gauge their students' level of interest, understanding, and participation. It follows that engaged and disaffected students are providing their teachers with very different feedback about the success of their teaching practices, which may result in very different perceptions of their effectiveness as instructors. Indeed, educational researchers have suggested that teachers are likely to view themselves as valuable and their work meaningful to the extent that their students are paying attention and interacting positively with the learning activities (Pines, 2002).

The following section explores the limited research on how aspects of student motivation may be linked to teachers' perceptions of themselves as educators. Most mentions of the connection between student engagement and teachers' perceptions of their own value and efficacy come from large reviews or chapters on teacher stress and burnout that only include a passing mention of the potential connection between these two constructs (Hastings \& Bham, 2003; Sutton \& Wheatley, 2003). The study by Martin that was previously mentioned (2006) appears to be the only empirical study that looks specifically at the impact student motivation on teachers' self-perceptions. Although there appears to be a dearth of empirical studies directly examining the influence of student motivation on teachers' self-perceptions, the following section summarizes Martin's study as well as two empirical studies that examined the impact of two key indicators of engagement; namely student participation and responsiveness. 
Martin's 2006 study appears to be the only study that looks specifically at the impact of student motivation on teacher self-perceptions, specifically, educators' confidence in teaching (2006). The author measured student motivation using teacherreports of six adaptive dimensions of engagement and motivation; namely self-efficacy, valuing of school, mastery orientation, as well as planning, study management, and persistence. Each of these teacher-reported components of student motivation were strongly correlated with teacher confidence. Behavioral aspects of motivation seemed to be the most salient for teachers as student persistence and student planning were the strongest correlates of teachers' confidence in teaching and appeared to be relatively independent of years teaching experience. These results suggest that aspects of motivation, particularly the easier-to-observe behavioral indicators of engagement, may have the power to impact how efficacious teachers feel in their profession.

During the course of evaluating a program aimed at improving student engagement and decreasing teacher burnout, Covell and colleagues investigated the impact of student participation on teachers' sense of achievement (2009). 127 teachers from 15 schools participated in the intervention project and thus filled out questionnaires assessing their perceptions of their students' engagement as well as their own burnout. The authors used a three dimensional conception of student engagement that measured teachers' perceptions of the extent to which students showed respect for the rights of others, respect for property, and participated in the various aspects of the school and classroom. Although respect for the rights of others and property are not included in the 
current study's definition of student engagement, student participation is often considered a key component of behavioral engagement.

Unsurprisingly, student participation predicted higher levels of teachers' sense of personal achievement. Specifically, the more students participated in class, the more teachers' felt a sense of personal accomplishment from teaching. Student participation also predicted lower levels of teachers' depersonalization, suggesting that high student participation is associated with teachers' increased sense of empathy with their students. These findings indicate that there is a connection between aspects of student behavioral engagement and teachers' perceptions of their work.

Similarly, Mottet and colleagues (2004) found that students' verbal responsiveness, and to a greater extent students' nonverbal responsiveness, may influence teachers' perceptions of their effectiveness as educators. 112 instructors from a US university ranging from graduate students to full professors watched simulated classroom videos manipulated to display four different types of student responsiveness conditions; namely, High non-verbal responsiveness, Low non-verbal responsiveness, High verbal responsiveness, and Low verbal responsiveness. After watching the simulated classroom videos the teachers were asked to respond to the question "If the students in the video were your students, how effective would you be in getting them to learn?". Following this question, teacher subjects were asked to circle the number that most accurately reflected their judgment or assessment of their teaching effectiveness if the students in the video had been their own using the following bipolar adjectives: Effective/ /neffective, Efficient/Inefficient, Skilled/Unskilled, Capable/Incapable, Successful/Not Successful. 
Similarly, teachers' job satisfaction was measured by asking teachers "If the students in the video were your students, how satisfied would you be in teaching them?" and again asking them to choose which bipolar adjective best exemplifies how they would feel if the student actors in the video were their students.

Results indicated that students' verbal and nonverbal responsiveness in the classroom accounted for over a quarter of the total variance in teacher self-efficacy and over half the total variance in teacher job satisfaction. Two separate $2 \mathrm{X} 2$ analyses of variance were used to examine whether the four videotaped classroom conditions could potentially affect teachers' self-efficacy and job satisfaction. Findings indicated that teachers who were exposed to high verbally and nonverbally responsive students perceived themselves to be more self-efficacious than teachers who were exposed to low verbally and nonverbally responsive students, lends support to the hypothesis that aspects of student engagement may impact how teachers view themselves professionally. Although the research is still sparse about the potential connection between students' engaged behaviors and teachers' sense of efficacy and accomplishment, these three studies lend support for this possible association. These findings suggest that positive aspects of student motivation appear to be capable of impacting teachers' sense of accomplishment and teaching efficacy as well as their emotions.

Disaffection. Another lens by which we can conceptualize the value of student engagement to educators is by examining the potential toll unmotivated or disaffected students can take on teachers. The other side of engagement, disaffection, not only 
represents a lack of engagement, but also describes a state resulting from low student motivation. Disaffection encompasses such varied emotional states as boredom, frustration, and anxiety, which, although very different, all make it difficult for a student to positively interact with learning activities. Disaffection can manifest as withdrawal from learning activities or passively 'going through the motions' and also encompasses disruptive off-task behavior such as refusing to participate or attempting to undermine other students' learning experiences (Jimerson, Campos, \& Greif, 2003; Skinner \& Belmont, 1993; Skinner, Kindermann, Connell \& Wellborn, 2009; Skinner, Furrer, Marchand, \& Kindermann, 2008). Not surprisingly, issues stemming from students exhibiting low motivation or disruptive behaviors are among the top stressors reported by teachers (Chang, 2009; Sutton \& Wheatley, 2003; Tsouloupas, Carson, Matthews, Grawitch, \& Barber, 2010).

\section{Disaffection as a Stressor for Teachers}

Although research examining the specific impact of student disaffection on teachers is rare, the literature on teacher burnout has long identified aspects of student motivational problems as major sources of teacher stress and burnout. Student misbehavior has consistently been found to be one of the strongest predictors of teacher burnout (Covell, McNeil, \& Howe, 2009; Evers, Tomic, \& Brouwers, 2004; Pines, 2002; Hastings \& Bham, 2003; Spilt, Koomen, \& Thijs, 2011; Sutton \& Wheatley, 2003). Research demonstrates that the amount of time teachers spend on behavior management is associated with heightened levels of teacher stress (Clunies-Ross, Little \& Kienhuis, 
2008). Indeed, in a recent review, Chang concludes that student behavior stressors, resulting from pupil inappropriate behavior, are the primary antecedents of teacher burnout (2009). In his seminal study examining the student behavior patterns that contribute to burnout, Friedman's findings identified disaffected behaviors such as inattentiveness/unwillingness to learn, talking out of turn, and hostility towards others as robust predictors of teacher burnout (1995). In a later replication, researchers corroborated Friedman's findings that student disrespect and lack of sociability predicted multiple dimensions of teacher burnout including depersonalization and decreased personal accomplishment (Hastings \& Bham, 2003).

Even when combined in models examining the predictive utility of a plethora of demographic, personality, and work-related stressors on teacher burnout, managing student misbehavior has emerged as a one of the strongest predictors of teacher burnout (Kokkinos, 2007). Data from the National Center for Education Statistics suggests that student discipline problems have been found to be a major reason for teachers' dissatisfaction with their jobs, second only to low compensation (Steven \& Meyer, 2005). Other student behaviors related to disaffection, such as disruptive, resistant, or aggressive actions, are habitually reported as a major source of teacher stress (Boyle, Borg, Falzon, \& Baglioni, 1995).

Clearly, student problem behavior in the classroom can exert a powerful effect on teachers' experiences of stress and burnout. Although none of these studies directly examined the impact of student disaffection, which encompasses a broader swath of emotions and behaviors than student misbehavior, these findings do lend support to the 
hypothesis that aspects of student disaffection are not simply an annoyance but rather can create lasting impacts on teachers' wellbeing.

Before reviewing the literature on how aspects of student disaffection associated with misbehavior may impact teachers' emotions and self-perceptions, it is important to pause and further clarify why disaffection cannot be fully explained by problem behavior alone. Although especially salient to teachers, (which may explain why it dominates the research literature) disruptive or resistant actions and emotions reflect only one aspect of disaffection. More so than engagement, disaffection encompasses varied emotional states that may, in turn, be driving different disaffected behaviors. Beyond misbehavior and teacher-student relationship conflict, the multifaceted construct of disaffection includes less obvious ways to be disengaged such as withdrawal and lack-luster, grudging participation, which may reflect negative emotional states such as boredom and apathy. Other disaffected students may also withdrawn or decline to participate in class but they may do so because of anxiety or fear instead of boredom or disinterest. Therefore, the full spectrum of disaffected emotions and behaviors will not be explored in this literature review, which, due to the content of the research base, includes mostly aspects of disaffection related to misbehavior and teacher-student conflict. However, highlighting the multifaceted nature of disaffection will be important in later sections of this study when we consider whether different aspects of student disaffection may be diagnostic of different student inner experiences.

Teacher negative emotions. The following subsection reviews research findings that suggest aspects of student disaffection, such as misbehavior and rule breaking, may 
increase teachers' experience of negative emotions. Specifically, the first section discusses the potential connection between student problem behavior and teacher emotion exhaustion. Then, the role of student misbehavior in inciting teacher anger will be examined, and the research on teachers' experiences of guilt will be reviewed. Throughout the following subsection, the role of teachers appraisals and assumptions about student behavior will be discussed as a potentially important mediator through which student behavior may influence teachers' emotions.

Aspects of student disaffection such as misbehavior have been shown to be important contributors to teachers' experiences of emotional exhaustion and negative emotions. Teaching is consistently ranked as one of the professions with the highest stress-related outcomes and some researchers believe this is due to the emotional labor and emotional involvement that characterizes teachers' relationships with their students (Johnson, Cooper, Cartwright, Donald, Taylor, \& Millet, 2005). Teachers report that dealing with student misbehavior often leaves them feeling emotionally drained (Chang \& Davis, 2009). It is thus unsurprising that teacher perceptions of student misbehavior are directly and positively associated with emotional exhaustion (Tsouloupas et al. 2010; Hastings \& Bham, 2003; Chang \& Davis, 2009). A large-scale study of Norwegian teachers found that emotional exhaustion fully mediated the negative impact of student discipline problems on teacher job satisfaction, highlighting not only the impact of student disaffected behaviors on teachers' satisfaction but suggesting that teachers' emotional exhaustion may play a key role in how student behaviors influence teachers. 
Researchers interested in highlighting the role of emotions in teachers' professional lives have also explored the connection between aspects of student disaffection and teachers' experiences of anger (Hargreaves, 1998; Chang, 2009). Research suggests that teacher anger is particularly tied to disciplinary problems in the classroom and is frequently a reaction to student misbehavior or failure (Chang, 2009; Hargreaves, 2000). The finding that teachers are more likely to express anger towards disruptive students indicates that aspects of student disaffection are capable of eliciting anger from instructors. Specifically, student misbehavior and violation of rules has been found to contribute to teachers' experiences of anger and frustration in the classroom (Emmer, 1994a; Hargreaves, 2000). Teachers feel angry when they perceive their students as lazy, uncooperative, or unappreciative of their efforts during instruction (Hargreaves, 2000; Sutton, 2007).

Additionally, research suggests teachers' appraisals of student misbehavior can increase these feelings of anger if the teachers perceive the misbehaviors as intentional or controllable or if they feel the misbehaviors are disrespectful (Brophy \& McCaslin 1992; Prawat, Byers, \& Anderson, 1983). Similarly, research suggests teachers become angry when their students do not put forth effort in their schoolwork, especially if the teachers perceive the pupils to be high-ability students (Prawat, Byers, \& Andreson, 1983). Research based on a Goal Theory conception of teacher appraisals suggests that teacher anger is likely to occur when a desired goal is not attained and the cause of the failure is attributed to others (Smith \& Lazarus, 1993). This perspective suggests that disaffected behaviors such as disruptive behavior, withdrawal from learning activities, or 
unwillingness to participate, could all be capable of catalyzing teacher anger due to their ability to thwart a teacher's goal of getting all her students to successfully learn the course content.

Beyond anger, teachers' experiences of guilt have also been tied to aspects of student disaffection in the classroom. Research on people in caring professions, such as teaching, posits that teachers are likely to experience guilt if they feel they are not reaching their goals of supporting those they care for. In fact, teachers particularly dedicated to caring for their students may be the most likely to experience guilt, suggesting that disaffected students' apathy, alienation, or lack of motivation may be interpreted as failure by their teachers which could elicit feelings of guilt (Hargreaves \& Tucker, 1991). Research supports this hypothesis that students' lack of motivation predicts teachers' feelings of guilt (Prawat, Byers, \& Andreson, 1983). As with anger, it appears that teachers' assumptions about the causes of students' disaffected behaviors appear to be the drivers of their emotional experiences. Prawat et al (1983) found that the highest levels of teacher guilt were experienced when students displayed an abrupt decline in effort and success because this prompted teachers to question whether this drop was a result of their poor teaching. This linkage between teachers' experiences of guilt and their feelings of personal responsibility for their students decreased motivation or poor performance suggest that taking student disaffection personally can increase teachers' experiences of guilt.

Negative teacher self-perceptions. Interacting with students who are displaying disaffected behaviors and emotions may also be harmful to teachers because of their 
impact on teachers' perceptions of themselves and their effectiveness as educators. Although research on the specific influence of student disaffection on teachers' efficacy is lacking, constructs related to student disaffection such as lack of sociability and teacher-student conflict have been examined in terms of their ability to damped teachers' sense of efficacy and accomplishment. If, as mentioned earlier during the discussion of how engaged behaviors may influence teachers' efficacy perceptions, a lack of responsiveness may communicate the opposite feedback to teachers; namely that they aren't doing a good job captivating and educating their students. Specifically, the next section reviews findings that suggest that lack of responsiveness and teacher-student conflict appear to influence how competent teachers feel and how meaningful they judge their work to be.

Student lack of sociability has been shown to predict decreases in teachers' sense of personal accomplishment (Hastings \& Bham, 2003). This seems to suggest that students displaying disaffected behaviors such as withdrawal or lack of participation may prompt teachers to feel less successful as educators. Pines offers an explanation for this connection between student unresponsiveness and teacher lack of efficacy by suggesting that when students react to teachers' efforts with a lack of attention and interest, it makes teachers feel unimportant and find their work less meaningful, which in turn depletes their sense of accomplishment (2002).

Teacher-student relationship conflict, which is related to student maladaptive and problem behavior, also seems to be an important factor influencing teachers' perceptions of themselves and their sense of competence in the classroom. This is unsurprising as 
previous research has long acknowledged that the quality of teacher-student relationships is the central factor differentiating low and high efficacy teachers (Ashton, 1984). Indeed, the proportion of teacher-student relationships that teachers label as negative is associated with the amount of stress and negative emotions teachers' experience in the classroom (Yoon, 2002). Consequently, teacher-student relationships high in conflict appear to impact teacher's efficacy. Specifically, teacher's perceptions of teacher-student conflict, but not closeness, predicted their efficacy beliefs about themselves as educators (Spilt, Koomen, Mantzicopoulos, 2010). These findings are supported by cross-cultural research by Yoon and colleagues (2002) who found that teacher-student conflict significantly predicted teachers' perceptions of their teaching efficacy in the domains of instructional strategies and classroom management.

Taken together, these findings suggest that experiences of high teacher-student conflict can affect teachers by undermining their efficacy beliefs and evoking feelings of helplessness. Although teacher-student relational conflict is by no means a direct analogy to student disaffection, we can hypothesize that, because of their lack of participation, drive, and interest, disaffected students would me more likely to have less close and more conflictual relationships with their teachers.

Again, just as we can effortless envision how student engagement creates the type of optimal classroom climate that is ideal for teachers, we can easily imagine why disaffected students can be a powerful source of stress and exhaustion for teacher. Both intuitive and empirical findings are in agreement in suggesting that experiences stemming from student disaffection and lack of motivation can have serious consequences for 
teachers' health and retention in the profession (Chang, 2000; Evers, Tomic, \& Brouwers, 2004; Sutton \& Wheatley, 2003). Thus, at both ends of the motivational spectrum, the manifestations of student motivation in the classroom are salient and significant to teachers.

\section{Reciprocal Effects}

The previous section of the literature review suggests that student motivation may not solely impact the students themselves, but may also be capable of affecting their teachers' experiences of positive and negative emotions in the classroom as well as educators' perceptions of their teaching efficacy. In the following section, this line of thought is taken a step further with the suggestion that because of their effects on teachers' experiences, student engagement and disaffection may also impact the quality of teachers' subsequent interactions with students. If students' motivational states in the classroom are indeed affecting such essential aspects of teachers' daily experiences, it follows that these teacher experiences may, in turn, influence the types of interactions and relationships that teachers and students have. If aspects of students' engagement and disaffection are capable of eliciting joy, anger, burnout, and professional fulfillment in their teachers, then it seems possible that student motivation could also impact how teachers behave towards students. Simply put, if students are capable of impacting teachers' emotions, they are probably also able to impact teachers' actions.

The proposition that student characteristics may be capable of impacting teacher behavior has already been tested in several lines of research. Although little research has investigated whether teachers treat students differently based on students' academic 
motivation, there is an extensive history of research on teachers' differential treatment of students based on other student characteristics. Student race and gender, socioemotional adjustment, attachment, as well as teacher expectancies for student achievement and students' past achievement have all been shown to result in teachers' differential treatment of students (for reviews, see Sadker, Sadker \& Klein 1991; Babad 1993; Nurmi, 2012). Additionally, the parenting literature has readily documented the potential influence that child characteristics play in eliciting differential behavior from adults. Beginning in the late 1960s, researchers began considering children as active interaction partners capable of shaping the behavior of the adults in their lives which spawned experimental research systematically assessing parents' reactions to children (Bell, 1968; Bell, 1977). Findings from these parent-child reciprocal effects experimental studies suggest that how children behave towards adults predict the type and quality of adults' subsequent interactions with these children. For example, studies that utilize child confederates in order to systematically assess adults" reactions to "easy" and "difficult" child behavior conditions have found that children's behavior is capable of affecting adults' verbal and non-verbal behavior, the quality of child-adult interactions, and adult's provision of autonomy support (Jelsma, 1982; Brunk \& Henggeler, 1984). Although reciprocal effects studies of children and parents may not be completely generalizable to student-teacher relationships, these studies provide strong causal support for Bell's model of parent-child bidirectionality and thus the idea that children are not simply sponges to absorb adult input but are also members of a dyadic system that helps produce their social contexts via their impacts on the adults in their lives. 
Although the idea that child characteristics can educe differential behaviors from teachers is not novel (see Nurmi 2012 for a meta-analysis), research that explicitly investigates the impact of student motivation on teachers' behavior is thin. Only a dozen could be located. The following section reviews the limited research literature on the impacts of student motivation on teacher behavior and teacher-student relationships. Although only two of the twelve studies reviewed specifically measure engagement and disaffection, the constructs the other ten studies explore directly tap emotional and behavioral components of engagement and disaffection in the classroom.

First, two studies assessing the effects of student engagement and disaffection and three additional studies examining the impact of student motivation on teachers are reviewed. The remaining studies investigate constructs that are often operationalized as indicators of student engagement and disaffection. Specifically, two studies examining participation and two studies assessing student enjoyment are reviewed. Although not strictly studies of motivation, active student participation can be conceptualized as a key indicator of student behavioral engagement and enjoyment of school can be considered a key component of student emotional engagement. Finally, six studies that examine the influence of varied metrics of student problem behavior are reviewed to help our understanding of the impact of student disaffection on the quality of teacher student interactions and relationships. Specially, the reviewed studies examined maladaptive classroom behaviors using measures of internalizing and externalizing behaviors, antisocial behaviors, aggressive and withdrawn behaviors, as well as student anger and shyness. By reviewing studies assessing student characteristics such as student 
participation and school liking, as well as aspects of student misbehavior, this section hopes to coalesce key findings of related research to compensate for the dearth of research directly assessing the reciprocal effects of engagement and disaffection on changes in teacher support. (See table 1.1 for a summary of reciprocal effects research studies). 


\begin{tabular}{|c|c|c|c|}
\hline 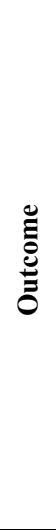 & 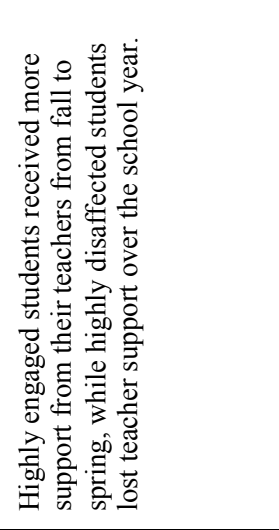 & 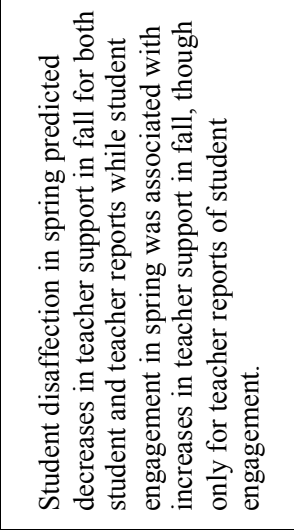 & 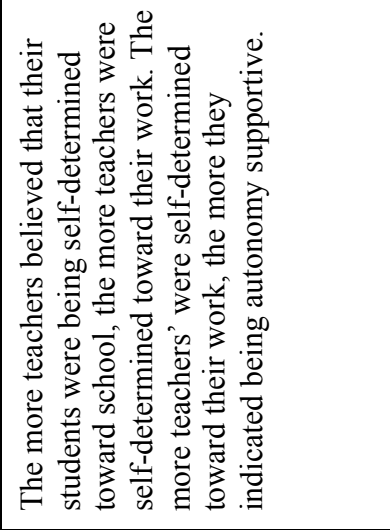 \\
\hline 它 & 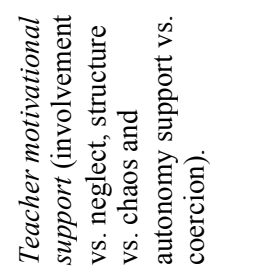 & 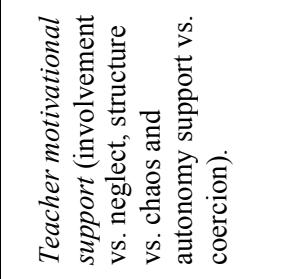 & 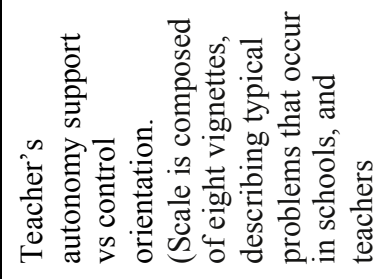 \\
\hline$\geq$ & 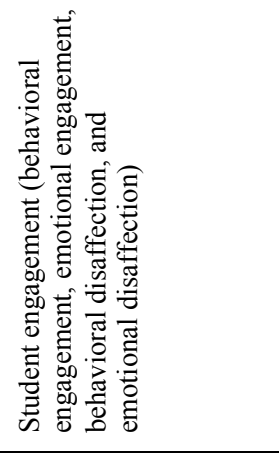 & 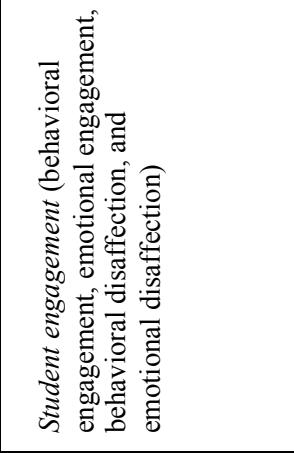 & 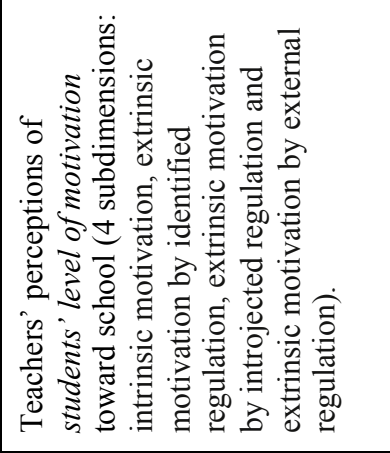 \\
\hline 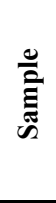 & 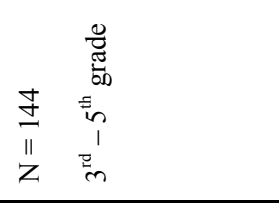 & 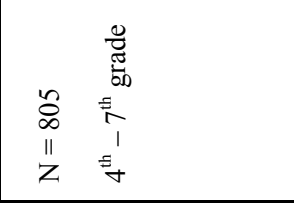 & 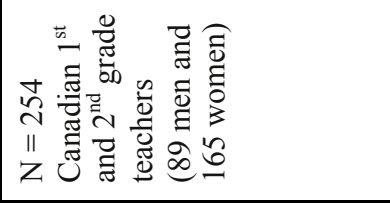 \\
\hline 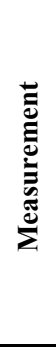 & 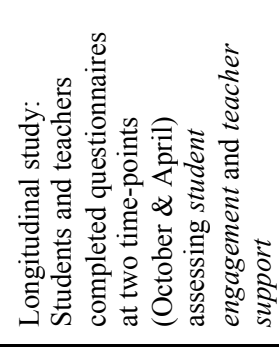 & 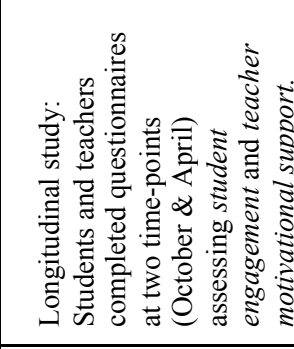 & 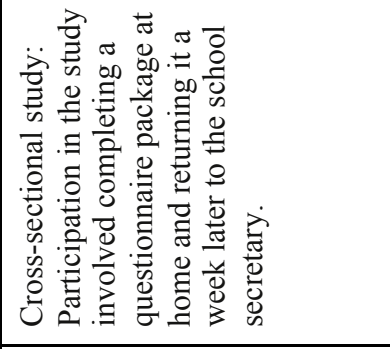 \\
\hline 胥 & 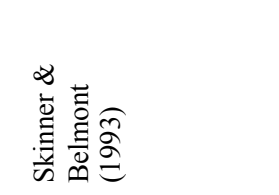 & 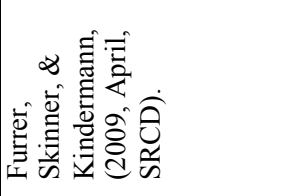 & 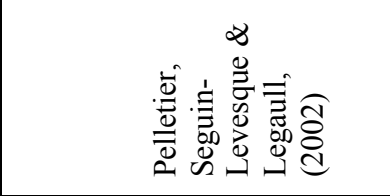 \\
\hline
\end{tabular}




\begin{tabular}{|c|c|c|c|}
\hline 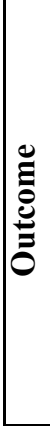 & 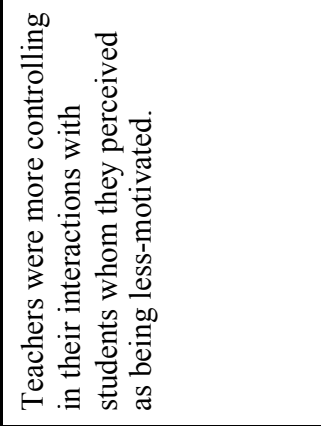 & 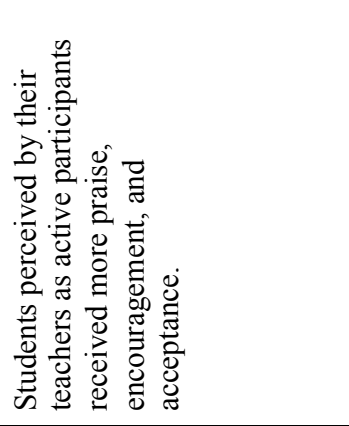 & 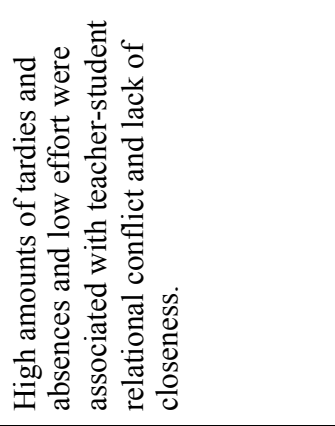 \\
\hline$\vec{\theta}$ & 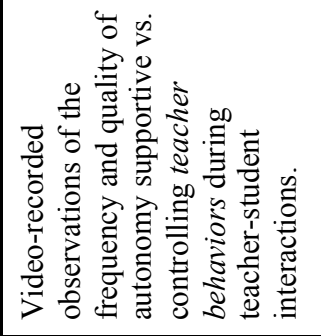 & 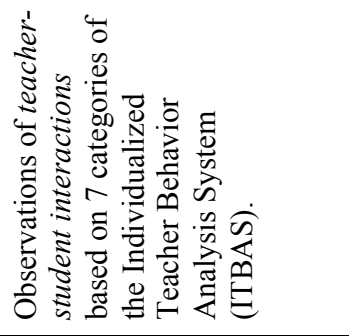 & 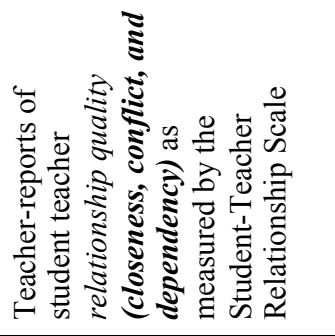 \\
\hline $\mathbb{Z}$ & 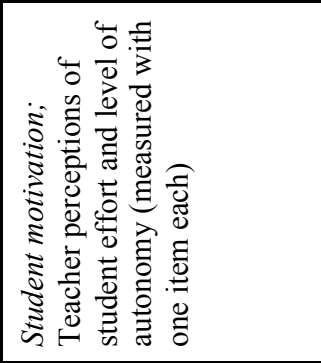 & 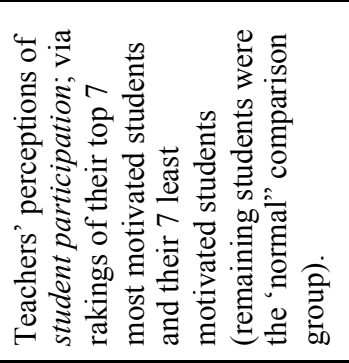 & 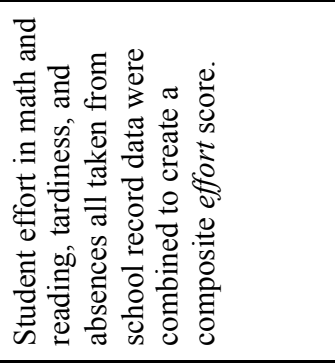 \\
\hline 咅 & 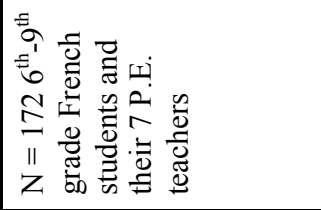 & 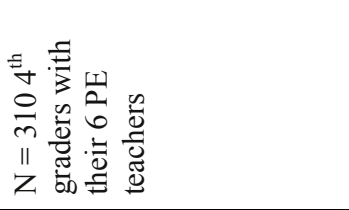 & 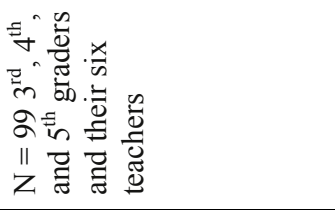 \\
\hline 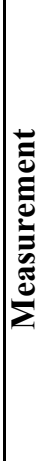 & 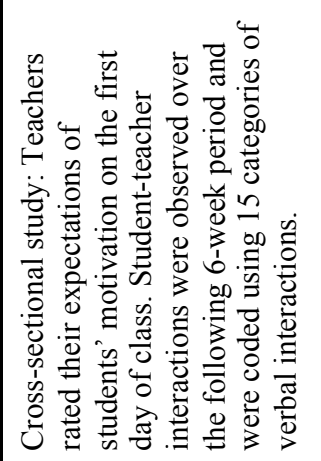 & 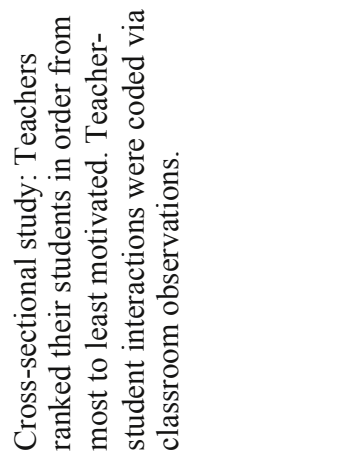 & 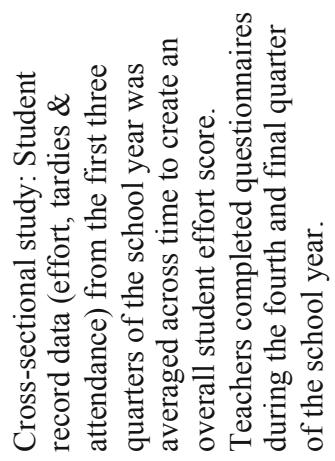 \\
\hline 突 & 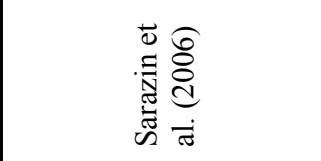 & $\begin{array}{l}\stackrel{0}{\circ} \\
\stackrel{\partial}{a} \\
\stackrel{a}{\Xi}\end{array}$ & 离蛋舌 \\
\hline
\end{tabular}




\begin{tabular}{|c|c|c|c|c|}
\hline 芯 & 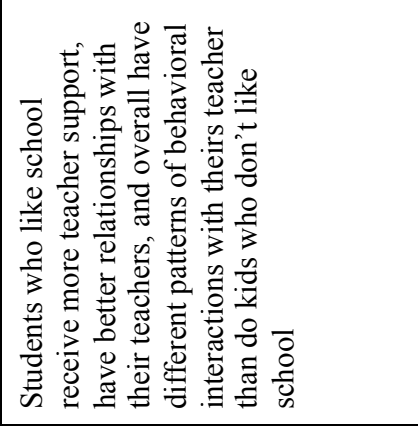 & \multicolumn{3}{|c|}{ 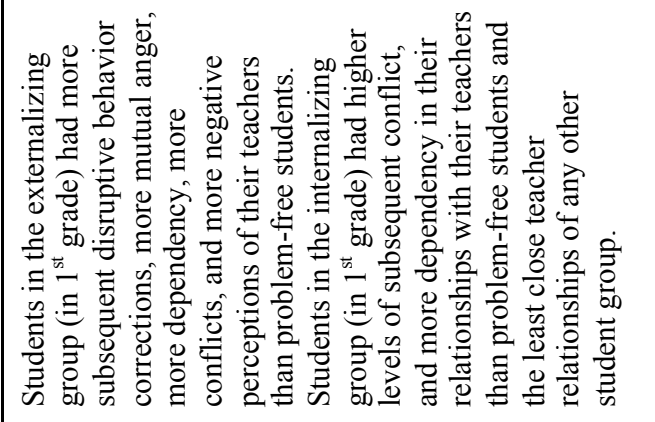 } \\
\hline$\vec{b}$ & 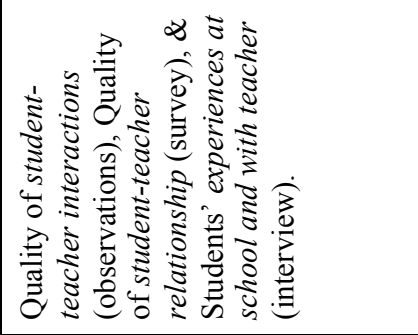 & 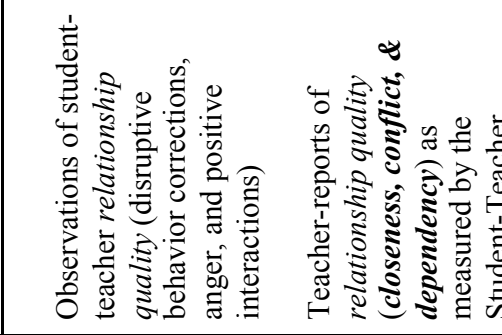 & & 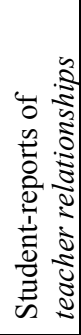 \\
\hline $\mathbb{Z}$ & 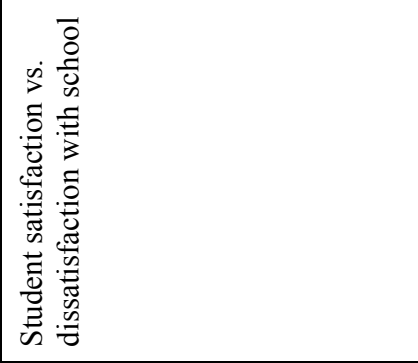 & 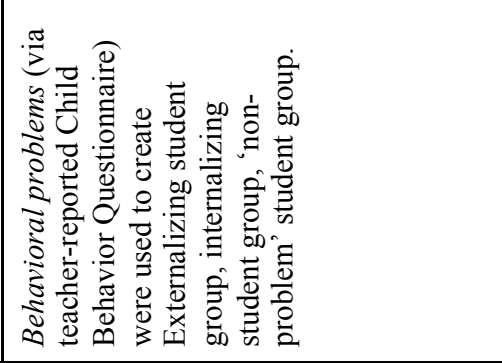 & & \\
\hline $\mid \frac{0}{\bar{z}}$ & 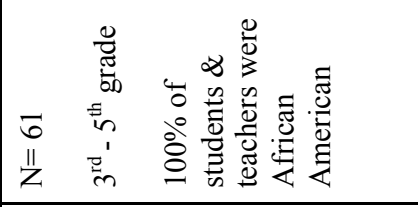 & 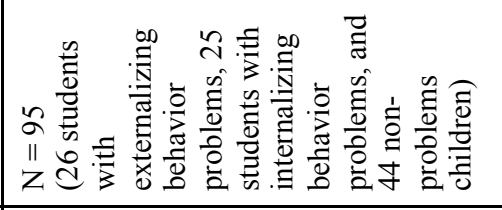 & & \\
\hline 芦 & 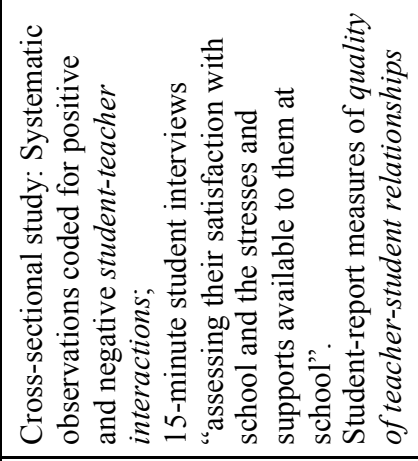 & 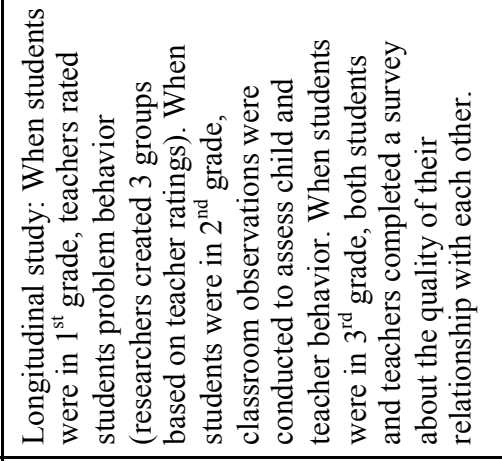 & & \\
\hline$\frac{\vec{b}}{\dot{n}}$ & 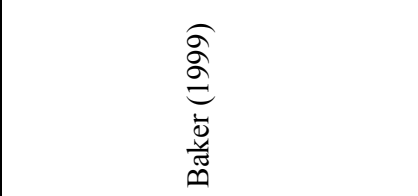 & 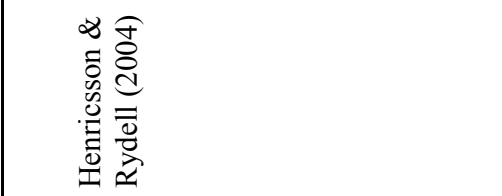 & & \\
\hline
\end{tabular}




\begin{tabular}{|c|c|c|}
\hline 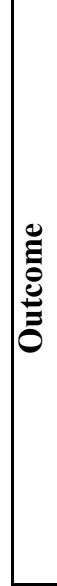 & 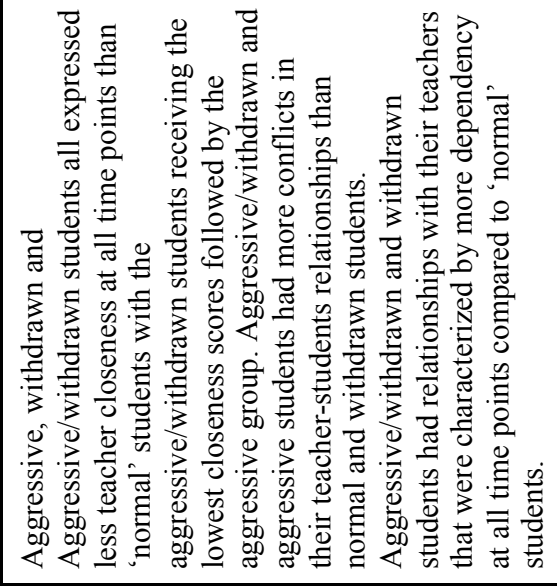 & 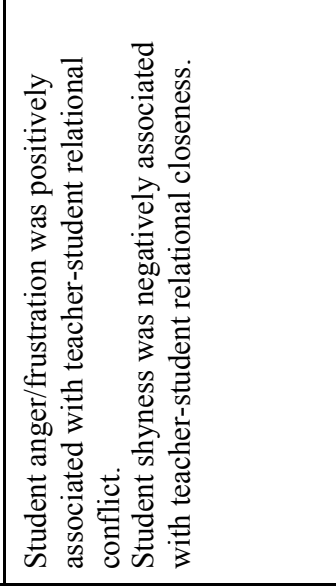 \\
\hline$\vec{a}$ & 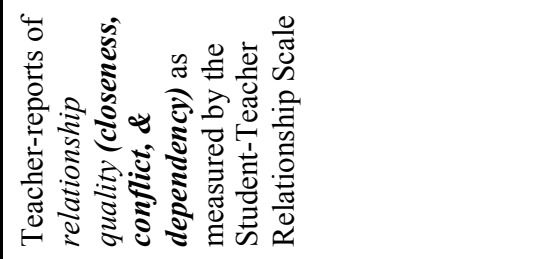 & 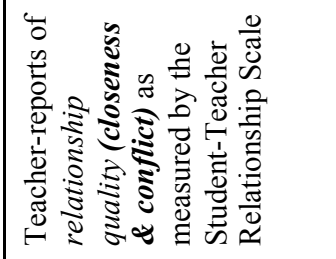 \\
\hline $\mathbb{Z}$ & 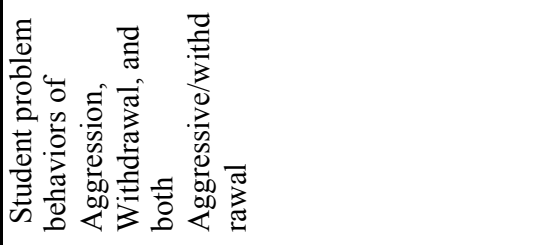 & 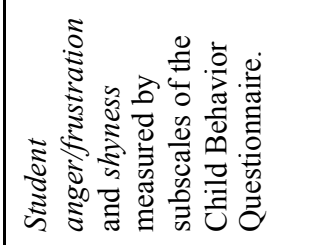 \\
\hline מू̆ & 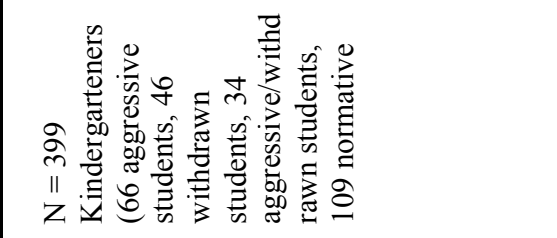 & 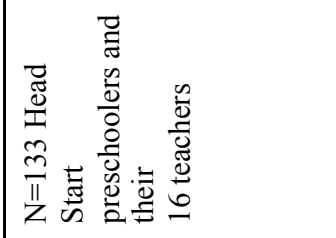 \\
\hline 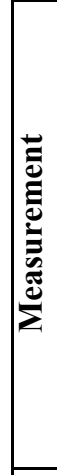 & 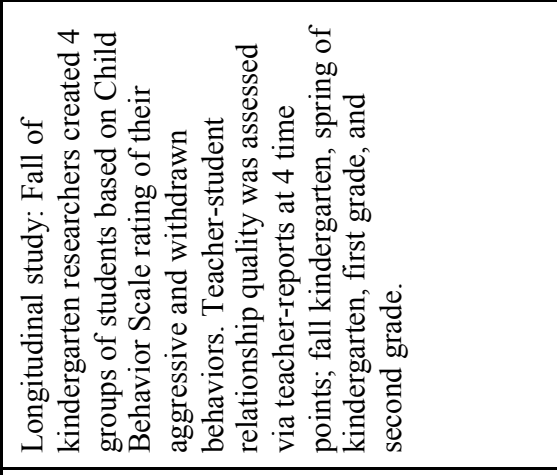 & 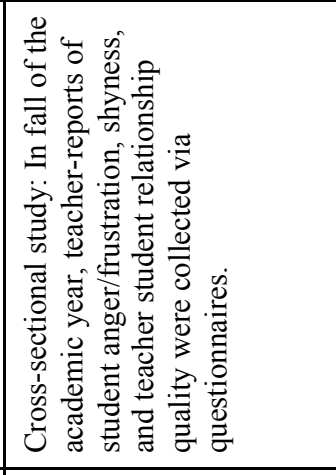 \\
\hline 它 & 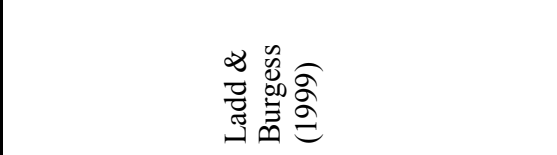 & 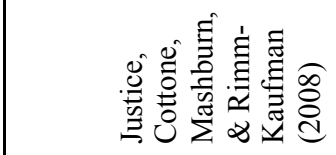 \\
\hline
\end{tabular}




\begin{tabular}{|c|c|c|}
\hline 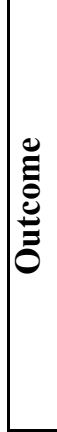 & 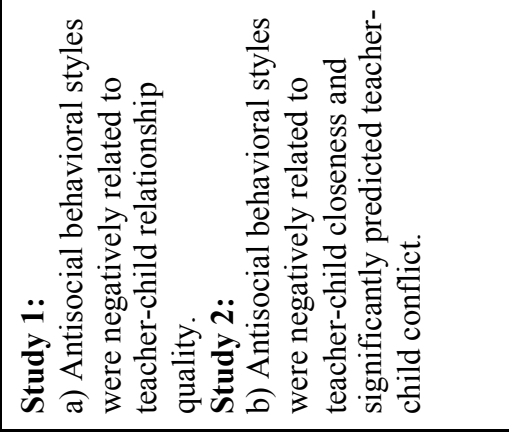 & 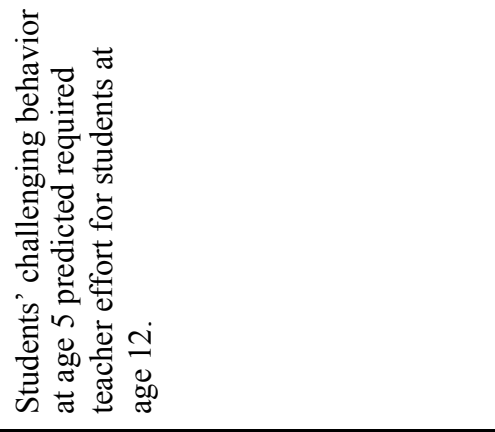 \\
\hline 方 & 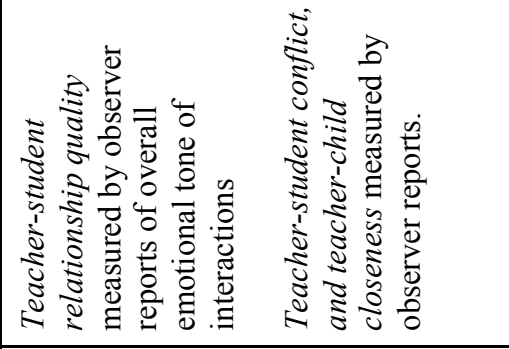 & 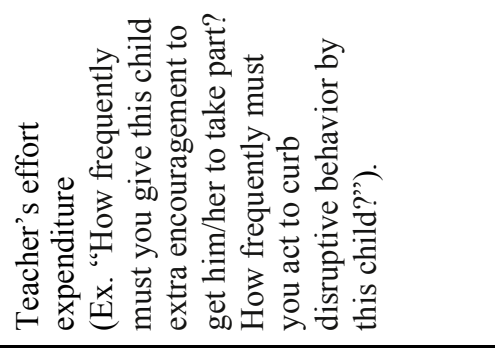 \\
\hline$\geq$ & 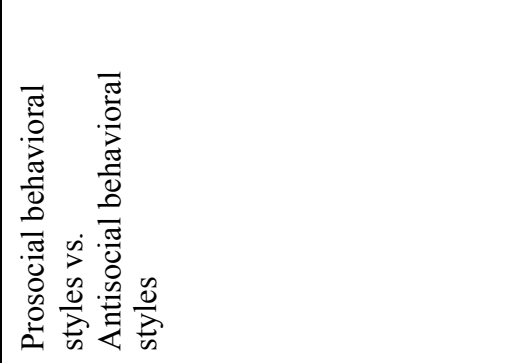 & 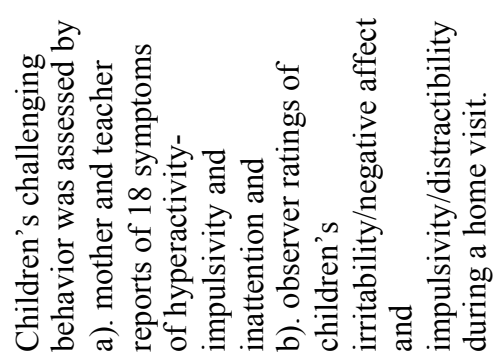 \\
\hline $\mid \frac{0}{\bar{z}}$ & 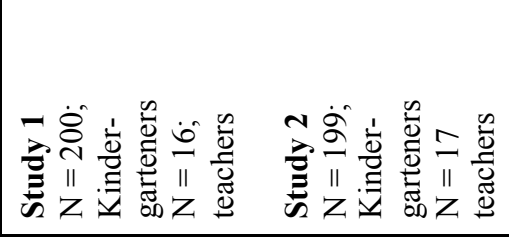 & 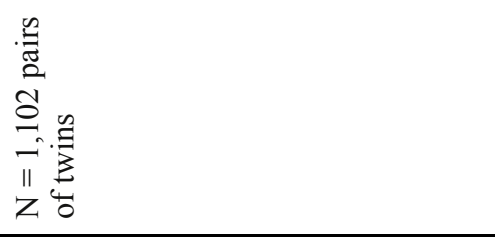 \\
\hline 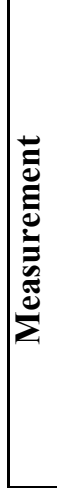 & 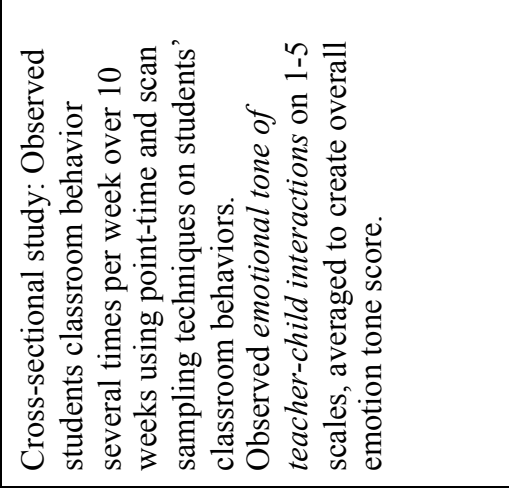 & 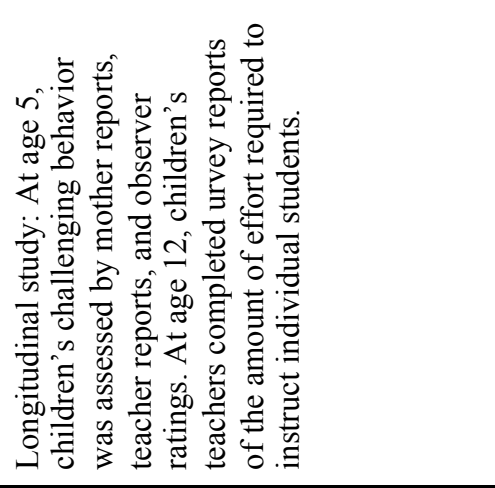 \\
\hline$\frac{\tilde{E}}{\tilde{E}}$ & 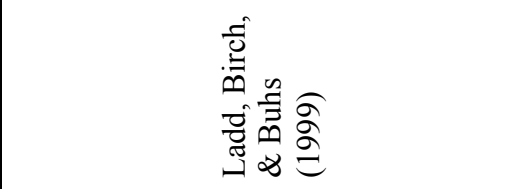 & 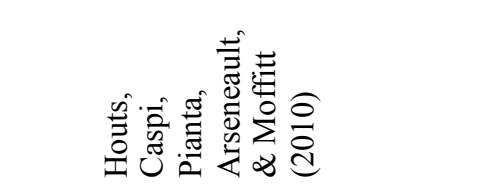 \\
\hline
\end{tabular}




\section{Student Engagement and Disaffection}

1. Skinner and Belmont (1993). Skinner and Belmont (1993) conducted one of the only studies that directly examined the reciprocal effects of student engagement on changes in teachers' provision of motivational support over time. In accordance with a self-system model of motivational development, which assumes an individual's motivational outcomes are optimized when her interactions with her social contexts fulfill the three universal psychological needs for relatedness, competence and autonomy outlined by Deci and Ryan's (1985) self-determination theory, this study tested a model specifying the feedforward and feedback relationships between student motivation and teacher support. More specifically, the full model explored the typical feedforward effect, examining whether teachers' provision of motivational support could predict changes in students' perceptions of that support, which could in turn predict changes in students' emotional and behavioral engagement. The feedback or reciprocal effects, on which this review will more closely focus, were also investigated. The study examined whether teachers' perceptions of students' emotional and behavioral engagement predicted changes in teachers' reports of the motivational support they subsequently provided to students.

Student motivation was assessed by measures of (1) emotional engagement, which tapped students' emotional reactions in the classroom and (2) behavioral engagement, which tapped students' effort, attention, and persistence in learning activities. Teacher motivational support was measured by assessing the extent to which teachers provided their students with involvement, structure, and autonomy support. 
Students and teachers completed questionnaires at two time-points, fall and spring (October \& April), assessing student engagement [61 item student-report; 33 item teacher-report] and teacher support [65 item student-report; 62 item teacher-report]. By utilizing two time points, this study was able to assess how levels of teacher support changed across the school year. By collecting ratings from student and teacher reporters for both of the constructs of interest (although only teacher reports of student engagement were used in the examination of reciprocal effects), this study has the added benefit of utilizing multiple perspectives through which to view the association between student motivation and teacher support over time.

In a sample of $3^{\text {rd }}$ through $5^{\text {th }}$ grade students, the authors conducted a time-lagged path analysis such that the dependent variable was the target construct measured in spring and the predictor variables were all the constructs measured in fall that preceded the target construct in the model. Though each link in the path analysis was examined, of specific relevance to this review are the findings from regression analyses examining the effects of teachers' perceptions of students' engagement in the fall on changes in teacher and student reports of the three sub-dimensions of teacher support from fall to spring. . In spite of the high stabilities (cross-year correlations) of teacher support, findings demonstrated that student behavioral engagement uniquely predicted changes in teacher support from fall to spring. For both student and teacher reports, findings suggest that students who were perceived by their teachers as being highly behaviorally engaged in fall received increasingly more of all three teacher support behaviors in spring than students who were perceived as less engaged. Unfortunately, students who were 
perceived as more behaviorally disaffected in fall were more neglected, more coerced, and treated with less consistency and contingency by their teachers in spring. However, teachers' perceptions of students' emotional disaffection in fall were positively related to changes in teachers' provision of autonomy support, suggesting that teachers may attempt to compensate for students' negative emotions in the classroom by providing students with more choices and more opportunities for self-direction.

2. Furrer, Skinner, and Kindermann (2003). Further evidence for the reciprocal effects of student motivation on changes in teacher support was found by Furrer, Skinner, and Kindermann (2003). In order to establish the direction of effects, the authors utilized a similar two time-point design in which students and teachers completed surveys assessing student motivation and teacher support in fall and spring of the same school year. Both student and teacher surveys measured four indicators of student motivation (behavioral engagement, emotional engagement, behavioral disaffection, and emotional disaffection) as well as six-sub dimensions of teacher motivational support (involvement vs. neglect, structure vs. chaos and autonomy support vs. coercion). Unlike Skinner and Belmont (1993) who relied on reverse coding engagement items, the authors made a distinction between engagement and disaffection in order to distinguish the reciprocal effects of engagement from those of disaffection.

Consistent with Skinner and Belmont's findings, this study found that engaged students gained teacher support while disaffected students lost teacher support from fall to spring. Across reporters, students who were more disaffected in the fall experienced greater declines in teacher support over the school year, with the most consistent 
predictor across reporters being behavioral disaffection. The findings concerning emotional disaffection were somewhat more contradictory as students who reported experiencing higher anxiety rated their teachers as withdrawing support whereas teachers reported that they increased their involvement with students who displayed such aspects of emotional disaffection. The effects of engagement were not as pronounced as those for disaffection. For teacher reports, both emotional and behavioral engagement predicted modest increases in teacher support from fall to spring. However, for student reports, the authors found no significant association between engagement and teacher support. Finally, the authors confirmed their hypothesis that teacher perceptions of students' engagement mediated the association between students' reports of their engagement and teachers' provision of motivational support.

Taken together, Skinner and Belmont (1993) and Furrer, Skinner, and Kindermann (2003) suggest that teacher support and student motivation not only feed forward, as previously established, but may also feed backwards, suggesting the possibility of a self-perpetuating cycle. While engaged students are receiving more motivational fuel from their teachers, disaffected students, who would seem to need teacher support the most, are receiving less of it, thereby setting the stage for further erosion of their academic motivation.

\section{Student Motivation}

3. Pelletier, Seguin-Levesque and Legaul (2002). Although there appear to be no other studies that look explicitly at the constructs of engagement and disaffection, there 
are several studies that examine how similar student behaviors and attitudes affect teachers' behavior. Namely, Pelletier, Sequin-Levesque and Legaul also utilized a selfdetermination theory (SDT) framework to examine how students' motivation in the classroom may influence the quality of teachers' autonomy support. Although the crosssection study design does not allow the researchers to establish the direction of effects, this study does add to the underdeveloped research on the feedback effects of students' motivational states on their teachers.

Pelletier, Sequin-Levesque and Legaul, who were particularly interested in exploring the possible determinants of teachers' autonomy supportive behaviors in the classroom, examined how teachers' perceptions of student motivation can impact teachers' motivation towards their work and teachers' consequent provision of autonomy support. Findings suggested that the more teachers perceived their students to be extrinsically motivated, the more they themselves indicated being extrinsically motivated towards teaching, and the less likely they were to be autonomy supportive in their interactions with their students.

Participants were 254 Canadian $1^{\text {st }}$ and $2^{\text {nd }}$ grade teachers who completed a questionnaire package at home measuring their perceptions of strain, student motivation, their own motivation towards teaching, and their provision of autonomy support. Student motivation and teacher motivation were measured by four subscales, designed to assess the motivational constructs identified by SDT, tapping intrinsic motivation, extrinsic motivation by identified regulation, extrinsic motivation by introjected regulation, and extrinsic motivation by external regulation. In order to create a composite score of how 
self-determined students and teachers were overall, intrinsic motivation by identified regulation items were assigned weights of 2 and 1, and introjected and external regulations were assigned weights of -1 and -2 , respectively. While the current study focuses solely on the impact of student motivation, Pelletier, Seguin-Levesque and Legaul also considered the impact of professional strain as measured by scales tapping pressure from colleagues, school administration, and performance standards/curriculum, to gain a more holistic view of the stressors teachers face every day. Teacher's autonomy support versus control orientation was measured by teachers' responses to eight vignettes describing typical problems that occur in the classroom. Teachers' ways of dealing with the problems presented were coded as either highly autonomy supportive, moderately autonomy supportive, moderately controlling, or highly controlling.

Using structural equation modeling, the authors found support for their proposed four factor mediated model which suggests that student motivation may affect teachers' own motivation and their behavior towards students. Results indicated that the mediated model provided the best fit with the data: Teachers' motivation towards work mediated

The relationship between teachers' perceptions of student motivation and teacher provision of autonomy support versus coercion was mediated by teachers' motivation towards work such that teachers' motivation explained $13 \%$ of the variance of teachers' autonomy support. It appears that the more teachers believed their students were selfdetermined (intrinsically motivated), the more self-determined teachers were towards their own work. In turn, the more self-determined teachers were towards their work, the more autonomy supportive their behavior were towards students. Although the study's 
design, in which all measures were collected as at single time point, prevents this study from establishing directional causality, this study highlights the burgeoning work exploring how students' motivation in the classroom is linked to teachers' provision of autonomy support.

\section{Sarrazin, Tessier, Pelletier, Trouilloud, \& Chanal (2006). Sarrazin and}

colleagues investigated whether teachers' expectations of their students' motivation was related to the quality of teachers' interactions with students across a 6-week P.E. lesson. Specifically, building on the work done by Skinner, Pelletier, and their colleagues, the authors hypothesized that teachers would provide more autonomy support to students' whom they perceived as being more intrinsically motivated and, conversely, that teachers would be more controlling in their interactions with students whom they viewed as being less motivated. Utilizing video-taped observations of teacher-student interactions during PE lessons over the course of 6 weeks, the authors' findings suggested that, surprisingly, teachers interacted less with students they judged as more motivated. Perhaps this decrease in the frequency of interactions may be conceptualized by teachers as a form of autonomy support; specifically they may think 'this student is doing well on her own. I don't need to intervene'. More consistent with previous findings, results also found that students' who were perceived to be less motivated were treated in a much more controlling way by their teachers. Thus, these cross-sectional findings partially align with previous findings utilizing a similar SDT-perspective that indicates the possibility of 
vicious cycles wherein the students that would benefit the most from teacher autonomy support are the least likely to receive it.

The authors utilized teacher reports, student reports, and observer ratings to assess the relationship between students' motivation styles and teachers' provision of autonomy supportive vs. controlling instruction. Specifically, at the conclusion of the first day of an 8-week gymnastics course, teachers rated their expectations for each student in terms of the effort and level of autonomy teachers felt each student was capable of. The authors also administered questionnaires to assess student-reported motivation to create a composite variable (the self-determination index) indicating students' actual level of selfdetermined motivation, which they controlled for in all their analyses, perhaps because the authors were interested in isolating teacher perceptions. The frequency and type (autonomy supportive vs. controlling) of all individual teacher-student interactions were computed for each student from 15 categories of verbal interactions (e.g., questions, encouragements, perspective-talking statements, and criticism). $1726^{\text {th }}-9^{\text {th }}$ French students and their seven PE teachers were videotaped for 6 weeks and coding of the resulting 6,369 teaching behaviors directed at individual students suggested that, across participants, teachers showed a prevalence of controlling behaviors.

Partial correlations between teachers' expectations of motivation and teaching behaviors while controlling for differences in students' self-determined motivation indicated that, contrary to other findings, teachers initiating fewer interactions with students they judged to be highly motivated. Perhaps more worrying than a lack of initiated interactions with highly motivated students, teachers were more controlling with 
students they perceived as being less motivated. Specifically, when teachers had expectations of low student motivation, they were more likely to give organizational communications in a controlling way, provide hints in a controlling way, to ask controlling questions, to criticize, to give negative communications related to the student's social behavior or work and they were less likely to ask autonomy-supportive questions.

These findings suggest that teachers' beliefs about their students' abilities to demonstrate effort and self-directed spontaneous involvement in school activities influence their teaching behaviors. Specifically, it appears that teacher expectations about the lack of motivation among some students can potentially guide them to adopt a controlling and coercive interaction style with these students. Consistent with the previous studies, these findings suggest that teachers may react to unmotivated students in a way that research suggests will likely lead to less self-determined motivation and quality engagement among students, which would eventually confirm the teachers initial beliefs.

\section{Participation and Effort}

Although there appear to be no other empirical studies specifically examining the reciprocal effect of student motivation, the following two studies tap behavioral engagement by examining student participation, effort, and attendance. As discussed

previously, measurement work on the constructs of engagement and disaffection suggest that each is comprised of an emotional and a behavioral component. Structural analyses 
of items tapping both engagement and disaffection indicate that a four-factor model, which separates both engagement and disaffection into their emotional and behavioral components, best reflects the structure of engagement in elementary and middle school (Skinner, Furrer, \& Kindermann, 2009). Thus, while some studies fall short of examining these complex motivational constructs in their entirely, studies that examine indicators of behavioral engagement still hold value in terms of strengthening the assertion that aspects of student motivational states in the classroom may be capable of influencing the way teachers react to their students.

5. DeVoe (1991). DeVoe was interested in examining how teachers' perceptions of students' level of class participation could potentially impact teachers' behaviors. Specifically, the author used teacher-ratings of students' levels of participation and observations of teachers' behavior towards individual students to examine the potential relationship between the participation aspect of behavioral engagement and the quality of teacher instruction. Findings suggest that students perceived by their teachers as having high participation received more positive teacher behaviors than their peers. The crosssectional findings suggest that students who teachers viewed as possessing high levels of aspects of student engagement at the beginning of class appear to elicit more subsequent overall teacher interactions as well as more positive teacher interactions.

The participants in this study were $3264^{\text {th }}$ graders and their six PE teachers who were observed over the course of 36 class sessions using the Individualized Teacher Behavior Analysis System (ITBAS). First, instructors were asked to rank their students as 
having either high participation (top 7 students) low participation (bottom 7 students) or medium participation (remaining students). Then, observers coded teacher-student interactions based on seven categories of the ITBAS including accepts feelings, praises or encourages, accepts or uses ideas, asks questions, lecturing giving directions, and criticizing or justifying authority. Across the six teachers, instructors directed 4,632 individualized teacher behaviors towards 310 students over the course of the 36 observed classes.

Findings suggest that differential levels of student participation did appear to elicit differential teacher behaviors. Namely, utilizing $2 \mathrm{X} 3$ multivariate analyses of variance, the author found than students who were perceived as having high participation received more subsequent praise and encouragement than students perceived as having low participation. Additionally, the observations also revealed that teachers accepted or used ideas from students with high participation more than from students viewed as displaying low participation. Finally, when looking at total teacher behaviors across categories, high participation students received a higher number of teacher interactions overall than did either their medium or low participation peers. Taken together, these results suggest that students judged as being active participants in learning activities are likely to garner more attention, praise, and respect for their ideas from their teachers. As participation is a key indicator of behavioral engagement, these results further support the idea of the existence of virtuous cycles in which students' high engagement elicits the kinds of positive teacher behaviors and support which in turn are likely to encourage increases in student engagement. 
6. Murray and Murray (2004). Murray and Murray were also interested in how participation and effort may impact teachers' interactions and the quality of their relationships with students. The authors were particularly focused on how student demographics (gender and race) may interact with students' levels of effort and attendance to elicit differential amounts of teacher-rated conflict, closeness, and dependency in the teacher-student relationship. Results suggest that these student variables accounted for a significant amount of the variance in teachers' rating of the levels of conflict and closeness in teacher-student relationships. Specifically, high amounts of tardies and absences, and low levels of effort were associated with teacherstudent conflict and lack of closeness. These results expand on the research on teacher differential behavior towards students of different races and genders and add to the sparse research on how student participation also factors into the complex way that students shape the quality of teacher-student relationships.

The authors used school record data from the first three quarters of the school year to predict the quality of teacher-reported teacher-student relationships at the end of the school year. Specifically, student effort was collected via students' report cards as all students received a grade for "effort in reading" and "effort in math" each quarter of the school year (these scores were averaged across discipline and over time to create an “overall effort" variable). Student participation was measured by the number of absences and tardies each student had across the first three quarters of the school year, giving each student overall scales for both absenteeism and tardiness. The quality of teacher-student 
relationships was assessed via the 28-item Student Teacher Relationships Scale (STRS) that measures attachment-like qualities and is divided into three categories, namely conflict, closeness, and dependency. Study participants were 99 third, fourth, and fifth grade students and their six teachers. $86 \%$ of the students were students of color and $96 \%$ of them were from lower SES backgrounds.

Multiple regression analyses were conducted to assess the combined and unique contributions of student demographics and indicators of student behavioral engagement (effort and attendance) on the teacher-student relationship patterns. After controlling for student demographic variables, student academic effort accounted for a significant portion (about a quarter) of the variance in subsequent teacher-student conflict scores. Effort's significant negative association with conflict indicates that students with higher effort scores had lower conflict scores, which suggests this aspect of behavioral engagement seems to be a protective factor against subsequent teacher-student relational conflict. Similarly, effort but not attendance, was significantly associated with later teacher-student relational closeness such that effort during the first part of the year accounted for about $10 \%$ of the variance in closeness scores at the end of the year. Thus, student effort appears to support closeness in teacher-student relationships. Finally, neither effort nor attendance contributed significantly to later dependency scores, suggesting that students' academic exertion and participation does not appear to influence teachers' perceptions of how dependant students are on them for emotional and physical support. In conclusion, this study lends empirical support to the hypothesis that 
behavioral aspects of student engagement such as effort are capable of influencing the quality of teacher student relationships.

\section{Satisfaction with School}

In addition to studies examining the impacts of components of students' behavioral engagement such as participation and effort on teachers, the following empirical study examined the influence of aspects of emotional engagement. Less observable, but arguably more powerful, emotional engagement often proceeds and guides behavioral engagement and thus has the potential to influence how teacher-student relationships and interactions (Skinner, Kindermann, \& Furrer, 2008). The following study examined the extent to which satisfaction (vs. dissatisfaction) with school potentially influence teachers' differential relationships with students.

7. Baker (1999). A study by Baker (1999) investigated whether student satisfaction or dissatisfaction with school was related to the quality of student-teacher relationships and the extent to which students felt that their teachers and classrooms were supportive and positive. Presumably, students who like school would be more highly engaged while students who dislike school would be more likely to be disaffected. The authors used a cross-sectional, multi-methods approach utilizing observations, qualitative interviews, and surveys to assess the differential association between teacher-student interactions and relationship quality for students who are satisfied with school compared to students who are dissatisfied with school. Participants were 61 African American $3^{\text {rd }}-5^{\text {th }}$ grade students selected from a pool of 126 students based on their scores on the Multidimensional 
Student Life Satisfaction Scale. Students who scored in the upper quartile were placed in the "satisfied with school" group while students who scored in the lower quartile made up the "dissatisfied with school" group. While this extreme group design excluded students with ambivalent or neutral attitudes towards school, it served the important function of creating groups that were more likely to reflect meaningfully different motivational states.

Utilizing logistic regression analyses, the author found that students who liked school received more teacher support, had better relationships with their teachers, and overall had different patterns of behavioral interactions with theirs teacher than did children who did not like school. Baker found that dissatisfied students received almost twice as many behavioral reprimands and 5.5 times more negative comments from their teachers than did their satisfied peers. Student interviews revealed that students who were dissatisfied with school, in comparison to satisfied students, were more likely to report getting in trouble at school, more likely to report they had problems getting along with their teachers, less likely to report their teacher cared about them, and less likely to cite their relationship with their teacher as what made their classroom a nice place to be. Finally, students who were highly satisfied with school reported that they received more social support from teachers and reported experiencing "a significantly more positive and caring classroom social environment than did their dissatisfied peers" (p 64).

These findings support the idea that students who like school and students who don't like school may have different experiences at school because of the differential ways their teachers interact with and relate to them. This study posits that student school 
satisfaction and dissatisfaction can potentially manifest as salient, observable constructs that influence teacher support and the overall student-teacher relationship. However, considering the measures were concurrent, it is not really possible to determine whether these are feedforward or feedback effects. Though the researchers' interpretation of this study suggests that students who are highly satisfied with school forge better relationships with their teachers, these findings could also be interpreted as indicating that students who have high quality relationships with their teachers are more likely to report high overall satisfaction with school. The indefinite nature of these interpretations emphasizes the need for longitudinal studies that directly assess the causal impacts of student motivational states.

\section{Student Maladaptive Behavior}

In this final section exploring research on the reciprocal effects of aspects of student motivation on teachers, we will examine findings related to how student problem behavior can impact teachers. In the same way that student problem behavior is one of the strongest predictors of teacher stress, burnout, and negative emotions, research suggests that maladaptive student behavior appears to be capable of shaping how teachers react and relate to their students. Specifically, the following section reviews qualitative and quantitative findings on the potential influence of varied markers of challenging student behavior on teacher-student relationships. Although these student behaviors and characteristics do not capture all of the components of disaffection (especially the multidimensional construct of emotional disaffection), they do tap important indicators of 
disaffection and thus could shed light on the current study's investigation of how student disaffection in the classroom may be related to how teachers subsequently interact with their students.

The following section reviews six studies that examine the potential influence of aspects of student disaffection on teacher-student relationship quality. Studies are grouped by the nature of the maladaptive student behavior. Specifically, one longitudinal study examined the potential impact of students' internalizing and externalizing behaviors on teacher-student relationship quality (Baker 2006; Henricsson \& Rydell, 2004). Next, two studies examined the possible influence of student anger/aggressive behavior and shy/withdrawn behavior. Then, we reviewed an observation study by Ladd, Birch, and Buhs (1999) investiagted students' presenting pro- vs. anti-social behavior styles in the classroom. Then, we'll review a study by Houts, Caspi, Pianta, Arseneault, \& Moffitt (2010) concerned with how early problem behavior can later predict teachers' perceptions of how challenging students' are to teach. Finally, a qualitative interview study by Newberry and Davis (2008) that examines how the match between student and teacher personality, students' problem behavior, and students' press for relationship may influence the quality of their relationships with their teachers, will be discussed. Taken together, these findings suggest that constructs tapping problem behavior similar to disaffection appear to be capable of influencing how teachers' connect with their students. Results that indicate maladaptive student behavior patterns may influence teachers' perceptions of their students' and the quality of their relationships with students 
lends support to the current study's hypothesis that student disaffection may be capable of impacting the quality of teachers' interactions with their students.

\section{Internalizing \& Externalizing Behaviors}

8. Henricsson and Rydell (2004). Henricsson \& Rudell (2004) conducted a multimethods, longitudinal study to investigate whether students identified as presenting either externalizing, internalizing, or non-problematic behavior may develop different types of relationships with their teachers across the next two school years. The authors were interested in identifying whether these different student behavior styles in first grade were predictive of the level of closeness, conflict, and positive and negative affect present in later teacher-student relationships according to classroom observers in second grade and teacher- and student-reports in third grade.

In first grade, teachers rated 527 Swedish children on externalizing and internalizing problem behaviors. Of those children, 100 were selected based on their problem behavior scores and categorized into three groups (externalizing group, internalizing group and a larger non-problematic group). Then, in second grade, students' relationships with their teachers were assessed via naturalistic classroom observations and were organized into the following categories; Aggressive peer behaviors, withdrawn/uncertain behaviors, disruptive behavior - correction interactions, mutual anger interactions, and positive interactions. Finally, in third grade, students and teachers each completed questionnaires about their perceptions of the quality of their relationships 
with each other. All but three (out of 23) classes had the same teacher across all three years of the study.

Analysis of variance tests with planned contrasts between all three groups were used to examine the authors' hypotheses that students in the externalizing group would have less positive and more negative relationships with their teachers. Results from the observational measures indicated that, students in the externalizing group in first grade had higher subsequent amounts of disruptive behavior-correction interactions in second grade than the internalizing and nonproblematic groups. Additionally, students identified as externalizing earlier were observed to have had more subsequent interactions characterized by mutual anger with their teachers in second grade than the nonproblematic group. Interestingly, the externalizing group also had more subsequent positive teacher interactions than the nonproblematic group, suggesting that perhaps these students get more overall teacher attention, not just negative attention. The internalizing and nonproblematic groups did not significantly differ on any of the observation scales.

The teacher-report data painted a similar portrait; namely, by third grade, teachers perceived their relationships with students in both problem groups to be more negative than their relationships with students in the nonproblematic group. Students with externalizing problems in first grade also had higher teacher conflict by third grade than those with internalizing problems. In term of third grade teacher-student closeness, surprisingly, the students with early externalizing problems did not significantly differ from students in the early nonproblematic group. Teachers reported the least closeness with students in the early internalizing group, whose subsequent closeness rating was 
significantly lower than either of the other two groups. This is particularly interesting as it potentially suggests that perhaps these shyer and more withdrawn students get forgotten or passed over by their teachers across time.

Finally, results from student-reports of relationship quality indicated that students labeled as having externalizing problems in first grade reported experiencing a significantly less positive relationships with their teachers by third grade than did students in the non-problem group. No other significant differences were found across the three student behavior groups.

The results of this multiple-reporter, multiple time-point study posits that student behavioral issues can predict the subsequent quality of teacher-student relationships. Specifically, results suggested that students with early externalizing problems had more negative relationships with their teachers' one year later and more conflictual relationships with their teachers by third grade than did untroubled students. Additionally, students with internalizing problems in first grade had more dependant and conflictual relationships with their teachers two years later than did untroubled students. Finally, students labeled as externalizing in first grade reported having less positive relationship with their teachers by third grade than did students in the nonproblem group. Taken together, this longitudinal study lends support to the hypothesis that problem behavior appears to be capable of influencing teacher behavior and teacher-student relationship quality over time.

Although internalizing and externalizing behavior are by no means equivalent to disaffection, they do contain some key aspects of disaffection. Specifically, Henricsson \& 
Rydell's (2004) measure of externalizing and internalizing behavior includes acting out behaviors, withdrawal, and worry/anxiety, all of which are including in the current study's conceptualization of disaffection. Although student externalizing and internalizing behavior are not the same as student disaffection, their shared components (e.g., disruptive behavior, anxious/fearful emotions, and withdrawal) lend support to the current study's hypothesis that student disaffection may be capable of impacting the way teachers subsequently treat students across time.

\section{Aggression vs. Withdrawal}

Similar to the above mentioned study of externalizing and internalizing student behaviors, the following section reviews two articles that examine two dimensions of student problem behaviors related to aspects of disaffection. Specially, one study examines aggressive and withdrawn student behaviors and the second looks at the similar constructs of student anger and shyness. These studies are pertinent to the current study as they encompasses not only the more widely studied acting out, frustration-fueled student behaviors that are indicative of disaffection but also the less conspicuous forms of inattention and lack of participation that stem from withdrawal and anxiety. Together, they lends support to the current study's hypothesis that both types of behavior may potentially influence the way teachers treat their students.

9. Justice, Cottone, Mashburn, and Rimm-Kaufman (2008). Similarly to Ladd and Burgess's (1999) study of the influence of young students' aggression and withdrawal on their subsequent relationships with their teachers, Justice and colleagues 
examined how preschoolers' exhibiting shyness and anger in their Head Start classrooms experienced different types of relationships with their teachers. Specially, four year old's shyness appeared to predict decreased closeness in the teacher-student relationships. Additionally, students who displayed greater anger in the classroom had more conflict in their relationships with their teachers. These results support those found by Ladd and Burgess (1999) that indicate anger and aggression appears to be a strong predictor relational conflict while withdrawal and shyness appear to be most strongly related to decreased relational closeness between students and their teachers.

The study sample consisted of 133 Head Start preschoolers and their 16 teachers. In the fall of the academic year, students were rated by their teachers on the Anger/Frustration and Shyness subscales of the Child Behavior Questionnaire. Specifically, the anger/frustration subscale measures affectivity when students' ongoing activities or goals are interrupted. The shyness subscale tapped students'speed of approach and discomfort in social situations. Also in the fall, researchers collected teacher-reports of student-teacher relationship quality, specifically closeness and conflict. Finally, the authors also collected data on students' receptive and expressive language skills.

Utilizing multiple regression analyses, the authors examined the associations between all student characteristics (student anger, shyness, and language skills) and students' relationships with their teachers simultaneously. Results indicated that teacherreported shyness and students' language skills were significantly associated with closeness of the relationship such that less shy students and those with better language 
skills had closer relationships with their teachers compared to shyer and less languagecapable students. It appears that being a shy student may function as a risk factor for a less-close relationship with one's teacher. Additionally, students who teachers' perceived as expressing greater anger in the classroom had relationships with their teachers that were characterized by higher conflict than students who expressed less anger. In fact, although the combined contribution of all the predictors (shyness, anger, language skills) accounted for $44 \%$ of the explained variance in teacher-student conflict, student anger alone accounted for $39 \%$ of that explained variance. Taken together, these findings suggest that student characteristics that are similar to aspects of disaffection, such as student anger and shyness, appear to be capable of influencing teachers' perceptions of the closeness and level of conflict present in their relationships with their students.

10. Ladd \& Burgess (1999). Ladd and Burgess (1999) conducted a longitudinal study of 399 kindergarten students and their teachers in order to examine the quality of teacher-student relationships over time for children exhibiting differently levels of peer aggression and withdrawal in the classroom. Overall, their results suggested that students labeled as both aggressive and withdrawn had the most troubled relationships with their teachers across the four timepoints, followed by aggressive students who had more conflictual relationships with their teachers across timepoints, and withdrawn students whose relationships with teachers most resembled the students in the control group except for initially less close and more dependant relationships. These findings indicate 
that these maladaptive student behaviors may be capable of subsequently impacting the quality of students' relationships with their teachers over time.

When participants were in the fall of their kindergarten year, researchers created four groups of student participants based on teachers' ratings of the students on the aggressive with peers and asocial with peer subscales of the Child Behavior Scale. The measure of aggression tapped both verbal and physical aggression, and the measure of asocial behaviors tapped passive-withdrawn student behaviors. Students who scored above the $67^{\text {th }}$ percentile on the aggression subscale and below the $33^{\text {rd }}$ percentile on the asocial scale were assigned to the aggressive group. Students whose scores were the exact opposite were placed in the withdrawn group and students who scored above the $67^{\text {th }}$ percentile on the aggression subscale and the asocial subscale were assigned to the aggressive/withdrawn or comorbid group. The control group was composed of students who fell below the $33^{\text {rd }}$ percentile on both subscales. The researchers then assessed teacher-student relationship quality via teacher-reports of closeness, dependency, and conflict at four time points; fall of kindergarten, spring of kindergarten, fist grade, and second grade.

The authors utilized 4X4 ANOVA's to assess differences in student group, time, and groups over time, all of which were significant, thus necessitating tests of simple effect and post hoc tests of the means. Results for teachers' ratings of teacher-student closeness showed that students in the aggressive/withdrawn group, compared to the control group, experienced significantly less closeness at all time points. Similarly, students in the aggressive group, compared to the control group, experienced 
significantly lower levels of teacher-reported closeness at the first three time points (these difference were not significant in $2^{\text {nd }}$ grade). Finally, withdrawn students had significantly lower teacher-rated closeness scores, compared to control group students, only for the first time point.

Results for the second dimension of teacher-student relationship quality, dependency, indicated that, again, the comorbid group fared the worst across time in terms of their relationship with their teachers. Specifically, compared to students in the control group, student in the aggressive/withdrawn group were rated by their teachers as significantly more dependant at the first three time points. Students in the withdrawn group, but not in the aggressive group, were also rated by their teachers as being more dependant compared to the control group but only at the first time point.

Results for the third and final dimension of teacher-student relationship quality, conflict, were as expected. Namely, students in the aggressive/withdrawn group and the aggressive group had significantly higher teacher-rated relational conflict scores than did children in the withdrawn and control groups at all four time points. Additionally, students in the comobid group, compared to those in aggressive group, had significantly higher levels of conflict in their relationships with their teachers but only at the spring of kindergarten time point.

Taken together, these results indicate that students' aggression and withdrawal may negatively influence multiple aspects of their relationships with their teachers. It appears that exhibiting high aggressive and high withdrawal behaviors seems to increase the risk of having a relationship that teachers' perceived as less close, more dependent, 
and more conflictual across time. Additionally, aggressive students also have less close and more conflictual relationship with their teachers over time. Finally, withdrawn students appear to have less close and more dependant teacher-student relationships but only at the beginning of kindergarten. In sum, these results suggest a cumulative risk model wherein the more maladaptive classroom behaviors a student exhibits, the less positive her subsequent relationships with her teachers will be across time. These studies not only lend support to the current study's hypothesis that there may be types of students' teachers are able to distinguishing between in the classroom, but also support the ides that emotions may be core features of these different types of student motivation.

\section{Challenging Behavioral Styles}

11. Ladd, Birch, and Buhs (1999). Ladd, Birch, and Buhs were interested in examining the potential impact of student characteristics and interaction styles on the quality of teacher-student relationships. The aims of their study were similar to those of the current study as they both focus on how the individual characteristics that students carry with them into their interactions with teachers affects the subsequent ways their teachers interact with them. Specifically, Ladd, Birch, and Buhs observed students with prosocial and antisocial behavioral styles to better understand how these types of student interaction styles relate to teacher-student closeness, conflict, and relationship quality. Findings suggest that kindergarteners exhibiting antisocial behavioral styles have lower quality relationships with their teachers characterized by less closeness and more conflict. 
In study 1 of this two-part, short-term longitudinal research project, observations of 200 kindergarteners and their 16 teachers were conducted over the course of 14 weeks beginning at kindergarten entry. Children's behavioral style was assessed during the first 10 weeks by trained observers who used a combination of time-point and scan sampling techniques to observe kindergarteners during free play periods, and coded children's behavior into one of six codes with an interrater agreement reliability of $77-90 \%$. Composite scores for prosocial behavioral styles were created by summing kindergarteners scores on social conversation, cooperative play, and friendly touch whereas the composite scores for antisocial behavioral styles consisted of ratings of aggression, object possessiveness, and arguing. Student-teacher relationship quality was assessed by observer reports of the emotional tone of teacher-child interactions as rated on a 5-point Likert type scale ranging from very negative (mutually argumentative or negative toned talk or actions) to very positive (warm, nurturant, containing positive verbal and physical expressions). Study 2 used the same measures and procedures with a second sample of kindergarteners $(\mathrm{N}=199)$ and their teachers $(\mathrm{N}=17)$ to increase generalizability by replication. However, instead of utilizing an overall emotional tone measured of relationship quality, Study 2 used an observational measure of teacher-child closeness and teacher-child conflict.

Results of lagged regression analysis revealed that kindergarteners' behavioral styles in the classroom predicted the types of teacher relationships they formed above and beyond the contributions of gender, cognitive maturity, and preschool experience in both Study 1 and Study 2. Specifically, student antisocial behavioral styles were negatively 
related to teacher-child relationship quality in Study 1. Similarly, in Study 2, student antisocial behavioral styles were negatively related to teacher-child closeness, and significantly predicted teacher-child conflict. Student prosocial behavioral styles were not significantly related to measures of teacher-student relationship quality. However, they were significantly positively associated with peer relationship quality measures such as peer acceptance and number of mutual best friends. These findings support the overarching hypothesis of the present study, namely, that how students interact with their teachers in the classroom impacts how supportive and close their teachers are to them.

\section{Houts, Caspi, Pianta, Arseneault, \& Moffitt (2010). Utilizing data from a} nationally representative birth cohort assessed in the British E-Risk Longitudinal Twin Study, Houts et al. (2010) expanded on the work investigating reciprocal effects by examining how student personal characteristics in childhood affected the amount of teacher effort required to instruct students at age 12. At age five, children's challenging behavior was assessed by mother and teacher reports of 18 symptoms of hyperactivityimpulsivity and inattention as well as observer ratings of children's irritability/negative affect and impulsivity/distractibility during a home visit. The authors used a composite score of mother, teacher, and observer reports in their analyses. IQ scores for children at age five were also obtained. When the children were 12 years old, their teachers completed survey reports of the amount of effort that was required to teach these children. Teachers were asked about their effort expenditures for individual students (e.g.,. "How frequently must you give this child extra encouragement to get him/her to take part?" "How frequently must you act to curb disruptive behavior by this child?"). 
The authors found that students' challenging behavior (i.e., irritable, impulsive, hyperactive, and inattentive behavior) at age 5 was positively correlated with the effort required of teachers at age $12(r=.33)$, demonstrating that early student characteristics can predict teachers' later responses. Also, children's IQ scores at age five were negatively correlated with the effort required by teachers at age $12(r=-.20)$. Students with lower IQ scores who displayed challenging behavior at school entry required greater teacher effort later than students who did not exhibit challenging behavior. Interestingly, whereas the findings of this study suggested that teachers react to challenging student characteristics by increasing their responsiveness in an attempt to compensate for student difficulties, other studies have documented the reverse reaction, namely that teachers withdraw their effort and attention from challenging students (Skinner \& Belmont, 1993). Such conflicting results highlight the need for more research on reciprocal effects in order to better understand how the classroom context and individual teacher characteristics may influence teachers' differential reactions to students exhibiting challenging behavior. In sum, this study suggests that individual student characteristics may have a long-term impact on the quantity and quality of support they receive from their teachers.

13. Newberry and Davis (2008). A qualitative study by Newberry and Davis (2008) furthers the investigation of how student characteristics similar to engagement and disaffection are linked to the quality of teacher's responses to their students. Through structured interviews with teachers, the authors examined the student factors that 
influence how teachers understand and express closeness to students in their classes, and how feelings of closeness, in turn, affect teachers' interactions and relationships with their students. The researchers conducted interviews with three Caucasian elementary school teachers guided by the overall question of 'How do these teachers understand their feelings of closeness and connection to their students'? Combining the interview data with teachers' closeness rating for each of their students, each individual student-teacher relationship was classified in terms of the dominant interaction-approach orientation the teacher used with that particular student.

Systematic analyses of qualitative interview data allowed the researchers to formulate a grounded model of teachers' conceptions of the three factors that shape their experience of closeness to their students and how their experiences of closeness relate to five different teacher interaction-approach orientations. The first two student factors found to impact teacher closeness, namely, the match or mismatch of a students' personality with their teacher's personality and the way challenges, such as students' problem behavior, create emotionally charged or draining interactions with teachers, were both influenced by the third factor, namely, students' press for a relationship with their teacher, such that when teachers felt students pressed them to develop a closer relationship, teachers found it easier to respond to students regardless of student personality or presence of challenges. These three student factors in turn appeared to influence whether teachers responded to students in one of five ways; with feeling of affinity, by being reflective, by implementing strategies, by treating students casually, or by acting professional. 
Findings suggested that student personality, challenges, and press for relationships each led to different teacher reactions such that students with easy personalities, low levels of challenges, and an average press for academic and emotional teacher support were treated in a more emotionally open and supportive way by their teachers whereas students with difficult personalities, high levels of challenges, and very low or very high levels of push received less emotionally open and more distant treatment from their teachers. Specifically, teachers reported 'feeling affinity' towards students who were friendly, polite, bright, and capable. Conversely, teachers were more likely to use an 'acting professional' (unemotional, detached) interaction approach to students whom they perceived to be as aggressive, competitive, manipulative, or odd and were more likely to 'act casually' (polite but reserved) with students they perceived as quiet, timid, or shy. In terms of challenges posed by students, those that were familiar to teachers were related to an 'implementing strategies' approach while unfamiliar challenges tended to lead to 'treating casually' or 'acting professional' approach orientations.

Students' press for relationship appeared to be the most important student factor that influenced the type and quality of teacher's emotional support, not only because of its impact on teacher's evaluation of the other two student factors, but because student press for relationship determined the amount of academic and emotional labor teachers dedicated to a given student. Relational press describes the demands placed on the teacher to meet students' academic and emotional needs. Findings suggest that teachers reacted favorably to students' press for academic needs, most likely because this makes the teacher feel needed. While students who exerted average levels of press for 
relationship tended to require less effort to reciprocate, students who exerted high levels of need for relationship were viewed as emotionally draining and treated with more distant approach orientations by teachers. Similarly, students who did not press for a relationship were viewed by their teachers as "not needing my help" and were consequently treated with distant approach orientations.

In sum, while the student factors of personality, presence of challenges, and press for teacher academic and emotional support are not identical to the target constructs of the current study, Newberry and Davis's study supports the idea that how students behave in the classroom impacts the quantity of support they receive and the overall quality of their relationships with their teachers. Students who are friendly and bright, pose few challenges, and actively seek a close relationship with their teachers' have higher quality relationships with their teachers and receive more emotionally supportive interactionapproaches from their teachers. Conversely, students who are more difficult to get along with, pose many challenges to teachers, and are either uninterested in having a close relationship or require a great amount of teacher effort to interact with, appear to make teachers feel vulnerable and as a result are more likely to be marginalized by their teachers. This exploratory study provides new insight into how the interaction between student characteristics and teachers' perceptions of students affects whether teachers move towards, away, or against developing relationships with their students.

Although the studies summarized in this portion of the literature review do not all directly target engagement and disaffection per se, they do provide vital information about how students' emotions and actions impact the ways their teachers treat them. 
Whether comparing externalizing vs. internalizing behavior, aggressive vs. withdrawn behavior, or examining other indices of student challenging behavior, these studies encompass aspects of student emotional and behavioral disaffection in the classroom and indicate there is a relationship between these aspects of disaffection and teachers' differential perceptions of and relationships with students.

\section{Summary}

This literature review sought to examine the limited research on how student motivation in the classroom may influence how teachers subsequently interact and relate to their students. Although decades of research has documented the kinds of teacher behaviors that support high-quality student motivation, little research has examined how teachers respond to students' motivational states in the classroom. Although only 4 of the 13 studies reviewed explicitly examined the construct of student engagement, the remaining studies, that examined varied aspects of motivation, still lend additional support to the hypothesis that students' actions and emotions in the classroom are capable of influencing how their teachers respond to them.

The majority of the findings from studies on the influence of student motivation on teacher behavior suggest that students with high motivation are more likely to experience the types of teacher behaviors and adaptive relationships that research suggests bolsters student motivation. Specially, the first four studies in this review found that highly motivated students experienced increases in teachers' provision of warmth, structure, and/or autonomy support across the school year (Skinner \& Belmont 1993; Furrer, C., 
Skinner, E., \& Kindermann, T., 2009, April; Pelletier, Seguin-Levesque \& Legaull, 2002; Sarazin et al., 2006). Similarly, studies 5 and 6 of this review, which examined the influence of student participation and effort on teacher-student relationships, found that students who displayed high levels of participation and effort received more positive teacher behaviors and had relationships with their teachers that were closer and less conflictual than did their less-involved peers (DeVoe, 1991; Murray and Murray, 2004). Finally, study 7 of this review indicated that students that were more satisfied with school enjoyed better relationships with their teachers, received more teacher support, and had more constructive interaction patterns with their teachers than did students who disliked school (Barker, 1999).

Unfortunately, the findings from studies examining the effects of student maladaptive behavior on teachers suggest that less motivated students may not be experiencing these supportive teacher behaviors. Instead, students with behavior problems are more likely to have more conflictual, less close relationships with their teachers. Studies 8-13 examined varied components of disaffection and their findings suggest that these students' unmotivated behaviors may be capable of negatively impacting their teachers, as seen by the differential quality of their relationships with their teachers. Specifically, studies 8-13 demonstrated that student internalizing and externalizing behavior, antisocial behavior, anger and shyness, and aggression and withdrawal were all negative predictors of student-teacher relationship quality (Henricsson \& Rydell, 2004; Ladd \& Burgess, 1999; Justice, Cottone, Mashburn, \& Rimm-Kaufman, 2008; Ladd, Birch, \& Buhs, 1999; Houts, Caspi, Pianta, Arseneault, \& 
Moffitt, 2010; and Newberry \& Davis, 2008). These concerning findings suggest that although highly motivated students enjoy increased teacher motivational support and close teacher relationships, motivational-struggling students, who are in the most need of their teachers' support, are being met with more controlling teacher behaviors, more conflictual and less close teacher relationships, and less positive teacher responses. Although understandable when considering the intensely stressful job of teaching disaffected students, this pattern of teachers' punitive reactions towards motivationally at-risk students highlights the need to continue studying reciprocal effects in the hopes of finding ways to help teachers respond in compensatory ways.

\section{Critique of Research on Reciprocal Effects}

In addition to the paucity of studies assessing reciprocal effects, four further critiques of the field are important to note. These are detailed in the following sections. First, many of the studies reviewed in this chapter are cross-sectional and thus the direction of effects cannot be determined. Secondly, many of the measures of engagement and disaffection are conceptually or psychometrically weak; some rely on only one-item measures and most examine only one component of engagement. Additionally, almost all measure only behavioral motivation thus ignoring the arguably more important emotional components of engagement and disaffection. Thirdly, all of the studies in this review utilized only variable-centered analyses, limiting the perspective of the work. Finally, although the reviewed literature attempts to describe the relationship between student motivation and teacher differential behavior, none have progressed to 
explaining why this pattern is occurring and gathered information that could help us understand how to intervene on these potentially self-amplifying feedback loops to help struggling students get the teacher support they need to become more motivated. In order to optimize students' motivation and success in school, it is imperative that studies provide actionable information about how to intervene in this process and help teachers learn to support their challenging students.

Longitudinal Design. Of the 13 studies examined in this review chapter, eight were cross-sectional making it impossible to draw conclusions about the direction of effects. Although interpreted as students' effects on their teachers, these studies could just as easily be documenting the influence of teachers' behaviors and interaction styles on students' motivation. In order to accurately assess the reciprocal effects of students' motivation on teachers' subsequent provision of support, at least two time points are needed to be able to examine student motivation as a potential predictor of changes in teachers' behavior over time.

Additionally, even the studies that did contain at least two time points, and thus could make inferences about the direction of effects, were limited by the large gaps between measurement points. Assuming that students have a different teacher each academic year, a study design only utilizing one measurement point per school year does not allow researchers to examine changes in a specific teacher's behavior towards a given student over time. Instead, this design is only capable of examining the impact of a student's motivation on two different teachers, not changes in a teacher's behavior. The findings from longitudinal studies that assessed a different interaction partner at each 
time point cannot determine whether any changes in the quality of teacher-student interactions were due to the student's motivation or whether that student simply got along better with one teacher than the other. To answer the question of whether the quality of a student's engagement in the classroom can, over time, influence how that teacher acts towards that student, the study design would need to include at least two measurement points during the same school year to ensure the same teacher-student dyads are measured at each time point.

Quality of measures. A second critique of the reciprocal effects research concerns the quality of the measures of engagement and disaffection the researchers used; specifically, their limitations in fully and accurately covering the conceptual space of each construct (note, that the measures of student motivation used in each study are listed in the fourth column of Table 1.1). Firstly, some studies only utilized one or two items to measure motivation, which could pose potential psychometric problems. For example, DeVoe (1991) assessed the quality of student participation with one item that asked teachers' to rank each of their students, from highest to lowest, on their class participation. Sarrazin, Tessier, Pelletier, Trouilloud, and Chanal's study (2006) measured motivation with only two items; one assessing effort and one assessing the extent to which students are 'able to work in an autonomous way', the combination of which may not satisfy many engagement researchers who posit a richer and more complex definition of the construct (Fredrickson et al. 2004; Reschly, \& Christenson, 2012). 
Additionally, some of the measures fell short in capturing student engagement due to their operationalization of the study constructs. For example, Murray and Murray (2004) assessed student effort with an aggregate measure containing one item assessing effort in math, one item assessing effort in English, and the number of tardies and absences students' had. Not only are two items about specific domains not an appropriate estimate of students' overall school effort, but tardies and absences are poor estimates for student effort considering that many other factors may result in missed school outside of the realm of students' effort (transportation issues, illness, etc). Similarly, Ladd and Burgess's measures of maladaptive classroom behavior (1999) relied on measures of aggression and shyness with peers, which may or may not generalize well to how these students interact with their teachers in the classroom.

Most importantly, with the exception of the studies conducted by Skinner and Belmont (1993) and Furrer, Skinner, and Kindermann (2003), all of the studies reviewed relied solely on behavioral indicators of students' motivation. These studies did not include any measures of the emotional components of motivation. Although the behavioral indicators of motivation are inherently easier to observe, studies utilizing both teacher- and student-reports of both behavioral and emotional components of engagement and disaffection generally report high correlations between the constructs across reporters, suggesting that teachers' perceptions of the emotional components of student motivation are fairly accurate (Skinner, Kinderman, \& Furrer, 2009; Skinner, \& Belmont, 1993; Skinner, Furrer, Marchand, \& Kindermann, 2008). Thus, teachers should be 
considered capable reporters of their students emotional as well as behavioral engagement and disaffection (Skinner, Kinderman, \& Furrer, 2009).

Considering that some findings suggest that the emotional components of student motivation may be guiding students' behavior, it is even more critical that researchers do not neglect to measure the emotional components of student motivation. (Skinner, Furrer, Marchland, Kindermann, 2008). Teachers' perceptions of students' emotions may be an active ingredient in the mechanisms behind reciprocal effects. If the emotional aspects of engagement and disaffection indeed catalyze, or at least influence, students' actions, measuring these emotional states may help us better understand changes in students' motivation over time. Especially for emotional disaffection, which encompasses varied emotional states from worry to anger, failure to measure and consider the influence of these emotional components of student motivation may lead to an impoverished view of this complex construct. For example, if researchers assess withdrawal behaviors (a behavioral indicator of disaffection), but do not measure emotions, they will be unable to tease apart whether the withdrawal stemmed from anxiety, boredom, or frustration, which may represent three distinct paths to or types of disaffection, to which teacher may respond differentially.

Most of the studies reviewed here not only failed to measure the emotional components of motivation, but also often failed to consider both the positive dimension and the negative dimension of this construct in the same study. Most of the studies reviewed focused on either the positive (engagement, participation, school liking) aspects of motivation or the negative (internalizing behavior, aggression, misbehavior) aspects of 
motivation but few looked at both within the same study. This is a potential problem because structural analyses of items tapping both engagement and disaffection indicate that a four-factor model, which distinguishes both engagement and disaffection into their emotional and behavioral components, best reflects the structure of motivation in elementary and middle school (Skinner, Furrer, \& Kindermann, 2003). Thus, studies that focused on only one aspects of student motivation by, for example, only examining externalizing behavior without looking at particpations, may have an incomplete, misleading view of how certain components of motivation coalesce to create the student motivational states teachers see in the classroom.

This conceptual complexity and richness is important to examine because the previously reviewed studies suggest that all of these related components of student engagement and disaffection appear to be capable of influencing teachers' responses to and their relationships with their students. Taken together, findings from this review indicate that behavioral components of engagement (participation, effort) and disaffection (misbehavior, withdrawal, internalizing and externalizing) as well as emotional components of engagement (school liking, enjoyment, enthusiasm) and disaffection (frustration, boredom, anxiety) are all capable of impacting how teachers treat their students. Previous findings suggest that all of these varied, positive and negative, behavioral and emotional components seem to play a role in shaping teacher behavior.

Thus, to effectively study how these aspects of student motivation may influence teachers, we need to examine them all, not just the behavioral aspects or the positive indicators, but the full spectrum of components that together make up these complex 
constructs. Teachers are not responding to only one or two components of student motivation, nor are they responding to these components separately. Rather, teachers are responding to students' simultaneous expression of many of these components across situations and time. Thus, when attempting to study a multi-dimensional construct, having a measure that is comprehensive, and multifaceted may allow for a more nuanced investigation that better parallels the complex expression of students' motivation.

Approach. A third major critique of the research on the reciprocal effects of student' motivation on teachers' provision of support is the almost exclusive use of traditional variable-centered analysis approaches. Although examining relations among relevant variables is certainly a useful tool for gathering information about a phenomena of interest, solely relying on one analytic approach may be limiting our scope and constraining our understanding of these complex, dynamic interactions over time. To investigate the 'types' of students that teachers see in their classrooms and their subsequent differential behavior towards these students, we need not only the multiple indicators and conceptual richness discussed in the previous section but also a personcentered approach to these complex constructs.

Put plainly, teachers see students, not variables. Teachers are responding to engaged and disaffected behaviors and emotions across time, not isolated variables. The reviewed studies examined one or two components of engagement as separate variables, which is potentially misaligned with the teacher perspective. When teachers are answering survey questions about their students or being observed interacting with their students, they are responding to a culmination of expressed variables that together make 
up an individual. Within a single interaction, these individual students may be simultaneously expressing a complex combination of the subcomponents of engagement and disaffection. Although the variable-centered reciprocal effects studies reviewed here have allowed for a deep investigation of a single construct in isolation, a person-centered analysis approach would be necessary to conduct a broader and more holistic study of how these related but distinguishable components manifest in individuals. Due to the holistic way that teachers view their students and the multidimensionality of the constructs examined, there are potentiality far more complex combinations of these constructs than can be examined by traditional variable-centered analectic approaches. If researchers want to understand the teachers' perspective, and teachers interact with students, not variables, then they must begin to incorporate methodological approaches that have the individual as the level of analysis. In addition to studying reciprocal effects by tracing the trajectories of individual variables, research should also employ analectic techniques that attempt to assess how variables aggregate and function at the individual level.

It is important to note that this discussion of the potential value of person-centered analysis approaches further highlights the need for conceptually rich and thorough measures of multiple aspects of student engagement and disaffection. Although findings from this review suggest that many different emotional and behavioral aspects of student engagement appear to be capable of influencing how teachers subsequently treat their students, most studies only examined a few of these student variables in a given paper. Perhaps one reason for this is that assessing a large number of related constructs using a 
variable-centered approach can become overwhelming and more obscuring than enlightening. However, a person-centered perspective may allow the current study to examine these subcomponents as they manifest within individuals. If teachers are responding to whole students' displaying patterns of engaged and disaffected behaviors and emotions over time, to understand teacher's subsequent responses, we need to view student motivation as teachers' view student motivation. To achieve this more nuanced view using a person-centered approach, comprehensive, multifaceted measures of aspects of students' engagement and disaffection are needed because students' actual manifestation of motivation in the classroom may be far more complex than can be understood by using narrow, restricted measures of these extensive constructs.

Actionable information. Finally, the fourth major criticism of the reciprocal effects research literature addresses the need for an applied perspective that opens up an avenue for intervention. All of the studies previously reviewed have attempted to describe the relationship between students' motivation and teachers' subsequent behavior towards students, but none have progressed to trying to uncover why students are acting this way and how we can help teachers' find more adaptive ways of responding to student disaffection. Specifically, findings from the previous review examine the impact of student motivation on teachers' provision of support and relationship quality across time, but none of them have expanded their line of questioning to address what processes may be shaping students' motivation. If order to find an avenue for intervention, research needs to identify which, if any, student inner experiences, beliefs, and perceptions may be helping to create and maintain students' manifestation of motivation in the classroom. In 
order to provide teachers with evidence-based practices to effectively support students' classroom motivation, we need to better understand what is happening within students that may be causing these outwards manifestations of motivational problems. Fortunately, there is a sizable research literature that has examined student-variables that predict motivation.

Many motivational researchers conceptualize student engagement and disaffection as student states, not traits, and highlight this assumption about the malleability of motivation by studying the types of student inner experiences that can increase or decrease students' classroom motivation. A broad range of student experiences and self-perceptions predict student motivation (Wingfield et al., 2015). This suggests the plausibility and potential value of examining students' inner experiences as predictors of the quality of their motivation. Yet none of reciprocal effects studies reviewed have examined aspects of the student experience that may be influencing the specific patterns or profiles of motivation that students display in the classroom. Once understood, this vital information could be used to provide teachers with interventions targeted at these potential sources of motivational issues. Without being able to look 'under the hood' and see what's really going on for students, research cannot then use this information to help teachers create targeted interventions that address students' specific motivational problems. The reviewed studies are examining a relationship between two variables but not gathering the necessary information that would generate applicable findings that could support intervention efforts. 
In sum, the preceding review examined the literature on the reciprocal effects of aspects of student engagement and disaffection on teachers' behavior towards their students. The findings suggest that many aspects of student motivation, both behavioral and emotional, seem to be capable of impacting how teachers respond to their students over time. However, four key limitations of this research literature emerged. First, for many studies, a lack of longitudinal, within year measurement points made drawing conclusions about the direction of effects impossible. Second, many of the measures used are conceptually and/or psychometrically weak. Thirdly, all the studies reviewed used a variable-centered analysis plan, potentially limiting the scope of the findings. Finally, none of the studies reviewed examined any potential underlying mechanisms that may be influencing these reciprocal effects or investigated any prospective avenues for intervention. 


\section{Chapter 3}

\section{Purpose of Study}

The main purpose of the current study was to closely examine reciprocal effects by using a longitudinal design, a more comprehensive assessment of behavioral and emotional engagement and disaffection, and a person-centered approach to investigate whether potential factors influencing the quality of students' classroom engagement can help inform more targeted intervention efforts. The goal of this study was to use profiles of student engagement and disaffection to holistically investigate what student experiences (or lack thereof) may be shaping the classroom engagement of students in a given profile and whether profile-specific intervention strategies would be an effective way of combating the negative interaction cycles that occur between students with maladaptive motivation and their teachers. Instead of continuing to document teachers' positive responses to students with high motivation and punitive responses to students with poor motivation, this study hoped to go beyond the current reciprocal effects literature by using a person-centered analysis approach and previous findings on the predictors of student motivation to help identify the types of teacher behaviors that would be most likely to increase the motivation of students who are struggling. To that end, the current study had four main goals.

First, this study examined the feasibility of a person-centered approach to creating profiles of student motivation based on teachers' perceptions of their students' emotional and behavioral engagement and disaffection in the classroom. Second, this study examined the utility of these profiles in investigating the reciprocal effects of student 
engagement and disaffection on changes in teacher support across the school year. Thirdly, the connections between students' inner experiences and their outward manifestations of classroom engagement were examined to determine whether students with different motivation profiles showed meaningful differences in their psychological experiences and self-perceptions, differences that might require differing levels of specific types of teacher support to be optimized. Finally, this study assessed whether students who received more of the type of teacher support that research suggests would increase their motivation (based on their profile membership), became more motivated across the school year.

This study was designed to overcome some of the major limitations of previous research. Specifically, the current study is longitudinal within year, uses well-established, comprehensive measures of engagement and disaffection, and utilizes a person-centered approach. A brief review of person-centered research assessing student engagement and disaffection will be presented as it offers a template for the current study's conceptualization of student motivation profiles. Additionally, based on selfdetermination theory, this chapter will explore the underlying mechanisms shaping students' motivational states in the classroom and use this information to create and assess potential intervention efforts. Specifically, after creating student motivation profiles based on teachers' perceptions of their students engagement and using theory to link these specific profiles to the unobservable student experiences that may be giving rise to them, this study assessed whether receiving more of the targeted "treatment" (profile-specific teacher supportive behaviors) helped optimize student motivation over 
time. Each of these contributions are described in the following sections in more detail, followed by the research questions that guided this study.

\section{Longitudinal Design and Multi-dimensional Measures}

The current study used longitudinal data in order to bolster claims of the direction of effects. Specifically, the current study assessed students at two time points, once in the fall and once in the spring of the same school year, and thus was capable of investigating whether a student's motivation profile at the beginning of the year predicted increases or decreases in teachers' provision of motivational support across the school year. This study design allowed us to move beyond the majority of the reciprocal effects literature that rely on cross-sectional data and instead look at changes in teacher behavior. Additionally, because the two measurement time points occur within a given academic year, the current study's design allowed for the examination of changes over time within a specific teacher-student dyad, as opposed to other longitudinal study designs that examined the reciprocal effects of a student's motivation across multiple teachers.

The current study also aimed to overcome a limitation of current research by utilizing a robust, well-established, and multi-dimensional measure of students' manifested motivation. Specifically, the current study's measure of student motivation included behavior and emotional components of both engagement and disaffection. This multi-dimensional measure allows for a richer understanding of these two multidimensional constructs. As the preceding literature review shows, there is evidence that many varied components of student motivation, from students' participation and school liking to their externalizing behaviors and anxiety, may all be potentially 
important factors shaping teachers' responses and subsequent behaviors towards students. Thus, this study utilized a set of comprehensive measures to capture many of these components.

This thorough investigation of both positive and negative as well as behavioral and emotional aspects of student engagement was important because of the potential diversity of these subcomponents at the individual level. Specifically, students' actual manifestation of motivation in the classroom could potentially include behavioral and emotional aspects of both engagement and disaffection concurrently. Although the prototypical engaged student and disaffected student represent the extreme ends of the motivation continuum, it may be possible that the middle of the motivational spectrum is made up of students whom teachers perceive as simultaneously exhibiting indicators of both engagement and disaffection in the classroom. Thus, it may be useful for researchers to go beyond studying engagement and disaffection separately and consider the possibility that what students' actually express in the classroom may be a combination of these four components (behavior engagement, emotional engagement, behavioral disaffection, emotional disaffection) which cannot be accurately captured by any onedimensional operalization.

For an illustration, let's consider student emotional disaffection as it encompasses multiple 'types' of negative emotional states including boredom, anxiety, and frustration, all of which may interfere with students' ability to enthusiastically participate in class but not necessarily in the same manner. For example, it is possible that a student may report being behaviorally engaged (works on his homework and participates in class) but may 
also endorse the bored and apathetic dimension of emotional disaffection, suggesting he is simply 'going through the motions'. Due to the multifaceted nature of emotional disaffection in particular, another student could also be behavioral engaged but highly endorse the anxious, worried, pressured, dimension of emotional disaffection, which suggests she is fearful, as opposed to bored with school. These nuanced differences in students' emotional experiences in the classroom were hypothesized to be a core component creating meaningful distinctions in the quality of students' classroom motivation and thus may have be integral to our understanding of what 'types' of students teachers see in their classrooms and how they differentially respond to students with these different motivational profiles.

By assessing not only engagement and disaffection but taking this a step further and allowing the components within emotional disaffection to vary separately, we were allowed to potentially uncover evidence of a richer, more complex manifestation of student motivation. At least for these hypothetical students, examining engagement or disaffection alone or only assessing behavioral indicators would result in an incomplete and incorrect view of these students' motivation in the classroom. Simply put, the richer the information we can gather about the quality of the motivation students are displaying in the classroom, the greater the likelihood that we can accurately make sense of teachers' subsequent responses to their students. The current study capitalized on the richness provided by the multi-dimensional measures of student engagement and disaffection by using a person-centered analytic approach to discovering how these multifaceted components actually combined to manifest within individuals. 


\section{Person-centered approach}

The current study utilizes a person-centered approach to examine the relationship between students' engagement and disaffection and teachers' subsequent reactions. The majority of previous studies on these reciprocal effects have used variable-centered approaches that examined relationships between constructs on which students may vary. However, this approach cannot help researchers understand how these constructs are organized within individual students. In contrast, the more holistic, person-centered approaches focus on the patterning or organization of constructs within individuals. This type of analytic approach to classification allows researchers to view the full spectrum of motivation for each student and create meaningful homogenous subgroups of students based on their personal constellation of engagement and disaffection. Simply put, a person-centered analysis approach is aligned with the current study's assumption that teachers respond to whole students, not isolated aspects of behavior or emotion. This study's use of person-centered analyses was guided by previous studies that have utilized this approach to examine profiles of student motivation.

Previous person-centered studies of engagement and disaffection. In recent years, developmental researchers have used person-centered approaches to create student profiles containing aspects of student motivation. More specifically, eight studies were found that examined aspects of student motivation within a person-centered perspective (See Table 3.1 for a summary of these studies). Although these studies utilized different person-centered analytic techniques and found different types of student profiles, together 
they lend support to the current study by highlighting the utility of this perspective for examining student motivation. 


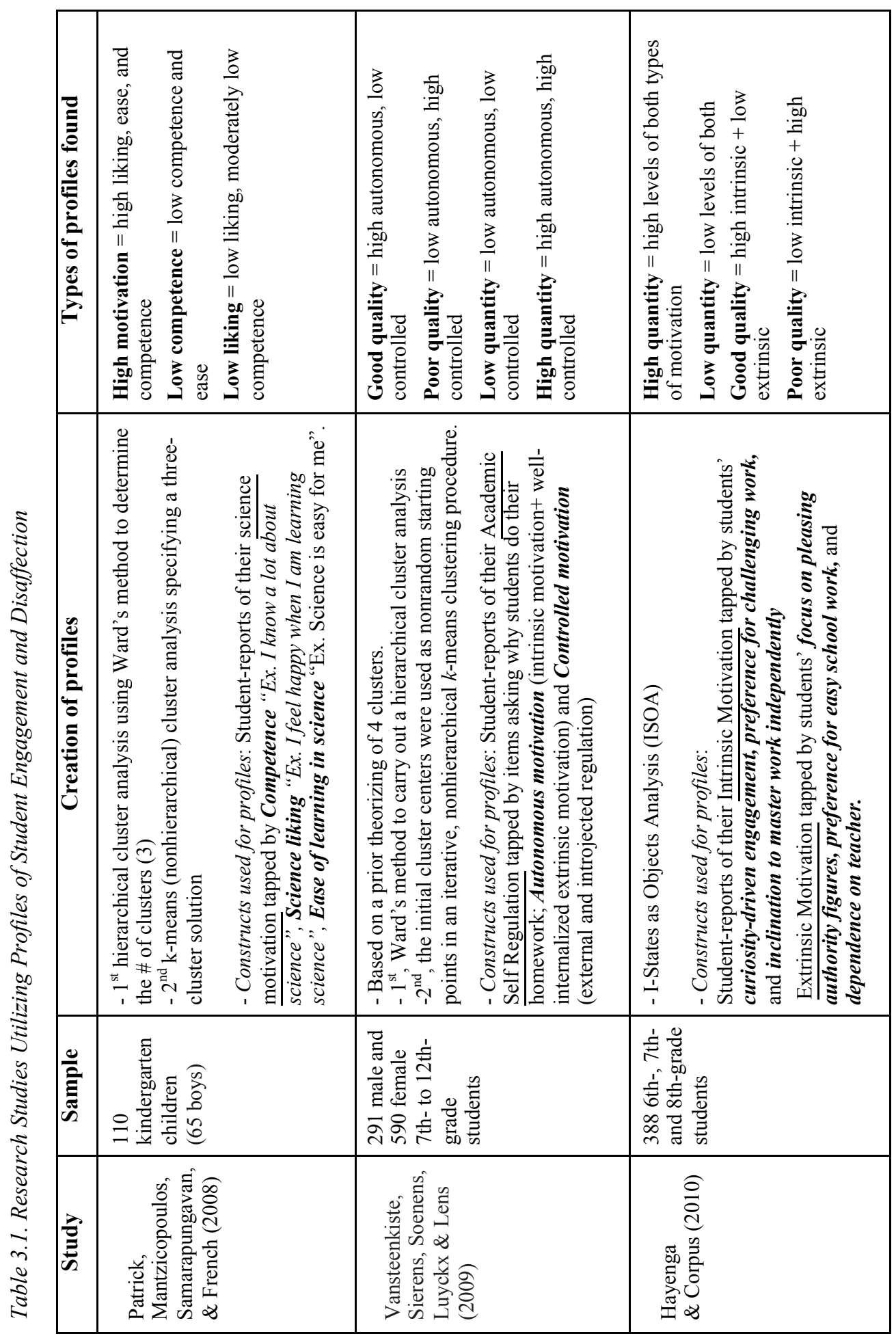




\begin{tabular}{|c|c|c|}
\hline 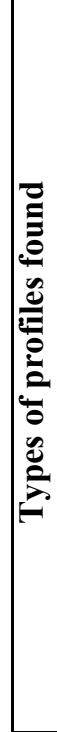 & 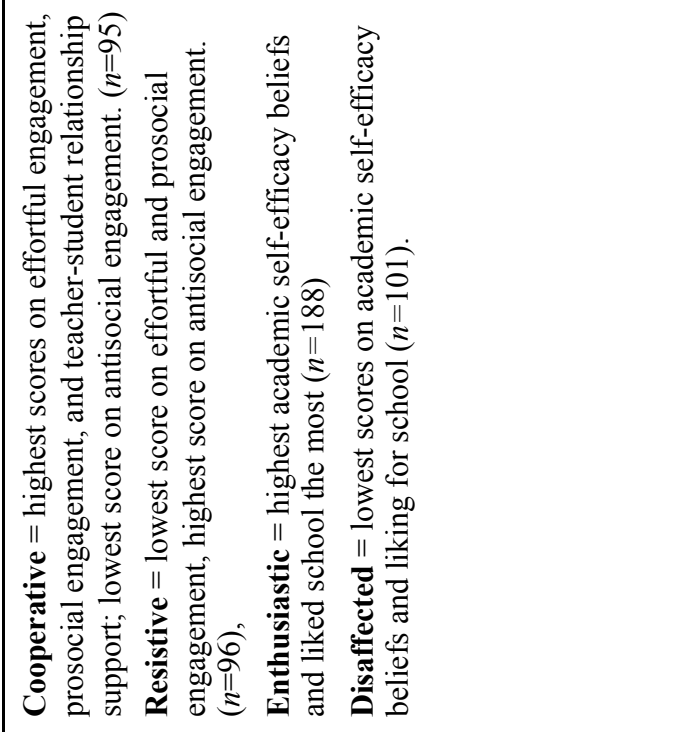 & 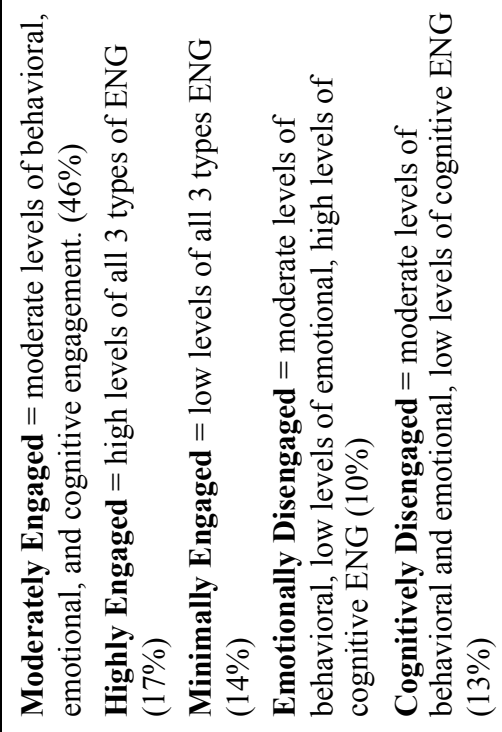 \\
\hline & 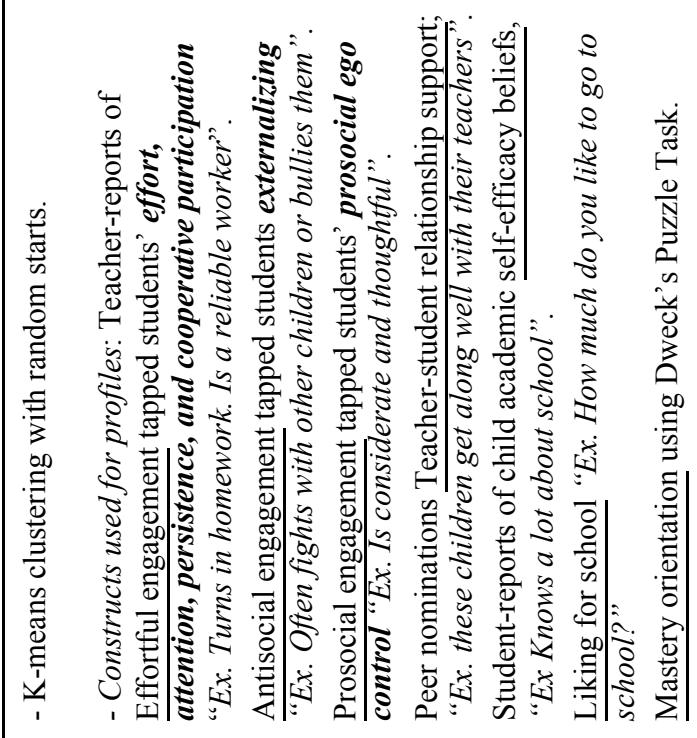 & 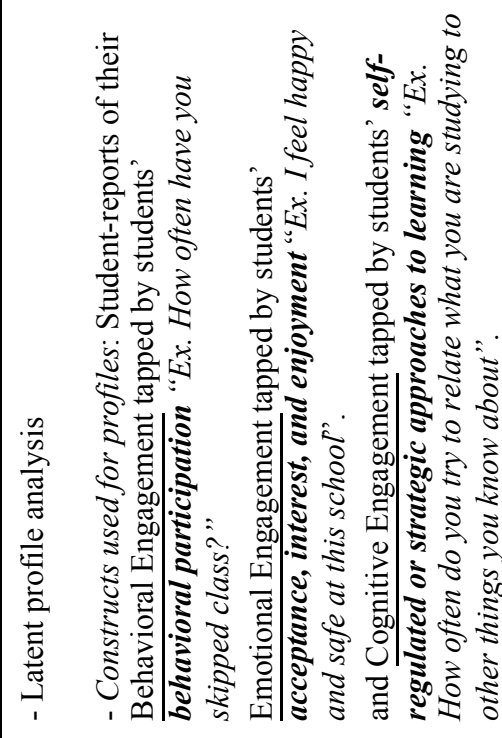 \\
\hline $\begin{array}{l}\text { है } \\
\text { है } \\
\text { है }\end{array}$ & 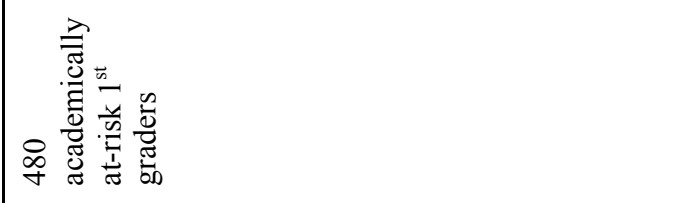 & 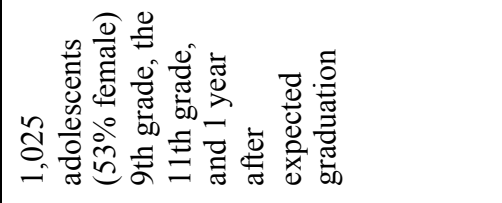 \\
\hline$\underbrace{E}_{0}$ & 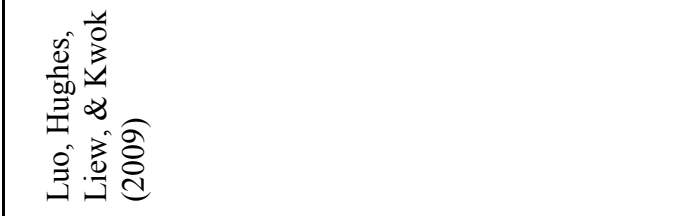 & 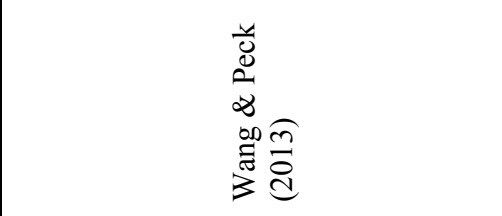 \\
\hline
\end{tabular}




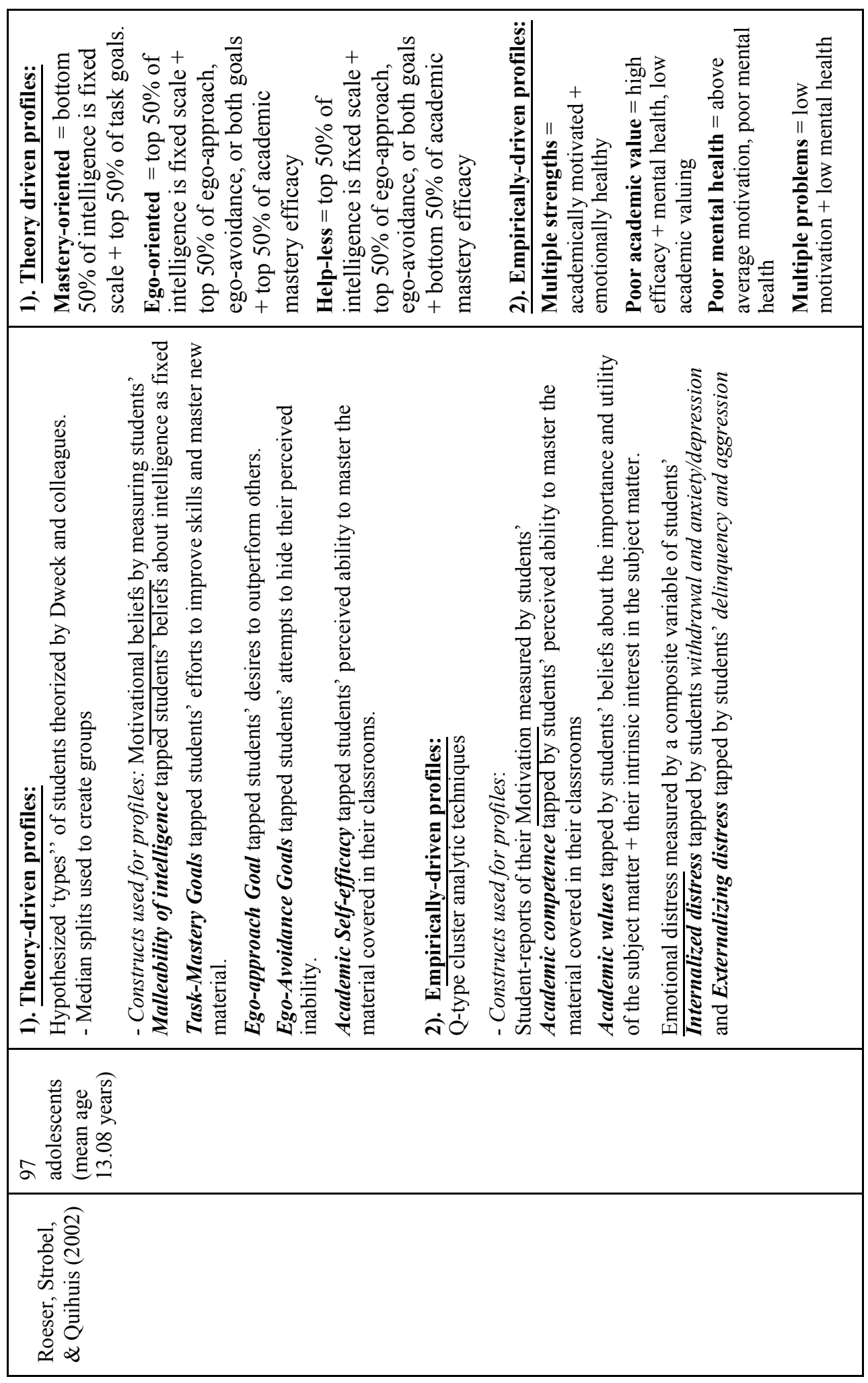


Using the pattern of information, and not the variable, as the focus, findings from these studies indicate that profiles can be a meaningful way to examine how student characteristics similar to engagement and disaffection manifest within students.

As seen in Table 3.1, although the researchers took a variety of approaches to creating student engagement profiles, two general kinds of studies can be distinguished. First, two studies relied on theory and used a more top-down approach to identifying groups or types of students based on their motivation. These studies relied on teacher ratings of a priori researcher-created groups of students. Specifically, Roeser and Lau (2002) created three hypothesized groups of students using teachers' nominations of students based on a set of behavioral descriptors written by the researchers. Similarly, Connell \& Wellborn (1991) used teacher-ratings of students' as either good or poor exemplars of six descriptors of hypothesized 'types' of engaged students.

The second set of person-centered studies of student motivation relied on empirical methods to differentiate between groups of students based on a combination of their motivation and other related constructs. These five studies, which relied almost exclusively on student-report information, utilize a more bottom-up approach and relied on a variety of analyses to help them identify different student profiles. Specifically, the authors used person-centered approaches, including cluster analysis, later profiles analysis, and I-states as Objects Analysis, to create homogenous subgroups of students based on the quality of their motivation. Finally, one study utilized both a theory-driven and an empirically-based approach in the same study in order to compare the resulting sets of student profiles (Roeser, Strobel, \& Quihuis, 2002). Although differences in the 
methods, measures, and reporters make direct connections to the current study somewhat difficult, this body of research does support the goals of the current study by showing the feasibility and value of using person-centered analysis to examine aspects of student motivation in the classroom and perceived as leaders while students in the aggressive group displayed misbehavior and required more discipline, and students in the withdrawn group were shy, often alone, and struggled to stand up for themselves. When compared to a “normative' group composed of students who were not nominated for membership in either of the three groups, students in the well-adjusted group enjoyed higher teacherrated competence, while students in the withdrawn and aggressive groups showed lower levels of teacher-rated competence, received less teacher support, and displayed lower levels of mastery-orientation. It's important to note that although Roeser and Lau (2002) based their student groups on a motivational theory, their groups were primarily created based on measures tapping students' socio-emotional functioning and well-being.

Similarly, Connell and Wellborn (1991) also used teachers' ratings of preconceived groups based on descriptions written by the researchers. The authors employed a Self-Determination Theory framework of motivation to create 6 prototypical patterns of student engagement and disaffection. Students were rated by their teachers as being either good or poor exemplars of each of the following types of student classroom motivation: Enmeshed Engagement (takes school too seriously), Conformist Engagement (prototypical good student/teacher's pet), and Innovative Engagement (inconsistency due to independence/personal interest) as well as Withdrawn Disaffected (has given up), Ritualistic Disaffection (going through the motions), and Rebellious Disaffected 
(disruptive, angry). Instead of relying on analytic methods, these studies built on theory, used teacher as informants, and capitalized on the multidimensionality of student motivation to create a priori hypothesized profiles of student motivation in the classroom.

\section{Contributions and Critiques of Theory-driven Profiles}

Taken together, these findings support the goals of the current study by suggesting that teachers may not only be capable reporters of their students' motivation, but, more importantly, that teachers have a nuanced view of their students' motivation and are capable of detecting complex patterns of emotions and behaviors within their students. Put simply, teachers don't just see motivated and unmotivated students; their endorsement of these more complex motivational configurations suggest that they see at least 6 different types of students, perhaps more. Teachers' abilities to detect these subtle differences in their students' emotions and behaviors, as opposed to viewing student motivation as a unitary bipolar measure, was important for the current investigation because of the multidimensionality of the engagement and disaffection constructs used in this study.

However, an important critique of these two person-centered approaches to examining student motivation is that the researchers, not the teachers, dictated the types of motivation profiles that could be identified. By establishing the student motivation profiles prior to conducting the study, this type of study design is limited in that it can only confirm the hypothesized groups and doesn't allow researchers to explore any other possible groupings that may or may not be supported by teachers' perspectives. This 
study design cannot tell us how many groups or profiles of student motivation teachers actually see in their classrooms or the qualities of motivation that teachers believe differentiate students from one another. For the purposes of the current study, the teacher's perspective, not the researcher's, was the key factor because, in order to understand the reciprocal effects of student motivation on teachers' provision of support, we needed to know how teachers perceive, and consequently respond, to their students. The active ingredient is teachers' views of their students' engagement and disaffection.

\section{Empirically-driven profiles.}

In addition to the two studies that used theoretically driven, a priori groupings to investigate this phenomena, a second group of person-centered studies focusing on student engagement relied on specific analytic techniques to identify groups of individuals with similar scores on the dimensions of the study constructs. Of these five studies, each took a slightly different approach in terms of the variables included and the methods used to identify the student groups. Four of the studies used a cluster analyses, one study used I-States as Objects Analysis (ISOA), and one study used Latent Profile Analysis (LPA). The following section will briefly summarize these studies in terms of the person-centered analyses that were used, the variables included, and the number and types of student motivation groups that were identified.

Patrick, Mantzicopoulos, Samarapungavan, \& French (2008) and Vansteenkiste, Sierens, Luyckx, and Lens (2009) both first used hierarchal cluster analysis, to determine the number of clusters, and then conducted k-means cluster analysis in order to determine the qualities of each student motivation profiles. Using kindergartners student-reports of 
three variables tapping their science motivation, (namely, science liking, ease, and competence), Patrick et al (2008) identified three groups of students, specifically, a high motivation group (high science liking, ease, and competence), a low competence group (low science competence and ease), and a low school liking group (low science liking and moderately low competence). Their results align with previous reciprocal effects findings such that students in the high motivational group reported receiving the most teacher support and enjoyed the least conflictual and negative relationships with their teachers while students in both of the maladaptive groups reported receiving less teacher support and experiencing more teacher unsupportive interactions.

Similarly, Vansteenkiste et al (2009), using a Self Determination framework, uncovered four different types of student motivation groups based on adolescents' selfreports of their intrinsic and well-internalized (autonomous) motivation and their external and introjected (controlled) motivation. The authors found four student motivation profiles, namely, a good quality profile (high autonomous, low controlled), a poor quality profile (low autonomous, high controlled), a low quantity profile (low autonomous, low controlled), and a high quantity profile (high autonomous, high controlled). Results indicate that the more autonomous motivation a student has (good quality and high quantity), the better her learning and achievement outcomes will be.

Although they used ISOA, as opposed to clustering, the student groups identified by Hayenga and Corpus (2010) are similar to those identified by Vansteenkiste et al (2009). Specially, analysis of middle school students' reports of their intrinsic and extrinsic motivation led to the identification of four student motivation groups; namely 
high quantity (high intrinsic and high extrinsic), low quantity (low intrinsic and low extrinsic), good quality (high intrinsic, low extrinsic), and poor quality (low intrinsic, high extrinsic). Aligned with Vansteenkiste et al (2009)'s results, this study found that students with good quality motivation (high intrinsic with low extrinsic) performed better academically than their peers in other profiles.

In the fourth empirically-based study reviewed, Luo, Hughes, Liew, and Kwok (2009) used k-means clustering with random starts to identify homogenous groups of students based on their engagement, self-efficacy, school liking, and mastery orientation. Luo et al (2009) used teacher-report measures of students' effortful engagement tapping student effort, attention, persistence, and cooperative participation, antisocial engagement tapping student externalizing behavior, and prosocial engagement tapping student prosocial behavior and ego control combined with students' self-efficacy, mastery orientation, and teacher-student relational support to create 4 distinct student profiles; namely, Cooperative (highest effortful and prosocial engagement, lowest anti-social engagement), Resistive (lowest effortful and prosocial engagement, highest anti social engagement), Enthusiastic (average engagement, highest self-efficacy and school liking ) and Disaffected (average engagement, lowest school liking and self-efficacy). Unsurprisingly, students in the cooperative group developed at a faster rate in math and had higher math achievement three years later than their peers, and students in both the cooperative and the enthusiastic group outperformed their peers in reading in the first year of the study. 
The fifth empirically-driven study, Wang \& Peck (2003) utilized latent profile analysis to uncover five different student motivation profiles. Specifically, the authors used students' reports of their behavioral, emotional, and cognitive engagement (tapped using measures of student behavioral participation, student acceptance, interest and enjoyment at school, and student self-regulated or strategic approach to learning) to create the following profiles; Moderately engaged, Highly engaged, Minimally engaged, Emotionally disengaged (low emotional, high cognitive, moderate behavioral), and Cognitively disengaged (moderate emotional and behavioral, low cognitive). Students in the highly and moderately engaged groups had the highest GPA's, educational aspiration, and college enrollment rates while students in the minimally engaged group had the lowest scores on these outcomes and also had a significantly higher risk of drop out than any of the other groups.

Contributions and Critique of Empirically-driven Profiles. Taken together, these studies highlight the utility of relying on bottom-up, empirical methods to identify meaningful subgroups of students based on aspects of their motivation in the classroom. Unlike the studies that limited the type and number of profiles they could potential find by creating the profiles a priori, these six studies called upon the data itself to help them uncover homogenous subgroups of students in their samples. This data-driven approach does not put any limitations on the number or composition of the profiles of student motivation that will be found in a given data set and thus offers a more flexible, bottomup approach to examining potential clusters or subgroups of students. 
However, these empirically-driven, person-centered studies have two crucial limitations. First, the measures used were described as motivation but examination of the underlying subcomponents and individual items reveal that many of these measures assess student values and beliefs, not student engagement and disaffection. Specifically, Patrick et al.'s (2008) student motivation measure is comprised of students' reports of their science competence and ease of learning science, both of which seem to tap selfefficacy beliefs more than the quality of students' motivation in the classroom. Similarly, Vansteenkiste et al's (2009) and Hayenga and Corpus's (2010) measures of motivation tell us more about students' perceived level of autonomy vs. control in school than they do about how their motivation actually manifests in engaged behaviors and emotions in the classroom.

Additionally, Luo et al (2009) and Roeser et al (2002) used very few variables that could be considered indicators of engagement and created their student groups mainly based on student's reports of their efficacy beliefs, valuing of school, mental heath, and relational support. Finally, although Wang and Peck used variables they call engagement, examination of the original scales form which they were adapted as well as the subcomponents and individual items that make up their measures of behavioral, emotional, and cognitive engagement reveal these researchers have a very different conception of engagement than the author of the current study. For example, Wang and Peck's (2013) cognitive engagement measure was adapted from the Self-Regulation Learning Scale and thus taps teachers' perceptions of students' self-regulation skills and strategic approach to learning. Thus, the adapted 'cognitive engagement' items assess the 
types of strategies and skills students employ in the classroom in order to be successful, not their motivation for engaging in learning activities per se.

The second major critique of these empirically-driven person-centered studies is they almost exclusively utilize student-reports of classroom engagement. Although examining the student perspective is important for our overall understanding of classroom motivation, relying solely on student reports does not further our understanding of reciprocal effects. Specifically, research investigating whether student motivation may influence how teachers subsequently react to students inherently relies on the teachers' perceptive of their students' motivation. Teachers aren't responding to the types of motivated actions and emotions their students think they're displaying or even on what students actually exhibit in the classroom. Instead, teachers are responding to their own interpretations and perceptions of their students' motivation. Thus if we want to understand why teachers treat students differently based on their classroom engagement, we need to rely on the teacher's perspective of student motivation because that is what teachers are responding to. The preceding empirically-driven profiles were identified based on students' views of aspects of their motivation and thus do not give us any information about what engaged actions and emotions their teachers are detecting and subsequently responding to.

Both Theory-driven and Empirically-driven Profiles. Finally, the study by Roeser, Strobel, \& Quihuis (2002) is unique in that it is the only article reviewed that utilizing both theoretically-driven and empirically-driven methods in one study in order 
to produce two sets of profiles. First, based on Dweck's prior theorizing and grounded in Goal Theory, the authors created three groups of students based on adolescents' selfreported motivational beliefs. The authors used measures of students' views on the malleability of intelligence, the quality of their goals namely, mastery goals vs. egoapproach goals vs. ego-avoidant goals as well as students sense of academic self-efficacy to identify hypothesized "types" of students. To create the Dweck subgroups, the authors used median splits on these measures to create three groups, namely, Mastery-Oriented (bottom 50\% of intelligence is fixed scale and top 50\% of task goals), Ego-Oriented (top $50 \%$ of intelligence is fixed scale and top $50 \%$ of ego-approach, ego-avoidance, or both goals and top 50\% of academic mastery efficacy) and Helpless (top 50\% of intelligence is fixed scale and top 50\% of ego-approach, ego-avoidance, or both goals and bottom $50 \%$ of academic mastery efficacy). Compared to both master-oriented and ego-oriented students, helpless students were less engaged, more distracted, and acted out and withdrew more frequently in the classroom.

Next, the researchers created a second set of student motivation profiles by relaying on empirical methods, specifically Q-type cluster analyses. They indentified four student motivation groups using student-reports of their competence tapped by students' perceived ability to master the material covered in their classrooms, valuing of learning/school tapped by students' beliefs about the importance and utility of the subject matter and their intrinsic interest in the subject matter, and their emotional distress tapped by internalizing and externalizing distress. The authors identified four motivation profiles, namely Multiple strengths (motivated and emotional healthy), Poor academic 
value (high efficacy and mental health but low academic valuing), Poor mental health (above average motivation but poor mental health), and Multiple problems (low motivation and low mental health). Unsurprisingly, the students in the multiple strengths group was overall the most successful group across the academic and socio-emotional domains. Students in the multiple problems youth reported the least engagement, the most attentional distraction, the most behavioral disengagement, the lowest self-esteem, and the poorest moods compared to youth in all of the other groups.

After comparing the two sets of student motivation profiles, three key findings emerged. First, the theoretically derived mastery-oriented students were overrepresented in the multiple strengths group and under-represented in the multiple problems group. Second, the ego-oriented students were over-represented in the poor mental health group. Finally, the helpless students were over-represented in the multiple strengths group and under-represented in the multiple problems groups.

\section{Profiles for the Current Study}

The current study built on Roeser, Strobel, \& Quihuis's (2002) work by using two different strategies to identity student motivation profiles. First, this study relied on Selfdetermination Theory and previous conceptualizations by Connell and Wellborn (1991) to describe seven hypothesized profiles of student motivation based on the subcomponents of engagement and disaffection. Second, model-based cluster analysis was used to empirically identify homogenous subgroups of students based on their behavioral and emotional engagement and disaffection. Due to the limited number of 
studies and the lack of person-centered approaches that characterize the reciprocal effects research, the current study was exploratory and thus was interested in investigating multiple methods for identifying student motivation profiles.

For the theoretically-driven person-centered approach, the current study hypothesized seven student profiles based on Connell and Wellborn's six theorized types of motivated students (1991). The current study capitalized on a rich conceptualization of engagement and disaffection to identify distinguishable groups of students who display differing levels of the behavioral and emotional subcomponents of motivation. Specifically, these theoretically-driven hypothesized profiles were based on students' levels of behavioral engagement, behavioral disaffection, emotional engagement, and emotional disaffection. Due to the current study's conceptualization of emotional disaffection as an especially multidimensional construct that includes multiple, discernible emotions, the construct of emotional disaffection was initially divided into its three key subcomponents, namely, anxiety/worry, boredom/apathy, and frustration/anger.

Although Connell and Wellborn used teacher rankings of behavioral descriptors to investigate their student motivation profiles as opposed to the current study that will rely on teacher-reports of students' behavioral engagement, emotional engagement, behavioral disaffection, anxiety/worry, boredom/apathy, and frustration/anger, the resulting groups are similar (see Table 3.1for descriptions of the seven hypothesized groups). The existence of the following seven hypothesized groups were investigated. Specifically, the current study's hypothesized Optimal profile (called 'Conformist' by Connell and Wellborn) represented the prototypical good student who exhibits high 
behavioral engagement (works hard, actively participates, listens carefully, tries their best), and high emotional engagement (interest, enthusiasm, and enjoyment) while working on learning activities. The current study's second hypothesized profile, the Enmeshed profile, was assumed to be very similar to Connell and Wellborn's profile of the same name which reflects students who are behaviorally engaged but also endorse experiencing the anxiety/worry subcomponent of emotional disaffection (scared, nervous, worried) while working in the classroom. Aligned with Connell and Wellborn's descriptions of this Enmeshed student as an individual who "takes school too seriously", students in this motivation profile were hypothesized to feel pressured and worried as opposed to comfortable and curious during learning activities.

The current study's hypothesized Ritualistic profile was assumed to align with Connell and Wellborn's profile of the same name that describes a student who is behaviorally engaged but whose disaffected emotions surrounding schoolwork take the form of boredom, apathy, and tiredness in the classroom. Described by Connell and Wellborn as "going through the motions", these students may be continuing to participate in class but experience no enjoyment or personal interest in what they are doing. The next hypothesized profile, referred to as Withdrawn, was conceptualized as what could happen to a ritualistic student over time as their emotional disaffection (boredom, disinterest) begins to chip away at their behavioral engagement. The Withdrawn student profile is similar to the Ritualistic except that the student is no longer behavioral engaged but is behaviorally disaffected (unprepared, doesn't pay attention, does just enough to get by). This student, like the Ritualistic student, is bored and apathetic about their schoolwork, 
but unlike the Ritualistic student, they have stopped going through the motions and have withdrawn from learning activities and no longer try or participate in class.

The fifth student motivation profile hypothesized by the current study is called Helpless and referred to students who are behaviorally disaffected and emotionally worried and scared about school. Although not hypothesized by Wellborn and Connell, the current study was interested in whether there was a group of students who had stopped participating in class (behaviorally disaffected) but who endorsed experiencing high level of anxiety and worry. Unlike the Enmeshed group of students who were hypothesized to be able to activity participate and work hard in the classroom despite feeling nervous and worried about their assignments and activities, the Helpless student profile would describe students whose anxiety and worry about school interfered with their ability to partake fully in learning activities and assignments. Helpless students may have become overwhelmed by their fear and anxiety about performing in school and consequently stopped partaking in school activities and assignments.

The sixth hypothesized student profile, Rebellious, aligned with Connell and Wellborn's profile of the same name which describes a student who is behavioral disaffected and endorses experiencing high levels of the angry and frustrated disaffected emotions (appears angry, fights me at every turn, becomes frustrated). In the same way that the Optimal profile represents the prototypical "good student" the Rebellious profile was conceptualized as the classic difficult, misbehaving, disruptive student. This student declines to participate in classroom activities, does the least amount of work possible, and 
appears to actively resist involvement while displaying resentment and frustration towards schoolwork and potentially the teacher herself.

Finally, the Burnt-out student profile attempted to represent a student who is behaviorally disaffected and also endorses experiencing more than one of the subcomponents of emotional disaffection. Although the study hypothesized that these subcomponents of emotional disaffection may operate separately, it is also likely that these subcomponents may manifest simultaneously for some students. Similar to Roeser and Lau's Multiple Problems group, students in the Burnout group may be experiencing boredom and anger or anxiety and frustration or all three together. For Burnt-out students, all three subcomponents of emotional disaffection may be present and possibility interacting with each other to create a particularly maladaptive motivational state for these students. Taken together, by building on the student profiles developed by Wellborn and Connell, the current study investigated whether the seven preceding student motion profiles could be identified in the current study's sample of students. 
Table 3.2 The current study's seven hypothesized student motivation profiles.

\begin{tabular}{|c|c|c|c|}
\hline Profile & Behaviors & Emotions & Description of profile \\
\hline Optimal & $\begin{array}{l}\text { Behavioral } \\
\text { Engagement }\end{array}$ & $\begin{array}{l}\text { Emotional } \\
\text { Engagement }\end{array}$ & $\begin{array}{l}\text { 'Prototypical good student'; works } \\
\text { hard, actively participates, } \\
\text { enthusiastic and curious learner. }\end{array}$ \\
\hline Enmeshed & $\begin{array}{l}\text { Behavioral } \\
\text { Engagement }\end{array}$ & $\begin{array}{l}\text { Anxiety/worry } \\
\text { (disaffected } \\
\text { emotions) } \\
\end{array}$ & $\begin{array}{l}\text { 'Takes school too seriously'; works } \\
\text { hard and participates, but worried, } \\
\text { scared, and nervous in class. }\end{array}$ \\
\hline Ritualistic & $\begin{array}{l}\text { Behavioral } \\
\text { Engagement }\end{array}$ & $\begin{array}{l}\text { Boredoms/apathy } \\
\text { (disaffected } \\
\text { emotions) }\end{array}$ & $\begin{array}{l}\text { 'Going through the motions'. } \\
\text { Participates but is bored by and } \\
\text { apathetic towards schoolwork. }\end{array}$ \\
\hline Withdrawn & $\begin{array}{l}\text { Behavioral } \\
\text { Disaffection }\end{array}$ & $\begin{array}{l}\text { Boredoms/apathy } \\
\text { (disaffected } \\
\text { emotions) }\end{array}$ & $\begin{array}{l}\text { "Has given up". Student does not or } \\
\text { very minimally participates or pays } \\
\text { attention. Student appears bored and } \\
\text { tired in class. }\end{array}$ \\
\hline Helpless & $\begin{array}{l}\text { Behavioral } \\
\text { Disaffection }\end{array}$ & $\begin{array}{l}\text { Anxiety/worry } \\
\text { (disaffected } \\
\text { emotions) } \\
\end{array}$ & $\begin{array}{l}\text { Student does not or very minimally } \\
\text { participates. Student appears } \\
\text { nervous, scared, and worried in class. }\end{array}$ \\
\hline Rebellious & $\begin{array}{l}\text { Behavioral } \\
\text { Disaffection }\end{array}$ & Frustration/anger & $\begin{array}{l}\text { Student does not or very minimally } \\
\text { participates. Student appears angry, } \\
\text { becomes frustrated, 'fights teacher at } \\
\text { every turn'. }\end{array}$ \\
\hline Burnt out & $\begin{array}{l}\text { Behavioral } \\
\text { Disaffection }\end{array}$ & $\begin{array}{l}\text { Multiple components } \\
\text { of emotional } \\
\text { disaffection }\end{array}$ & $\begin{array}{l}\text { "Given up" Student does not } \\
\text { participate and endorses } \\
\text { experiencing at least two of the } \\
\text { following subcomponents: anxiety, } \\
\text { apathy, and anger. }\end{array}$ \\
\hline
\end{tabular}

The current study also utilized an empirical approach to identifying homogenous subgroups of students based on their levels of engagement and disaffection. Model based cluster analyses was used to statistically identify groups of students that display similar levels of study variables. Specifically, a composite variable representing behavioral engagement (created by reverse coding behavioral disaffection items and combining them with the behavioral engagement items), emotional engagement, and the three subcomponents of emotional disaffection (anxiety, anger, and apathy) was used to 
identify student profiles. The current study used both empirically-driven and theoretically-driven person-centered approaches to inform our understanding of the 'types' of students that teacher saw in their classrooms. Utilizing two separate lens to investigate student motivation profiles created a broader and richer view of how students motivational states in the classroom influence the subsequent quality of teacher support.

\section{Student Experience: Self-system Model of Motivational Development}

In addition to a person-centered assessment of the reciprocal effects of student motivation on teachers' provision of support, this study sought to examine measures of students' underlying psychological processes to gain insight into the causes of potential motivational profiles. Thus, the third goal of the present study was to examine students' inner experiences that may shape their motivation profiles and whether targeted teacher support for these underlying student processes helped students adopt more adaptive motivation profiles over time. By relying on the Self-systems Model of Motivation Development (SSMMD) based on Self Determination Theory (SDT), this study aimed to uncover the connection between students' inner experiences and the types of motivation their teachers' perceived them to have in the classroom (Deci \& Ryan, 1985; 2000;

Connell \& Wellborn, 1991). Specifically, the current study moved backward through the SSMMD to examine whether students' membership in a particular motivation profile is related to their internal experiences of need fulfillment.

Overview of SSMMD. This model of motivational development has been helpful in organizing and understanding the dynamic relationships between student motivation 
and its antecedents and consequences (Skinner et al., 2008). Grounded in selfdetermination theory, the self-system model of motivational development (SSMMD) describes the dynamic processes that engender individuals' motivated actions and the impacts of those actions on the individual and his or her contexts and social partners (Connell, 1990; Connell \& Wellborn, 1991). The SSMMD provides a framework for conceptualizing how different social environments can promote or hinder volitional, high quality motivation and engagement based on the environment's ability to fulfill three basic psychological needs, namely, relatedness, competence, and autonomy (Skinner, Kindermann, Connell, \& Wellborn, 2009). The SSMDM allows motivational researchers an avenue for investigating the influence of these three needs by empirically measuring the extent to which an individual experiences herself as belonging, competent, and autonomous in a given context. By measuring students self-system processes, namely how connected and cared for, competent, and autonomous they feel, the current study will attempt to investigate the possible connection between the quality of students experiences of these self system processes and the quality of their engagement in the classroom.

The model asserts that all humans come with these innate needs that, when met, optimize motivational outcomes by encouraging interest and volitional participation in learning activities. The intention of the current study is to move backwards through the model to uncover whether student experiences of these three needs are differentially related to specific motivation profiles that teachers see in the classroom. If, as empirical examinations of this model have shown, students' experiences of their sense of 
relatedness, competence, and autonomy predict the quality of their engagement, then students' individual perceptions of these three self-system processes may predict the form or profile their motivation takes in the classroom (Skinner, Furrer, Marchand, \& Kindermann, 2008). The SSMMD is dynamic and thus highlights the interconnectedness and reciprocal nature of contextual need supports, individuals' perceptions of their need fulfillment, and high quality engagement. Specifically, these feed-forward and feedback causal effects among context, self, action, and outcomes result in feedback loops or “cycles" of engagement (Skinner et al., 2008). (See Figure 3.3).

Figure 3.1 The Self-system Model of Motivational Development (SSMMD)
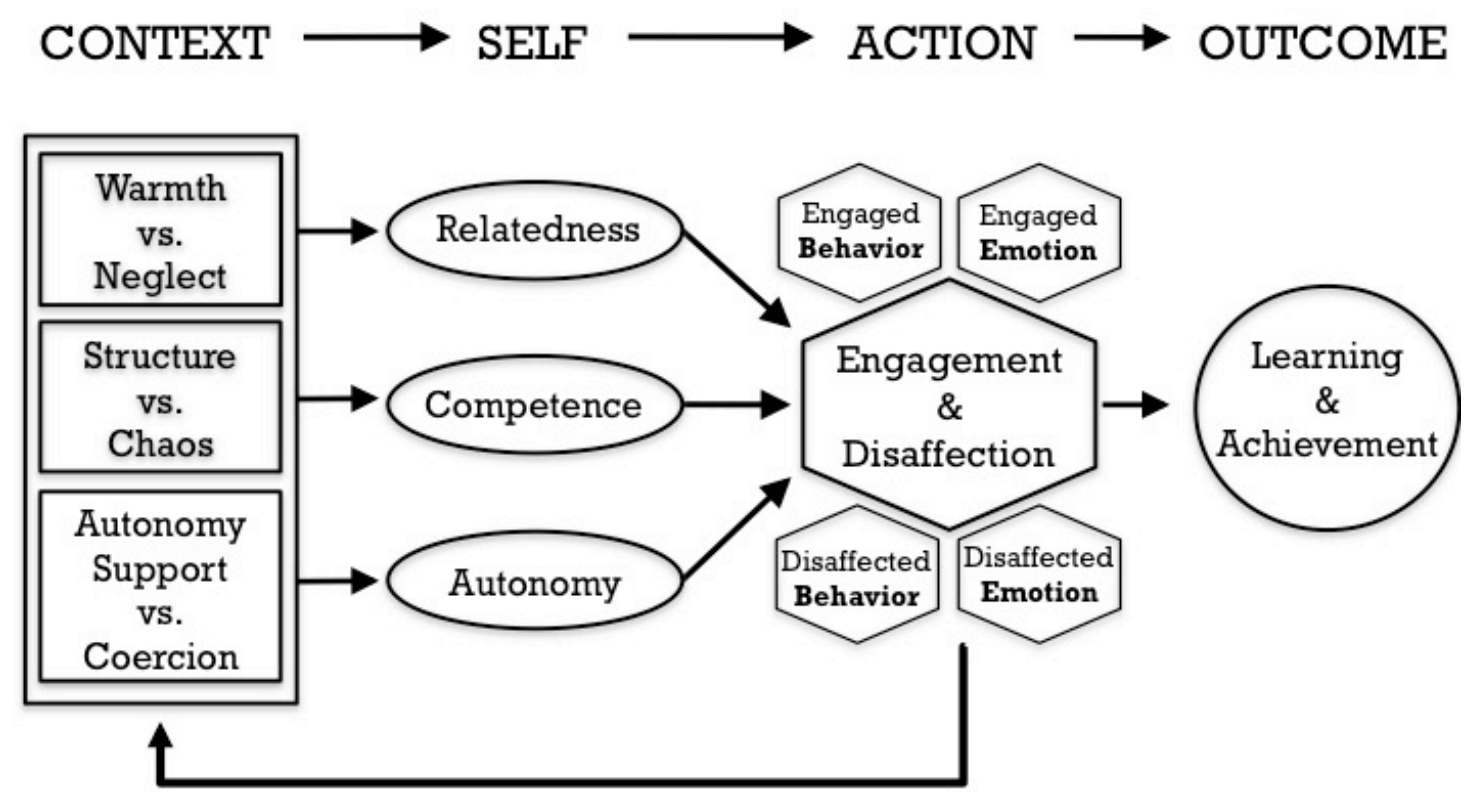

Self-system processes. The three basic psychological needs that the SSMMD outlines include the need for relatedness, competence, and autonomy (Deci \& Ryan, $1985 ; 2000)$. The associated self-system processes of the same names are used to measure 
the extent to which individuals experience themselves as related, competent, and autonomous in a given context. Specifically, the need for relatedness refers to the need to feel connected and accepted by others. The need for competence concerns the need to experience oneself as effective in producing desired outcomes and experiencing mastery. Finally, the need for autonomy is the need to feel that one's actions emanate from one's self, the need to be in charge of steering the course of one's own life (Connell, 1990; Connell \& Wellborn, 1991).

Over time, students' experiences of whether these needs are being met impact students' self-concepts and shape how they think about themselves as learners. Repeatedly experiencing the behaviors and emotions that accompany the fulfillment or thwarting of these needs creates a mindset about who students are in school. These mindsets or self-system processes (SSP's) describe deeply held beliefs students have of themselves and their potential to enjoy and succeed in school. The development of these SSP's is based on whether their classroom context is meeting their three basic needs (Skinner et al., 2008). Specifically, if a students' need for belonging is consistently being met, that student will perceive herself as a valued and accepted member of her classroom and thus experience high levels relatedness. Similarly, a student who experiences herself as competent feels that she has the skills and abilities to do well in school. Finally, students whose need for autonomy is being supported in the classroom are likely to feel a sense of ownership and personal commitment to their learning as well as the belief that their schoolwork is valuable and relevant to their lives. These SSP's or studentconstructed views of themselves as learners are not only important because they allow 
researchers to empirically assess the extent to which individuals experience need fulfillment, but they also act as resources to support or undermine engagement in the classroom (Skinner \& Pitzer, 2012; Skinner, Kinderman, \& Furrer, 2009).

Previous research has shown that these three SSP's are important predictors of student engagement. Specifically, students with high perceived relatedness, sense of belonging, and secure relationships with their teachers exhibit higher classroom and school engagement (Connell \& Wellborn, 1991; Furrer \& Skinner, 2003; Ryan, Stiller, \& Lynch, 1994; Osterman, 2000; Goodenow, 1993; Goodenow \& Grady, 1993). Similarly, students who perceive themselves as competent, self-efficacious, and in control of their academic success are more likely to have higher behavioral and emotional engagement in elementary and middle school (Connell et al., 1994; Rudolph et al., 2001; Skinner, Wellborn, \& Connell, 1990; Skinner, Zimmer-Gembeck, \& Connell 1998). Finally, having high perceived autonomy has also been linked to student engagement and academic success (Connell, \& Wellborn, 1991; Fredricks, Blumenfeld, \& Paris, 2004; Brian, Skinner, \& Connell, 1993).

Due to their utility in predicting student engagement, we are interested in examining whether these self-system processes may also be utilized in the current study's person-centered framework to differentiate students across motivation profiles. If, students' perceptions of their relatedness, competence, and autonomy are indeed different for students in different motivation profiles, then this implies that what teachers can see (student engagement and disaffection) actually gives them valuable information about what they can't see (students' inner self-system processes). Gaining access to students' 
SSP's may help teachers 'diagnose' the underlying student factors that may be influencing students' classroom engagement and disaffection. Instead of relying on assumptions about why a student may be exhibiting motivation problems in their class, knowing a students' motivation profile may allow teachers access to actionable information about what type/s of SSP's that student may be lacking. Put another way, we may be able to use students membership in a given motivation profile to diagnose the underlying student factors that are influencing students' engagement and disaffection, namely their self-system processes. Consequently, teachers can use this insider information to respond to that student's motivational problem in class with the specific type of motivational support he or she is lacking.

Teacher Support. The SSMMD not only allows us to investigate how students' unobservable need fulfillment (or lack thereof) may be shaping the quality of students' motivation in the classroom or, but it also offers us concrete, targeted treatment prescriptions for members of different motivation profiles based on the quality of the three student self-system processes. Specifically, in order to help students develop the type of student experiences that allow them to view themselves as competent, committed learners who belong in school, teachers can provide their students with targeted support for these three needs, namely, involvement/ warmth, structure, and autonomy support.

The SSMMD suggests that classroom contexts powerfully influence students' engagement by supporting or undermining students' SSP's or experiences of themselves as belonging, competent to succeed, and as autonomous or self-determined learners. 
Specifically, teachers can help fulfill students' three basic psychological needs by providing students with involvement, structure, and autonomy support (versus neglect, chaos, and coercion). Teachers help support students' need for relatedness when they provide students with high quality involvement, by expressing caring, being emotionally available, and spending time with students. Involvement/warmth from teachers provides the required emotional security and instrumental support that students need to feel connected to their teacher, and activity explore and effectively deal with their worlds (Furrer, Skinner \& Pitzer 2014).

In order to fulfill students' need for competence, teachers can supply their students with structure by clearly communicating expectations, giving consistent and predictable responses, and adjusting their teaching to the level of the student. Optimal structure includes helping student break down learning tasks into manageable components, expressing confidence in students' abilities as well as helping students figure out how to reach high levels of understanding and performance (Stipek, 2002). Another key aspect of structure involves teachers' provision of feedback that gives students clear information about why they did not meet expectations and how to improve. Taken together, these aspects of teacher structure help students understand what it takes to do well in school and gives them confidence in their ability to enact successful strategies.

Finally, autonomy supportive teachers make lessons relevant to their students' lives, give their students choices, and allow their students to work at their own pace and in their own way (Reeve et al. 2004; Skinner \& Belmont, 1993; Connell \& Wellborn, 
1990; Reeve, 2012). When teachers treat students with respect and listen to, and value their ideas and options, students are more likely to willing engaged in the hard work of learning (Reeve \& Jang, 2006; Stefanou, Perencevich, DiCintio, \& Turner, 2004). When teachers show their students this freedom to investigate their authentic selves and encourage them to take ownership over their learning, teachers help their students internalize the value of learning and thus become self-regulated learners (Deci \& Ryan, $1985 ; 2000)$.

In sum, according to the SSMMD, classroom contexts, or more specifically, teachers behaviors towards their students, differentially provide students with opportunities to fulfill their fundamental psychological needs through provision of teacher support. Based on these experiences, students construct self-system processes that are organized around relatedness, competence, and autonomy and contribute to positive self-perceptions that that in turn provide a motivational basis for students' patterns of engagement versus disaffection with learning activities. Student engagement with interesting and meaningful academic activities then facilitates learning and academic success. These dynamics may be responsible for the high stability of engagement and disaffection, and may underlie inter-individual differences in trajectories of motivation over a student's school career.

\section{Summary}

The current study was designed to investigate the reciprocal effects of student engagement and disaffection on teachers' subsequent provision of motivational support. 
To better understand how students' classroom motivation impacts the way their teachers treat them, this study utilized a longitudinal design, comprehensive multi-dimensional measures, a person-centered analysis approach, and the Self System Model of Motivational Development (SSMMD). Specifically, by incorporating two time points (fall and spring of the same school year) the current study bolstered evidence of the direction of effects and added to the limited findings from reciprocal effects studies that utilize a longitudinal design. Based on the literature view in chapter 2 that suggests a broad and varied set of positive and negative aspects of student motivation are capable of influencing how teachers treat their students, this study used comprehensive, multidimensional measures of behavioral and emotional engagement and disaffection. To gain a more holistic view of these reciprocal effects that is better aligned with the teacher's perspective, this study utilized a person-centered approach to identifying student motivation profiles based on the student behaviors and emotions teachers saw in their classrooms. Finally, this study built on Self-determination theory and the SSMMD to investigate whether the types of student motivation profiles teachers observed can provide them with actionable information about their students' unobservable, inner experiences. Taken together, these key features of the current study allowed us to answer four sets of research questions about students' classroom motivation.

\section{Research Questions}

The present study aimed to further our understanding of the reciprocal effects of student engagement and disaffection on teachers' provision of support across the school 
year by addressing the following four sets of research questions. Firstly, this study assessed the feasibility and value of identifying profiles of student motivation by utilizing a person-centered analysis approach. These first research questions focused on creating two sets of motivation profiles based on students' behavioral and emotional engagement and disaffection in the classroom. Specifically, this study created one a priori set of student profiles based on an application of self-determination theory proposed by Connell and Wellborn and another set of profiles that were empirically derived using model-based clustering. This research question also examined the alignment between these two sets of profiles to investigate whether these two methods converged.

Secondly, the relationship between students' classroom motivation and teachers' subsequent provision of support was examined. Specifically, the second set of research questions used student motivation profiles to predict changes in teachers' provision of support over the school year. Thirdly, the current study assessed whether students' internal self-system processes differed as a function of their teacher-rated motivation profiles. The connection between specific student motivation profiles and students' experiences and self-perceptions surrounding school were assessed in an attempt to use observable student profiles to 'diagnose' motivational issues that stem from these unobservable student self-system processes. Finally, the current study examined whether students who received high levels of the specific type of teacher support that their profile membership suggests they need exhibited more adaptive motivation patterns over time. 
RQ 1: Creation of Student Motivation Profiles. In order to better understand the teacher perspective on reciprocal effects, which views whole persons and not variables as the unit of analysis, the current study used a person-centered analytic approach to create both theoretically-driven and empirically-driven student motivation profiles based on teachers' reports of their students' motivation. Aligned with Roeser, Strobel, \& Quihuis (2002) multiple-methods approach, this study first created student motivation profiles using a priori theoretically-driven perspective and then again using empirical means. These theory-driven profiles were based on Connell and Wellborn's (1991) descriptions of prototypical student types. The previously discussed seven student profiles utilized by the current study are reproduced below. 
Reproduction of Table 3.1. Hypothesized seven student motivation profiles

\begin{tabular}{|c|c|c|c|}
\hline Profile & Behaviors & Emotions & Description of profile \\
\hline Optimal & $\begin{array}{l}\text { Behavioral } \\
\text { Engagement }\end{array}$ & $\begin{array}{l}\text { Emotional } \\
\text { Engagement }\end{array}$ & $\begin{array}{l}\text { 'Prototypical good student'; } \\
\text { works hard, actively participates, } \\
\text { enthusiastic and curious learner. }\end{array}$ \\
\hline Enmeshed & $\begin{array}{l}\text { Behavioral } \\
\text { Engagement }\end{array}$ & $\begin{array}{l}\text { Anxiety/worry } \\
\text { (disaffected } \\
\text { emotions) }\end{array}$ & $\begin{array}{l}\text { 'Takes school too seriously'; } \\
\text { works hard and participates, but } \\
\text { worried, scared, and nervous in } \\
\text { class. }\end{array}$ \\
\hline Ritualistic & $\begin{array}{l}\text { Behavioral } \\
\text { Engagement }\end{array}$ & $\begin{array}{l}\text { Boredoms/ apathy } \\
\text { (disaffected } \\
\text { emotions) }\end{array}$ & $\begin{array}{l}\text { 'Going through the motions'. } \\
\text { Participates but is bored by and } \\
\text { apathetic towards schoolwork. }\end{array}$ \\
\hline Withdrawn & $\begin{array}{l}\text { Behavioral } \\
\text { Disaffection }\end{array}$ & $\begin{array}{l}\text { Boredoms/apathy } \\
\text { (disaffected } \\
\text { emotions) }\end{array}$ & $\begin{array}{l}\text { "Has given up". Student does not } \\
\text { or very minimally participates or } \\
\text { pays attention. Student appears } \\
\text { bored and tired in class. }\end{array}$ \\
\hline Helpless & $\begin{array}{l}\text { Behavioral } \\
\text { Disaffection }\end{array}$ & $\begin{array}{l}\text { Anxiety/worry } \\
\text { (disaffected } \\
\text { emotions) }\end{array}$ & $\begin{array}{l}\text { Student does not or very } \\
\text { minimally participates. Student } \\
\text { appears nervous, scared, and } \\
\text { worried in class. }\end{array}$ \\
\hline Rebellious & $\begin{array}{l}\text { Behavioral } \\
\text { Disaffection }\end{array}$ & Frustration/anger & $\begin{array}{l}\text { Student does not or very } \\
\text { minimally participates. Student } \\
\text { appears angry, becomes } \\
\text { frustrated, 'fights teacher at every } \\
\text { turn'. }\end{array}$ \\
\hline Burnt out & $\begin{array}{l}\text { Behavioral } \\
\text { Disaffection }\end{array}$ & $\begin{array}{l}\text { Multiple } \\
\text { components of } \\
\text { emotional } \\
\text { disaffection }\end{array}$ & $\begin{array}{l}\text { "Given up" Student does not } \\
\text { participate and endorses } \\
\text { experiencing at least two of the } \\
\text { following subcomponents: } \\
\text { anxiety, apathy, and anger. }\end{array}$ \\
\hline
\end{tabular}

Research question 1a was thus interested in examining whether the data support the existence of these hypothesized profiles. This question sought to determine whether the seven profiles sufficiently cover or encapsulate the vast majority of students. Specifically, we were interested in examining whether there was a sufficient amount of students that could be categorized by or placed within each profile. Do most students fit into one of the 
seven categories or are the majority of students displaying other variations of engagement and disaffection in the classroom?

Research Question 1a. Do the seven hypothesized student motivation groups provide a good fit for the pattern of interrelationships among multiple components of behavioral and emotional engagement and disaffection? Is there evidence to suggest that these profiles can be found in the current data set? Are these profiles adequate to characterize a substantial portion of the students sampled?

Additionally, this study also used empirical means to identify interpretable, homogenous subgroups of students based on teacher-reports of students' behaviors and emotions in the classroom. Specifically, five variables (behavioral engagement vs. behavioral disaffection, emotional engagement, behavioral disaffection, anxiety/worry, boredom/apathy, and frustration/anger) will be included in a model-based cluster analysis in an attempt to capture naturally occurring groups of students who scored similarly on these variables. The aim of research question $1 \mathrm{~b}$ is to determine whether meaningful, interpretable groups will emerge from this data-driven investigation.

Research Question 1b. Utilizing an empirical approach, what subgroups of students emerge based on their patterns of behavioral and emotional engagement and disaffection in the classroom? Do the resultant profiles make sense conceptually, that is, are they easily interpretable? 
Finally, the current study is interested in examining the alignment and convergence of the profiles identified by these two methods. Do these two varied approaches produce similar groups? Will the data-driven findings support the theoretical conceptualizations or will the two methods produce contradictory findings?

Research Question 1c. How well do the two sets of student motivation profiles align? Is there overlap between the theoretically-derived and the empiricallyderived set of profiles?

\section{RQ2: Reciprocal Effects of Student Motivation on Changes in Teacher Support}

The second research question will use the two sets of student motivation profiles identified in RQ 1 to examine the reciprocal effects of student engagement and disaffection on changes in teacher support from fall to spring. Previous research suggests that students with high levels of engagement and motivation gain teacher support across the school year (Skinner \& Belmont, 1993; Pelletier, Seguin-Levesque \& Legaull; 2002; Sarazin et al., 2006). In contrast, students with high disaffection, low motivation, and behavior problems tend to lose teacher support and experience lower quality instruction from and relationships with their teachers (Skinner \& Belmont, 1993; DeVoe, 1991; Jelsma, 1982). Although the current study differs from previous variable-centered reciprocal effects studies by adopting a more complex, person-centered approach, this study hypothesizes that students in different profiles will exhibit differing combinations of motivational subcomponents. Consequently, their teachers will treat them differently 
based on their specific profile. Put another way, we hypothesize that students in different motivation profiles will experience different patterns of change in teacher support from fall to spring.

Research Question 2. Do students in different motivational profiles experience differential changes in teacher support from fall to spring?

It is hypothesized that these patterns, in which highly motivated students gain support and highly disaffected students lose support, will be replicated within the current study's person-centered framework but perhaps in more nuanced ways. Specifically, because the current study goes beyond bi-polar conceptualizations of engagement and disaffection and instead allows for a more complex configuration of the varied behavioral and emotional subcomponents of this multidimensional construct, students may experience steeper increases or declines in teacher support depending on how teachers perceive students in the different motivation profiles.

The optimal profile is expected to be the most adaptive, and thus students in this profile are hypothesized to garner the largest increases in teacher motivational support across the school year. It is expected that these optimal students, who exhibit high behavioral and emotional engagement, will be perceived by their teachers as enthusiastic, curious, hard-working learners who are a pleasure to teach. When faced with this prototypical 'good student', we expect teachers to react by providing them with more warmth, more structure, and more autonomy support in the classroom. 
Although previous research suggests that disaffected students lose teacher support across the school year, it's unknown whether some of the remaining six student profiles may suffer increases, maintenance, or declines in teacher support. Perhaps profiles that include components of both engagement and disaffection may elicit increases or maintenance of teachers' provision of support over time instead of declines. However, it is likely that profiles that only contain disaffected behaviors and emotions will more negative effects, or greater losses in teacher support, than profiles that include some engagement behaviors or emotions.

Specifically, students in the enmeshed profile and ritualistic profile are a combination of behavioral engagement and emotional disaffection and thus are hypnotized to be less adaptive than the optimal profile but not as maladaptive as the remaining profiles that are composed of both disaffected behaviors and disaffected emotions. Perhaps teachers will perceive enmeshed students, who work hard but are worried and anxious during class, as especially dedicated students, and thus react to them with increases in support. In particular, teachers may increase their provision of warmth towards these students in an attempt to assuage their fears and anxieties in the classroom. However, it is also possible that teachers may view enmeshed students' worrying as needy, annoying, or draining and thus teachers may withdraw their support from these students over time.

Similarly, ritualistic students also continue to participate in class (behavioral engagement) but they feel bored and apathetic about their work (emotional disaffection). Teachers may perceive these ritualistic students as 'easy' since they are on task and aren't 
disruptive and thus may not require a lot of the teacher's time and energy. This would suggest that teachers' might react to ritualistic students with increases in or maintenance of their support over time. Perhaps teachers may increase their provision of autonomy support in an attempt to ignite passion and interest in these students by providing them with increased freedom and a broader array of choices that may better fit with their personal interests. However, it is also possible that teachers may perceive these ritualistic students as lazy or infuriatingly passive, especially if they believe the students are underperforming due to disinterest, and thus may react by withdrawing their support from these students. Teachers may become more coercive with these apathetic students in an attempt to force them to engage emotionally despite their apparent boredom.

The helpless profile and withdrawn profile are characterized by the same emotionally disaffected subcomponents as the enmeshed and ritualistic student profiles, however, instead of behavioral engagement, students in these profiles display behavioral disaffection. The helpless student is not participating in class and appears worried and fearful in class. If teachers perceive the helpless students' anxiety as a personality trait or signs of an underlying issue that the student is unable to control, they may sympathize with the student and consequently withdrawn their support less from these students than from other disaffected profiles.

The withdrawn student is not actively working on learning activities and appears bored or uninterested in class. Teachers may provide withdrawn students with less support if they perceive students' lack of participation and seeming apathy as an insult related to their teaching. Teachers may take withdrawn students' boredom personally and 
interpret their off-task behavior and apathy as a personal affront. Thus teachers may feel defensive or hurt which could result in decreases in their provision of support to these students. This interpretation may lead teachers to become more rejecting and more coercive with withdrawn students.

Finally, the students that are hypothesized to experience the least teacher support and the sharpest losses in support over time are those with either a rebellious profile or a burnt out profile. Rebellious students are behaviorally disaffected and display frustration and anger in the classroom. Teachers may perceive these students as the prototypical disruptive student whose combative and aggressive refusal to constructively participate could be seen as a challenge to the teacher's authority. Consequently, these students may be the most difficult for teachers to interact with, and thus they may experience the steepest declines in teacher motivational support. Teachers are likely to increase coercion and decrease their provision of autonomy support when faced with rebellious students in an attempt to establish their authority over these combative students.

Burnt out students who exhibit all three subcomponents of emotional disaffection (i.e. worry, boredom, and frustration) may potentially lose more teacher support over time than their rebellious peers. Perhaps these multi-risk students may be triaged as 'lost causes' by their teachers such that teachers withdraw their support from burnt out students in order to divert their energy towards students whom they believe would be more likely to benefit from their attentions. In contrast, it is also possible that the rebellious students' anger is more salient and disruptive to teachers than the burnt out 
students' overall disaffected profile, and thus burnt out students may lose less support than their rebellious peers.

In sum, since the exploratory nature of the current study leaves little information from which to draw concrete hypotheses, the hypotheses for research question 2 are tentative. The current study aims to use the findings from research question 2 to inform our underdeveloped understanding of how teachers perceive and consequently react to different types of student motivation profiles.

Hypothesis 2a. Students with an optimal motivation profile will experience increases in teacher support from fall to spring.

Hypothesis $2 \boldsymbol{b}$. Students with enmeshed and ritualistic motivation profiles will experience increases in or maintenance of teacher support from fall to spring.

Hypothesis 2c. Students with withdrawn and helpless profiles will experience decreases in teacher support from fall to spring.

Hypothesis 2d. Students with rebellious and burnt out motivation profiles will experience the greatest decreases in teacher support from fall to spring.

\section{RQ 3: Profiles as Diagnostic of Student Experiences}

The current study's third area of investigation explores the connection between students' motivation profile group membership and their self-perceptions and experiences 
of school. Specifically, this set of research questions will address whether students with different motivation profiles endorse experiencing differing levels of the three selfsystem processes; namely, sense of relatedness, competence, and autonomy. Put simply, do students in some profiles feel a greater sense of belonging, and/or competence, and/or autonomy than their peers in other profiles? Previous research has found that these three student experiences are powerful predictors of the quality of students' classroom engagement (Furrer, Skinner, \& Pitzer, 2014; Skinner, Furrer, Marchand, \& Kindermann, 2008; Skinner, Kindermann, Connell, \& Wellborn, 2009; Skinner, Kindermann, \& Furrer, 2009). This suggests that these unobservable student experiences may influence the quality of students' classroom motivation. Thus, the goal of this research question is to discover whether students' profile membership can tell us something important about these inner student experiences that may be contributing to students' outward manifestations of motivation.

Connecting student motivation to the presence or lack of certain self-system processes could potentially allow researchers to use students profile membership as a diagnostic tool to identify which students may be lacking which key experiences. Although self-determination theory posits that all people need all three needs fulfilled, the extent to which individuals perceive themselves as connected, competent, and autonomous students can vary greatly and is highly influenced by their environment's ability to provide need support. Thus, due to previous findings that indicate students' self-system processes have an important effect on the quality of their academic 
motivation, this study hypothesizes that students in different motivation profiles will exhibit differing levels of these self-system processes.

Research Question 3. Do students who belong to the different motivation profiles also differ in their sense of relatedness, competence, and autonomy?

Due to the exploratory nature of the current study, there are few findings on which to build concrete hypotheses. However, a few clues about potential links between motivation profiles and self-system processes may allow us to make some tentative hypotheses. It is important to note that in an attempt to further differentiate students in different profiles, the current study will not use a composite variable of autonomy but instead examine the four components of students' autonomy orientation individually, namely (1) Intrinsic self-regulation, (2) Identified self-regulation, (3) Introjected selfregulation, and (4) Extrinsic self-regulation. These subcomponents address distinctions between students who report participating in learning activities because they derive satisfaction and enjoyment from the tasks (Intrinsic), or because they have a desire for learning and understanding (Identified), or because they would feel guilty and ashamed of themselves if they didn't participate (Introjected), or because they would be punished if they didn't participate (Extrinsic).

It is hypothesized that the most adaptive student motivation profile, the optimal profile, will have the highest levels of all three self-system processes. Research suggests that all three SSP's, competence, relatedness, and autonomy, are important unique and combined predictors of engagement (Skinner et al, 2008; Furrer, Skinner, \& Pitzer, 2014; 
Skinner, Kindermann, Connell, \& Wellborn, 2009; Skinner, Kinderman, \& Furrer, 2009). Thus, this study hypothesizes that the most highly engaged students, residing in the optimal group, will report experiencing high levels of relatedness, competence, and autonomy. Specifically, it is hypothesized that these students will report higher levels of intrinsic and identified self-regulation, which indicates theses students have a greater sense of personal autonomy.

Due to the anxious and worried emotions experienced by students in the enmeshed student motivation group, this study hypothesizes that these students will endorse experiencing low competence in the classroom. Their experiences of high anxiety and worry surrounding school suggest that these students may suffer from a lack competence and low self-efficacy for academics. Another source of this worry may be a lack belongingness and connection with others in the classroom. If a student doesn't feel like she belongs and is psychologically safe in her classroom, this stress and lack of security may manifest as the anxiety and worry that characterizes enmeshed students. Thus, students in the enmeshed profile may also endorse experiencing low levels of relatedness in the classroom as well as low competence. A final contribution to these students' anxieties in the classroom may be that they rely on introjected self-regulation and thus their feelings of worthiness and value may be dependent on success in school.

The ritualistic student, who participates in class without interest or enjoyment, may be experiencing high competence but low autonomy. Specifically, theses students may recognize that they have the skills and capacities to do well in school but their boredom with school work may stem from a perception that school activities are 
meaningless and unrelated to their lives suggesting they are lacking a sense of autonomy. By 'going through the motions', these students may be more likely to endorse having an introjected and external self-regulation style. These ritualistic students do not appear to enjoy or care about leaning, and perhaps the reason they participate in class work is because they want to avoid punishment and the feelings of shame that would occur if they stopped participating.

Similarly, students in the withdrawn student group, who exhibit behavioral disaffection and boredom and apathy in the classroom, may also potentially be suffering from low autonomy. Perhaps their boredom and withdrawal from class stems from their experience of their learning activities as meaningless and unimportant. Thus, it is hypothesized that these students are more likely to endorse an introjected and/or extrinsic self-regulation style. Additionally, a lack of relatedness in class could contribute to their decision to not activity participate in learning activities with their peers. Not feeling like an accepted member of the learning community would exacerbate their tendency to withdraw from learning activities.

Helpless students, who express both behavioral disaffection (lack of participation) and emotional disaffection (worry), are hypothesized to experience low levels of both relatedness and competence similar to enmeshed students. A lack of confidence about one's ability to success in school coupled with feeling like an outsider who can't rely on his teacher or classmates for support, would likely make a student feel helpless in class.

Students in the rebellious group, who are characterized by behavioral disaffection and feelings of anger and frustration towards learning activities, are hypothesized to 
endorse experiencing low levels of autonomy. Perhaps these students are rebelling against classwork because they do not see it as relevant and meaningful to their lives and thus gain no sense of ownership over or purpose in their work. They may feel coerced or controlled in the classroom instead of empowered to make school serve their own academic interests and passions. This suggests that rebellious students are likely to have an extrinsic self-regulation style.

Finally, it is hypothesized that students in the burnt-out profile will have the lowest levels of all three self-system processes. Burnout students have, sadly, 'given up'; they do not participate in school and endorse experiencing all three of the emotional components of disaffection, namely, anxiety, boredom, and frustration. As the most maladaptive student motivation profile, burnout out students are hypothesized to endorse experiencing the lowest levels of all three SSP's. See table 3.3 for a summary of these tentative hypotheses.

Hypothesis 3a: Students in the Optimal group will report significantly higher levels of all three self-system processes (relatedness, competence, and autonomy) than students in other groups.

Hypothesis 3b: Students in the Enmeshed and Helpless groups will reports significantly lower competence and relatedness than students in other groups. Hypothesis 3c: Students in the Rebellious and Withdrawn groups will report significantly lower extrinsic and identified self-regulation and significantly higher introjected and extrinsic self-regulation than students in other groups. 
Hypothesis 3d: Students in the Burnt Out group will report significantly lower levels of all three self-system processes than students in other groups.

Table 3.3 Summary of Hypotheses 3a-3d.

\begin{tabular}{c|c|c|c|c|c|c} 
& Relatedness & Competence & Intrinsic & Identified & Introjected & Extrinsic \\
\hline Optimal & + & + & + & + & - & - \\
\hline Enmeshed & - & - & & & + & \\
\hline Ritualistic & & + & & & + & + \\
\hline Withdrawn & - & & & & + & + \\
\hline Helpless & - & - & & & & \\
\hline Rebellious & & - & & & & + \\
\hline Burnt out & - & - & - & - & + & +
\end{tabular}

\section{RQ 4: Using Student Motivation Profiles to Create Targeted Treatments}

The final set of research questions explores whether students who receive high levels of the types of teacher support they need most, based on what their profile membership tells us about their SSP's, will exhibit more adaptive patterns of change in engagement across the school year. Previous research suggests that when teachers provide their students with motivational support in the form of warmth, structure, and autonomy support, student motivation increases over time (Furrer, Skinner, \& Pitzer, 2014; Skinner, Furrer, Marchand, \& Kindermann, 2008; Skinner, Kindermann, Connell, \& Wellborn, 2009; Skinner, Kinderman, \& Furrer, 2009; Deci \& Ryan, 2000). Although research suggests that all individuals need all three components of motivational support, the current study hypothesizes that experiencing high levels of the specific type/s of support that students' SSP's suggest they lack, may be especially helpful in supporting 
their overall motivation. Thus, if findings from RQ 3 suggest that students with different motivational profiles have different teacher support needs, then it follows that if they receive the prescribed 'treatment' for their particular profile, their engagement should increase. The current study will rely on students' reports of their engagement to answer RQ 3, as opposed to the teacher-reports of engagement used to create the profiles. Presumably, the students themselves will be better able to report on whether the "treatment" is working for them.

However, it is important to note that student engagement generally declines across the school year, such that maintaining the same level of engagement from fall to spring would be considered an adaptive pattern of change in the face of such steady declines (Skinner \& Belmont, 1993; Fredricks, Blumenfeld, \& Paris, 2004; Janosz, Archambault, Morizot, \& Pagani, 2008). Thus, the current study hypothesizes that students who receive more targeted teacher support will either experience gains in their engagement, maintenance of level of engagement, or less severe declines in their engagement from fall to spring than their peers who did not receive quality teacher support.

Research Question 4. Based on their motivation profile in (as reported by teachers), do students who receive higher amounts of the types of teacher support they need experience more adaptive patterns of change in their engagement (as reported by students) from fall to spring?

Hypothesis 4a: Students who receive high amounts of the types of teacher support they need will maintain or exhibit increases in their levels of engagement from fall to spring. 


\section{Chapter 4}

\section{Methods}

\section{Participants}

This study uses data collected as part of a larger, district-wide evaluation of a rural-suburban school district in upstate New York. 1608 elementary and middle school students (grades 3 through 7) completed surveys about their engagement, disaffection, and experiences in school. Fifty-three of their teachers also participated by completing questionnaires about their perceptions of their students as well as their experiences interacting with these students. Data were collected using a cohort-sequential design, with data collected in fall (October) and spring (May) for four consecutive years. Achievement scores were also obtained from school records for a subset of the participants. For a complete description of the larger study, see Skinner et al. (1998).

The current study only uses data from $3^{\text {rd }}$ through $6^{\text {th }}$ grade students in the third year of the project. 1018 students' total participated in year three of the study, including $1383^{\text {rd }}$ grade students ( 66 boys and 72 girls), $3424^{\text {th }}$ grade students (172 boys and 170

girls), $1705^{\text {th }}$ grade students (78 boys and 92 girls), and $3686^{\text {th }}$ grade students (192 boys and 176 girls); two students were missing grade and/or gender data. The majority of students were Caucasian, with less than 5\% identifying as non-white, and their families' socioeconomic status (determined by parent occupation and education level) were primarily working to middle class. 


\section{Procedures}

All students in the district were invited to participate in the study. Parents were notified prior to data collection, and passive consent procedures were employed for each participant. Students' assent to participate was also obtained prior to their completing the surveys. Trained research assistants explained to student participants that there would be no penalty for not participating, that their responses would not affect their grades in any way, and that the information they provided would be confidential and anonymous.

Pairs of trained research assistants administered the questionnaires to students during three 40-minute class sessions. During each session, one of the interviewers read the questions aloud to the students as they marked their answers on the questionnaire, while the second interviewer circulated around the classroom to answer students' questions. The students' teachers were not present in the classroom during the collection of student data and students were reminded that their teachers would not have access to their responses.

\section{Measures}

Teachers completed sets of items tapping their perceptions of their students' emotional and behavioral engagement and disaffection. Students completed sets of items tapping their appraisals of their self-system processes (sense of relatedness, competence, and autonomy) and their experiences of teacher support (teacher provision of warmth, structure, and autonomy support). Students and teachers rated all items using a 4-point Likert scale to indicate whether each item was (1) Not at all true for me, (2) Not very true 
for me, (3) Sort of true for me, or (4) Very true for me OR (1) Not at all true for this student, etc. Negatively worded items were reverse coded, and items were averaged within constructs to create composite scale scores. These scale scores could range from 1 to 4, with higher numbers indicating more of the respective construct. (See Appendix A for a list of all items).

\section{Student Engagement and Disaffection: Teacher-Reports}

Student Engagement. Students' engagement was assessed using a 6-item Likerttype scale that was designed to measure teacher perceptions of student academic engagement (Wellborn, 1991). Teachers reported on the behavioral and emotional engagement of their students. Behavioral engagement was measured with two items tapping student effort and participation. Example items include "When we start something new in class, this student participates in discussion" $(r=.52)$. Emotional engagement was assessed by four items tapping student enjoyment and interest. Example items include, "In my class, this student appears enthusiastic" $(\alpha=.85)$. Prior research has indicated that the two components are significantly intercorrelated $(\mathrm{r}=.31, \mathrm{n}=144$; Wellborn, 1991; r=.72, n=1,018; Skinner, Kindermann, \& Furrer, 2008) and that they form an internally consistent indicator of engagement $(\alpha=.95, \mathrm{n}=144$; Wellborn, 1991; $\alpha=.90, \mathrm{n}=1,018$; Skinner et. al, 2008).

Student Disaffection. Disaffection was assessed by 12 items examining students' lack of motivation, negative emotions towards schooling, and giving up in the face of difficulties. Specifically, behavioral disaffection was measured by five items tapping lack 
of effort, 'going through the motions', and withdrawal from learning activities. Example items include, "When we start something new in class, this student doesn't pay attention", and "In my class, this student does just enough to get by" $(\alpha=.90)$.

Due to its dimensionality, the construct of emotional disaffection was separated into its three distinguishable subcomponents, namely the boredom/apathy, the anxiety/worry, and the frustration/anger dimension. Although the full measure of emotional disaffection has been validated and shown strong evidence of internal consistency ( $\alpha=.85$; Skinner, Kindermann, $\&$ Furrer, 2008), the current study is the first to separate the construct into its three major subcomponents. Student anxiety/worry was measured by two items including, "When I explain new material, this student seems worried" ( $r=.59)$. Boredom/apathy was measured by one item, including "When working on classwork in my class, this student appears bored". Student frustration/anger was measured by four items including, "When working on classwork in my class, this student appears frustrated", and "In my class, this student appears angry" $(\alpha=.85)$. Similar to engagement, prior research has indicated that the emotional and behavioral components of disaffection are significantly intercorrelated $(r=.65, n=1,018$; Skinner, Kindermann, \& Furrer, 2008) and are internally consistent when combined $(\alpha=.85$, n=1,018; Skinner et. al, 2008).

\section{Student Self-system Processes: Student-reports}

Student Relatedness. Students' sense of belonging and connection to their teachers and classmates was assessed using a 8-item scale $(\alpha=.84)$. Four items tapped 
students' feelings of connectedness and emotional security with their teachers, and four items tapped students' sense of relatedness with their classmates. Example items include "When I am with my teacher, I feel accepted" and "When I'm with my classmates, I feel unimportant (reverse-coded)".

Student Competence. Perceptions of student competence were measured with 22 items adapted from the Student Perceptions of Academic Control Questionnaire (Skinner, Wellborn, \& Connell, 1990). The measure assessed students' expectations about the extent to which they can produce desired academic outcomes and avoid negative ones. Example items include "If I decide to learn something hard, I can" and "I don't have the brains to do well in school" (reverse-coded) $(\alpha=.89)$.

Student Autonomy Orientation. Students' perceptions of autonomy were measured by 17 items adapted from Ryan and Connell (1989) assessing students' reasons for participating in academic activities ( $\alpha=.85$ Skinner, Kindermann, $\&$ Furrer, 2008). Items were grouped into their four subcomponents that vary on a continuum of selfregulation: (1) Intrinsic Self-Regulation (4 items), which refers to doing academic work because it is inherently enjoyable; (2) Identified Self-Regulation (5 items), which refers to doing academic work because of a desire for learning and understanding; (3) Introjected Self-regulation (4 items), which refers to doing schoolwork in order to demonstrate ability and maintain self worth; and finally (4) Extrinsic self-regulation (4 items), which refers to doing schoolwork for external demands or rewards. Example items include "Why do I do my classwork?...”Because it is fun.” (Intrinsic); "Because 
doing well in school is important to me" (Identified); "Because I'll be ashamed of myself if it doesn't get done" (Introjected); and "So my teacher won't yell at me" (Extrinsic).

\section{Teacher support: Student-reports}

Teacher Warmth. Students reported on the amount of interpersonal closeness felt between themselves and their teachers. Students completed 16 items covering five facets of teacher warmth, namely the extent to which their teachers spent time with them, showed them affection, and were available, knowledgeable, and dependable (Skinner \& Belmont, 1993). Specifically, two items tapped the time spent interacting with students (e.g., "My teacher talks with me"). Three items refer to the extent to which the teacher likes, appreciates, and shows affection towards the student (e.g., "My teacher really cares about me"). Three items measured availability or the teacher's ability to devote time to the student (e.g., "My teacher is always there for me"). Three items tapped knowledge, that is, the teacher's understanding of the student and his/her situation (e.g., "My teacher just doesn't understand me," reverse-coded). Finally, five items measured students' perceptions of the dependability of their teachers (e.g., "I can rely on my teacher to be there when I need him/her").

Teacher structure. Students reported on the extent to which their teacher provided them with structure by responding to 29 items tapping whether teachers offered clear expectations, contingent responses, help and support, and attuned teaching strategies. Specifically eight items tapped contingency (e.g., "When my teacher tells me he/she will do something, I know he/she will'), seven items tapped expectations (e.g., 
"My teacher makes is clear what he/she expects of me in school"), six items tapped help/support (e.g., "Even when I run into problems, my teacher doesn't help me" reverse coded), and eight item tapped adjustment/monitoring (e.g., "My teacher makes sure I understand before he/she goes on").

Teacher Autonomy Support. Teachers' provision of autonomy support was assessed by 21 items tapping the extent to which teachers provided students with choices, exerted control over them, offered respect for their ideas and opinions, and explained the relevance of learning activities. Specifically, four items tapped choice (e.g., "My teacher gives me a lot of choices about how I do my schoolwork"), four items tapped control (e.g., "My teacher tries to control everything I do"), seven items tapped respect (e.g., "My teacher never listens to my side" reverse-coded), and six items tapped relevance (e.g., "My teacher talks about how I can use things we learn in school").

\section{Student Engagement and Disaffection: Student-reports}

In addition to using teacher-reports of student engagement and disaffection to create motivation profiles, the current study will also use student-reports of student engagement and disaffection. Student self-reported engagement was assessed using 5 items tapping engaged behaviors (e.g., "I participate in class discussions") and 6 items tapping engaged emotions (e.g., "When we start something new in school, I feel interested". Student self-reported disaffection was assessed using 5 items tapping disaffected behaviors (e.g., "When I'm in class, I just act like I'm working") and 9 items tapping disaffected emotions (e.g., "When I'm doing my work in class, I feel worried"). 


\section{Chapter 5}

\section{Results}

\section{Descriptive Information}

Missingness report. Missing data were examined using SPSS version 23.

Missing values were evaluated using both variable-wise and case-wise analyses to determine whether the data fulfilled requirements to be considered missing at random (MAR), missing completely at random (MCAR), or not missing at random (NMAR). For this study, at each time point, each of the student participants in this study had the opportunity to respond to 138 items and teachers completed 18 items about each student. The items were a subset of the total items available from the larger longitudinal study. A case-wise analysis demonstrated that almost $68 \%$ of individual participants had at least one missing value on a variable. A variable-wise analysis showed that all of the 12 analysis variables had at least one missing value on a case.

Further analysis of the missing values did not reveal any distinct patterns, and thus it was determined that the data were missing at least at random. The data were imputed five times using multiple imputation. All grades and time points were imputed together. All further analyses were completed using the imputed dataset.

Descriptives. All analyses were conducted using SPSS 24.0 (IBM Corp., 2013)

and R (R Core Team, 2013). Internal consistencies, mean levels, and standard deviations for each variable at each time point are presented in Table 5.1.

Assessed by Cronbach's alpha, internal consistencies for all scales with at least 3items demonstrated adequate internal consistency (i.e., $\alpha>.70$ ). The only exception was 
for student reports of behavioral disaffection in fall $(\alpha=.67)$ which was slightly lower than adequate. Of the 21 variables utilized, three variables contained less than 3 -items each. For both of the two-item scales, (teacher-reported student behavioral engagement and student anxiety) correlations were used to assess reliability as Cronbach's alpha is not appropriate for scales with less than 3-items. At both time points, the correlations between the two behavioral engagement items were moderate ( $\mathrm{r}=.50, .52$ respectively) and the correlations between the two student anxiety items were strong $(\mathrm{r}=.59, .60$ respectively). Finally, one variable, teacher-reported student boredom was assessed with only one item and thus no reliability coefficient is available. 


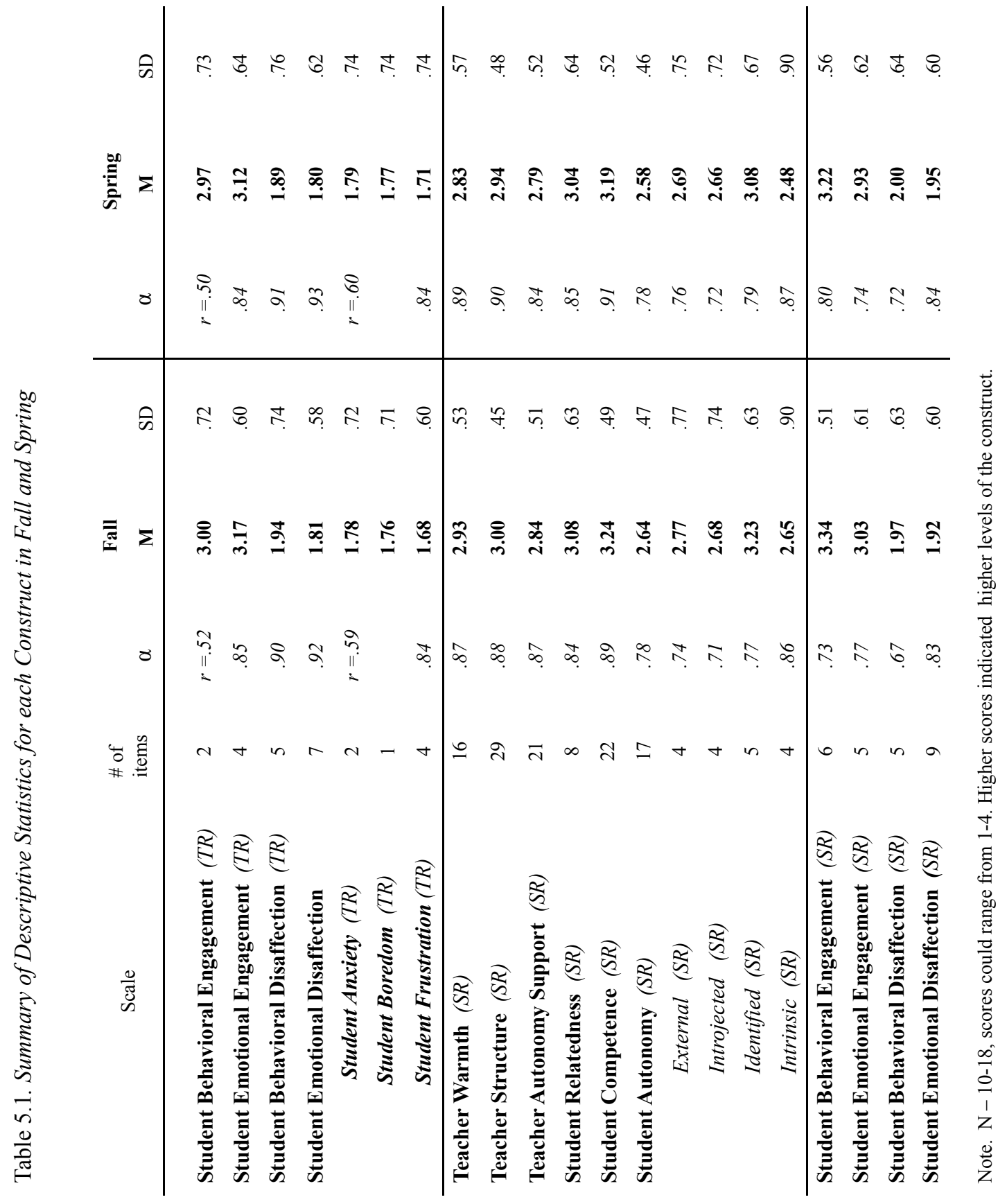


Mean Levels: Engagement The mean levels of student engagement and disaffection, student self-system processes, and teacher support were examined to better understand the overall functioning of the sample. Mean levels of student behavioral engagement were fairly high at both time points for both teacher-reports $(\mathrm{Ms}=3.00$ and 2.97, in fall and spring respectively) and student-reports $(\mathrm{Ms}=3.34$ and 3.22 , in fall and spring respectively). (Note that because scales ranged from 1-4, with 1 being 'not at all true' and 5 being 'totally true', the midpoint of all these scales was 2.5).

Similarly high levels of student emotional engagement were reported at both time points by teachers $(\mathrm{Ms}=3.17$ and 3.12 , in fall and spring respectively) and students $(\mathrm{Ms}=$ 3.03 and 2.93, in fall and spring respectively). Both teachers and students reported that students had higher emotional engagement than behavioral engagement, which is interesting since teachers made this judgment by relying solely on outward indicators to infer students' inner experiences. Reporters did disagree somewhat with students reporting being significantly more behaviorally engaged than their teachers' perceived them to be $(t(1017)=13.93, p<.001)$ although teachers significantly overestimate students' emotional engagement compared to students' own reports. $(t(1017)=6.01, p<$ $.001)$.

As expected given previous findings, both sources reported losses in student engagement over the school year. Students reported significant losses from fall to spring in both behavioral engagement $(t(1017)=7.14, p<.001)$ and emotional engagement $t(1017) 5.87, p<.001)$. Although teachers also reported losses in both components of 
engagement across the school year, these decreases were only significant for emotional engagement $t(1017) 4.05, p<.001)$.

Mean Levels: Disaffection. Students and teachers reported moderate behavioral disaffection at both time points $(\mathrm{Ms}=1.94$ and 1.89 for teacher-reports; $\mathrm{Ms}=1.97$ and 2.00 for student-reports). Teachers reported significant decreases in student behavioral disaffection across time $t(1017)=2.94, p<.01)$ but students reported experiencing nonsignificant increases in behavioral disaffection from fall to spring. Previous findings suggest that, on average, students' disaffection increases from fall to spring and from year to year as students progress through their academic careers. In the current sample, levels of student emotional disaffection were similar across time points and reporters $(\mathrm{Ms}=1.81$ and 1.80 for teacher-reports; $\mathrm{Ms}=1.92$ and 1.95 for student-reports $)$. The three teacher-reported subcomponents of emotional disaffection (teacher-reports only) also reflected very similar mean levels across time points; namely anxiety $(\mathrm{Ms}=1.78$ and 1.79), boredom $(\mathrm{Ms}=1.76$ and 1.77$)$ and frustration $(\mathrm{Ms}=1.68$ and 1.71) suggesting teachers saw very little change over time in these components of student disaffection. Although the mean levels of all three components of emotional disaffection were very similar, anxiety was the most teacher-cited disaffected emotion, followed by boredom and finally frustration. Overall, in comparing students' and teachers' reports of disaffection, it appears that teachers underestimated both students' behavioral disaffection (although this difference was not significant) and their emotional disaffection $(t(1017)=-4.85, p<.001)$ compared to students' own reports. 
Mean Levels: Student experience. Students also reported on their self-system processes and their experiences of teacher support. Specifically, students reported experiencing high levels of relatedness with their teachers and peers $(\mathrm{Ms}=3.08$ and 3.04) and feelings of competence $(\mathrm{Ms}=3.24$ and 3.19). However, at both time points, studentreported autonomy $(\mathrm{Ms}=2.64$ and 2.58) was significantly lower than both their sense of relatedness $($ Fall $=t(1017=22.29, p<.001$ and Spring $=t(1017)=22.63, p<.001)$ and their sense of competence $($ Fall $=t(1017=36.08, p<.001$ and Spring $=t(1017)=34.04$, $p<.001)$. All three self-system processes declined significantly $(p<.05)$ from fall to spring indicating students felt less connected to others, less self-efficacious, and less ownership over their learning across the school year.

Similarly, students' experiences of each component of teacher support, namely teacher warmth, structure, and autonomy support, were moderately high and also decreased across the school year. Specifically, students reported experiencing significant decreases in teacher warmth, $2.83 t(1017)=6.73, p<.001)$, structure $t(1017)=4.84, p$ $<.001$ ), and autonomy support $t(1017)=3.22, p<.01)$ from fall to spring. Unsurprisingly, students' experiences of need fulfillment was a function of the amount of the associated type of teacher support they received such that structure was the most cited component of teacher support received and competence in turn had the highest reported mean levels of all the SSP's. In contrast, students' reported experiencing significantly less autonomy support than either of the other two components of teacher support and this seems to be reflected in students' perceptions of their own autonomy, which was significantly lower than either of their other self-system processes. 
Examination of the range statistics for each scale at each time point revealed that for 14 of the scales including student-reported engagement and teacher support, no student endorsed the lowest response option for every item (1; not at all true). Additionally, for 5 scales including student-reported emotional disaffection and teacher support, no student endorsed the highest response for every item (4; totally true). All scales had moderate standard deviations, ranging from $.45-.90$. No floor or ceiling effects were detected, as would be indicated by the minimum or maximum scale scores falling within one standard deviation of the scale mean.

Mean Levels: Gender and Grade differences. Finally, we investigated the presence of significant gender and grade differences in mean levels of study variables. No significant gender differences were present for any of the teacher-reported engagement and disaffection variables, suggesting teachers do not perceive boys' and girls' motivation differently. For the student-reported variables, significant gender differences were found at both time points for behavioral engagement $($ Fall $=t(946)=-4.90, p<.01 ;$ Spring $=t(946)$ $=-4.45, p<.01)$ and emotional engagement $($ Fall $=(t(946)=-3.78, p<.01 ;$ Spring $=(t(946)$ $=-3.78, p<.01$ ), but not disaffection. Girls rated themselves as more engaged than did boys which corroborates previous findings that indicating that girls are more engaged than boys on average (Skinner, Kindermann, Connell, \& Wellborn, 2009; Skinner, Kinderman, \& Furrer, 2009; Skinner, \& Belmont, 1993).

For student self-system processes, gender differences were found for competence and aspects of autonomy orientation. Specifically, girls reported having a higher sense of competence at both time points $($ Fall $=t(946)=-3.50, p<.05 ;$ Spring $=t(946)=-3.65, p$ 
$<.05)$. Additionally, girls also reported significantly higher levels of introjected autonomy orientation in spring $t(946)=-1.80, p<.01)$, higher identified autonomy orientation at both time points $($ Fall $=t(946)=-6.02, p<.001 ;$ Spring $=t(946)=-4.78, p<.05)$, and higher intrinsic autonomy orientation in fall $t(946)=-4.90, p<.01$; Spring $=t(946)=-4.45, p$ $<.01$ ), suggesting perhaps girls' autonomy orientation may be more self-determined than boys. Finally, no significant gender differences were found in overall teacher support or either of the three components of teacher support at either time point.

In terms of significant mean level differences by grade, results favored younger students in earlier grades. Specifically, the pattern of mean level differences in components of motivation, self-system processes, and teacher support indicated younger students generally had higher engagement, lower disaffection, higher competence, relatedness, and autonomy as well as experienced more teacher warmth, structure, and autonomy support. Although the majority of the mean levels followed this pattern of favoring younger students, these differences were significant for only about a quarter of the variables.

Correlations: Student engagement and disaffection. Table 5.2 depicts the intercorrelations among teacher-reported (TR) and student reported (SR) student engagement and disaffection in fall and spring.

Teacher-reports. Correlations between teacher-reported aspects of student motivation were moderate to strong, ranging from $r=.34-.79$ with within time-point correlations generally higher than across time correlations. The strongest correlations 
were between the behavioral and emotional components of disaffection and the weakest correlation was between behavioral engagement and anxiety.

It is important to note the correlations among the teacher-reported subcomponents of emotional disaffection. Although boredom and anxiety were moderately correlated $(r=$ $.33)$, the strong correlation between anxiety and frustration $(r=.76)$ was one of the highest correlation coefficients found among motivation variables. This strong 


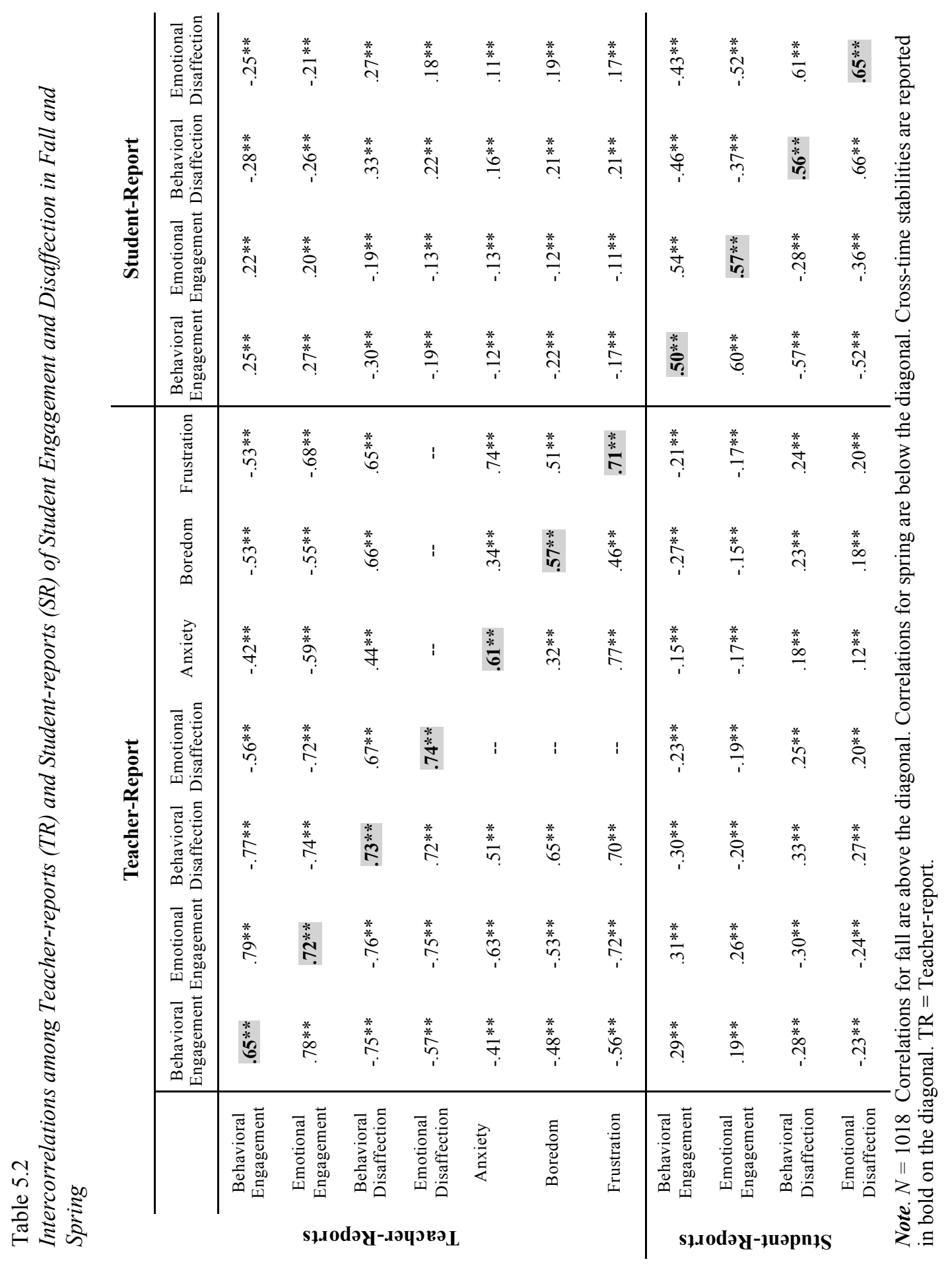


connection between teacher-reports of student anxiety and frustration suggests that teachers are not as skilled at differentiated between these two emotional states. This led us to combine these two scales into a composite anxious/frustrated variable during our empirical profile creation (see page 142)

Student-reports. Student reports of the components of student motivation were less strongly coupled with correlations ranging from $r=.28-.66$. The strongest correlations were between the two components of disaffection and the weakest correlation was between behavioral disaffection and emotional engagement.

Cross-reporter. Across-reporter correlations between student- and teacherreported student engagement were relatively low, averaging .25 . The cross-reporter correlations for both components of engagement were higher in the spring than the fall, suggesting perhaps that with time teachers become more aware of their students' engagement as they get to know their students better and thus their ratings align better with students' own reports as time passes. Student- and teacher- ratings of student disaffection were also moderately correlated, averaging .29. Although one might expect to find higher cross-reporter correlations, this moderate convergence was expected and aligns with previous findings that highlight the power of perspective in influencing the ratings of these motivational states.

Finally, although the cross-reporter correlations were relatively low, the crosstime stabilities for each motivational construct (found on the diagonal in Table 5.2) were moderate to high, ranging from $.50-.77$. This stability across the school year made 
predicting change over time more difficult as there was not a great deal of change to explain.

Correlations: Student experience. Table 5.3 contains the intercorrelations among students' reports of their experiences of teacher support in fall and spring, and Table 5.4 contains the intercorrelations among student-reports of their self-system processes in fall and spring. The three components of teacher support were strongly related to each other with correlation coefficients between $.80-.83$. The cross-time stabilities for each component were moderate, as indicated by correlation coefficients that ranged between $.59-.64$.

The strength of the relationships between the three SSP's was more variable, likely due to the further dividing of autonomy into its four subcomponents. Specifically, relatedness, competence, and autonomy were relatively strongly related to one another ( $r$ $=.38-.56)$. However, the relationship between the four types of autonomy were less strongly related to the other SPP's, with correlations ranging widely from -.01-.52, including non-significant relationships. This was expected considering how each of the four types of autonomy orientation represent an continuum of self-determination and have been previously associated with different outcomes and qualities of motivation (Deci \& Ryan, 1989). In addition, the cross-time stabilities for student SSP's were relatively high, ranging from .48 - .66 , which made predicting change over time more difficult. 


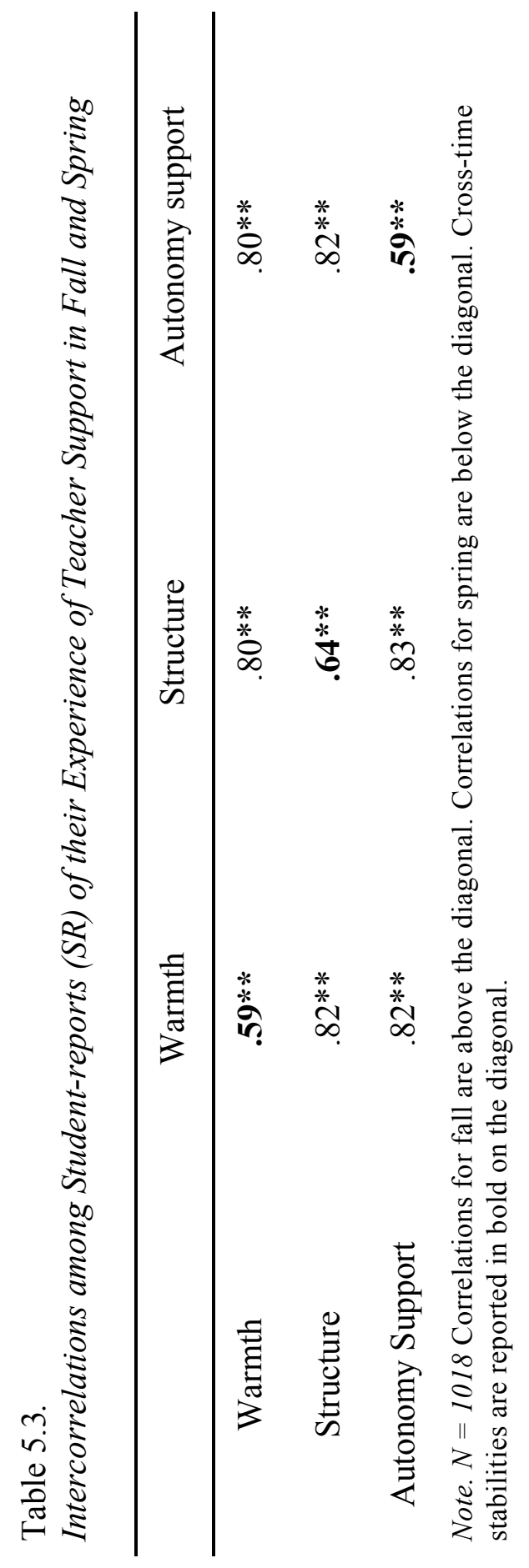




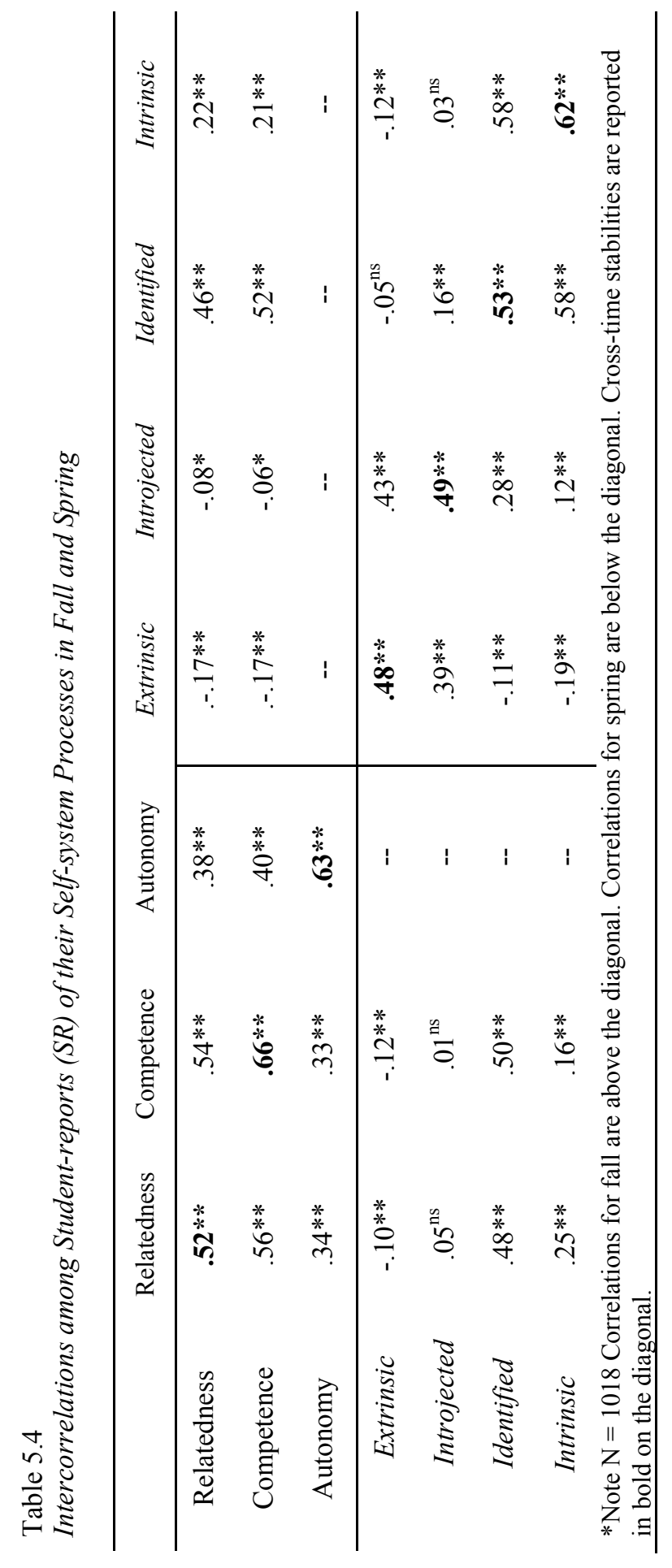




\section{Research Questions and Analyses}

Research Question 1a. Do the seven hypothesized student motivation groups provide a good fit for the pattern of interrelationships among multiple components of behavioral and emotional engagement and disaffection? Is there evidence to suggest that these profiles can be found in the current data set? Are these profiles adequate to characterize a substantial portion of the students sampled?

RQ 1a: Coverage. The first research question sought to identify whether the current study's seven theoretically-derived student engagement profiles were an accurate description of the types of students that teachers saw in their classrooms. The overarching question in RQ \#1 was one of coverage: Do these hypothesized groups characterize a substantial part of the student population? Put another way, are most students represented by one of these profiles? The proceeding section details the process by which the quantitative data from the current study were used to model the theoretical groups followed by a description of the resulting profiles that emerged and the extent to which the students in this sample could be classified into one of the seven hypothesized groups.

Identification of target variables. It is important to note that initial examination of the data revealed a larger-than-expected overlap amongst groups, especially concerning the subcomponents of emotional disaffection. Specifically, the vast majority of students who were perceived by their teachers as highly anxious were also rated as highly frustrated, as indicated by the high correlation between teacher-reports of student anger and anxiety $(r=.77)$ discussed in the previous section. Additionally, the three 
disaffected emotions (anxiety, frustration, boredom) are more commonly examined as a composite variable, as opposed to individually, and thus their ability to be combined has been previously established. As such, anxious and frustrated were combined into a composite variable that was used to create the theoretically-based profiles. Boredom, the third component of emotional disaffection, was kept as a separate variable, as it was not as strongly intercorrelated with the other two components.

Identification of thresholds. Initially, thresholds based on tertile splits were used to create the student hypothesized student profiles. Specifically, each profile was described in terms of its levels of specific subcomponents of behavioral and emotional engagement and disaffection. Students who scored in the top third of all participants on a given subcomponent were considered to exhibit high levels of that subcomponent. Thus, students who scored in the top third on the specific subcomponents that defined a given profile (and the bottom third on all other subcomponents) were placed in that profile (See Table 3.1 for a list of the variables that define each profile). For example, students in the Optimal profile are characterized by high behavioral engagement and high emotional engagement. Thus, students who scored in the top third on behavioral engagement and the top third on emotional engagement and the bottom third on behavioral and emotional disaffection were placed in the Optimal group. However, using these mutually exclusive categories to define each of the seven profiles failed to produce adequately sized groups. In order to make sense of this lack of coverage for the hypothesized profiles we attempted to understand students' levels of each motivation variable visually in Table 5.5. Based on Table 5.5, which depicts the number of students in each tetile for each variable, 
we relaxed some of the restrictions on each profile in order to increase the number of students in each group. 
Table 5.5

Tertiary splits for mean levels of motivational components for all students in fall

BEHAVIORAL \& EMOTIONAL ENGAGEMENT

\begin{tabular}{|c|c|c|c|c|c|c|c|c|c|c|c|}
\hline \multirow{3}{*}{\multicolumn{3}{|c|}{ al }} & \multicolumn{3}{|c|}{ Low Behavioral } & \multicolumn{3}{|c|}{ Med Behavioral } & \multicolumn{3}{|c|}{ High Behavioral } \\
\hline & & & $\begin{array}{l}\text { Low } \\
\text { Emo }\end{array}$ & $\begin{array}{l}\text { Med } \\
\text { Emo }\end{array}$ & $\begin{array}{l}\text { High } \\
\text { Emo }\end{array}$ & $\begin{array}{l}\text { Low } \\
\text { Emo }\end{array}$ & $\begin{array}{l}\text { Med } \\
\text { Emo }\end{array}$ & $\begin{array}{l}\text { High } \\
\text { Emo }\end{array}$ & $\begin{array}{l}\text { Low } \\
\text { Emo }\end{array}$ & \begin{tabular}{|l} 
Med \\
Emo
\end{tabular} & $\begin{array}{l}\text { High } \\
\text { Emo }\end{array}$ \\
\hline & & & & & & & & & & & \\
\hline \multirow{9}{*}{$\begin{array}{l}\text { Low } \\
\text { Behav } \\
\text { DIS }\end{array}$} & \multirow[t]{3}{*}{ Low Bored } & Low Anx/frust & 3 & 3 & 2 & & 12 & 12 & & 12 & 150 \\
\hline & & Med Anx/frust & 2 & 2 & 2 & 2 & 6 & 7 & 1 & 5 & 57 \\
\hline & & High Anx/frust & 1 & & & & 3 & & 2 & 3 & 5 \\
\hline & \multirow[t]{3}{*}{ Med Bored } & Low Anx/frust & & & & 1 & & 1 & & 2 & 20 \\
\hline & & Med Anx/frust & 1 & & & & 4 & 1 & 1 & 3 & 16 \\
\hline & & High Anx/frust & & 1 & & & & & 1 & 1 & 1 \\
\hline & \multirow[t]{3}{*}{ High Bored } & Low Anx/frust & & & & & & & & & \\
\hline & & Med Anx/frust & & & & & & & & & 1 \\
\hline & & High Anx/frust & & & & & & & & & \\
\hline \multirow{9}{*}{$\begin{array}{l}\text { Med } \\
\text { Behav } \\
\text { DIS }\end{array}$} & \multirow{3}{*}{ Low Bored } & Low Anx/frust & & 5 & 4 & & 4 & 7 & & 1 & 13 \\
\hline & & Med Anx/frust & 2 & 3 & & & 5 & 4 & 1 & 3 & 10 \\
\hline & & High Anx/frust & 1 & 1 & & 6 & 2 & & 1 & 2 & 2 \\
\hline & \multirow[t]{3}{*}{ Med Bored } & Low Anx/frust & 2 & 3 & 1 & 1 & 9 & & & 1 & 22 \\
\hline & & Med Anx/frust & 10 & 18 & 1 & 12 & 34 & 7 & & 8 & 15 \\
\hline & & High Anx/frust & 20 & 10 & & 16 & 23 & 2 & 2 & 5 & 5 \\
\hline & \multirow{3}{*}{ High Bored } & Low Anx/frust & & 1 & & & 2 & & & 2 & 1 \\
\hline & & Med Anx/frust & 4 & 3 & & & 5 & & & & 1 \\
\hline & & High Anx/frust & 3 & & & 7 & 2 & & & & \\
\hline \multirow{9}{*}{$\begin{array}{l}\text { High } \\
\text { Behav } \\
\text { DIS }\end{array}$} & \multirow[t]{3}{*}{ Low Bored } & Low Anx/frust & 2 & 3 & 1 & & 1 & 1 & & & \\
\hline & & Med Anx/frust & 8 & & & & 3 & 1 & & & \\
\hline & & High Anx/frust & 10 & 2 & & 2 & & & & & \\
\hline & \multirow[t]{3}{*}{ Med Bored } & Low Anx/frust & 3 & 3 & 2 & 1 & 2 & & & & 2 \\
\hline & & Med Anx/frust & 30 & 16 & 1 & 2 & 6 & 2 & 1 & 3 & 2 \\
\hline & & High Anx/frust & 61 & 17 & & 17 & 7 & & & 1 & \\
\hline & \multirow[t]{3}{*}{ High Bored } & Low Anxy/frust & 2 & 3 & & & 1 & 1 & & & 1 \\
\hline & & Med Anx/frust & 27 & 5 & 1 & 2 & 5 & & & & 1 \\
\hline & & High Anx/frust & 52 & 14 & & 5 & 2 & & 1 & & \\
\hline
\end{tabular}


Resultant groups. However, even with these relaxed inclusion criteria, we found evidence for the existence of only four of the seven hypothesized groups. Specifically, only the Optimal, Enmeshed, Withdrawn, and Burnt-out out profiles contained at least 20 students each. A fifth group was added, labeled Middle, which was made up of students who scored in the middle tertile on each motivation variable. Table 5.6 depicts sample sizes and mean levels of each component of motivation for each of the five hypothesized variables that appear to be represented in the current data set.

Table 5.6

Sample sizes and mean levels of motivational components in fall for theory-driven profiles

Theoretically-Driven Profiles

\begin{tabular}{lccccc}
\hline & Optimal & Enmeshed & Middle & Withdrawn & Burnt-out \\
& $N=150$ & $N=30$ & $N=34$ & $N=47$ & $N=52$ \\
\hline $\begin{array}{l}\text { Behavioral } \\
\text { Engagement }\end{array}$ & 3.9 & 3.7 & 3.0 & 2.2 & 2.0 \\
$\begin{array}{l}\text { Emotional } \\
\text { Engagement }\end{array}$ & 3.9 & 3.3 & 3.0 & 2.7 & 2.3 \\
$\begin{array}{l}\text { Behavioral } \\
\text { Disaffection }\end{array}$ & 1.0 & 1.6 & 1.9 & 2.9 & 3.1 \\
$\begin{array}{l}\text { Boredom } \\
\text { Anxiety \& }\end{array}$ & 1.0 & 1.5 & 2.0 & 3.0 & 3.1 \\
Frustration & 1.0 & 2.4 & 1.7 & 1.6 & 2.6
\end{tabular}

Profiles. Of the profiles that could be found in the current sample, the Optimal profile was significantly bigger than the other four profiles with 150 students followed by the Burnt-out profile $(n=52)$ and the Withdrawn profile $(n=47)$ with the least populated group being the Enmeshed group $(n=30)$. As per selection criteria, the most adaptive profile, Optimal, had the highest levels of engagement and the lowest levels of all three 
disaffected emotions. Students in the enmeshed group had the second highest levels of engagement but were also perceived by their teachers as having the second highest levels of anxiety/frustration compared to the other groups. The Burnt-out profile was the most maladaptive and distinguished itself from the other suboptimal Withdrawn profile by having much lower levels of emotional engagement and the highest levels anxiety and frustration of any group. Figure 5.1 displays standardized z-scores for each variable in each profile to allow comparisons across the student profiles. Figure

Figure 5.1

Z-scores of each theory-driven profiles' mean levels of engagement and disaffection in fall

Theory-driven Student Motivation Profiles

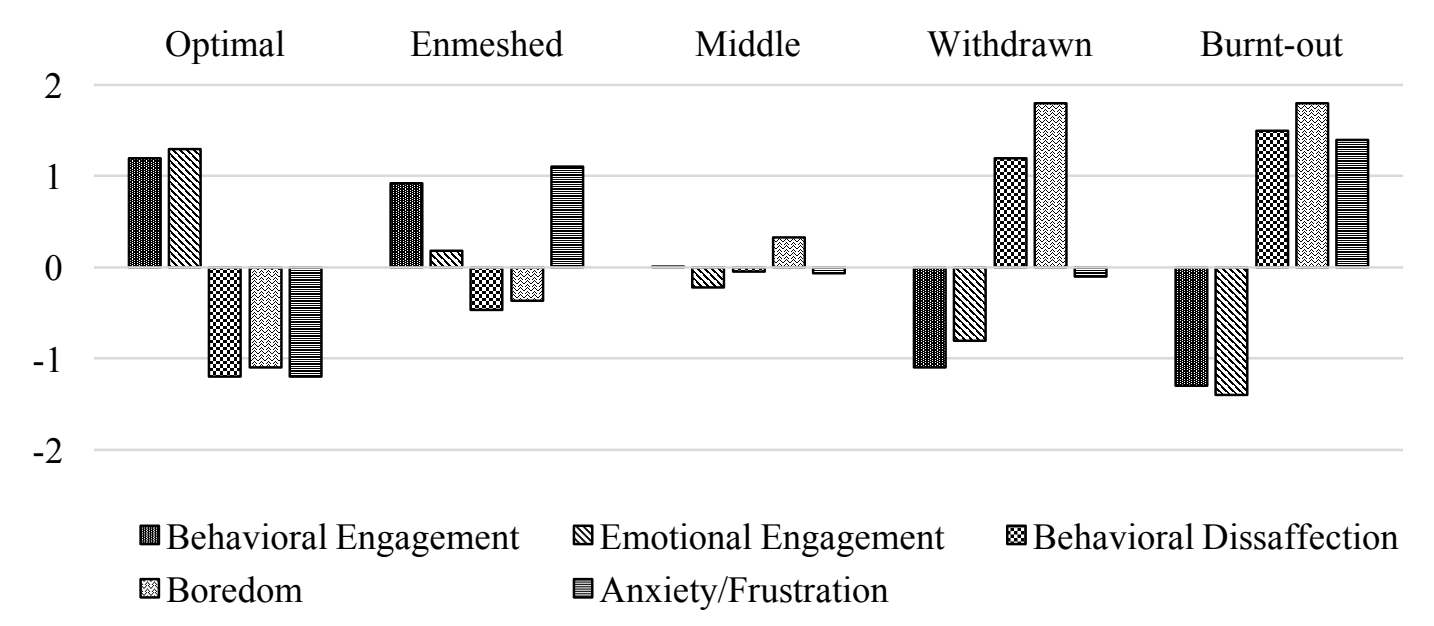

Coverage. Overall, results suggest that Connell and Wellborn's (1991) profiles failed to completely capture teachers' experiences of the types of students they see in their classrooms. $70 \%$ of the students in the current sample could not be categorized as one of the seven profiles. Teachers didn't appear to perceive their students as Ritualistic, 
Helpless, or Rebellious as there were only a handful of students out of over a thousand that were categorized by those profiles. Not only did we fail to find support for the existence of 3 or the 7 hypothesized profiles, but the remaining four student profiles (plus the middle profile) only described $30 \%$ of student sample. The remaining 704 students displayed motivational profiles that fell outside the spectrum defined by the hypothesized profiles and thus could not be classified. This failure to recover three of the hypothesized profiles combined with the fact that only $30 \%$ of students fit into one of the remaining profiles, suggested that the hypothesized groups were not a good fit for the current data and failed to capture the majority of students' motivation profiles in the classroom.

Research Question 1b. Utilizing an empirical approach, what subgroups of students emerge based on their patterns of behavioral and emotional engagement and disaffection in the classroom? Do the resultant profiles make sense conceptually, that is, are they easily interpretable?

RQ 1b: Interpretability. In order to identify the empirically-derived motivation profiles, model-based cluster analyses were conducted in $\mathrm{R}$ using the package mclust. Unlike other cluster analyses that require the researcher to decide a priori the number of clusters contained in a given sample, model-based clustering uses a formal statistical model that relies on probability functions. This type of clustering methodology aims to optimize the fit between the data and mathematical models. Specifically, model-based cluster analysis assumes that the subpopulations or clusters within a given population have their own probability density functions that together combine to determine the 
whole population's probability density. By estimating the parameters of this assumed mixture of probability density functions, and then using those estimated parameters to calculate the probabilities of cluster membership, we can produce multiple solutions. The best model among all the computed solutions, that differ in terms of the number of clusters and the distributions of those clusters, is then chosen based on certain criteria.

Selection criteria. For the current study, two criteria were used to determine the best cluster solution for research question 1b. First, the Bayesian Information Criterion (BIC) index of model fit was examined, with lower values indicating better model fit (Nylund, Asparouhoy, \& Muthen, 2007). As the current study is exploratory and cannot rely on previous work to guide our empirical inquiry, a large number of models were tested to determine the optimal solution. Fifteen different cluster solutions were examined with different model parameters including different number of variables. Specifically, behavioral engagement and behavioral disaffection were examined separately and as a combined variable with behavioral disaffection reverse-coded and added to behavioral engagement. Similarly, anxiety and frustration were examined separately and as the combined anxiety/frustration variables used to identify the theoretically-driven profiles.

The five best-fitting models, according to BIC, were examined using the second criteria, namely, their theoretical interpretability. It was vital to the current study that the empirically identified clusters represented meaningful groups of real students. Model preference was also based on whether each of the profiles was substantively distinguishable from each of the other profiles and reflected meaningful differences across students. For example, the best fitting model was not chosen even though it had 
the lowest BIC because that model only had two groups, a somewhat motived and a somewhat unmotivated group, and thus failed to capture interpretable, distinguishable, and meaningful groups of students. In contrast, the chosen model produced profiles that lent themselves to intuitively understandable labels, such that the profiles seemed to describe naturally-occurring kinds of students that teachers could recognize in their classrooms.

Resultant groups. The chosen model incorporated five variables, which were combined to create five student engagement profiles that were ellipsoidal, with equal volume, shape, and orientation (EEE; Fraley et al., 2014). Similar to the theory-driven profiles, a 'good news' adaptive profile and a 'bad news' maladaptive profile emerged as empirical categories. Specifically, students in the Adaptive profile $(n=346)$ were characterized by the highest levels of teacher-perceived engagement and the lowest levels of teacher-perceived disaffection. Students in the profile labeled Checked-out $(n=155)$ were characterized by the lowest levels of engagement, high anxiety and frustration, and the highest levels of boredom of any group. The smallest profile $(n=57)$, named Distressed, was characterized by the highest levels of anxiety coupled with high frustration and low engagement and boredom. The fourth and fifth classes consisted of a Going Through the Motions student profile which boasted modest levels of engagement and disaffection, and an At Risk profile describing students with low engagement and moderate levels of all three components of emotional disaffection. Table 5.7 depicts sample sizes and mean levels of each component of motivation for each of the five profiles described by the chosen model. 
Table 5.7

Sample sizes and mean levels of motivational components in fall for empirically-derived profiles

Empirically-Driven Profiles

\begin{tabular}{lccccc}
\hline & Adaptive & $\begin{array}{c}\text { Going } \\
\text { through the } \\
\text { motions }\end{array}$ & Distressed & At risk & $\begin{array}{c}\text { Checked- } \\
\text { out }\end{array}$ \\
& $n=346$ & $n=160$ & $n=57$ & $n=300$ & $n=155$ \\
\hline $\begin{array}{l}\text { Behavioral } \\
\begin{array}{l}\text { Engagement } \\
\text { reverse-coded } \\
\text { behavioral disaffection) }\end{array}\end{array}$ & 3.6 & 3.3 & 2.9 & 2.6 & 2.3 \\
$\begin{array}{l}\text { Emotional } \\
\text { Engagement }\end{array}$ & 3.7 & 3.4 & 2.8 & 2.8 & 2.6 \\
$\begin{array}{l}\text { Boredom } \\
\text { Anxiety }\end{array}$ & 1.0 & 2.0 & 1.0 & 2.0 & 3.0 \\
Frustration & 1.2 & 1.4 & 2.9 & 2.3 & 2.1 \\
& 1.2 & 1.3 & 2.1 & 2.2 & 2.1
\end{tabular}

Figure 5.2

Z-scores of each empirically-derived profiles'mean levels of engagement and disaffection in fall

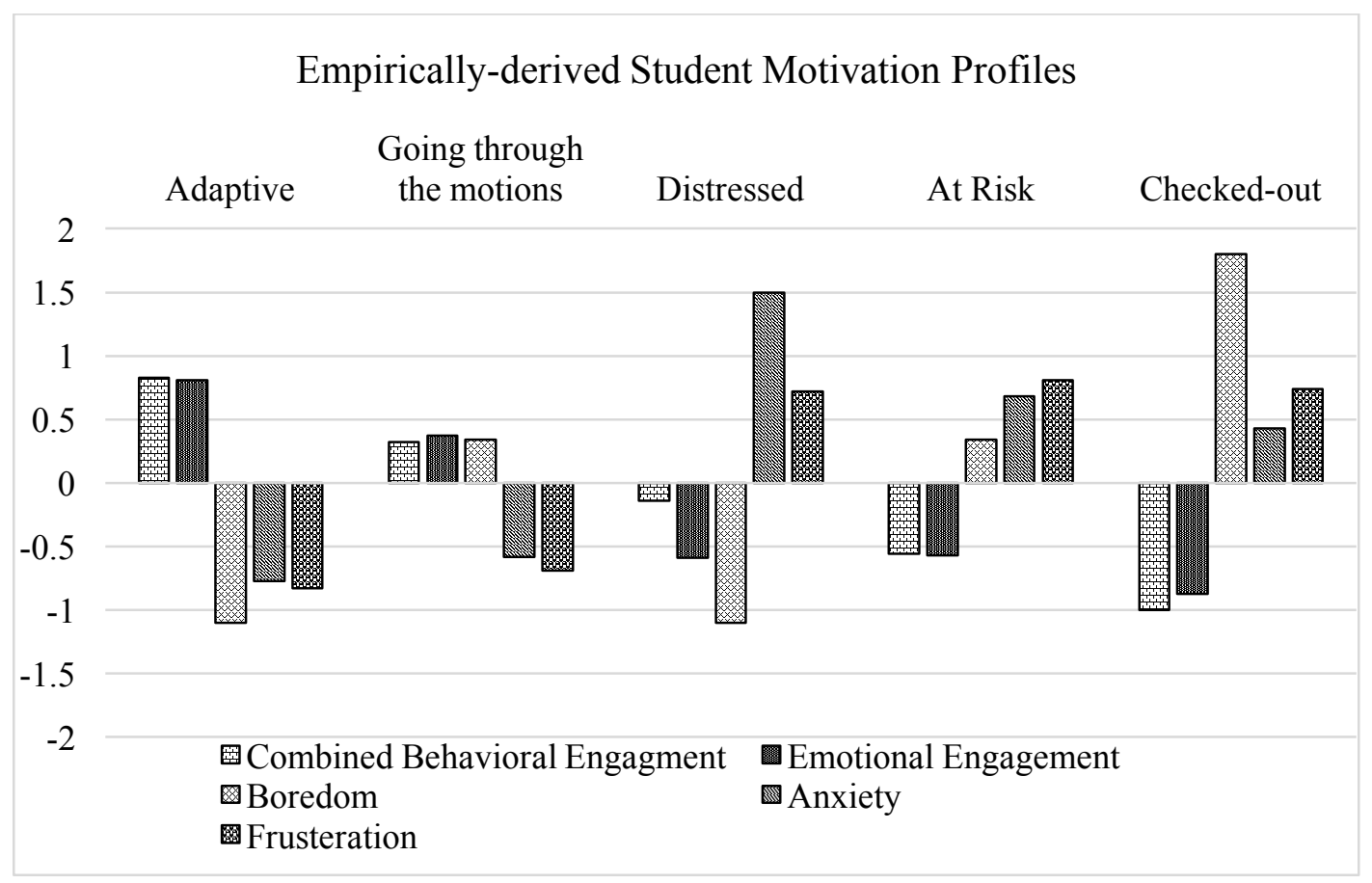


Research Question 1c. How well do the two sets of student motivation profiles align? Is there overlap between the theoretically-derived and the empiricallyderived set of profiles?

RQ 1c: Alignment. In research question 1c, the overlap between the two methods for identifying meaningful student motivation profiles was examined. Due to the exploratory nature of the current study, we were interested not only in using multiple person-centered approaches to create student motivation profiles, but also in determining whether these different methodologies produced a similar set of profiles. Comparable results across methodologies would increase our confidence in the selection of groups. Thus, the number and qualities of the two different sets of profiles were compared. Then, we examined alignment at the student level by cross-classifying individual students, that is, we took students categorized into each of the seven theory-based profiles and determined which of the empirically-derived groups they would fall into.

Both person-centered approaches to creating student motivation profiles produced five student groups. Although we hypothesized seven theory-driven student motivation profiles, support was only found for four of those profiles (and a fifth was added to better understand the 'average' student'). Both sets of profiles appear to include a "good news" profile, (labeled Optimal for the theory-driven and Adaptive for the empirically-derived) that included students with the highest engagement and the lowest disaffection. These groups are well aligned as evidenced by the fact that all 150 of the students characterized as Optimal using thresholds were also classified as Adaptive using model-based clustering (see Table 5.8) Similarly, a "bad news" profile, which contained the students 
with the lowest engagement and the highest disaffection, was also identified by both approaches, (labeled Burnt-out for the theory-driven and Checked-out for the empiricallyderived). All 52 of the students identified as Burnt-out using our theory-driven method were also placed in the empirical Checked-out group.

Table 5.8

Alignment between theoretically-derived and empirically-derived student motion profiles in fall

\section{Theoretically-derived Profiles}

\begin{tabular}{cccccc}
\hline Empirically-derived & $\begin{array}{c}\text { Optimal } \\
\text { Profiles }\end{array}$ & $\begin{array}{c}\text { Enmeshed } \\
(n=30)\end{array}$ & $\begin{array}{c}\text { Middle } \\
(n=34)\end{array}$ & $\begin{array}{c}\text { Withdrawn } \\
(n=47)\end{array}$ & $\begin{array}{c}\text { Burnt-out } \\
(n=52)\end{array}$ \\
$\begin{array}{c}\text { Adaptive } \\
(n=346)\end{array}$ & 150 & 3 & -- & -- & -- \\
$\begin{array}{c}\text { Going Through the } \\
\begin{array}{c}\text { Motions } \\
(n=160)\end{array}\end{array}$ & -- & -- & 20 & -- & -- \\
$\begin{array}{c}\text { Distressed } \\
(n=57)\end{array}$ & -- & 12 & -- & -- & -- \\
$\begin{array}{c}\text { At Risk } \\
(n=300)\end{array}$ & -- & 15 & 14 & -- & -- \\
$\begin{array}{c}\text { Checked-out } \\
(n=155)\end{array}$ & -- & -- & -- & 47 & 52 \\
\hline
\end{tabular}

However, the two person-centered approaches did not appear to reach consensus on what constitutes the basis for classification for the remaining three profiles. Specifically, the Checked-out group not only included all the Burnt-out student but also all of the students classified as Withdrawn. Unlike students in the Burnt-out profile who had the highest levels of anxiety/frustration, students in the Withdrawn profile had some of the lowest levels of anxiety/frustration as well as higher engagement than the Burnt- 
out group. However, this didn't appear to be a meaningful enough distinction for the empirical methodology to be able to differentiate between these two theorized groups.

Similarly, students in the Middle theoretical group where categorized empirically as either Going Through the Motions $(n=20)$ or At Risk $(n=14)$. The Middle group, defined as students who scored in the middle third on all motivation variables, was created in an attempt to strengthen the theoretically-driven profiles by bolstering the number of students represented and help us better understand what the average student in our sample looked like. It's interesting that no such 'average' student group emerged from our empirical examination. However, it makes sense that these 'average' kids would be split across the clusters that represent the less extreme ends of the engagement continuum. This may suggest there is a thin line between these two groups or perhaps the existence of a downward trajectory where students Going Through the Motions may become At Risk without positive intervention.

Finally, the Enmeshed group, theorized as students who were behaviorally engaged but whose participation is characterized by high levels of worry and anxiety, did not appear to have a counterpart in the empirically-derived profiles. Specifically, students in the theorized Enmeshed group were classified across three empirical groups. Namely, of the 30 Enmeshed students, 15 were in the At Risk profile, 12 were in the Distressed profile, and 3 were in the Adaptive profile. The Enmeshed profile appears to be the most diverse/broad including more students from separate empirically-derived groups. This breadth, combined with the fact that it was the most sparsely populated group, suggests that an Enmeshed profile was not common in this data set. 
Summary of Research Question 1. The purpose of research question one was to use two different person-centered approaches to create two sets of student motivational profiles and then compare them to better understand the types of students that teachers see in their classrooms. RQ1a examined whether Connell and Wellborn's (1991) theoretical groups adequately characterized a substantial portion of our student population. The lack of evidence for the existence of three of the seven hypothesized profiles, combined the fact that only $30 \%$ of students populated the remaining profiles, indicated that the theoretically-derived groups were not a good fit for the current data set, and failed to describe the majority of students' motivation profiles in the classroom. RQ1b utilized model-based clustering in an attempt to empirically create meaningful, interpretable student motivation profiles. This methodology classified the entire student sample into one of five interpretable motivation profiles. Finally, the resultant profiles from the two person-centered methodological approaches were compared in RQ1c. Although they both contained a highly engaged group and a highly disaffected group, they did not agree on how to categorize the remaining students who had a more nuanced combinations of engaged and disaffected behaviors and emotions.

Research Question 2. Do students in different motivational profiles experience differential changes in teacher support from fall to spring?

Research Question 2. The second research question examined whether students' motivation had an impact on the way their teachers treated them over the school year. 
Specifically, the reciprocal effects of student motivation on changes in teacher support from fall to spring was examined for each set of motivation profiles to determine whether students in different profiles experienced differential changes in teacher support over time. A $5 \times 2$ mixed factorial ANOVA where the between subjects factor is profile membership and the within subjects factor is time (Fall or Spring) was used to determine the effect of profile membership on changes in teacher support over time.

Theory-driven profiles. The main effect for profile was significant $F(4,308)$ $=11.92, p<.001$, partial $\eta^{2}=.13$. Averaging across time, there were significant differences in students' experiences of teacher support across the 5 profile groups. Post hoc analyses were conducted to pinpoint these differences in teacher support amongst profiles. Pairwise comparisons among the five profiles were conducted using Bonferroni's at each time point. Specifically, in fall and in spring, students in the Optimal profile reported experiencing significantly higher levels of teacher support than students in the Withdrawn and the Burnt-out profiles. Additionally, in spring, students in the Enmeshed profile reported experiencing significantly higher levels of teacher support than students in the Burnt-out profile.

However, the main effect for time was not significant, $F(1,308)=.33, p>.05$, partial $\eta^{2}=.00$. Averaging across profiles, there were no significant changes in teacher support from fall to spring. Examining mean level teacher support in fall and spring illustrates how very little change occurred across time (see Table 5.9). 
Table 5.9

Mean levels of teacher support in fall and spring for theory-driven profiles

\section{Teacher support}

\begin{tabular}{lll} 
Theory-driven profiles & Fall & Spring \\
\hline Optimal & 3.08 & 3.02 \\
Enmeshed & 2.95 & 2.97 \\
Middle & 2.91 & 2.87 \\
Withdrawn & 2.70 & 2.73 \\
Burnt-out & 2.66 & 2.63
\end{tabular}

It is thus unsurprising that the interaction between time and profile was not significant, $F(4,308)=.58, p>.05$, partial $\eta^{2}=.01$. Students in different motivational profiles did not experience differential changes in teacher support from fall to spring (because there were no significant changes in teacher support from fall to spring). Figure 5.3 illustrates these findings. Hypotheses $2 \mathrm{a}-2 \mathrm{~d}$, which proposed that each profile would experience differential changes in teacher support, were not supported. 
Figure 5.3

Changes in student-reports of teacher support from fall to spring for theory-derived profiles

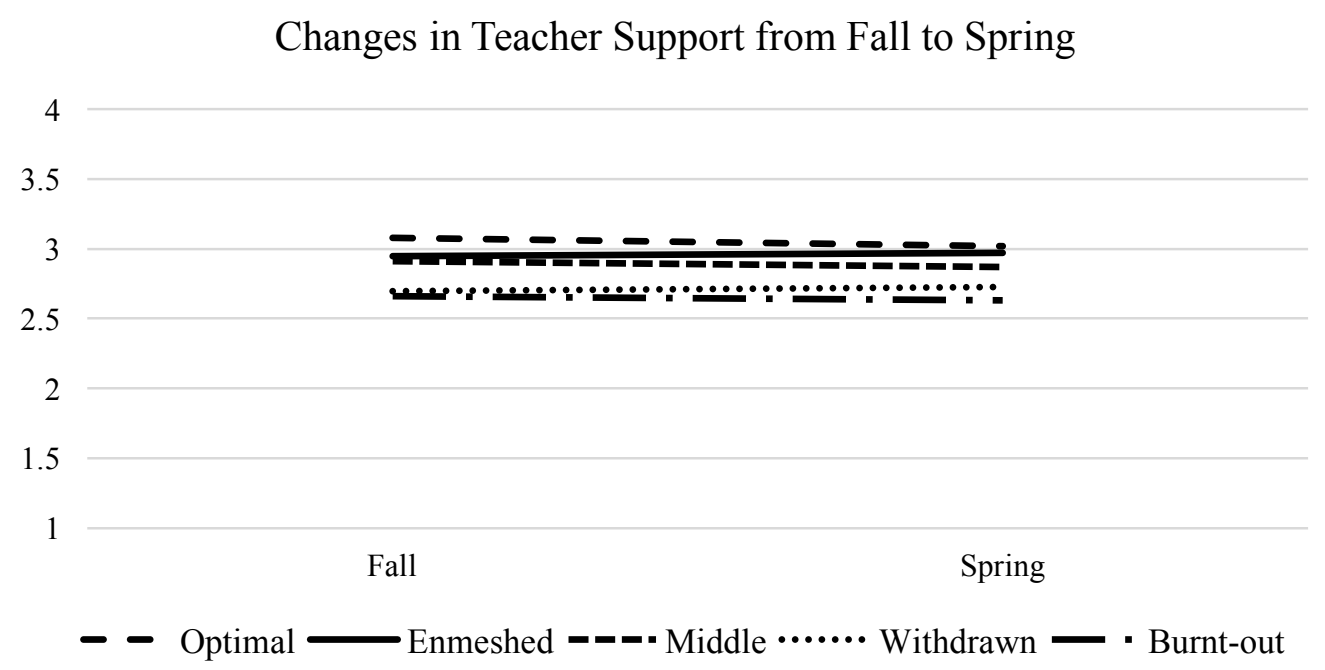

Empirically-driven profiles. A second $5 \times 2$ mixed factorial ANOVA was conducted with the empirically-derived student motivation profiles. The main effect for profile was significant $F(4,1013)=12.57, p<.001$, partial $\eta^{2}=.08$. Averaging across time, there were significant differences in students' experiences of teacher support across the 5 empirically-derived profile groups. Pairwise comparisons among the five profiles were conducted using Bonferroni's at each time point. In fall, students in the Adaptive group experienced significantly more teacher support than students in the At Risk profile and students in the Checked-out profile. Also, students in the Going Through the Motions, Distressed, and At Risk profiles experienced significantly higher levels of teacher support than did students in the Checked-out profile. In spring, students in the Adaptive profile again experienced significantly more teacher support than students in the At Risk and the Checked-out profiles. Additionally, students in the Going Through the 
Motions profile reported significantly more teacher support than did students in the Checked-out profile. (See Table 5.10)

Table 5.10

Mean levels of teacher support in fall and spring for empirically-derived profiles

\begin{tabular}{lll} 
& \multicolumn{2}{l}{ Teacher support } \\
Empirically-driven profiles & Fall & Spring \\
\hline Adaptive & 3.07 & 2.99 \\
Going Through the Motions & 2.96 & 2.88 \\
Distressed & 2.95 & 2.82 \\
At Risk & 2.84 & 2.77 \\
Checked-out & 2.71 & 2.68
\end{tabular}

The main effect for time was also significant, $F(1,1013)=25.27, p<.001$, partial $\eta^{2}=.03$. Averaging across profiles, there were significant changes in teacher support from fall to spring. Specifically, post hoc comparisons indicated that for all profiles except Checked-out, students experienced significant decreases in teacher support from fall to spring. Mean levels of teacher support for each profile at both time points are presented in Table 5.10.

However, although there were significant mean level differences in teacher support across profiles and across time, the interaction between time and profile was not significant, $F(4,1013)=.74, p>.05$, partial $\eta^{2}=.00$. Changes in teacher support across time did not depend on which profiles a student was classified into. Students in different motivational profiles did not experience differential changes in teacher support from fall to spring. Figure 5.4 illustrates these findings. Hypotheses $2 \mathrm{a}-2 \mathrm{~d}$, which proposed that 
each profile would experience differential changes in teacher support, were not supported.

Figure 5.4

Changes in student-reports of teacher support from fall to spring for empirically-derived profiles

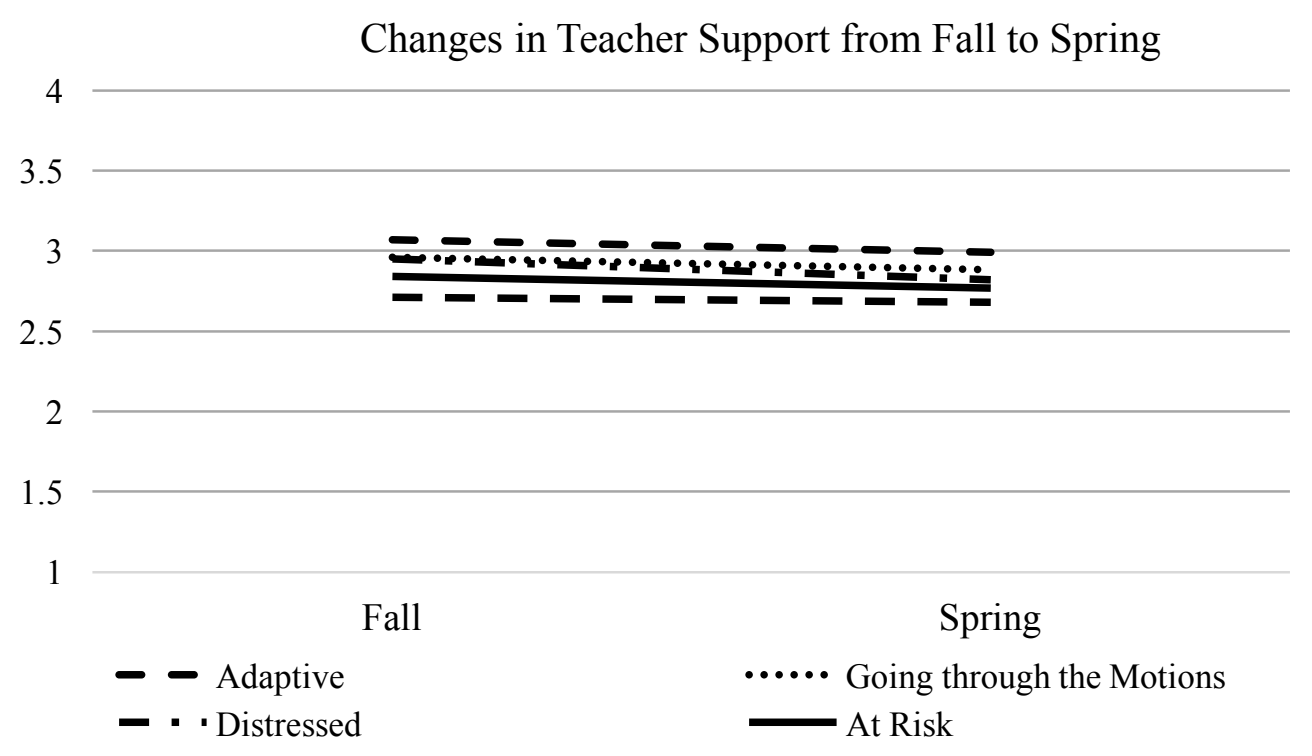

Research Question 3. Do students who belong to different motivation profiles also differ in their sense of relatedness, competence, and autonomy?

RQ 3. The current study's third area of investigation explored the connection between students' membership in specific motivation profiles and their self-perceptions and experiences of themselves in school. Specifically, research question three addressed whether students with different motivation profiles reported experiencing differing levels of the three self-system processes, namely, sense of relatedness, competence, and autonomy. To investigate potential differences in each of the three self-system processes for students in different motivation profiles, a one-way multivariate analysis of variances 
(MANOVA) was conducted. The independent variable was motivation profile and the dependent variables were students' levels of the relatedness, competence, and the four subcategories of autonomy, namely, intrinsic, identified, introjected, and extrinsic.

Results indicated that students in different motivational profiles reported significantly different levels of student self-system processes $F(24,1058)=4.26, p<$ .001 ,Wilk's $\Lambda=.73$, partial $\eta^{2}=.08$. The following sections examine these differences in students' levels of self-system processes for both sets of motivation profiles. First, descriptions of these differences for the theory-driven set of profiles will be discussed followed by an examination of the theory-driven hypotheses for RQ 3. Then, the results from the empirically-driven profiles will be presented. It is important to note, because we did not know the number or type of groups that would be created via model-based clustering, no hypotheses were proposed concerning differences in student's SSP's for the empirically-derived profiles.

\section{Theory-driven profiles}

Relatedness. Students in different theory-driven profiles experienced different levels of relatedness $F(4,308)=7.26, p<.001$, partial $\eta^{2}=.09$. Specifically, students in the Optimal profile enjoyed the highest levels of relatedness followed by the Middle and Enmeshed profiles, then Withdrawn students and finally Burnt out students experienced the lowest levels of relatedness (see Figure 5.5). However, only two of these differences were significant. Specifically, students in the Optimal profile had significantly higher 
levels of relatedness than did students in the Withdrawn and Burnt-out profiles. The other mean level differences across profiles were not significant.

Figure 5.5

Mean levels of relatedness for students in each theory-derived profile in fall Relatedness

4

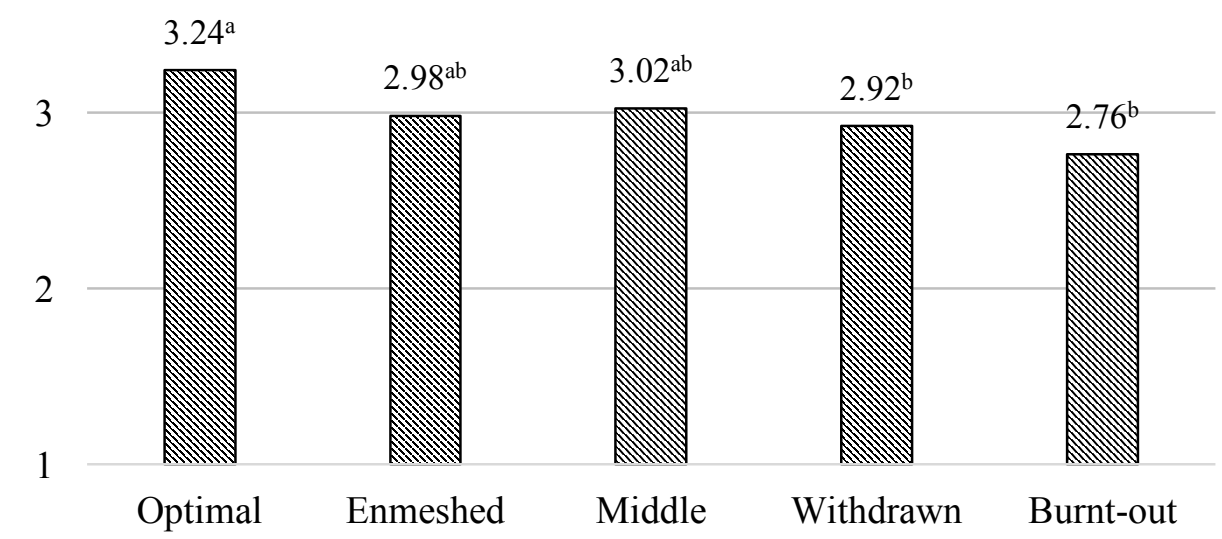

Note. Subscripts a-b : Mean level were significantly different across study variables at least at $\mathrm{p}<.05$ as determined by Bonferroni post hoc comparisons for all variables, except means marked by the same letter.

Competence. Students in different theory-driven profiles experienced different levels of competence $F(4,308)=23.58, p<.001$, partial $\eta^{2}=.23$. Descriptively, students in the Optimal profile enjoyed the highest levels of competence, and students in the Burnt out profile experienced the lowest levels of competence (see Figure 5.6). In terms of differences that were significant, students in the Optimal profile experienced significantly higher levels of competence than did students in the Middle, Withdrawn, and Burnt-out profiles. Additionally, students in both the Enmeshed and Middle profiles had 
significantly higher levels of competence than those in the Burnt-out profile. The other mean level differences across profiles were not significant.

Figure 5.6

Mean levels of competence for students in each theory-derived profile in fall

Competence

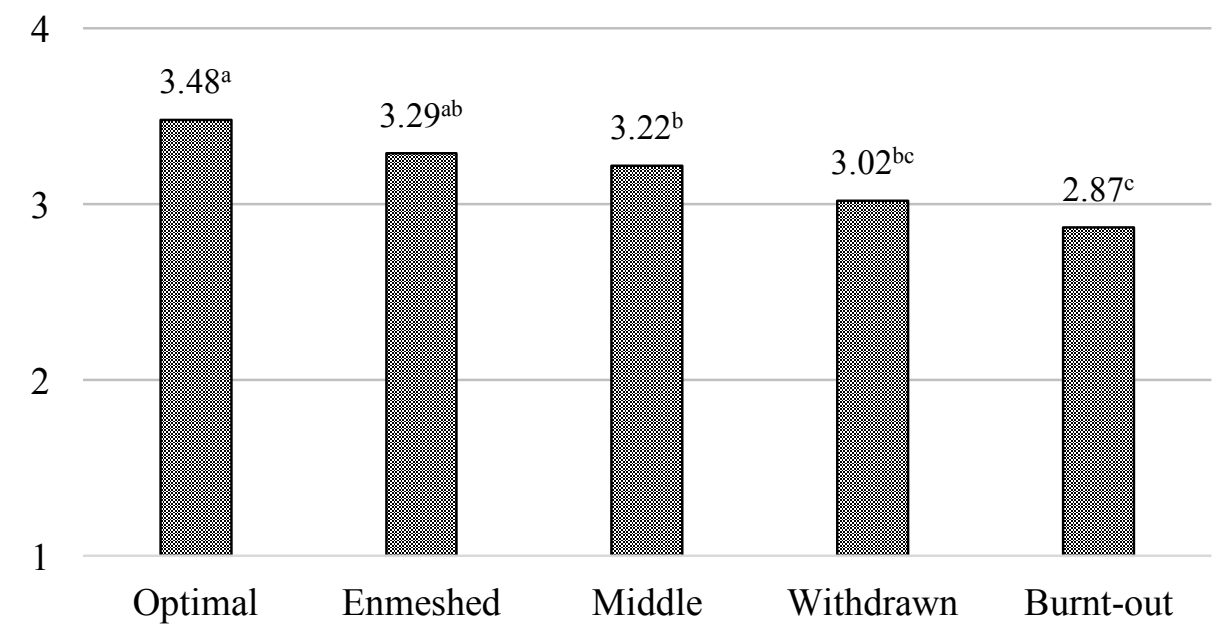

Note. Subscripts a-c : Mean level were significantly different across study variables at least at $\mathrm{p}<.05$ as determined by Bonferroni post hoc comparisons for all variables, except means marked by the same letter.

Autonomy Orientations. Although sometimes combined into a composite variable, the four different autonomy orientations were examined separately as they represent a spectrum of self-regulation indicating how self-determined a student's actions and attitudes towards school may be. A brief note on the level of autonomy present in each orientation: Students with the most autonomous orientation, Intrinsic SelfRegulation, participate in academic work because it is inherently enjoyable. Students with the second most autonomous orientation, Identified Self-Regulation, participate because of a desire for learning and understanding. Next, students with Introjected Self- 
regulation do schoolwork in order to demonstrate ability and maintain self-worth.

Finally, students with Extrinsic self-regulation participate in schoolwork because of external demands or rewards and are the least autonomous in their approach to selfregulation in school.

Students in different theory-driven profiles did not report significant differences in autonomy orientation except for Identified Self-Regulation $F(4,308)=11.09, p<$ .001 , partial $\eta^{2}=.13$. Students in the Optimal profiles enjoyed the highest levels of Identified Self-Regulation, while Burnt out students and Withdrawn students experienced almost identically low levels of Identified Self-Regulation (See Figure 5.7). In terms of significant differences, students in the Optimal profile experienced significantly higher levels of Identified Self-Regulation than did students in the Withdrawn and Burnt-out profiles. The other mean level differences across profiles were not significant.

Figure 5.7

Mean levels of identified self-regulation for students in each theory-derived profile in fall Autonomy Orientation: Identified Self-Regulation

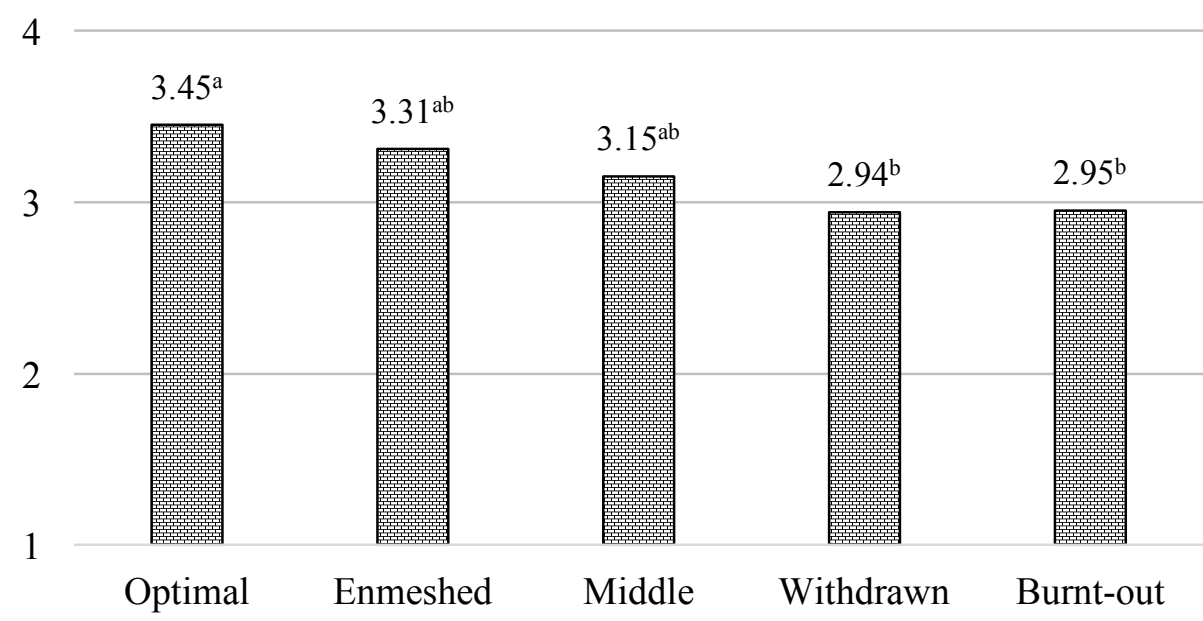

Note. Subscripts a-b : Mean level were significantly different across study variables at least at $\mathrm{p}<.05$ as determined by Bonferroni post hoc comparisons for all variables, except means marked by the same letter. 
Although no significant differences were found for Intrinsic, Introjected, and External autonomy orientations, Figure 5.8 depicts mean levels for each profile for descriptive purposes.

Figure 5.8.

Mean levels of intrinsic, introjected, and external self-regulation for students in each theory-derived profile in fall

Autonomy Orientaion:

Intrinsic, Intriojected, and External self-regaultion

4

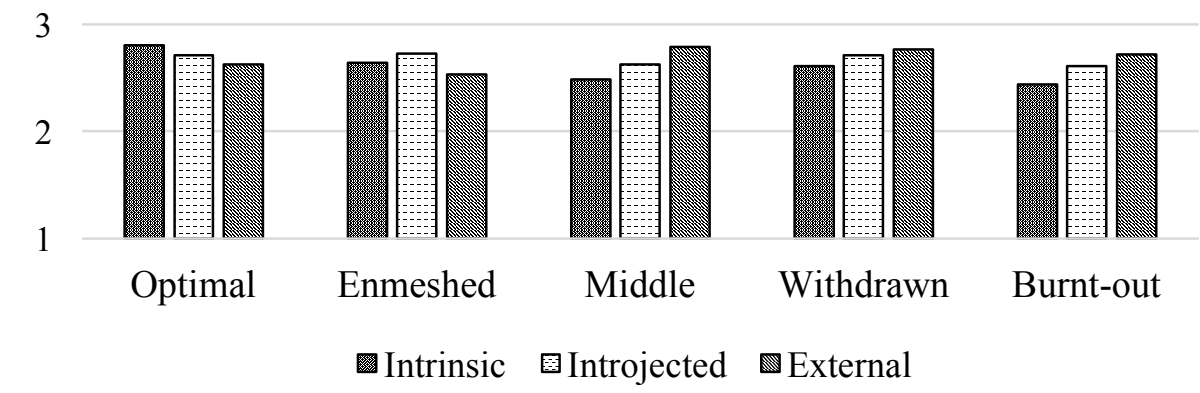

Results of hypotheses 3a-3d. For the theory-driven set of profiles, Research

Question 3 proposed four specific hypotheses concerning the relationship between students' profile membership and their experiences of self-system processes. Overall, there was mixed support for Hypotheses 3a-3d. Although many of the hypothesized mean level differences were not significant, results indicated that those significant differences that were found were in the hypothesized direction.

Hypothesis 3a: Students in the optimal group will report significantly higher levels of all three self-system processes (relatedness, competence, and autonomy) than students in other groups. 
Results indicated hypothesis 3a was somewhat supported. Specifically, students in the Optimal profiles had significantly higher levels of relatedness than did students in the Withdrawn and Burnt-out profiles but these differences were not significant for students in the Enmeshed or Middle profiles. Students in the Optimal profile also enjoyed significantly higher levels of competence than did Middle, Withdrawn, and Brunt-out students although these changes were not significant for students in the Enmeshed profile. Finally, students in the Optimal profile significantly endorsed experiencing higher levels of Identified Self-Regulation than did students in the Withdrawn or Brunt-out profiles but these differences were not significant for any of the other student motivation profiles or autonomy orientations. Overall, where significant differences were found among profiles across student self-system processes, they favored students in the Optimal profile as hypothesized.

Hypothesis 3b: Students in the Enmeshed and Helpless groups will report significantly lower mean levels of competence and relatedness than students in other groups.

Results indicated hypothesis $3 \mathrm{~b}$ was not supported. As we did not find support for the existence of a Helpless student motivation profile, this portion of hypothesis $3 \mathrm{~b}$ was unsupported. Secondly, students in the Enmeshed profile did not report experiencing significantly lower relatedness or competence compared to students in other profiles.

Hypothesis 3c: Students in the Rebellious and Withdrawn groups will report significantly lower extrinsic and identified self-regulation and significantly higher introjected and extrinsic self-regulation than students in other groups. 
Results indicated hypothesis $3 \mathrm{~b}$ was unsupported. As we did not find support for the existence of a Rebellious student motivation profile, this portion of hypothesis $3 \mathrm{c}$ was unsupported. Secondly, students in the Withdrawn profile did not report having significantly lower levels of Intrinsic and Identified self-regulation nor higher levels of Introjected and Extrinsic self-regulation than other profiles.

Hypothesis 3d: Students in the Burnt Out group will report significantly lower levels of all three self-system processes than students in other groups.

Results indicated hypothesis $3 \mathrm{~b}$ was somewhat supported. Specifically, students in the Burnt-out profile reported experiencing significantly lower levels of relatedness than students in the Optimal profile although these changes were not significant for students in the other profiles. Additionally, students in the Burnt-out profile reported significantly lower levels of competence than students in either the Optimal, Enmeshed, or Middle profiles. Finally, students in the Burnt-out profile experienced significantly lower levels of Identified self-regulation than students in the Optimal profile although these changes were not significant for students in the other profiles or for the other three autonomy orientations. Overall, where significant differences were found among motivation profiles across student self-system processes, they hobbled students in the Burnt-out profile as expected.

\section{Empirically-driven Profiles}

The preceding analyses were repeated using the empirically-derived set of student motivation profiles. Results indicate that students in different motivational profiles 
reported experiencing significantly different levels of student self-system processes $F(24,3517)=6.29, p<.001$,Wilk's $\Lambda=.86$, partial $\eta^{2}=.04$. The following sections examine differences in each of the student self-system processes separately. No formal hypotheses were proposed for the empirically-driven profiles.

Relatedness. Students in different empirically-derived profiles reported different levels of relatedness $F(4,1013)=12.02, p<.001$, partial $\eta^{2}=.05$. Specifically, students in the Adaptive profile enjoyed the highest levels of relatedness followed by the Going Through the Motions profile, the At Risk profile, then the Distressed profile, and finally the Checked-out profile who experienced the lowest levels of relatedness (See Figure 5.9). However, only four of these differences were significant. Specifically, students in the Adaptive profile had significantly higher levels of relatedness than did students in the At Risk and Checked-out profiles. Similarly, students in the Going through the Motions profile had significantly higher levels of relatedness than students in either the At Risk of the Checked-out profiles. The other mean level differences across profiles were not significant. 
Figure 5.9

Mean levels of relatedness for students in each empirically-derived profile in fall

\section{Relatedness}

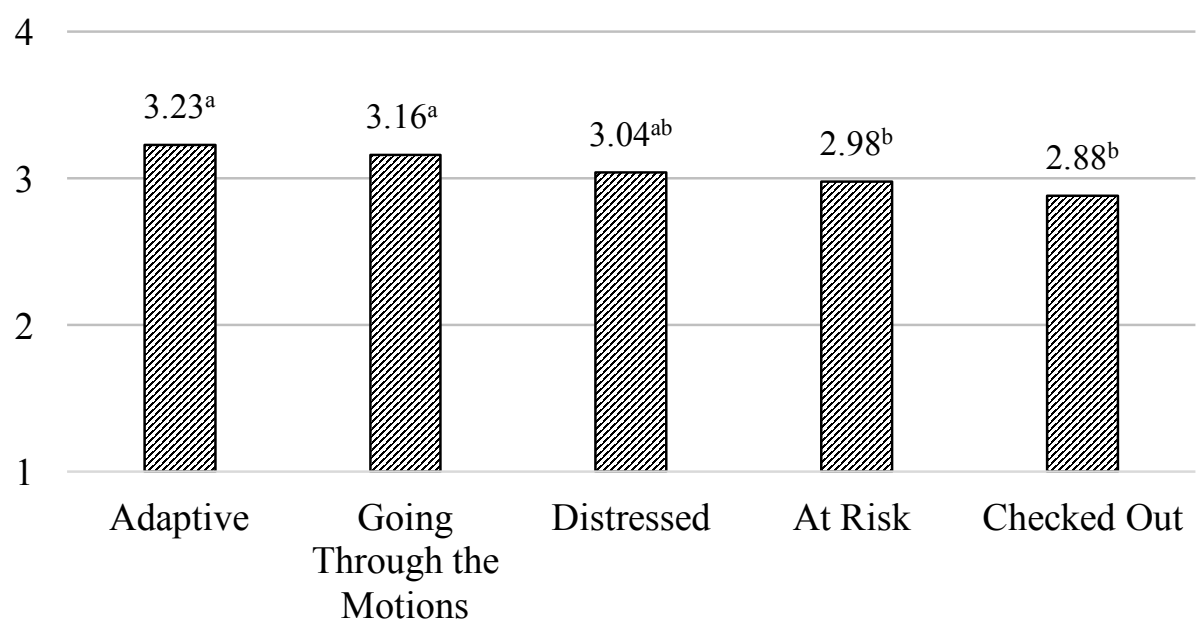

Note. Subscripts a-b : Mean level were significantly different across study variables at least at $\mathrm{p}<.05$ as determined by Bonferroni post hoc comparisons for all variables, except means marked by the same letter.

Competence. Students in different empirically-driven profiles experienced different levels of competence $F(4,1013)=25.93, p<.001$, partial $\eta^{2}=.09$. The five profiles had the same rankings for competence that they had for relatedness, with Adaptive students reporting experiencing the most competence and Checked-out students reporting the lowest sense of competence (See Figure 5.10). Examine pairwise comparisons revealed that there were five significant mean level differences in competence for students in different motivation profiles. Specifically, Checked-out students had significantly lower feelings of competence than did Adaptive, Going Through the Motions, and Distressed students. Additionally, students in the Adaptive profile and the Going Through the Motions profile enjoyed significantly higher levels of 
competence than did students in the At Risk profile. The other mean level differences in competence across profiles were not significant.

Figure 5.10

Mean levels of competence for students in each empirically-derived profile in fall

Competence

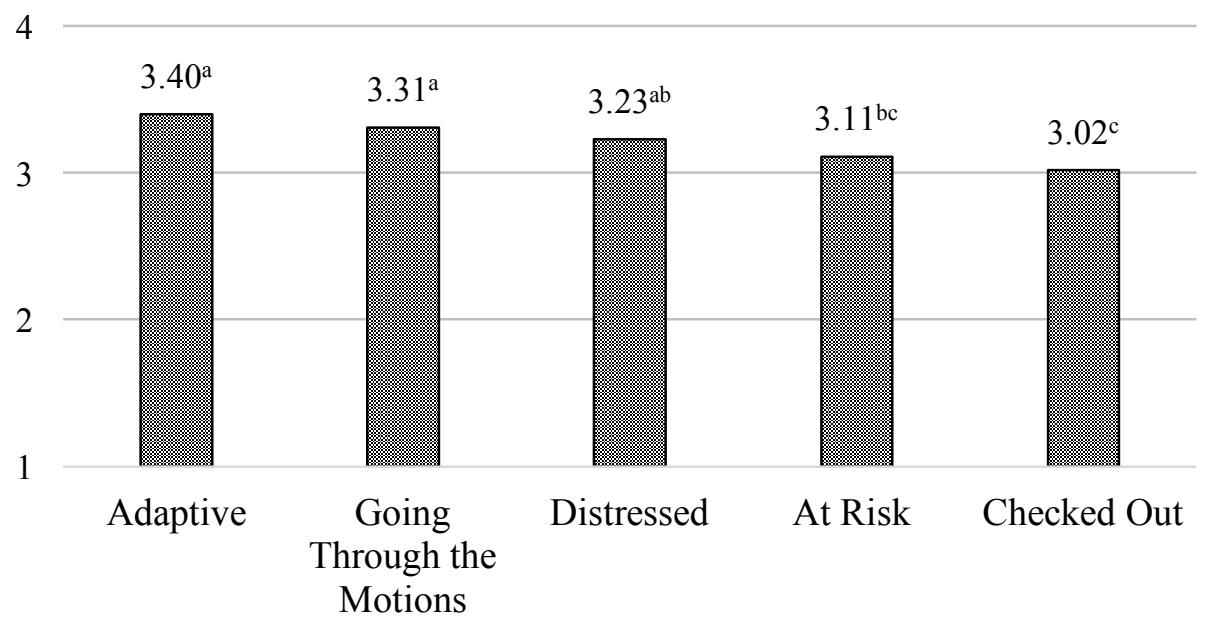

Note. Subscripts a-c : Mean level were significantly different across study variables at least at $\mathrm{p}<.05$ as determined by Bonferroni post hoc comparisons for all variables, except means marked by the same letter.

Autonomy orientation. Students in different empirically-derived profiles experienced significant differences in all four subcomponents of autonomy orientation except for Introjected Self-Regulation. Firstly, there were significant differences across profiles in students' self-reported Intrinsic Self-Regulation $F(4,1013)=5.05, p<.001$, partial $\eta^{2}=.02$ (See Figure 5.11). Results indicate that students in the Adaptive profile endorsed experiencing significantly more intrinsic self-regulation than did students in the Going Through the Motions profile. The remaining mean level differences in intrinsic self-regulation among profiles were non-significant. 
Figure 5.11

Mean levels of intrinsic self-regulation for students in each empirically-derived profile in fall

Autonomy: Intrinsic Self-regulation

4

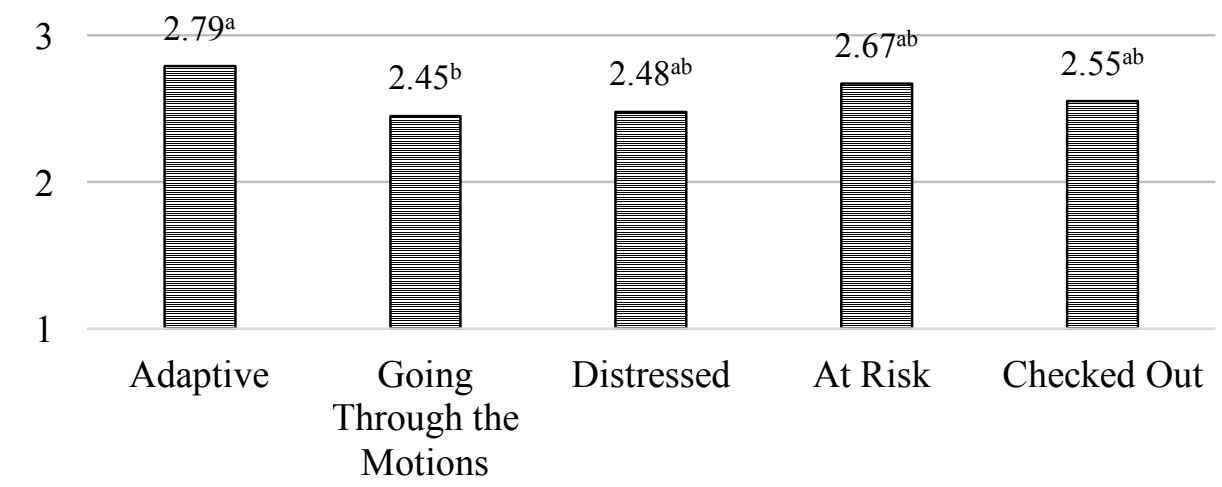

Note. Subscripts a-b : Mean level were significantly different across study variables at least at $\mathrm{p}<.05$ as determined by Bonferroni post hoc comparisons for all variables, except means marked by the same letter.

Secondly, there were also significant differences across profiles in students' selfreported Identified Self-Regulation $F(4,1013)=11.30, p<.001$, partial $\eta^{2}=.04$. Specifically, students in the Adaptive profile had significantly higher rates of Identified Self-Regulation than students in the Going Through the Motions profile, At Risk profile, and the Checked-out profile. Students in the Checked-out profile has significantly lower Identified Self-Regulation than students in the Going Through the Motions profile and At Risk profile. 
Figure 5.12

Mean levels of identified self-regulation for students in each empirically-derived profile in fall

Autonomy Orientation: Identified Self-regulation

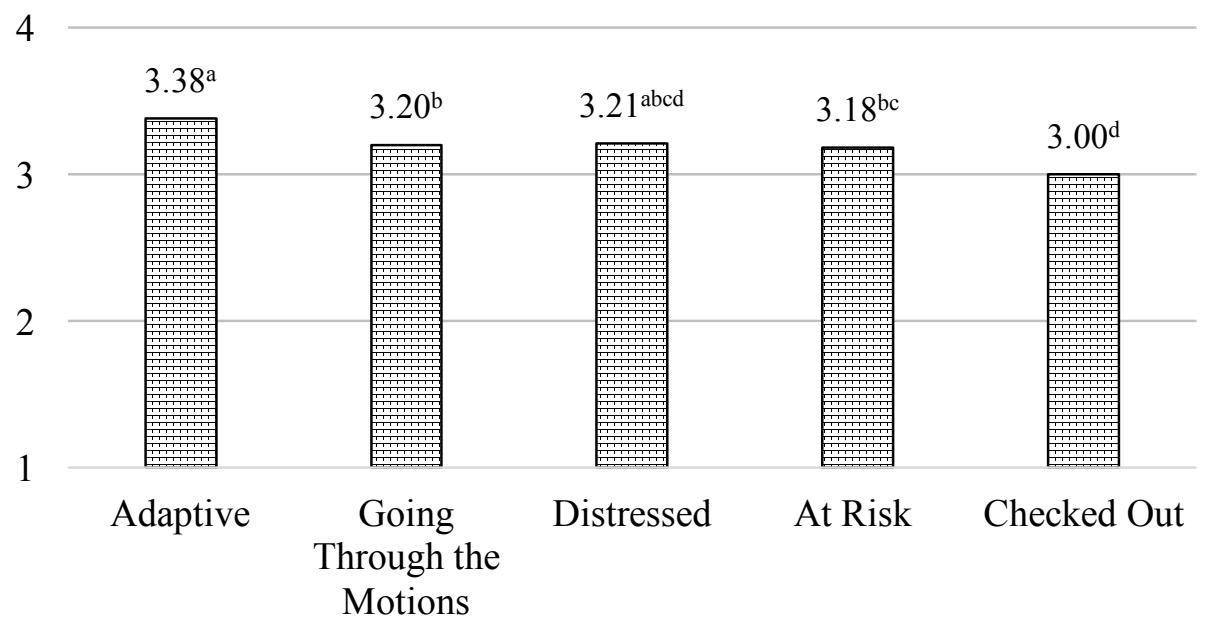

Note. Subscripts a-d : Mean level were significantly different across study variables at least at $\mathrm{p}<.05$ as determined by Bonferroni post hoc comparisons for all variables, except means marked by the same letter.

Finally, there were also significant differences across profiles in students' selfreported External Self-Regulation $F(4,1013)=6.22, p<.001$, partial $\eta^{2}=.02$. Interestingly, students in the At Risk profile reported significantly higher levels of External Self-Regulation than did students in the Adaptive, Going Through the Motions, and Distressed profiles. 
Figure 5.13

Mean levels of extrinsic self-regulation for students in each empirically-derived profile in fall

Autonomy Orientation: Extrinsic Self-Regulation

4

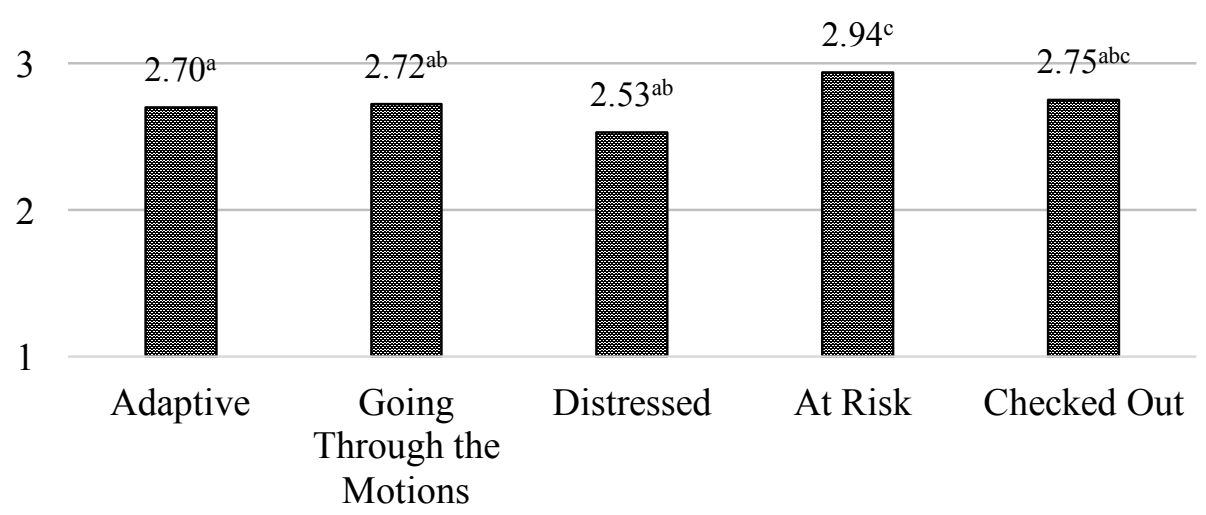

Note. Subscripts a-b : Mean level were significantly different across study variables at least at $\mathrm{p}<.05$ as determined by Bonferroni post hoc comparisons for all variables, except means marked by the same letter.

\section{Summary Research Question 3}

RQ 3 sought to determine whether knowledge of the motivation profile into which a student falls can tell us something meaningful about their self-system processes. RQ 3 and its hypotheses assumed that students in different profiles would lack different self-system processes and these mean level differences in relatedness, competence, and autonomy would help us explain differences between the different types of students teachers see in their classrooms. Descriptive statistics indicate the more adaptive profiles enjoyed higher levels of relatedness, competence, and intrinsic and identified selfregulation. Conversely, the more maladaptive profiles experienced lower levels of relatedness and competence as well as higher levels of external and introjected self- 
regulation. Although many of these mean-level differences were not significant, the nonsignificant differences still conformed to this trend- the less adaptive a student's profile, the less related, competent, and autonomous the student felt. These differences aligned with our expectations and hypothesis that the more motivated students would report experiencing higher levels of relatedness, competence, and intrinsic and identified selfregulation. See Figure 5.14 and Figure 5.15 for mean levels of SSP's for each set of profiles.

Figure 5.14

Mean levels of self-system processes for theory-derived profiles in fall

Theory-derived profiles: Mean Levels of Self-system

Processes

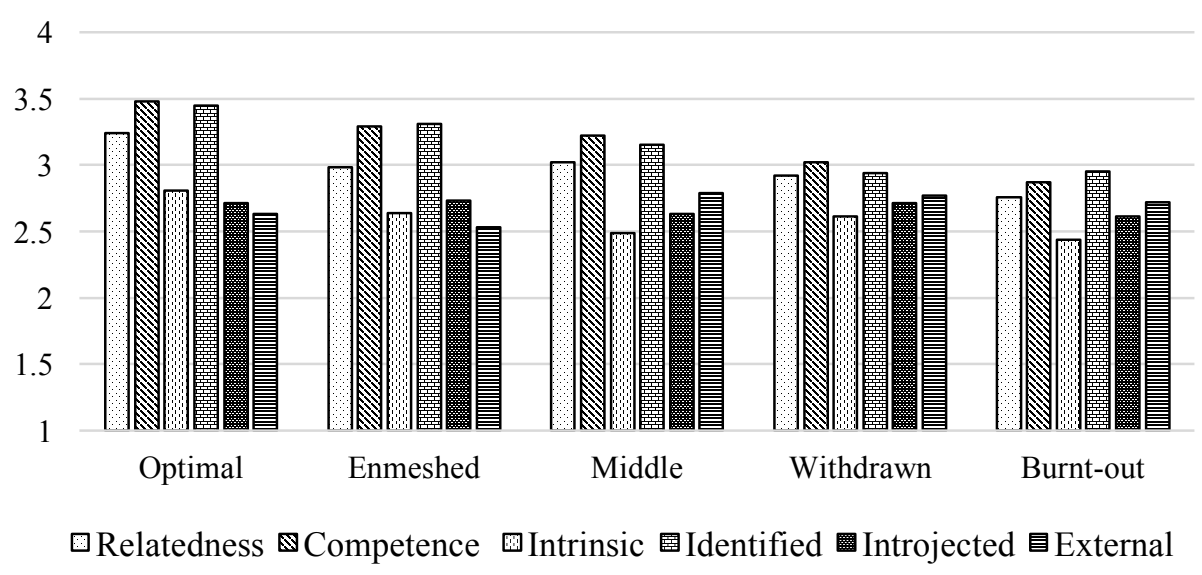


Figure 5.15

Mean levels of self-system processes for empirically-derived profiles in fall

\section{Empirically-derived Profiles: Mean Levels of Self-system}

Processes

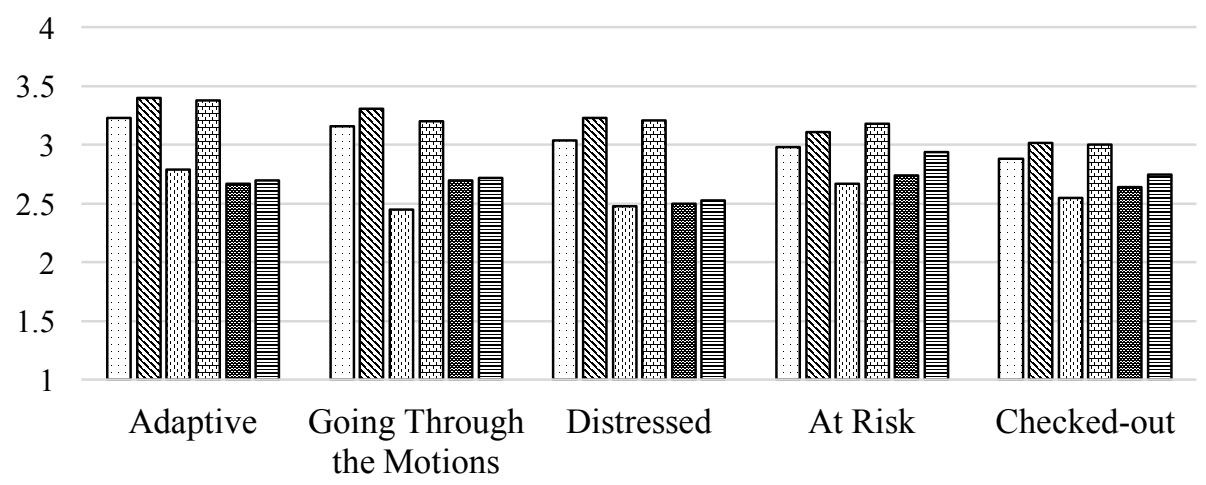

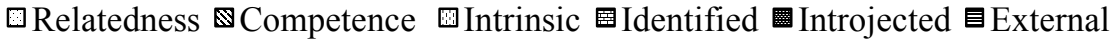

Although many differences were not significant, results from RQ 3 revealed some significant differences in students' experiences of relatedness, competence, and autonomy for both the theory-driven and empirically-driven sets of profiles. Specifically, there were two theory-driven and three empirically-driven profiles that had significantly lower levels of one or more SPP's than at least one other profile. We used this criteria, namely having mean levels significantly lower than at least one other profile, to 'diagnose' profiles as lacking a given SSP. Table 5.11 contains all profiles that had levels of SSP's that were significantly lower than at least one other profile. 
Table 5.11

Profiles with mean levels of SPP's that were significantly lower than at least one other profile

\begin{tabular}{|c|c|c|c|c|c|}
\hline & Relatedness & Competence & Intrinsic & $\begin{array}{l}\text { Autonomy Orientation } \\
\text { Identified Introjected }\end{array}$ & External \\
\hline \multicolumn{6}{|l|}{ Theory-driven } \\
\hline Withdrawn & Low & Low & & Low & \\
\hline Burnout & Low & Low & & Low & \\
\hline \multicolumn{6}{|l|}{$\begin{array}{l}\text { Empirically- } \\
\text { driven }\end{array}$} \\
\hline $\begin{array}{l}\text { Going Through } \\
\text { the Motions }\end{array}$ & & & Low & Low & \\
\hline At Risk & Low & Low & & Low & High \\
\hline Checked-out & Low & Low & & Low & \\
\hline
\end{tabular}

Table 5.11 suggests a less nuanced/more holistic view of how the three selfsystem processes may impact student profile membership. Specifically, the two least adaptive profiles for both the theory-driven and empirically-driven profile sets had significantly lower levels of all three SSP's. Only one profile, Going Through the Motions, had significantly lower levels of only one self-system process, namely autonomy. Instead of functioning separately in this sample, it appeared that levels of each of the three self-system processes co-varied with each other. Although this lack of differentiation by the individual SSP's was unexpected, because significant differences in students' relatedness, competence, and autonomy were found across student profiles, we were still able to investigate Research Question 4.

Research Question 4. Based on their motivation profile (as reported by teachers), do students who receive higher amounts of the types of teacher support they need experience more adaptive patterns of change in their engagement (as reported by students) from fall to spring? 
RQ 4. The purpose of RQ 4 was to use the results from RQ 3 to determine whether students who received high levels of the types of teacher support they need most, based on what RQ3 tells us about their SSP's, exhibited more adaptive patterns of change in engagement across the school year. Research question four was assessed by comparing the engagement of students within a given profile who received either high or low levels of the particular types of teacher support that RQ 3 suggested they needed based on their corresponding self-reported SSP's. Specifically, a student low in relatedness would be 'prescribed' teacher involvement and warmth, a student struggling with low competence would be supported by teacher structure, and a student low in autonomy (low extrinsic and identified self-regulation and high introjected and external self-regulation) would be bolstered by their teacher's provision of autonomy support. Using student-reports of teacher support in the fall, we examined whether students who experienced different levels of these three types of targeted teacher support in fall had differential changes in their engagement from fall to spring.

In order to determine which profiles required targeted teacher support, we relied on RQ 3. Results indicated five profiles had significantly low levels of one or more selfsystem processes. For the theory-driven profiles, the Withdrawn and Burnt-out profiles experienced levels of relatedness, competence, and Identified self-regulation that were significantly lower than at least one other profile. For the empirically-driven profiles, students in the Going Through the Motions profile also had significantly lower levels of intrinsic and identified self-regulation. The At Risk and Checked-out profiles also reported levels of relatedness, competence, and Identified autonomy that were 
significantly lower than at least one other profile. Students in these five profiles will be examined in RQ 4.

Within each of the above mentioned profiles, we first created a high support subgroup and low support subgroup of students using tertiary splits. Next, a 2X2 mixed factorial ANOVA where the between subjects factor is high vs. low teacher support and the within subjects factor is student engagement at two time-points (Fall or Spring) was used to determine the effect of teacher support on student engagement over time.

\section{Theory-driven profiles:}

Withdrawn Profile. According to the results of RQ 3, students in the Withdrawn group had significantly lower mean levels of all three SSP's, and thus their prescribed 'treatment' would be high levels of teacher warmth, structure, and autonomy support. Results revealed the main effect for group (High vs. Low teacher support) was not significant $F(1,19)=2.02, p>.05$, partial $\eta^{2}=.10$. Averaging across time, there were no significant differences in engagement between Withdrawn students in the High vs. Low teacher support subgroups. However, the main effect for time was significant, $F(1,19)=$ $6.38, p<.05$, partial $\eta^{2}=.25$. Averaging across the High vs. Low teacher support groups, there were significant decreases in Withdrawn students' reports of their engagement from fall to spring (see Table 5.12 for mean levels). 
Table 5.12

Withdrawn profile: Mean levels of student-reported engagement in fall and spring for students' in the high and low teacher support subgroups

\section{Student Engagement}

\begin{tabular}{lll} 
& Fall & Spring \\
\hline $\begin{array}{l}\text { HIGH Warmth, Structure, } \\
\text { and Autonomy Support } \\
\text { (N=11) }\end{array}$ & 3.27 & 3.08 \\
$\begin{array}{l}\text { LOW Warmth, Structure, } \\
\begin{array}{l}\text { and Autonomy Support } \\
(\mathrm{N}=10)\end{array}\end{array}$ & 3.04 & 2.75 \\
\hline
\end{tabular}

Finally, the interaction between group (High vs. Low teacher support) and time (Fall vs. Spring) was not significant $F(1,19)=.28, p>.05$, partial $\eta^{2}=.02$. Students who received more of the types of teacher support they needed did not experience differential changes in engagement across the school year. Thus, Hypothesis 4a, which posits students who receive high amounts of the types of teacher support they need will maintain or exhibit increases in their level of engagement from fall to spring, was unsupported. Both groups decreased in their engagement across the school year (See Graph 5.10) 
Figure 5.16

Withdrawn profile: Relationship between amount of teacher support received in fall and changes in student engagement from fall to spring

Student Engagment Withdrawn profile

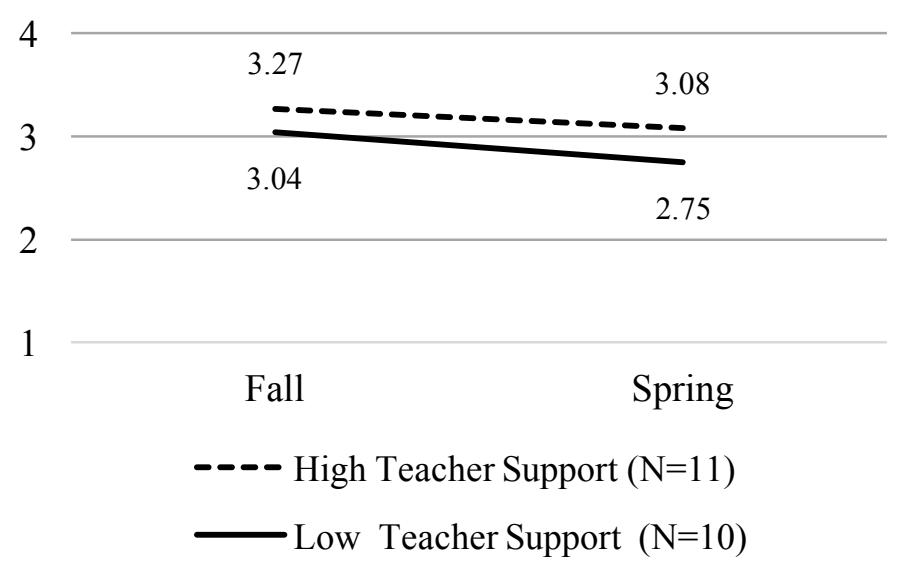

Burnt-out Profile. According to the results of RQ 3, students in the Burnt-out profile had significantly lower mean levels of all three SSP's, and thus their 'treatment' is high levels of teacher warmth, structure, and autonomy support. Results indicated that the main effect for group (High vs. Low teacher support) was significant $F(1,14)=4.99, p<$ .05 , partial $\eta^{2}=.26$. Averaging across time, there were significant decreases in engagement between Burnt-out students in the High vs. Low teacher support subgroups. However, the main effect for time was not significant, $F(1,14)=.05, p>.05$, partial $\eta^{2}$ $=.00$. Averaging across the High vs. Low teacher support groups, there were no significant changes in Burnt-out students' reports of engagement from fall to spring (see Table 5.13 for mean levels). 
Table 5.13

Burnt-out profile: Mean levels of student-reported engagement in fall and spring for students' in the high and low teacher support subgroups

\section{Student Engagement}

\begin{tabular}{lll} 
& Fall & Spring \\
\hline $\begin{array}{l}\text { HIGH Warmth, Structure, } \\
\text { and Autonomy Support } \\
(\mathrm{N}=10)\end{array}$ & 3.14 & 2.88 \\
$\begin{array}{l}\text { LOW Warmth, Structure, } \\
\text { and Autonomy Support }\end{array}$ & 2.47 & 2.80 \\
$(\mathrm{~N}=6)$ & & \\
\hline
\end{tabular}

Finally, the interaction between group (High vs. Low teacher support) and time (Fall vs. Spring) was not significant $F(1,14)=2.93, p>.05$, partial $\eta^{2}=.17$. Burnt-out students who received high levels of motivational support from their teachers did not experience differential changes in engagement across the school year. Thus, Hypothesis 4a, which posits students who receive high amounts of the types of teacher support they need will maintain or exhibit increases in their level of engagement from fall to spring, was unsupported. Interestingly, while Burnt-out students that received high teacher support decreased in engagement over time, the Burnt-out students with low teacher support actually gained teacher support from fall to spring (see Figure 5.17). 
Figure 5.17

Burnt-out profile: Relationship between amount of teacher support received in fall and changes in student engagement from fall to spring

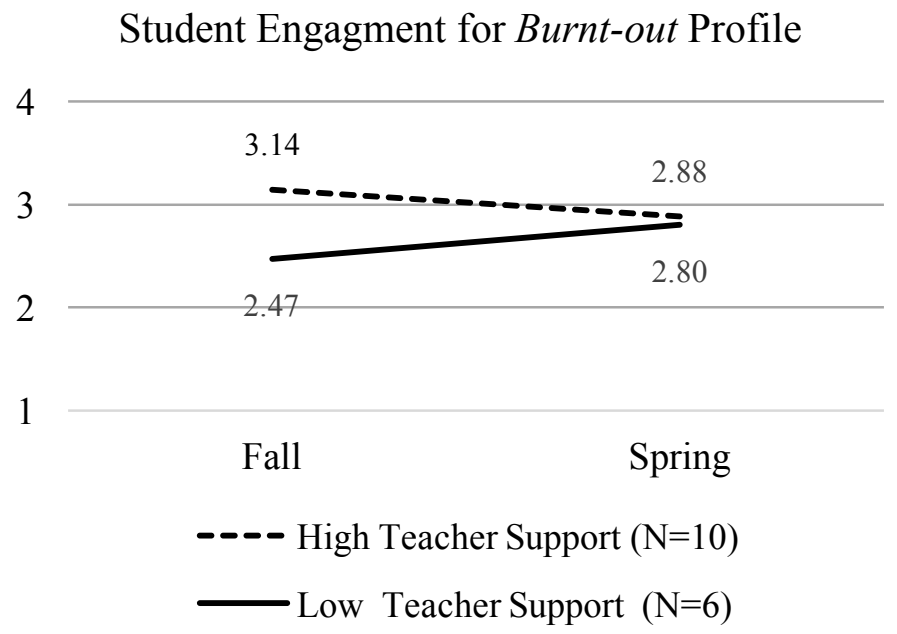

\section{Empirically-driven profiles}

Going Through the Motions Profile. According to the results of RQ 3, students in the Going Through the Motions profile had significantly lower mean levels of Intrinsic and Identified self-regulation (aka the most autonomous orientations). Thus, their 'treatment' is high levels of teacher autonomy support. The main effect for group (High vs. Low teacher autonomy support) was significant $F(1,104)=43.13, p<.001$, partial $\eta^{2}$ $=.29$. Averaging across time, there was a significant difference in engagement between Going Through the Motions students in the High vs. Low teacher autonomy support subgroups. Similarly, the main effect for time was also significant, $F(1,104)=5.11, p<$ .05 , partial $\eta^{2}=.47$. Averaging across the High vs. Low teacher autonomy support groups, 
there were significant decreases in Going Through the Motions students' reports of engagement from fall to spring (see Table 5.14 for mean levels).

Table 5.14

Going Through the Motions profile: Mean levels of student-reported engagement in fall and spring for students' in the high and low teacher autonomy support subgroups

\section{Student Engagement}

\begin{tabular}{lll} 
& \multicolumn{1}{c}{ Fall } & Spring \\
\hline $\begin{array}{l}\text { HIGH Autonomy Support } \\
(\mathrm{N}=53)\end{array}$ & 3.49 & 3.37 \\
$\begin{array}{l}\text { LOW Autonomy Support } \\
(\mathrm{N}=53)\end{array}$ & 2.97 & 2.93 \\
\hline
\end{tabular}

Finally, the interaction between group (High vs. Low teacher support) and time (Fall vs. Spring) was not significant $F(1,104)=1.23, p>.05$, partial $\eta^{2}=.01$. Changes in engagement from fall to spring did not depend on whether students received high or low teacher support. Thus, Hypothesis 4a, which posits students who receive high amounts of the types of teacher support they need will maintain or exhibit increases in their level of engagement from fall to spring, was unsupported. Both groups decreased in their engagement across the school year (See Figure 5.18). 
Figure 5.18

Going Through the Motions profile: Relationship between amount of teacher support received in fall and changes in student engagement from fall to spring

Student Engagement for

Going Through the Motions Profile

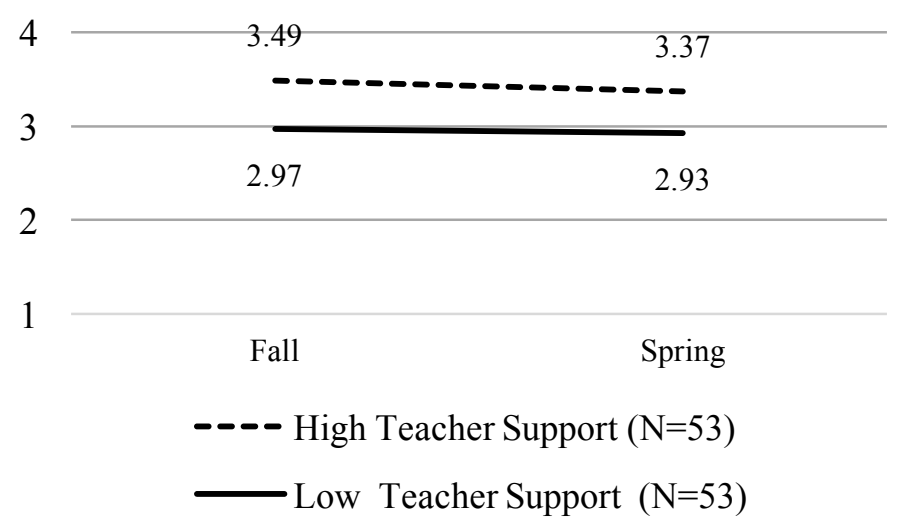

At Risk Profile. According to the results of RQ 3, students in the At Risk profile had significantly lower mean levels of relatedness, competence, and identified regulation as well as significantly higher levels of external self-regulation. Thus their 'treatment' is high levels of teacher warmth, structure, and autonomy support. The main effect for group (High vs. Low teacher support) was significant $F(1,115)=90.66, p<.001$, partial $\eta^{2}=.44$. Averaging across time, there was a significant difference in engagement between At Risk students in the High vs. Low teacher support subgroups. Similarly, the main effect for time was also significant, $F(1,115)=25.5, p<.001$, partial $\eta^{2}=.18$. Averaging across the High vs. Low teacher support groups, there were significant decreases in $A t$ Risk students' reports of engagement from fall to spring (see Table 5.15 for mean levels). 
Table 5.15

At Risk profile: Mean levels of student-reported engagement in fall and spring for students' in the high and low teacher support subgroups

\section{Student Engagement}

\begin{tabular}{lcc} 
& Fall & Spring \\
\hline $\begin{array}{l}\text { HIGH Warmth, Structure, } \\
\text { and Autonomy Support } \\
\text { (N=68) }\end{array}$ & 3.58 & 3.19 \\
$\begin{array}{l}\text { LOW Warmth, Structure, } \\
\text { and Autonomy Support } \\
(\mathrm{N}=49)\end{array}$ & 2.81 & 2.73 \\
\hline
\end{tabular}

Finally, the interaction between group (High vs. Low teacher support) and time (Fall vs. Spring) was significant $F(1,115)=9.94, p<.01$, partial $\eta^{2}=.08$. Changes in engagement from fall to spring depended on whether At Risk students received high or low levels of teacher support. Interestingly, the At Risk students who received little teacher support actually lost less engagement from fall to spring than their counterparts who received high levels of teacher support. (See Figure 5.19) 
Figure 5.19

At Risk profile: Relationship between amount of teacher support received in fall and changes in student engagement from fall to spring

Student Engagement At Risk Profile

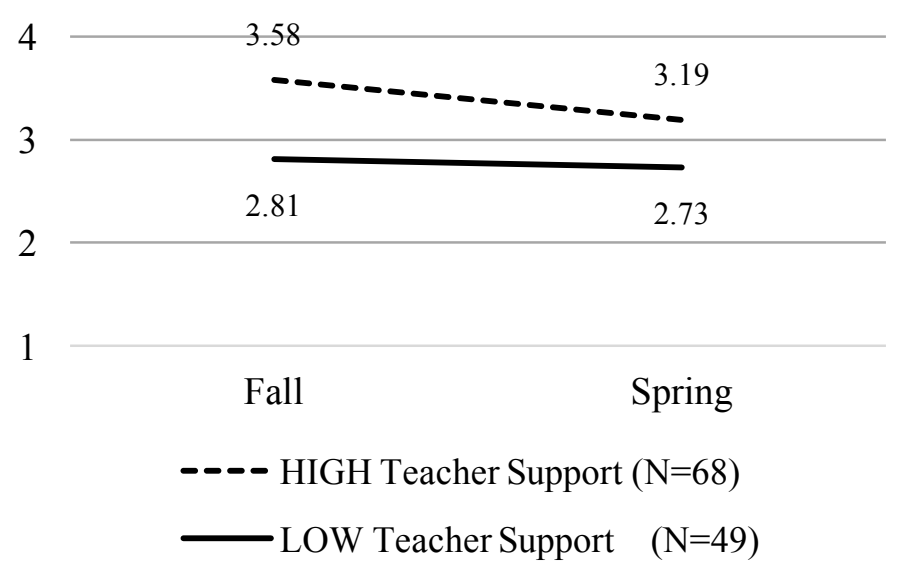

Checked-out. According to the results of RQ 3, students in the Checked-out profile had significantly lower mean levels of relatedness, competence, and identified self-regulation. Thus their 'treatment' is high levels of teacher warmth, structure, and autonomy support. The main effect for group (High vs. Low teacher support) was significant $F(1,53)=23.40, p<.001$, partial $\eta^{2}=.31$. Averaging across time, there was a significant difference in engagement between Checked-out students in the High vs. Low teacher support subgroups. Similarly, the main effect for time was also significant, $F(1$, $53)=5.35, p<.05$, partial $\eta^{2}=.09$. Averaging across the High vs. Low teacher support groups, there were significant decreases in Checked-out students' reports of engagement from fall to spring (see Table 5.16 for mean levels). 
Table 5.16

Checked-out profile: Mean levels of student-reported engagement in fall and spring for students' in the high and low teacher support subgroups

\section{Student Engagement}

\begin{tabular}{lll} 
& Fall & Spring \\
\hline $\begin{array}{l}\text { HIGH Warmth, Structure, } \\
\text { and Autonomy Support } \\
\text { (N=32) }\end{array}$ & 3.40 & 3.07 \\
$\begin{array}{l}\text { LOW Warmth, Structure, } \\
\text { and Autonomy Support } \\
(\mathrm{N}=23)\end{array}$ & 2.71 & 2.71 \\
\hline
\end{tabular}

Finally, the interaction between group (High vs. Low teacher support) and time (Fall vs. Spring) was significant $F(1,53)=5.61, p<.05$, partial $\eta^{2}=.10$. Changes in engagement from fall to spring depended on whether Checked-out students received high or low teacher support. Interestingly, the Checked-out students who received little teacher support maintained their engagement from fall to spring although their counterparts who received high levels of teacher support lost engagement across the school year. 
Figure 5.20

Checked-out profile: Relationship between amount of teacher support received in fall and changes in student engagement from fall to spring

Student Engagement Checked-out Profile

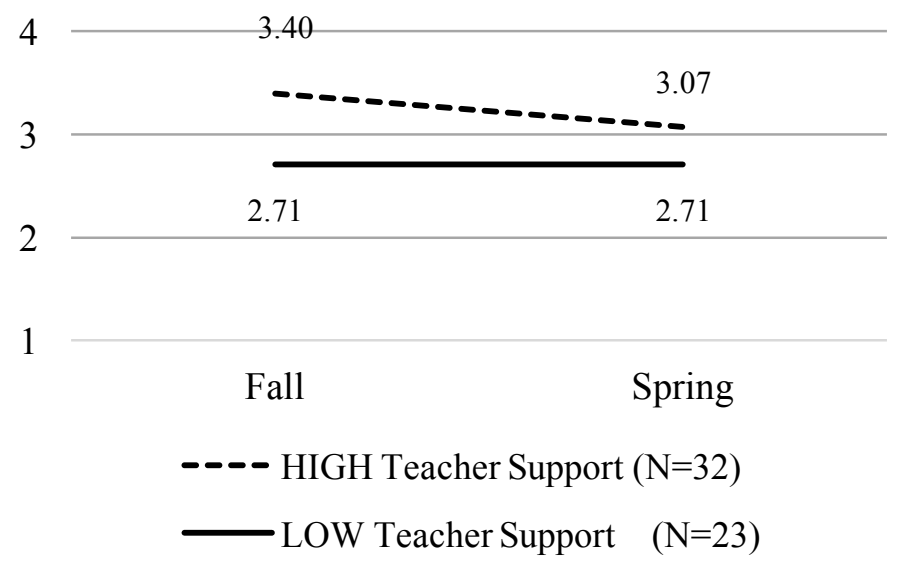




\section{Chapter 6}

\section{Discussion}

The main purpose of the current study was to closely examine reciprocal effects by using a longitudinal design, a more comprehensive assessment of behavioral and emotional engagement and disaffection, and a person-centered approach to investigate whether potential factors influencing the quality of students' classroom engagement can help inform more targeted intervention efforts. This study used profiles of student engagement and disaffection to holistically investigate the kinds of student experiences (or lack thereof) that appear to be shaping the classroom motivation of students in a given profile and whether profile-specific intervention strategies could be an effective way of combating the negative interaction cycles that occur between students with maladaptive motivational patterns and their teachers. This exploratory study found limited support for its hypotheses, suggesting that more research must be done in order to understand the complex interrelationships between teachers' perceptions of their students' motivation, students' self-system processes, and teachers' provision of motivational support.

\section{Summary of findings}

A summary of study results can be found in Table 6.1. Following a review of the descriptive findings, the results for each research question are summarized below. In terms of descriptive statistics, the constructs of interest displayed the expected patterns found in previous research. Satisfactory internal consistencies were found for all but one measure used in this study. Both student and teacher reporters perceived students as 
having relatively high levels of engagement and relatively low levels of disaffection at both time points.

Table 6.1

Summary of results

Summary of Results

\begin{tabular}{lll}
\hline \multicolumn{1}{c}{ Research Questions } & $\begin{array}{c}\text { Theory- } \\
\text { derived } \\
\text { Profiles }\end{array}$ & $\begin{array}{c}\text { Empirically- } \\
\text { derived Profiles }\end{array}$ \\
\hline $\begin{array}{l}\text { RQ 1a: Coverage Do the seven hypothesized } \\
\text { student motivation profiles provide a good fit for the } \\
\text { data? }\end{array}$ & No & -- \\
\hline $\begin{array}{l}\text { RQ 1b: Interpretability Utilizing an empirical } \\
\text { approach, what subgroups of students emerge from } \\
\text { the data? }\end{array}$ & & $\begin{array}{l}\text { 5 interpretable } \\
\text { profiles emerged; } \\
\text { Adaptive, Going } \\
\text { Through the }\end{array}$ \\
$\begin{array}{l}\text { Do the resultant profiles make sense conceptually, } \\
\text { that is, are they easily interpretable? }\end{array}$ & -- & $\begin{array}{l}\text { Motions, } \\
\text { Distressed, At } \\
\text { Risk, \& Checked- } \\
\text { out }\end{array}$ \\
\hline
\end{tabular}

RQ 1c: Convergence Do the two methods produce compatible sets of motivation profiles?

Partial support

RQ 2. Do students in different motivational profiles experience differential changes in teacher support from fall to spring?

Hypothesis 2a. Students with an Optimal motivation profile will experience increases in teacher support from fall to spring.

Hypothesis 2b. Students with Enmeshed and Ritualistic motivation profiles will experience increases in or maintenance of teacher support from fall to spring.

Hypothesis 2c. Students with Withdrawn and Helpless profiles will experience decreases in teacher support from fall to spring.

Hypothesis 2d. Students with Rebellious and Burn-out motivation profiles will experience the greatest decreases in teacher support from fall to spring.

No No

H2a.

Unsupported

$\boldsymbol{H} 2 \boldsymbol{b}$.

Unsupported

H2c.

Unsupported

H2d.

Unsupported 
RQ 3. Do students who belong to the different motivation profiles also differ in their sense of relatedness, competence, and autonomy?

Yes Yes

Hypothesis 3a: Students in the Optimal group will report significantly higher levels of all three SSP's than students in other groups.

H3a. Partial

Support

Hypothesis 3b: Students in the Enmeshed and Helpless groups will reports significantly lower competence and relatedness than students in other groups.

H3b. No

Yes

\begin{abstract}
Hypothesis 3c: Students in the Rebellious and Withdrawn groups will report significantly lower autonomy than students in other groups.

Hypothesis 3d: Students in the Burnt Out group will report significantly lower levels of all three SSP's than students in other groups.
\end{abstract}

\author{
H3c. No
}

H3d. Partial support

RQ 4. Based on their motivation profile, do students who receive higher amounts of the types of teacher support they need experience more adaptive patterns of change in their engagement from fall to spring?

Hypothesis 4a: Students who receive high amounts of the types of teacher support they need will maintain or exhibit increases in their level of engagement from fall to spring.

Hypothesis 4 b: Students who receive low amounts of the types of teacher support they need will exhibit decreases in engagement from fall to spring.

\begin{tabular}{|c|c|}
\hline No & $\begin{array}{l}\text { No; Students who } \\
\text { received less } \\
\text { teacher support } \\
\text { had more } \\
\text { adaptive patterns } \\
\text { of change over } \\
\text { time. }\end{array}$ \\
\hline $\begin{array}{c}\boldsymbol{H 4 a} . \\
\text { Unsupported }\end{array}$ & $\begin{array}{c}\boldsymbol{H} \mathbf{4 a} . \\
\text { Unsupported }\end{array}$ \\
\hline $\begin{array}{c}\boldsymbol{H} \boldsymbol{4} \boldsymbol{b} . \\
\text { Unsupported }\end{array}$ & $\begin{array}{c}\boldsymbol{H} \mathbf{4 b} . \\
\text { Unsupported }\end{array}$ \\
\hline
\end{tabular}

At the same time, however, for both student- and teacher-reports, engagement declined significantly across the school year. Interestingly, although students reported increases in behavioral disaffection from fall to spring, as expected, teachers conversely reported decreases in student behavioral disaffection across time. Students also reported 
significant decreases in all three self-system processes as well as teacher support from fall to spring.

Across-reporter correlations between student- and teacher-reported student engagement were significant but relatively low, averaging $r=.25$, as were cross-reporter correlations of student disaffection, averaging $r=.29$. This highlights the power of perspective in assessing these motivational constructs. Consistent with previous research, the correlations between teacher support and the components of motivation were moderate and in the expected directions (positive for engagement, negative for disaffection) for both reporters at both time points. Finally, cross-time stabilities for the constructs of interest were moderate to high, ranging from $50-.77$. These strong stabilities made it more difficult to predict change over time as there was relatively little change to explain.

RQ 1: Profile creation. The first set of research questions were concerned with using two person-centered methodologies to create student motivation profiles. The theory-derived profiles, modeled after Connell and Wellborn's seven hypothesized student types (1991), were a poor fit for the current student sample. Specifically, we failed to find support for the existence of 3 of the 7 hypothesized profiles and the remaining four student profiles (plus the post hoc added Middle profile) only described $30 \%$ of the student sample. The empirically-derived profiles, created using model-based cluster analysis, placed every student into one of five student motivation profiles, namely, an Adaptive profile characterized by high engagement and low disaffection, a Going through the Motions profile characterized by moderate engagement and disaffection, a 
Distressed profile with the highest levels of anxiety and frustration, an At Risk profile characterized by low engagement and high disaffection, and a Checked-out profile with the highest boredom levels and lowest engagement of any profile. Comparisons of the two sets of profiles indicated that although both methods produced a "good news" and a "bad news" profile, they did not reach consensus as to how to categorize the remaining students who do not fall into these prototypical motivated versus unmotivated profiles.

RQ 2: Reciprocal effects. Contrary to hypotheses, results did not find evidence of reciprocal effects of student motivation profiles on differential changes in teacher support from fall to spring for either of the two sets of profiles. For the theory-driven profiles, findings indicated that although there were significant differences in students' experiences of teacher support across the 5 profiles, there were no significant changes in teacher support over time, and thus changes in teacher support did not depend on group membership. The small sample sizes of the theory-derived profiles combined with the high cross-time stabilities for teacher support may have contributed to these nonsignificant results. For the empirically driven profiles, results showed significant differences in teacher support across profiles as well as significant differences in teacher support across time, however these changes did not depend on students' profile membership. Students in different profiles did not experience differential changes in teacher support across the school year. Instead, starting from different initial levels, students from the different profiles showed similar pattern of change from fall to spring modest declines. 
Despite the lack of evidence for RQ 2, researchers should continue to investigate how students' impact their teachers. The burgeoning research literature on the reciprocal effects of student motivational constructs on teachers' reactions should not be abandoned, but in contrast, should receive more attention. Although we were not able to document these effects using the current study's person-centered analysis approach and specific sample, prior research and common sense dictate that teachers likely respond to highly motivated enthusiastic leaners differently than disaffected, apathetic, and resistant students. Teachers are active interaction partners for students, not inert robots and the more researchers can learn about how students' motivation impacts their teachers the better able we will be to support both parties experiences in the classroom.

RQ 3. Linking motivation profiles to student SSP's. Results indicated that students in different motivational profiles reported significantly different levels of student self-system processes. For the theory-derived profiles, pairwise caparisons showed these significant differences were mostly between the Optimal profile and the more maladaptive profiles, namely, the Withdrawn and Burnt-out profiles. Specifically, students in the Optimal profile had significantly higher levels of relatedness, competence, and identified self-regulation than did students in the Withdrawn and Burnt-out profiles. This pattern of significant mean level differences in SSP's was similar for the empirically-derived profiles. Students in the Adaptive and Going Through the Motions profiles had significantly higher levels of relatedness and competence than did students in the more maladaptive profiles, namely, the At Risk and Checked-out profiles. However, students in the Adaptive profile had higher intrinsic and identified self-regulation than did 
students in the Going Through the Motions profile, indicating Adaptive students experienced more enjoyment and ownership over their academic work than students in the second-most adaptive profile.

These results were consistent with previous research indicating that student SSP's are strong, positive predictors of engagement, and thus confirmed hypotheses that students in the most engaged profiles would enjoy the highest levels of all three selfsystem processes. The only unexpected result was that students in the At Risk profile reported significantly higher levels of external self-regulation than did students in the Adaptive, Going Through the Motions, and Distressed profiles. Perhaps these At Risk students, who are characterized by their especially high levels of anxiety, feel outside pressures to succeed academically more acutely than students in other profiles.

RQ4. Targeted teacher support. Research question 4 examined whether students who received high levels of the types of teacher support they needed most, based on what RQ3 revealed about their SSP's, exhibited more adaptive patterns of change in engagement across the school year. Two theory-derived profiles (Withdrawn and Burntout) and three empirically-derived profiles (Going Through the Motions, At Risk, and Checked-out) were "diagnosed" in RQ 3 as profiles with students who had significantly lower levels of one or more self-system process (i.e. relatedness, competence, and autonomy). These profiles were then examined to determine if students in these profile who had received the "treatment" (i.e., higher levels of the type/s of targeted teacher support that correspond to their low SSP's) displayed more adaptive patterns of engagement across the school year. 
For students in the Withdrawn, Burnt-out, and Going Through the Motions profiles, changes in engagement from fall to spring did not depend on whether students received high or low teacher support. However, for students in the At Risk and Checkedout profiles, the interaction between profile and time was significant such that students in the high teacher support group and the low teacher support group experienced differential changes in their self-reported engagement from fall to spring. Interestingly and contrary to our hypotheses, the students who received the "treatment" (high levels of teacher support) had less adaptive patterns of change than those who received low levels of teacher support. Specifically, At Risk students who received more teacher support actually lost more engagement from fall to spring than their At Risk counterparts who received lower levels of teacher support. Similarly, Checked-out students who received high levels of teacher support lost engagement across the school year although their counterparts who received little teacher support maintained their engagement from fall to spring.

The pattern of findings from RQ 4 seemed to be in direct opposition to previous research indicating that teacher motivational support, specifically teacher warmth, structure, and autonomy support, are robust predictors of students' SSP's and subsequent engagement. However, some aspects of the pattern of findings aligned with our expectations. Specifically, students who received higher teacher support began the year with higher engagement in fall and continued to have higher engagement in spring compared to their low teacher support counterparts, suggesting the advantage as would be predicted by Self-determination Theory. In fact, although the students in the high teacher 
support subgroup were members of the two least adaptive profiles (At Risk and Checkedout) these students reported higher engagement levels at both time points than the average student (At Risk; $\mathrm{M}=3.58$ vs. 3.20 for fall, $\mathrm{M}=3.19$ vs. 3.09 in Spring, Checkedout; 3.40 vs. 3.20 for fall, $M=3.10$ vs. 3.09 ). Thus, two possible explanations emerge for the declines in engagement found for the high teacher support subgroups. Either high levels of teacher support must be supporting these students in some way or the reciprocal relationship must be true, namely, that students with high engagement elicited higher levels of motivational support from their teachers at both time points.

Overall, this suggests that high levels of teacher motivational support are connected to students' engagement, just not in the manner we expected. Looking at the graphs of these changes (Figures 5.19 and 5.20) suggests that perhaps students with high teacher support were being held aloft in fall by great teachers but this advantage decreased by spring. Possibly having high teacher support in fall gave those students an initial boost but it was not enough to help them maintain that head start across the school year. Perhaps the reason that the low teacher support subgroup started and ended the year with lower engagement was because teachers had already given up on these students. These students with low teacher support were struggling with their engagement in fall and they continued to do so throughout the school year. Indeed, students in the Checkedout profile began and ended the year with the same low levels of engagement $(\mathrm{M}=2.71$ in spring and fall), and students in the At Risk profile experienced a slight dip in engagement across time ( $\mathrm{M}=2.81$ in fall and 2.73 in spring). Finally, if we assume reciprocal effects may also be present, this could suggest that students who started the school year with 
higher engagement received more support from their teachers in fall and spring than did their less engaged peers, which explains their higher levels of teacher support at both time points.

Thus, although the changes over time for students in the high and low teacher support subgroups may have appeared to suggest that students in the low teacher support groups were faring better, examination of mean levels of engagement at both time points indicated students in the high teacher support groups were more engaged. In fact, perhaps these surprising findings occurred because At Risk and Checked-out students in the high teacher support subgroups had higher engagement in fall than their counterparts in the low teacher support subgroups. The high teacher support subgroup had more engagement to lose. Additionally, as discussed previously, cross-time stabilities for study variables were relatively high in the current sample. Thus, these declines in student engagement from fall to spring were very small, averaging 0.26 , which is about a $7 \%$ decrease on a 4 point scale. Perhaps these declines are so slight as to almost appear stable.

Clearly these findings, which could be so contradictory to our hypotheses and previous research, indicate the need for closer examination of these classroom dynamics. If future studies can create student profiles with large enough sample sizes, they may be able to select students within profiles who are starting the school year with similar levels of engagement and then trace their engagement over time to determine whether they show different patterns of changes with different levels of teacher support. Perhaps even at the beginning of the school year there was something differentiating students in the high versus low teacher support subgroups besides their experiences of teacher support. 


\section{Strengths and Limitations}

This study addressed a gap in the literature concerning the reciprocal effects of student engagement and disaffection on changes in teachers' provision of motivational support across the school year. The current study not only examined the nature of these reciprocal effects but also extended previous research by examining underlying predictors of the quality of students' classroom motivation and by investigating the impact of targeted teacher support as a potential intervention effort. The current study also expanded on previous research by utilizing a longitudinal study design, a comprehensive set of multidimensional measures, and a person-centered approach. Specific strengths and limitations will be discussed in regard to the sample, measurement, and study design.

Sample. A key strength of the current study was its comprehensive sample. The sample represented almost the entire student population in a northeastern town from grades 3-6. Unlike other studies that may lack generalizability due to assessing a potentially unrepresentative subgroup of a given student population, the current study allowed for a more accurate representation of all the students in a given location. However, the sample also possessed serious limitations in terms of the lack of ethnic and socioeconomic diversity, the uniqueness of the sample, and the time of measurement.

The homogeneity of the study sample represented a key limitation of the current investigation. Specifically, the study sample was almost exclusively made up of Caucasian students (95\% identify as white). Similarly, the vast majority of the students' SES, as identified by parents' occupation, was working class and middle class. This lack of ethnic and economic diversity severely limited the generalizability of the current 
study's findings. This is especially pertinent for the creation of the student motivation profiles as an urban or ethnically diverse sample may have produced entirely different profiles. The current sample was also particularly high functioning suggesting that study findings may not be accurate for or applicable to at-risk samples.

In addition, the current study's sample was part of a very large and comprehensive study of the students, teachers, and parents in the town. A school that allows researchers to conduct a five-year longitudinal study on all its students and teachers, which includes devoting multiple school days each year solely to the task of completing extensive assessments as well as sending surveys home with each student for their parents to fill out, can be assumed to be atypical. Participating in such a monumental project suggests that there may have been something unique about the school district that makes the generalizability of findings to other schools uncertain. Perhaps the same qualities that made this school open to such an immense longitudinal study could be partly responsible for the high levels of student engagement and the strong cross-year stabilities found in the current sample. Although unhelpful for supporting the current study's hypotheses, the fact that the student sample was so high-functioning and appeared to experience little change over time would be an asset to the students' themselves. Finally, the last limitation of the current study's sample concerns the age of the dataset. This data was collected almost 25 years ago and as such the sample may no longer be representative of today's students. Many of the changes that have taken place in public schools over the last two decades are likely to have had an impact on student 
engagement and disaffection, and so may have produced different kinds of motivation profiles.

Measures. The rich, multidimensional measures of the constructs of engagement and disaffection represent a significant strength of the current study. Many previous studies utilized measures that only examined one or two aspects of motivation instead of the full spectrum of behaviors and emotions that are considered indicators of motivation. Frequently, previous studies combined engagement and disaffection into a single bipolar variable thereby limiting the complexity and nuance that could be gained from examinations of these variables. In contrast, the current study's expansive measures included both behavioral and emotional components of engagement and disaffection. However, although these measures allowed the current study to potentially gain a richer view of these complex constructs by covering more of the conceptual space, they still possessed limitations.

Although more comprehensive than other measures, the current study's measures still failed to assess potentially important components of student motivation. Even though the current measures tap emotional and behavioral as well as positive and negative components of motivation, some researchers posit that there is also a cognitive component to engagement that was not addressed in the current study's measures. Cognitive engagement has been conceptualized as students' mental orientation during learning activities and has been operationalized as one's mastery orientation, preference for challenge, and use of regulation and coping strategies in the service of learning (Cleary \& Zimmerman, 2012). Similarly, the current study’s failure to include re- 
engagement, or students' capacity to bounce back from setbacks and reengage with learning activities after running into obstacles, also presents a limitation of its measures.

The current study's measures were also limited in that they did not assess students' disruptive misbehavior in the classroom. Although measures of emotional disaffection tap the emotions often associated with acting out behaviors, namely, anger and boredom, the behaviors themselves are not assessed by any disaffection items. As discussed in the literature review, teachers experience student disruptive misconduct as a highly salient and negative aspect of their jobs as student misbehavior consumes valuable instruction time, hinders other students' learning, and is emotionally draining for teachers (Chang, 2009; Steven \& Meyer, 2005; Boyle, Borg, Falzon, \& Baglioni, 1995). Thus, including these motivational components in future studies will add to our understanding of how teachers perceive and respond to different qualities of their students' motivation.

Finally, engagement and disaffection are salient and observable states and thus the study would have been strengthened by the inclusion of observational measures of students' classroom motivation. The addition of observational data would have been an effective way of reducing common-method bias. The addition of observational data could have further bolstered evidence of construct validity and perhaps elucidated the specific student actions or emotions that trigger provision or withdrawal of teacher support. Finally, due to the low correlations between teacher and student reports of student engagement, the addition of observational measures may have helped provide an external perspective on these classroom dynamics. 
Design. The current study was designed to circumvent one of the major limitations of the current reciprocal effects research. Namely, the majority of studies that examine how aspects of students' motivation may influence teachers' behaviors relies on one-time point correlational findings. Some of the few studies that do employ a longitudinal research design utilize only one time point per academic year, and so do not allow researchers to determine whether a given teacher's behaviors change over time -because each time point is assessing students' relationships with a different teacher. In contrast, the current study included two measurement points per year, one in fall and one in spring, thereby allowing for the investigation of how a given teacher's behavior changes from the beginning to the end of the same school year.

Although two data points per year is certainly an improvement over the more common one point design, the development of teacher-student interactions does not necessarily conform to a bi-yearly schedule. Two measurement points per year are likely not sufficient to capture the episodic and incremental developments that student-teacher relationships undergo daily. Perhaps with denser time-ordered measurement points, coupled with observational data, the current study could have found evidence for reciprocal effects in our student sample. Perhaps reciprocal effects were occurring but could not be captured by only two measurement points at the beginning and end of the year.

Additionally, in response to findings that indicate motivation suffers steep declines in the during the transitions from elementary school to middle school and again to high school, it is imperative that future research focus on these turning points 
(Wigfield, Eccles, Schiefele \& Roeser 2006; Gottfried, Fleming, \& Gottfried, 2001; Anderman \& Maehr, 1994 Janosz, Archambault, Morizot, \& Pagani, 2008). To better understand whether these dynamic relationships between aspects of student motivation and teacher behavior develop differently across school transitions, we need research that includes time points across transitions years.

The limitations detailed in the previous sections suggest that future studies are needed in order to replicate and expand on findings gained from the current study. Specifically, future studies could build on the current investigation by using more diverse participant samples, more exhaustive and mixed-method measures, more frequent measurement time points, and more varied person-centered methodologies. Due to the homogeneity of the current sample, replications with more diverse teacher and student samples are necessary in order to establish the generalizability of any potential findings. Future studies would also benefit from including observations of student motivation and teacher support in order to gain another perspective on these complex interactions. Similarly, including measures of cognitive engagement as well as other motivated behaviors and emotions -especially disruptive behaviors-- would expand our understanding of what teachers are responding to in the classroom and how these factors impact their subsequent behavior towards students. Additionally, study designs with denser time-ordered measurement points would allow future studies to more closely examine these dynamic, on-going interactions between students and teachers. 


\section{Implications}

Although the majority of the current study's hypotheses were not supported, we nevertheless gained valuable information about utilizing a person-centered approach to examining motivational dynamics between students and teachers in the classroom. The following sections discuss the implications of the current study's findings and how they can inform future studies. Firstly, we will discuss how results of the current study provide important suggestions for how we can apply person-centered approaches to the study of classroom motivation. Secondly, the current study's contribution to our understanding of how teachers' perceive their students' motivation will be discussed. The next section will discuss the implications of the findings linking motivation profiles to self-system processes and how to reconcile these with the self-system model of motivational development (SSMMD). The final section will examine how the surprising results of RQ 4 could inform how we think about and study the impact of teachers' provision of motivational support on students.

\section{Person-centered Approach}

This study sought to examine the feasibility and value of using a person-centered approach (PCA) to studying student motivation. Findings suggested that although we may have gained an expanded perspective on student motivation by utilizing a more holistic analysis approach, this new view is far from clear. It will take many replications with different samples and varied person-centered analysis methodologies before we can make any conclusions about the types of students teachers see in their classrooms. Without a substantial research literature to build from, this study's creation of student 
motivation profiles was exploratory and as such we were disappointed but not surprised at the inconclusiveness of results.

Theory-driven profiles. Overall, the theory-driven profiles did not accurately describe our student sample. Perhaps since Connell and Wellborn's student motivation profiles (as well as Roeser et al's who conducted the only other PCA study of student motivational constructs that relied on a priori theorized profiles) were created using vignettes and descriptions instead of teacher survey items, that method is more effective. Perhaps teachers can recognize these types of students but the current survey questions could not help teachers generate different student motivation profiles. Alternatively, perhaps researchers need help understanding how teachers categorize their students' motivation, and thus it may be more beneficial to allow the teachers themselves to inform the researchers about what student motivation profiles they believe exist. Another potential approach that was identified based on the results of the theory-derived profile set was the possibility of using table 5.5 (reproduced below) to determine post hoc where the students in a given sample tend to be congregating by visually identifying naturally occurring homogenous subgroups of students based on where they fall on measures of aspects of motivation. 
Table 5.5

Tertiary splits for mean levels of motivational components for all students in fall

BEHAVIORAL \& EMOTIONAL ENGAGEMENT

\begin{tabular}{|c|c|c|c|c|c|c|c|c|c|c|c|}
\hline \multirow{3}{*}{\multicolumn{3}{|c|}{$\mathbf{A V}$}} & \multicolumn{3}{|c|}{ Low Behavioral } & \multicolumn{3}{|c|}{ Med Behavioral } & \multicolumn{3}{|c|}{ High Behavioral } \\
\hline & & & $\begin{array}{l}\text { Low } \\
\text { Emo }\end{array}$ & $\begin{array}{l}\text { Med } \\
\text { Emo }\end{array}$ & \begin{tabular}{|l|} 
High \\
Emo
\end{tabular} & $\begin{array}{l}\text { Low } \\
\text { Emo }\end{array}$ & $\begin{array}{l}\text { Med } \\
\text { Emo }\end{array}$ & $\begin{array}{l}\text { High } \\
\text { Emo }\end{array}$ & $\begin{array}{l}\text { Low } \\
\text { Emo }\end{array}$ & \begin{tabular}{|l|} 
Med \\
Emo
\end{tabular} & $\begin{array}{l}\text { High } \\
\text { Emo }\end{array}$ \\
\hline & & & & & & & & & & & \\
\hline \multirow{9}{*}{$\begin{array}{l}\text { Low } \\
\text { Behav } \\
\text { DIS }\end{array}$} & \multirow[t]{3}{*}{ Low Bored } & Low Anx/frust & 3 & 3 & 2 & & 12 & 12 & & 12 & 150 \\
\hline & & Med Anx/frust & 2 & 2 & 2 & 2 & 6 & 7 & 1 & 5 & 57 \\
\hline & & High Anx/frust & 1 & & & & 3 & & 2 & 3 & 5 \\
\hline & \multirow[t]{3}{*}{ Med Bored } & Low Anx/frust & & & & 1 & & 1 & & 2 & 20 \\
\hline & & Med Anx/frust & 1 & & & & 4 & 1 & 1 & 3 & 16 \\
\hline & & High Anx/frust & & 1 & & & & & 1 & 1 & 1 \\
\hline & \multirow[t]{3}{*}{ High Bored } & Low Anx/frust & & & & & & & & & \\
\hline & & Med Anx/frust & & & & & & & & & 1 \\
\hline & & High Anx/frust & & & & & & & & & \\
\hline \multirow{9}{*}{$\begin{array}{l}\text { Med } \\
\text { Behav } \\
\text { DIS }\end{array}$} & \multirow[t]{3}{*}{ Low Bored } & Low Anx/frust & & 5 & 4 & & 4 & 7 & & 1 & 13 \\
\hline & & Med Anx/frust & 2 & 3 & & & 5 & 4 & 1 & 3 & 10 \\
\hline & & High Anx/frust & 1 & 1 & & 6 & 2 & & 1 & 2 & 2 \\
\hline & \multirow[t]{3}{*}{ Med Bored } & Low Anx/frust & 2 & 3 & 1 & 1 & 9 & & & 1 & 22 \\
\hline & & Med Anx/frust & 10 & 18 & 1 & 12 & 34 & 7 & & 8 & 15 \\
\hline & & High Anx/frust & 20 & 10 & & 16 & 23 & 2 & 2 & 5 & 5 \\
\hline & \multirow[t]{3}{*}{ High Bored } & Low Anx/frust & & 1 & & & 2 & & & 2 & 1 \\
\hline & & Med Anx/frust & 4 & 3 & & & 5 & & & & 1 \\
\hline & & High Anx/frust & 3 & & & 7 & 2 & & & & \\
\hline \multirow{10}{*}{$\begin{array}{l}\text { High } \\
\text { Behav } \\
\text { DIS }\end{array}$} & & & & & & & & & & & \\
\hline & \multirow[t]{3}{*}{ Low Bored } & Low Anx/frust & 2 & 3 & 1 & & 1 & 1 & & & \\
\hline & & Med Anx/frust & 8 & & & & 3 & 1 & & & \\
\hline & & High Anx/frust & 10 & 2 & & 2 & & & & & \\
\hline & \multirow[t]{3}{*}{ Med Bored } & Low Anx/frust & 3 & 3 & 2 & 1 & 2 & & & & 2 \\
\hline & & Med Anx/frust & 30 & 16 & 1 & 2 & 6 & 2 & 1 & 3 & 2 \\
\hline & & High Anx/frust & 61 & 17 & & 17 & 7 & & & 1 & \\
\hline & \multirow[t]{3}{*}{ High Bored } & Low Anxy/frust & 2 & 3 & & & 1 & 1 & & & 1 \\
\hline & & Med Anx/frust & 27 & 5 & 1 & 2 & 5 & & & & 1 \\
\hline & & High Anx/frust & 52 & 14 & & 5 & 2 & & 1 & & \\
\hline
\end{tabular}


The above table shows where each student in the sample falls on tertiary splits on all motivation variables. This table allowed us to visually inspect naturally occurring clusters of students and may be a useful tool in further studies applying PCA to the study of student motivation. For example, one value of this table is that it indicated the existence of clusters of students that were not conceived of previously in the theory-derived profiles and did not emerge from the empirical creation processes. Overall, the lack of fit between our seven hypothesized theory-derived profiles, especially in comparison to the naturally occurring clusters illustrated in Table 5.5, highlights the ability of theory to constrain our view of how these aspects of motivation occur within students.

Empirically-driven profiles. In terms of the empirically-derived student motivation profiles, the current study identified five interpretable, distinguishable student motivation profiles. Although there is a dearth of studies using person-centered approaches to examining student motivational constructs, a few comparisons to previous findings can be made. As reviewed previously in Chapter 3, the following four studies also utilized empirically-derived profiles to examine student motivation with varied results.

Firstly, Luo, Hughes, Liew, and Kwok (2009) used k-means clustering with random starts to identify homogenous groups of students based on teacher-report measures of students' effortful engagement, antisocial engagement, and prosocial engagement to create 4 distinct student profiles; namely, Cooperative (highest effortful and prosocial engagement, lowest anti-social engagement), Resistive (lowest effortful and prosocial engagement, highest anti-social engagement), Enthusiastic (average 
engagement, highest self-efficacy and school liking ) and Disaffected (average engagement, lowest school liking and self-efficacy). In terms of comparisons across studies, it appears that the Cooperative and Adaptive profiles, the Resistive and Checkedout profiles, and the Disaffected and Distressed profiles were characterized by similar levels of behavioral (or effortful) and emotional (or prosocial) engagement.

Secondly, Wang \& Peck (2003) utilized latent profile analysis to uncover five different student motivation profiles. Specifically, the authors used students' reports of their behavioral, emotional, and cognitive engagement to create the following profiles; Moderately engaged, Highly engaged, Minimally engaged, Emotionally disengaged (low emotional, high cognitive, moderate behavioral), and Cognitively disengaged (moderate emotional and behavioral, low cognitive). Wang and Peck's study and the current study both identified a "good news" (High engaged \& Adaptive) and a "bad news" (Minimally engaged \& Checked-out) profile. However, because the current study did not contain measures of cognitive engagement, the classification of the remaining profiles is unclear. Perhaps because both the Emotionally disengaged profile and the Distressed profile are most strongly differentiated from other profiles by their high levels of negative emotions (and lack of positive emotions) they may represent similar students.

Additionally, Roeser, Strobel, and Quihuius, (2002) used cluster analysis to identify four student motivation profiles, namely, Multiple strengths, Poor academic value, Poor mental health, and Multiple problems. With high emotional and behavioral engagement as well as low disaffection, our Adaptive profile appears similar to Roeser et al's Multiple strengths profile, and our Distressed profile, characterized by high anxiety 
and frustration, is most similar to their Poor mental health profile. Finally, our Checkedout profile may align with Roeser et al's Multiple problems profile, or perhaps because of these students' high levels of boredom, the current study's Checked-out profile may better align with the Poor academic value group.

Finally, using multi-group latent profile analysis, Salmela-Aro, Moeller, Schneider, Spicer, and Lavonen, (2016) also identified four groups of students based on their motivation, namely, an Engaged-exhausted profile that included students with high engagement and high burnout, a Burned out profile included students with low engagement and high burnout, a Moderate profile (which consisted of a subgroup of the engaged-exhausted students) had moderate levels of both and At Risk for Burnout which included students with elevated but still moderate burnout and lower engagement. Although the Engaged-exhausted profile does not appear to have a counterpart in the current study's empirically-derived set of profiles, it is worth noting that this profile seems similar to the Enmeshed theory-derived profile that tried to capture students that were both engaged but also displayed emotional disaffection. In addition, Salmela-Aro et al's Burnt-out profile appears most similar to our Checked-out profile while their Moderate Profile appears to be similar to the current study's Going Through the Motions profile. Finally, both Salmela-Aro et al's study and the current study found a group that we interpreted as students who were progressing down a negative trajectory into disaffection, or At Risk students. Although only a longitudinal examination of these students can indicate whether they will soon transition from the At Risk profile to more 
maladaptive profiles, it is interesting that both studies suggested the possibility of a “downward spiral" motivation profile.

Regardless of the varied number and qualities of student motivation profiles that may emerge, the current study's findings using empirically-derived methodologies revealed some of the key limitations of empirical approaches. Firstly, model-based clustering does not produce one solution, but rather supplies the researcher with many models and the power to further create groups based on the researchers' criteria. In the current study, the model that was eventually chosen as the final model was only one of over 20 potential models, some of which were better than the chosen model in some way. Specifically, multiple models had better fit indices than the chosen model or produced groups with larger sample sizes.

This person-centered approach to creating homogenous subgroups allows the researcher a great deal of leeway in determining which model to ultimately use. A PCA that relies so heavily on the researchers' choices may potentially introduce researcher bias into the study and make replication of results across researchers and samples very difficult. Depending on the requirements and goals of the research project, very different student motivation profiles may be chosen. Even without researcher bias, model-based clustering is entirety reliant on the number and mean levels of the variables entered into the algorithm, and even slight variations in these decisions may completely change the resulting profiles. For example, during the process of considering potential models, the high correlation between behavioral engagement and behavioral disaffection led us to combine these variables into a composite variable by reverse-coding the disaffection 
items. The final model for the current study utilized this composite engagement variable, but we could just as easily have kept the behavioral components of engagement and disaffection separate. Perhaps a different researcher with different criteria and hypotheses would have made a different choice and thus produced different student profiles.

Overall, more research that examines the stability of profiles across time and samples is needed. The current study revealed that model-based clustering is in some ways an artistic and personal approach to data analysis -- which makes it highly variable. Thus drawing conclusions across researchers and samples is difficult. We attempted to combat this by requiring that the resulting profile were "interpretable" or theoretically and intuitively sound.

Advantages and disadvantages of methods. Additionally, the current study's lack of significant findings using model-based clustering as a person-centered approach to creating motivation profiles also highlighted another possible issue with this methodology. Although the theory-derived profiles suffered due to small sample sizes, model-based clustering, in contrast, places every student into a profile thus categorizing the entire sample. Perhaps one of the reasons the empirically-derived student motivation profiles failed to differentially predict changes in teacher support was because some students were forced into a profile that they may not have been a good fit for them. Perhaps the profiles would have been more homogenous and thus more differentiated from other profiles if not all students were required to be placed into one profile.

Additionally, the current study examined student motivation profiles using the entire student sample, but it is important to remember that these investigations were 
conducted on students across four grade-levels. It is possible, if examined separately, analyses would have indicated students in third grade had a different set of motivation profiles than their pre-teen peers in $6^{\text {th }}$ grade. For example, perhaps in the younger grades, where there is traditionally less pressure to achieve, the Distressed profile might not exist because students have not yet become worried and anxious about their school performance.

Student motivation for school peaks the day before Kindergarten starts and suffers continuous declines until students graduate from (or drop out of) high school, with severe losses at the transitions to middle school and high school (Wigfield, Eccles, Schiefele \& Roeser 2006; Gottfried, Fleming, \& Gottfried, 2001; Anderman \& Maehr, 1994 Janosz, Archambault, Morizot, \& Pagani, 2008). Thus, we would expect that even if the same profiles were found across grades, the sample sizes for each profile may be different in different grades with the adaptive profiles becoming less and less populated in the higher grade-levels. Additionally, previous research suggests girls are more engaged than boys overall (Skinner, Kindermann, Connell, \& Wellborn, 2009; Skinner, Kinderman, \& Furrer, 2009; Skinner, \& Belmont, 1993). Thus, we may expect trends in which there are more girls and younger students in adaptive profiles and more boys and older students in maladaptive profiles. It will be an important next step to determine whether there are certain profiles that were populated by specific types of students and/or whether different sets of profiles are needed to account for students from different grades or genders.

In addition to the implications derived from the creation of the two sets of student motivation profiles, comparing the two methods also informed our understanding of the 
value and feasibility of examining student motivation with a person-centered approach. Specifically, the lack of convergence between the two models suggests that different methodologies do produce different resultant profiles. At least in the current sample, beyond the highly motivated and highly unmotivated profiles, no other trends were replicated across methodologies. As discussed above, we did find some comparable groups across studies, if not across methodologies. Specifically, there was some evidence to suggest the existence of a Moderate profile (Going Through the Motions) as well as an At-risk profile, and an emotionally struggling/poor mental health (Distressed) profile. For each of these profiles, there was at least one other study, besides the current study, that found these profiles in their sample. However, it is clear that before any conclusions can be drawn as to the types of student motivation profiles that exist, replications across methods and studies must be explored more thoroughly.

Finally, when exploring the advantages and disadvantages of the current study's method, it is important to note that our choice in perspective, as well as our choices in the type of person-centered analyses used, may have shaped our results. Specifically, before delving into how the current study's findings informed our understanding of the types of students teachers see in their classrooms, it is worthwhile to consider how the sets of profiles may have differed had we utilized students' own reports of their engagement instead of teachers' reports.

The two sets of profiles created using teacher-reports of students' behavioral and emotional engagement and disaffection were poor predictors of changes in teachers' provision of motivational support; however, using students' own perceptions of their 
classroom engagement may have produced different results. Previous research has indicated that teachers are reliable and accurate reporters of student engagement, however, we must assume that students, being the experts on their own motivation, may have a somewhat different perspective than their teachers (Skinner, Kinderman, \& Furrer, 2009). Thus, perhaps new and different profiles would have emerged had the current study utilized student-reports. Although student engagement and disaffection are observable states, teachers cannot directly view students' emotions in the classroom and thus may be relying on students' behavior to inform their inferences about what students are feeling. This could potentially explain why teachers' reports of behavioral and emotional engagement and disaffection were so highly correlated in the current study. This hypothesis also aligns with the findings that teachers appeared to struggle with differentiating between student anxiety and frustration in the classroom as evidenced by the very high correlation between the two variables. Overall, utilizing student reports may have given us different, more differentiated student motivation profiles.

\section{Teachers' Perspectives}

The current study sought to examine student motivation not only from a personcentered approach but specifically from the teacher's perspective. Teachers see students, not variables, and thus the purpose of using PCA was to gain a more holistic perspective on how teachers view their students' motivation. By using a person-centered analysis approach and multidimensional measures of motivation, we hoped to expand on previous reciprocal effects research by using a design that would allow for a richer, more complex 
conceptualization of student motivation that went beyond a view of students as either motivated or unmotivated.

The majority of previous reciprocal effects research has used a single motivation variable (or in some cases a composite variable of engagement and reverse-coded disaffection) to examine motivation, and the results were often examined as a single continuum with unmotivated at one pole and motivated at the other. We know based on the current study's findings that both PCA methods did recover a "good news" motivated and a "bad news" unmotivated group which aligns with this more traditional way of viewing student motivation. Perhaps this motivated versus unmotivated perspective, although limited, may hold for some teachers and their students. According to both of the current study's sets of profiles, teachers see more than simply motivated versus unmotivated students, otherwise, only these two groups would have emerged from the person-centered analyses. However, the lack of significant reciprocal effects findings suggests that these different student profiles don't seem to shape how teachers react to their students. Significant reciprocal effects findings would have suggested that teachers have a much richer, more nuanced view of their students with different student profiles eliciting different teacher responses. The lack of significant reciprocal effect findings begs the question, are these different profiles meaningful in terms of how they impact students' daily lives in the classroom? Do these profiles distinguish how students are treated (changes in teacher support) and how they experience school (levels of SSP's)?

Multiple aspects of the current study's findings suggest that teachers' views of their students' classroom motivation were not as differentiated and customized as 
expected. With the current sample, both PCA methods produced a motivated profile (Optimal \& Adaptive) and an unmotivated profile (Burnt-out \& Checked-out). These prototypical groups had the largest sample sizes. The majority of the significant differences found in student SSP's across profiles were between these adaptive versus maladaptive profiles, suggesting these profiles were more strongly distinguishable. Examination of Table 5.5 shows 150 students were high on all the engagement variables and low on all the disaffection variables (i.e. the motivated group) and 50 students were low on all the engagement variables and high on all the disaffection variables (i.e. unmotivated group).

Although dividing the components of motivation into separate variables (especially for emotional disaffection which was separated into its three subgroups of anxiety, boredom, and frustration) was meant to aid in the current study's goal of producing more nuanced views of students' motivation, the high correlations between the subcomponents suggested teachers' views may not have required such complexity. Specifically, the average correlation between engagement and disaffection variables was $r=.74$. Correlations between teacher-reports of behavioral and emotional aspects of motivation averaged $r=.75$. As mentioned earlier, this suggests teachers are not reporting a big distinction between these subcomponents of student motivation, perhaps because they are using behavior to infer emotion.

The most powerful example of teachers' lack of differentiation when it comes to motivational constructs concerns the subcomponents of emotional disaffection. Specially, in the current study anxiety and frustration were combined due to their high correlation ( $r$ 
$=.78$ ). This suggests teachers struggled to tell the difference between these two (subjectively) very different student emotions. This suggests one source of potential differentiation that we were not able to capitalize on may have come from the varied subcomponents of disaffected emotions. If the three disaffected emotions did help differentiate profiles from each other, the current study would not have been able to capture this as our findings suggest teachers may not be adept at distinguishing between these student emotional states, at least with the current measures.

In sum, perhaps teachers' views of their students' motivation is less differentiated than predicted and the research literature relying on bipolar conceptualizations of engagement are fairly accurate for some teachers. Together, these findings suggest that for some teachers and some students, a simple distinction between motivated versus unmotivated students characterizes teacher's views of their students' motivation. Perhaps this suggests that interventions could have as their goal to help teachers achieve a more differentiated and nuanced understanding of student motivation.

\section{Student Experience}

The third major goal of the current study was to determine whether the resulting student motivation profiles could provide us with meaningful information about students' experiences in school and ultimately help us "diagnose" students with maladaptive selfsystem processes. These self-system processes are so vital because of their role in the Self-system Model of Motivational Development (SSMMD) and their utility in predicting engagement and student academic success. If the student motivation profiles were diagnostic of these underlying, deeply-held student beliefs about themselves and their 
education, then not only would we know which SSP's they were lacking, but we'd be able to identify the corresponding type of teacher support that previous research suggests could increase the specific SSP.

However, results from the current study suggest that these three self-system processes, namely relatedness, competence, and autonomy, did not appear to function separately but instead appeared to co-vary. Specifically, with the exception of the Going Through the Motions profile, all the profiles identified as having low SSP's were low on all three SSP's. It seems that the motivation profiles were not distinguished by their lack of one of two SSP's as posited in the hypotheses but rather students who had high levels of one also had high levels of the other two and vice versa. This lack of differentiation between SSP's across profiles was not entirely unexpected considering SelfDetermination Theory postulates we all require all three experiences in order to be optimally successful.

However, it is interesting that these different experiences co-vary in the current sample. Perhaps a student who knows how to connect with others and feels accepted by her classroom interaction partners is also likely well-adjusted and have skills in other areas such that she also possess a confidence in her ability to succeed and a sense of ownership and purpose in her school work. Simply put, adaptive variables seem to cooccur within individuals and vice versa with maladaptive variables. Perhaps this is why instead of a differentiated view where students in a profile lack a specific SSP's, the current findings suggest a simpler relationship wherein students are either succeeding on all front or struggling on all fronts. If the most salient teacher perspective is viewing 
students as either motivated or unmotivated, then perhaps as a prerequisite for a student to be viewed as motivated, he must already have garnered high enough levels of competence, relatedness, and autonomy previously. In sum, it appears that the three selfsystem processes did not help differentiate the student motivation profiles from each other but instead acted together.

\section{Treating Motivational Issues}

The unexpected findings from research question four bring up important implications for how to structure teacher intervention efforts aimed at supporting student engagement. Research on the Self-System Model of Motivational Development has shown that teachers' provision of motivational support increases students' self-system processes which in turn increases their classroom engagement (Skinner, Furrer, Marchand \& Kindermann, 2008; Skinner, Kindermann, Connell \& Wellborn, 2009). Yet, findings from the current study indicated that for students in some motivational profiles, students who received higher doses of teacher motivational support experienced greater declines in engagement over time compared to their fellow profile members who received less support. When the overall patterns of findings are considered - including the absolute levels of engagement at the two time points for these groups of students - these differential declines in engagement do not clearly support the idea that having less teacher motivational support would be more beneficial to students. This notions is not only counter-intuitive, but counter to decades of previous findings. Thus, as with the findings from research question two and three, findings from research question four call for more investigation and study of these complex dynamics. 
Perhaps denser time-ordered measurement points would have helped tease apart these incongruous findings. By using only the fall measurement point to determine the quality of students experiences of teacher support, we were afforded a limited view of the quality of teacher support, one that assumed stability. Perhaps the students identified in the current study as having high versus low teacher support at the beginning of the year did not actually experience constant levels due to a multitude of possibilities that could influence how teachers responded to their students. Perhaps fluctuations in teacher support occurring between the two measurement points may have explained the odd findings in research question four. Additionally, future research should examine students for more than one school year. When trying to understand how students in the high teacher support subgroup started and ended the school year with higher engagement than their peers, it would be beneficial to know more about their past history of engagement. For example, growth curve analysis or other investigations of the trajectory of students' engagement across grades may provide some context to help us understand the current snapshot.

More measurement points or longitudinal analyses could also help us understand whether reciprocal effects may be impacting results. Specifically, perhaps by the time the fall data was collected, teachers had already begun to treat students differently based on their motivation, as this would explain why the high teacher support subgroup also had higher engagement in fall. Or perhaps there is some other, unmeasured characteristic or experience that students in each subgroup shared that resulted in the findings from 
research question 4. Future studies using more frequent measurement points may be able to help us understand these unexpected findings.

In addition to what these findings imply about directions for future studies, they also make suggestions about future interventions. Many of the hypotheses in the current study were contingent on the discerning eyes of teachers to label their students' motived behaviors and emotions. By creating student motivation profiles from teacher-reports, the current study aimed to understand how teachers see their students' classroom motivation. Thus, the subsequent research questions were contingent, in some part, on the keenness and accuracy of teachers' perceptions. Specifically, for the student motivation profiles to be diagnostic of students' deeply held beliefs about themselves and their ability to succeed in school and subsequently allow us to determine which types of teacher support they would benefit from, the profiles need to be distinguishable and meaningfully different. In order for such profiles to be created, teachers need to be able to distinguish between student anxiety and frustration and boredom as well as be accurate reporters of students' behaviors. Put simply, in order for student motivation profiles to be used to "diagnose" and subsequently "treat" maladaptive student motivational patterns, teachers must be able to accurately gage students varied behaviors and emotions. Perhaps this implies that intervention efforts aimed at helping teachers detect the nuances of their students' motivation may be key to unraveling these complex classroom dynamics. Helping teachers observe and identify their students' emotions in the classroom will hopefully also help teachers know how best to support students and their optimal engagement. 


\section{Conclusion}

This study sought to examine the relationship between student motivation and teachers' provision of support to better understand how teachers view and respond to their students and whether they can view these motivational states as containing diagnostic information about the types of supports their students may need in order to be engaged, enthusiastic learners. This dissertation was designed to circumvent some of the major limitations of previous reciprocal effect research by utilizing a longitudinal design and a more comprehensive assessment of behavioral and emotional engagement and disaffection. Most importantly, the current study explored the feasibility and value of using a person-centered approach to examining student motivation. Although some of our hypotheses were unsupported, this exploratory study did provide important findings that can be used to inform next steps in the study of these complex motivational classroom dynamics. 


\section{References}

Archambault, I., Janosz, M., Morizot, J., \& Pagani, L. (2009). Adolescent behavioral, affective, and cognitive engagement in school: Relationship to dropout. Journal of School Health, 79(9), 408-415.

Ashton, P. (1984). Teacher efficacy: A motivational paradigm for effective teacher education. Journal of teacher education, 35(5), 28-32.

Babad, E. (1993). Teachers' differential behavior.Educational Psychology Review, 5(4), 347-376.

Baker, J. A. (2006). Contributions of teacher-child relationships to positive school adjustment during elementary school. Journal of school psychology, 44(3), 211229.

Becker, E. S., Keller, M. M., Goetz, T., Frenzel, A. C., \& Taxer, J. L. (2015). Antecedents of teachers' emotions in the classroom: an intraindividual approach. Frontiers in psychology, 6.

Bell, R. Q. (1977) "Socialization findings reexamined." Child effects on adults (1977): $53-84$.

Bell, R. Q. (1968). A reinterpretation of the direction of effects in studies of socialization. Psychological Review; 75(2), 81.

Boyle, G. J., Borg, M. G., Falzon, J. M., \& Baglioni, A. J. (1995). A structural model of the dimensions of teacher stress. British Journal of Educational Psychology, 65(1), 49-67. 
Brophy, J., \& McCaslin, M. (1992). Teachers' reports of how they perceive and cope with problem students. The Elementary School Journal, 3-68.

Brunk, M. A., \& Henggeler, S. W. (1984). Child influences on adult controls: An experiment investigation. Developmental Psychology, 20(6), 1074-1081.

Chang M.-L. (2009) An appraisal perspective of teacher burnout: Examining the emotional work of teachers. Educational Psychology Review 21(3), 193-218

Chang, M. L., \& Davis, H. A. (2009). Understanding the role of teacher appraisals in shaping the dynamics of their relationships with students: Deconstructing teachers' judgments of disruptive behavior/students. Advances in teacher emotion research (pp. 95-127). Springer US.

Christenson, S. L., Reschly, A. L., \& Wylie, C. (Eds.). (2012). Handbook of research on student engagement. Springer Science \& Business Media.

Clunies-Ross, P., Little, E., \& Kienhuis, M. (2008). Self-reported and actual use of proactive and reactive classroom management strategies and their relationship with teacher stress and student behaviour. Educational Psychology, 28(6), 693710.

Connell, J. P. (1990). Context, self, and action: A motivational analysis of self-system processes across the life span. The self in transition: Infancy to childhood,8, 6197.

Connell, J. P., \& Wellborn, J. G. (1991). Competence, autonomy, and relatedness: A motivational analysis of self-system processes. 
Covell, K., McNeil, J. K., \& Howe, R. B. (2009). Reducing Teacher Burnout by Increasing Student Engagement A Children's Rights Approach. School Psychology International, 30(3), 282-290.

Deci, E. L., \& Ryan, R. M. (1985). Intrinsic motivation and self-determination in human behavior. Springer.

Deci, E. L., \& Ryan, R. M. (2000). The" what" and" why" of goal pursuits: Human needs and the self-determination of behavior. Psychological inquiry, 11(4), 227-268.

DeVoe, D. E. (1991). Teacher behavior directed toward individual students in elementary physical education.The Journal of Classroom Interaction, 9-14.

Dinham, S., \& Scott, C. (2000). Teachers' Work and the Growing Influence of Societal Expectations and Pressures.

Emmer, E. T. (1994). Classroom management for secondary teachers. Allyn \& Bacon, A Division of Simon \& Schuster, Inc., 160 Gould Street, Needham Heights, MA 02194..

Evers, W. J., Tomic, W., \& Brouwers, A. (2004). Burnout among teachers students' and teachers' perceptions compared. School Psychology International, 25(2), 131148.

Frenzel, A. C., Goetz, T., Stephens, E. J., \& Jacob, B. (2009). Antecedents and effects of teachers' emotional experiences: An integrated perspective and empirical test (pp. 129-151). Springer US. 
Friedman, I. A. (1995). Measuring school principal-experienced burnout. Educational and Psychological Measurement, 55(4), 641-651.

Friedman, I. A. (2000). Burnout in teachers: Shattered dreams of impeccable professional performance. Journal of clinical psychology, 56(5), 595-606.

Fredricks, J. A., Blumenfeld, P. C., \& Paris, A. H. (2004). School engagement: Potential of the concept, state of the evidence. Review of educational research, 74(1), 59109.

Finn, J. D. (1989). Withdrawing from school. Review of educational research, 59(2), 117-142.

Fuller, F. F. (1969). Concerns of teachers: A developmental conceptualization. American educational research journal, 207-226.

Furrer, C. Skinner, E. A. \& Kindermann, T. (2003, April). How the motivationally "rich" get "richer": Reciprocal effects of student engagement in the classroom on changes in teacher support over the school year. Poster session presented the biennial conference of the Society for Research in Child Development.

Furrer, C., Skinner, E., \& Pitzer, J. (2014). The influence of teacher and peer relationships on students' classroom engagement and everyday motivational resilience.National Society for the Study of Education, 113(1), 101-123.

Hayenga, A. O., \& Corpus, J. H. (2010). Profiles of intrinsic and extrinsic motivations: A person-centered approach to motivation and achievement in middle school. Motivation and Emotion, 34(4), 371-383. 
Hargreaves, A. (1998). The emotional practice of teaching. Teaching and teacher education, 14(8), 835-854.

Hargreaves, A. (2000). Mixed emotions: Teachers' perceptions of their interactions with students. Teaching and teacher education, 16(8), 811-826.

Hargreaves, A., \& Tucker, E. (1991). Teaching and guilt: Exploring the feelings of teaching. Teaching and Teacher Education, 7(5), 491-505.

Hastings, R. P., \& Bham, M. S. (2003). The relationship between student behaviour patterns and teacher burnout. School Psychology International, 24(1), 115-127.

Henricsson, L., \& Rydell, A. M. (2004). Elementary school children with behavior problems: Teacher-child relations and self-perception. A prospective study.Merrill-Palmer Quarterly, 50(2), 111-138.

Houts, R. M., Caspi, A., Pianta, R. C., Arseneault, L., \& Moffitt, T. E. (2010). The Challenging Pupil in the Classroom The Effect of the Child on the Teacher.Psychological science.

Janosz, M., Archambault, I., Morizot, J., \& Pagani, L. S. (2008). School engagement trajectories and their differential predictive relations to dropout. Journal of social Issues, 64(1), 21-40.

Jelsma, B. M. (1982). Adult control behaviors: The interaction between orientation toward control in women and activity level of children. Unpublished doctoral dissertation, University of Rochester. 
Jimerson, S. R., Campos, E., \& Greif, J. L. (2003). Toward an understanding of definitions and measures of school engagement and related terms. The California School Psychologist, 8, 7-27.

Johnson, S., Cooper, C., Cartwright, S., Donald, I., Taylor, P., \& Millet, C. (2005). The experience of work-related stress across occupations. Journal of managerial psychology, 20(2), 178-187.

Justice, L. M., Cottone, E. A., Mashburn, A., \& Rimm-Kaufman, S. E. (2008).

Relationships between teachers and preschoolers who are at risk: Contribution of children's language skills, temperamentally based attributes, and gender. Early Education and Development, 19(4), 600-621.

Klem, A. M., \& Connell, J. P. (2004). Relationships matter: Linking teacher support to student engagement and achievement. Journal of school health, 74(7), 262-273.

Kokkinos, C. M. (2007). Job stressors, personality and burnout in primary school teachers. British Journal of Educational Psychology, 77(1), 229-243.

Kunter, M., Frenzel, A., Nagy, G., Baumert, J., \& Pekrun, R. (2011). Teacher enthusiasm: Dimensionality and context specificity. Contemporary Educational Psychology, 36(4), 289-301.

Ladd, G. W., Birch, S. H., \& Buhs, E. S. (1999). Children's social and scholastic lives in kindergarten: Related spheres of influence?. Child development,70(6), 1373-1400.

Ladd, G. W., \& Burgess, K. B. (1999). Charting the relationship trajectories of aggressive, withdrawn, and aggressive/withdrawn children during early grade school. Child development, 70(4), 910-929. 
Luo, W., Hughes, J. N., Liew, J., \& Kwok, O. (2009). Classifying academically at-risk first graders into engagement types: Association with long-term achievement trajectories. The Elementary school journal, 109(4).

Marks, H. M. (2000). Student engagement in instructional activity: Patterns in the elementary, middle, and high school years. American educational research journal, 37(1), 153-184.

Martin, A. J. (2006). The relationship between teachers' perceptions of student motivation and engagement and teachers' enjoyment of and confidence in teaching.AsiaPacific Journal of Teacher Education, 34(1), 73-93.

Martin, N. K., Sass, D. A., \& Schmitt, T. A. (2012). Teacher efficacy in student engagement, instructional management, student stressors, and burnout: a theoretical model using in-class variables to predict teachers' intent-toleave. Teaching and Teacher Education, 28(4), 546-559.

Morrison, G. M., Robertson, L., Laurie, B., \& Kelly, J. (2002). Protective factors related to antisocial behavior trajectories. Journal of clinical psychology, 58(3), 277-290.

Mottet, T. P., Beebe, S. A., Raffeld, P. C., \& Medlock, A. L. (2004). The effects of student verbal and nonverbal responsiveness on teacher self-efficacy and job satisfaction. Communication Education, 53(2), 150-163.

Murray, C., \& Murray, K. M. (2004). Child level correlates of teacher-student relationships: An examination of demographic characteristics, academic 
orientations, and behavioral orientations. Psychology in the Schools,41(7), 751762.

Newberry, M., \& Davis, H. A. (2008). The role of elementary teachers' conceptions of closeness to students on their differential behaviour in the classroom.Teaching and Teacher Education, 24(8), 1965-1985.

Nurmi, J. E. (2012). Students' characteristics and teacher-child relationships in instruction: A meta-analysis. Educational Research Review, 7(3), 177-197.

Patrick, H., Mantzicopoulos, P., Samarapungavan, A., \& French, B. F. (2008). Patterns of young children's motivation for science and teacher-child relationships.The Journal of Experimental Education, 76(2), 121-144.

Pelletier, L. G., Séguin-Lévesque, C., \& Legault, L. (2002). Pressure from above and pressure from below as determinants of teachers' motivation and teaching behaviors. Journal of educational psychology, 94(1), 186.

Reschly, A. L., \& Christenson, S. L. (2012). Jingle, jangle, and conceptual haziness: Evolution and future directions of the engagement construct. In Handbook of research on student engagement (pp. 3-19). Springer US.

Pines, A. M. (2002). Teacher burnout: A psychodynamic existential perspective. Teachers and Teaching: theory and practice, 8(2), 121-140.

Prawat, R. S., Byers, J. L., \& Anderson, A. H. (1983). An attributional analysis of teachers' affective reactions to student success and failure. American Educational Research Journal, 20(1), 137-152. 
Ryan, R. M., \& Deci, E. L. (2000). Self-determination theory and the facilitation of intrinsic motivation, social development, and well-being. American psychologist,55(1), 68 .

Roeser, R. W., Strobel, K. R., \& Quihuis, G. (2002). Studying early adolescents' academic motivation, social-emotional functioning, and engagement in learning: Variable-and person-centered approaches. Anxiety, Stress \& Coping, 15(4), 345368

Sarrazin, P. G., Tessier, D. P., Pelletier, L. G., Trouilloud, D. O., \& Chanal, J. P. (2006). The effects of teachers' expectations about students' motivation on teachers' autonomy-supportive and controlling behaviors.International Journal of Sport and Exercise Psychology,4(3), 283-301.

Sadker, M., Sadker, D., \& Klein, S. (1991). The issue of gender in elementary and secondary education. Review of research in education, 17, 269-334.

Skaalvik, E. M., \& Skaalvik, S. (2011). Teacher job satisfaction and motivation to leave the teaching profession: Relations with school context, feeling of belonging, and emotional exhaustion. Teaching and teacher education, 27(6), 1029-1038.

Skinner, E. A., \& Belmont, M. J. (1993). Motivation in the classroom: Reciprocal effects of teacher behavior and student engagement across the school year. Journal of Educational Psychology, 85(4), 571-581.

Skinner, E., Furrer, C., Marchand, G., \& Kindermann, T. (2008). Engagement and disaffection in the classroom: Part of a larger motivational dynamic? Journal of Educational Psychology, 100(4), 765-781. 
Skinner, E. A., Kindermann, T. A., Connell, J. P., \& Wellborn, J. G. (2009). Engagement as an organizational construct in the dynamics of motivational development. In K. Wentzel \& A. Wigfield (Eds.), Handbook of motivation in school (pp. 223-245). Malwah, NJ: Erlbaum.

Skinner, E., Kinderman, T., \& Furrer, C. (2009). A motivational perspective on engagement and disaffection: Conceptualization and assessment of children's behavioral and emotional participation in academic activities in the classroom. Educational and Psychological Measurement, 69(3), 493-525.

Skinner, E. A., \& Pitzer, J. R. (2012). Developmental dynamics of student engagement, coping, and everyday resilience. In Handbook of research on student engagement (pp. 21-44). Springer US.

Skinner, E. A., Wellborn, J. G., \& Connell, J. P. (1990). What it takes to do well in school and whether I've got it: The role of perceived control in children's engagement and school achievement. Journal of Educational Psychology, 82, 2232.

Smith, C. A., \& Lazarus, R. S. (1993). Appraisal components, core relational themes, and the emotions.Cognition \& Emotion, 7(3-4), 233-269.

Spilt, J. L., Koomen, H. M., \& Mantzicopoulos, P. Y. (2010). Young children's perceptions of teacher-child relationships: An evaluation of two instruments and the role of child gender in kindergarten. Journal of Applied Developmental Psychology, 31(6), 428-438. 
Spilt, J. L., Koomen, H. M., \& Thijs, J. T. (2011). Teacher wellbeing: The importance of teacher-student relationships. Educational Psychology Review, 23(4), 457-477.

Stenlund, K. V. (1995). Teacher perceptions across cultures: The impact of students on teacher enthusiasm and discouragement in a cross-cultural context. Alberta Journal of Educational Research.

Sutton, R. E., \& Wheatley, K. F. (2003). Teachers' emotions and teaching: A review of the literature and directions for future research. Educational psychology review, 15(4), 327-358.

Sutton, R. E. (2007). Teachers' anger, frustration, and self-regulation. Emotion in education, 259-274.

Tsouloupas, C. N., Carson, R. L., Matthews, R., Grawitch, M. J., \& Barber, L. K. (2010). Exploring the association between teachers' perceived student misbehaviour and emotional exhaustion: The importance of teacher efficacy beliefs and emotion regulation. Educational Psychology, 30(2), 173-189.

Ullah, H., \& Wilson, M. A. (2007). Students' academic success and its association with learning and relationships with faculty and peers. College Student Journal, 41(4).

Upadyaya, K., \& Salmela-Aro, K. (2013). Development of school engagement in association with academic success and well-being in varying social contexts.European Psychologist. 
Vansteenkiste, M., Sierens, E., Soenens, B., Luyckx, K., \& Lens, W. (2009). Motivational profiles from a self-determination perspective: The quality of motivation matters. Journal of educational psychology, 101(3), 671.

Wang, M. T., \& Peck, S. C. (2013). Adolescent educational success and mental health vary across school engagement profiles. Developmental Psychology, 49(7), 1266.

S Yoon, J. (2002). Teacher characteristics as predictors of teacher-student relationships: Stress, negative affect, and self-efficacy. Social Behavior and Personality: an international journal, 30(5), 485-493. 
Appendix: Measures

\section{A). Engagements and Disaffection: Teacher-reports (TR)}

\section{Behavioral Engagement: (2 items)}

- When we start something new in class, this student participates in discussion.

- In my class, this student works as hard as he/she can.

Emotional Engagement: (4 items)

- When I explain new material, this student seems relaxed.

- In my class, this student appears happy.

- In my class, this student appears enthusiastic.

- When working on classwork in my class, this student appears involved.

\section{Behavioral Disaffection: (5 items)}

- When we start something new in class, this student doesn't pay attention.

- When we start something new in class, this student thinks about other things.

- In my class, this student does just enough to get by.

- In my class, this student comes unprepared.

- When faced with a difficult problem or assignment in my class, this student doesn't even try.

\section{Emotional Disaffection: (7 items)}

Bored: (1 item)

- When I explain new material, this student seems bored.

Anxious: (2 items)

- In my class, this student appears anxious. 
- When working on classwork in my class, this student appears worried.

Frustrated: (4 items)

- In my class, this student appears angry.

- When faced with a difficult problem or assignment in my class, this student becomes frustrated.

- When faced with a difficult problem or assignment in my class, this student gets angry.

- When working on classwork in my class, this student appears frustrated.

\section{B). Student Self-system processes: Student-report (SR)}

\section{Student Relatedness: (8 items)}

Emotional security with Teacher: (4 items)

○ When I'm with my teacher, I feel accepted.

- When I'm with my teacher, I feel like someone special.

○ When I'm with my teacher, I feel ignored. (-)

○ When I'm with my teacher, I feel unimportant. (-)

Emotional security with Classmates: (4 items)

○ When I'm with my classmates, I feed accepted.

○ When I'm with my classmates, I feel like I belong.

- When I'm with my classmates, I feel left out. (-)

○ When I'm with my classmates, I feel unimportant. (-)

\section{Student Competence: (22 items)}

Control: (6 items)

- If I decide to learn something hard, I can.

- I can do well in school if I want to. 
- I can get good grades in school.

- I can't get good grades in school no matter what I do. (-)

○ I can't stop myself from doing poorly I school. (-)

○ I can't do well in school, even if I want to. (-)

Means-Ends Unknown: (4 items)

○ When I do well in school, I usually can't figure out why. (-)

○ I don't know what it takes for me to get good grades in school. (-)

- When I do badly in school, I usually can't figure out why. (-)

- I don’t know how to keep myself from getting bad grades. (-)

Agency Effort: (6 items)

- When I'm in class, I can work hard.

○ I can work really hard in school.

○ When I'm doing my classwork, I can really work hard on it.

○ I can't seem to try very hard in school (-)

- When I'm in class, I can't seem to work very hard. (-)

○ I have trouble working hard in school. (-)

Agency Attributes: (6 items)

○ I think I'm pretty smart in school.

- When it comes to school, I'm pretty smart.

- I would say I'm pretty smart in school.

- I don't have the brains to do well in school (-)

○ I'm not very smart when it comes to schoolwork (-)

○ When it comes to schoolwork, I don't think I'm very smart. (-)

\section{Student Autonomy: (17 items)}

Intrinsic self-regulation: (4 items)

○ Why do I do my homework? Because it's fun. 
○ Why do I do my homework? Because I enjoy doing my homework.

○ Why do I work on my classwork? Because it's fun.

○ Why do I work on my classwork? Because I enjoy doing my classwork.

Identified self-regulation: (5 items)

○ Why do I do my homework? Because I want to understand the subject.

○ Why do I do my classwork? Because I want to learn new things.

○ Why do I work on my classwork? Because I think classwork is important for my learning

○ Why do I try to do well in school? Because I enjoy doing schoolwork well.

- Why do I try to do well in school? Because doing well in school is important to me.

Introjected self-regulation: (4 items)

○ Why do I do my homework? Because I'll feel bad about myself if I don't do it.

○ Why do I work on my classwork? Because I'll feel ashamed of myself if it doesn't get done.

○ Why do I try to do well in school? Because I'll feel really bad about myself if I don't do well.

- Why do I try to do well in school? Because I feel guilty when I don't do as well as I should have.

External self-regulation: (4 items)

○ Why do I do my homework? Because I'll get in trouble if I don't.

○ Why do I work my classwork? So my teacher won't yell at me.

○ Why do I work on my classwork? Because that's the rule.

○ Why do I work on my classwork? Because the teacher says we have to. 


\section{C). Teacher Support: Student-Report (SR) \\ Teacher Warmth/Involvement: (16 items)}

Time spent:

- My teacher spends time with me.

- My teacher talks with me.

Affection:

- My teacher likes me.

- My teacher really cares about me.

- My teacher doesn't seem to enjoy having me in her class. (-)

Availability:

- My teacher is always there for me.

- My teacher is never there for me. (-)

- My teacher never seems to be around for me. (-)

Knowledge:

- My teacher knows me well.

- My teacher just doesn't understand me. (-)

- My teacher doesn't know very much about what goes on for me outside of school. (-)

Dependability:

- I can count on my teacher to be there for me.

- I can rely on my teacher to be there when I need him/her.

- I can't depend on my teacher for important things. (-)

- I can't count on my teacher when I need him/her. (-)

- I can’t rely on my teacher when I really need him/her. (-) 


\section{Teacher Structure: (29 items)}

Contingency:

- When I do something right, my teacher always lets me know.

- My teacher treats me fairly.

- When my teacher tells me he/she will do something I know he/she will do it.

- I know what to expect from my teacher when I make a mistake.

- My teacher doesn't treat me like everyone else when I break the rules. (-)

- Every time I do something wrong, my teacher acts differently. (-)

- When I break the rules, I never know how my teacher will react. (-)

- My teacher keeps changing how he/she acts towards me. (-)

Expectations:

- My teacher makes it clear what he/she expects of me in school.

- I know what my teacher expects of me in class.

- My teacher tells me what he/she expects of me in school.

- I don't know what my teacher wants me to do in class. (-)

- My teacher doesn't make it clear what she expects of me in class. (-)

- My teacher doesn't tell me what he/she expects of me in school. (-)

- My teacher keeps changing the rules in our class. (-)

\section{Help/Support:}

- When I can't understand something in class, my teacher explains it a lot of different ways.

- My teacher shows me how to solve problems for myself.

- If I can't solve a problem, my teacher shows me different ways to try to.

- My teacher doesn't help me, even when I need it. (-)

- Even when I run into problems, my teacher doesn't help me. (-)

- My teacher doesn't seem to know when I need help. (-) 
Adjustment/Monitoring:

- My teacher doesn't go on to new things before he/she knows that I understand the old ones.

- My teacher makes sure I understand before he/she goes on.

- My teacher makes sure that he/she doesn't teach faster than I can learn.

- My teacher checks to see if I'm ready before he/she starts a new topic.

- My teacher begins new things before he/she makes sure I've learned the old ones. (-)

- My teacher doesn't check to see if I'm keeping up with him/her. (-)

- My teacher doesn't know when I'm ready to go on. (-)

- My teacher doesn't check to see if I understand before he/she goes on. (-)

Teacher Autonomy Support: (21 items)

Choice:

- My teacher gives me a lot of choices about how I do my schoolwork.

- When it comes to assignments, my teacher gives me all kinds of things to choose from.

- My teacher doesn't give me a chance to choose anything about my classwork. $(-)$

- My teacher doesn't give me many choices when it comes to doing assignments. $(-)$

Control:

- My teacher is always getting on my case about schoolwork. (-) 
- My teacher tries to control everything I do. (-)

- It seems like my teacher is always telling me what to do. (-)

- My teacher makes me do everything his/her way. (-)

Respect:

- My teacher lets me decide things for myself.

- My teacher encourages me to do things my own way.

- My teacher listens to my ideas.

- My teacher interrupts me when I have something to say. (-)

- My teacher doesn't encourage me to do things my own way. (-)

- My teacher doesn't listen to my opinion. (-)

- My teacher never listens to my side. (-)

Relevance:

- My teacher talks about how I can use the things we learn in school.

- My teacher talks to me about whether school is useful.

- My teacher encourages me to find out how schoolwork could be useful to me.

- My teacher doesn't explain why what I do in school is important to me.

- My teacher doesn't explain why we have to learn certain things in school.

- My teacher never talks about how I can use the things we learn in school.

\section{D). Engagements and Disaffection: Student-reports (SR)}

\section{Behavioral Engagement: 6 items)}

- I participate when we discuss new material.

- I work hard when we start something new in class.

- The first time my teacher talks about a new topic, I listen very carefully.

- I try very hard in school.

- I participate in class discussions. 
- When we start something new in school, I feel interested.

\section{Emotional Engagement: (5 items)}

- When my teacher first explains new material, I feel relaxed.

- When I'm working on my classwork, I feel relaxed.

- When I'm working on my classwork, I feel involved.

- When I'm in class, I feel good.

- When I'm in school, I feel happy.

\section{Behavioral Disaffection: (5 items)}

- When we start something new, I practically fall asleep.

- My mind wanders when my teacher starts a new topic.

- I never seem to pay attention when we begin a new subject.

- When I'm in class, I just act like I'm working.

- In class, I try to do just enough to get by.

\section{Emotional Disaffection: (9 items)}

- When we start something new in school, I feel worried.

- When my teacher first explains new material, I feel bored.

- When I'm working on my classwork, I feel nervous.

- When I'm working on my classwork, I feel mad.

- When I'm doing my work in class, I feel worried.

- When I'm doing my work in class, I feel bored.

- When I'm in class, I feel sad.

- When I'm in school, I feel bad.

- When I'm in school, I feel terrible 